\title{
Numerical Investigation and Experimental Validation of a Novel Thermal Architecture for Spacecraft Thermal Management
}

\author{
by
}

\author{
Alejandro Torres, \\ M.S. Aero \& Astro
}

A thesis submitted to the Faculty of Graduate and Postdoctoral Affairs in partial fulfillment of the requirements for the degree of

Doctor of Aerospace Engineering

Ottawa-Carleton Institute for

Mechanical and Aerospace Engineering

Department of Mechanical and Aerospace Engineering

Carleton University

Ottawa, Ontario, Canada

2014

Copyright (C) 2014

Alejandro Torres 
A novel satellite thermal architecture to maximize the available radiation area on a spacecraft is proposed. The proposed architecture implements the state-of-the-art technology for thermal control in space.

The research project is carried out in several steps. A transient numerical model is first developed to mathematically represent the novel architecture and analyze the critical mission cases. This is followed by the validation of the numerical model using flight data. For this, a large number of telemetry flight data is collected, organized, and analyzed. The model predictions and flight data compared very well within $4^{\circ} \mathrm{C}$ and without a significant time delay in the simulated results.

With the confidence gained from the satisfactory model validation, the mathematical model is then used to design a four-radiator/condenser specimen to demonstrate capability of the model to simulate a more complex and integrated thermal control system. 


\section{Preface}

This thesis is based on the following five manuscripts, four of which are published in peer-reviewed journals (Chapters 3, 4, 5 and 6) and one conference publication (Chapter 7):

Chapter 3

A. Torres, D. Mishkinis, A. Kulakov, F. Romera, C. Gregori, and T. Kaya, Thermal control of loop heat pipe with pressure regulating valve, Heat Pipe Science and Technology, Vol. 1(4), pp. 329-357, 2010.

DOI: 10.1615/HeatPipeScieTech.v1.i4.30.

Chapter 4

A. Torres, D. Mishkinis, F. Romera, J. Corrochano, and T. Kaya, Set-point active control of vapor-modulated loop heat pipe, Heat Pipe Science and Technology, Vol. 3(2-4), pp. 263-280, 2012.

DOI: 10.1615/HeatPipeScieTech.2013006631

Chapter 5

A. Torres, D. Mishkinis, T. Kaya, Mathematical modeling of a new satellite thermal architecture system connecting the east and west radiator panels and flight performance prediction, Applied Thermal Engineering, Vol. 65, pp. 623-632, 2014. http://dx.doi.org/10.1016/j.applthermaleng.2013.11.040 
Chapter 6

A. Torres, D. Mishkinis, T. Kaya, Mathematical model validation of a thermal architecture system connecting east/west radiators by flight data, Applied Thermal Engineering Vol. 66, pp. 1-14, 2014.

http://dx.doi.org/10.1016/j.applthermaleng.2014.01.050

Chapter 7

A. Torres, D. Mishkinis, T. Kaya, LHP as strategic thermal control element for space and planetary missions, $29^{\text {th }}$ International Symposium on Space Technology and Science, paper No: 2013-o-4-13, Nagoya, Japan, 2013. This manuscript was invited for publication and it is currently under review in The Special Journal Issue of Transactions for The Japan Society for Aeronautical and Space Sciences, and it is currently under review.

The work presented in this thesis is original and my own as described below. Manuscript of Chapter 3, co-authors with the following contribution:

A. Torres, PRV technology design for telecommunication applications responsible. Paragraphs 3.1, 3.2, 3.3, 3.6 and 3.7. Final manuscript reviewer.

D. Mishkinis, Test department responsible. Test programs advisor and adequacy of test plans. Paragraph 3.4 and 3.5 .

A. Kulakov, Test conductor, for planetary rover and thermal switch applications. Elaboration of test reports. Contribution to paragraphs 3.4 and 3.5.

F. Romera, Specific tests for planetary rover applications and elaboration of test reports. Contribution to paragraph 3.4.

C. Gregori, Specific tests for thermal switch applications and elaboration of test 
reports. Contribution to paragraph 3.5.

T. Kaya, supervisor and manuscript reviewer.

Manuscript of Chapter 4, co-authors with the following role:

A. Torres, PRV technology design for telecommunication applications responsible. Paragraph 4.1. and 4.3. Final manuscript reviewer.

D. Mishkinis, PRV Active control technology. Test department responsible. Test programs advisor and adequacy of test plans. Paragraph 4.2.

F. Romera, PRV Active control technology. Contribution to paragraph 4.2.

J. Corrochano, Test conductor for argon charged valve test (paragraph 4.2.1) and ammonia charged valve test (paragraph 4.2.2).

T. Kaya, supervisor and manuscript reviewer.

Manuscript of Chapter 5, co-authors with the following role:

A. Torres, Paragraphs 5.1, 5.2, 5.3, 5.4, 5.5 and 5.6. Final manuscript reviewer.

D. Mishkinis, advisor and manuscript reviewer.

T. Kaya, supervisor and manuscript reviewer.

Manuscript of Chapter 6, co-authors with the following role:
A. Torres, Paragraphs $6.1,6.2,6.3,6.4,6.5$ and 6.6. Final manuscript reviewer.
D. Mishkinis, advisor and manuscript reviewer.
T. Kaya, supervisor and manuscript reviewer. 
Manuscript of Chapter 7, co-authors with the following role:
A. Torres, Paragraphs 7.1, 7.2, 7.3, 7.4, and 7.5. Final manuscript reviewer.
D. Mishkinis, advisor and manuscript reviewer.
T. Kaya, supervisor and manuscript reviewer.

The supervisor of this thesis, hereby, attest that the information provided is accurate.

Dr. Tarik Kaya (Supervisor): 


\section{Acknowledgements}

All this effort would not have been possible without the support, patience and love of three incredible individuals with whom I share my life. They have shown to me the way to keep going regardless life circumstances.

First, I would like to express my sincere thanks and appreciation to Prof. Tarik Kaya, for his outstanding example of perseverance and patience with his alumni. His countless support and encouragement has been the driving force to complete the program.

Second, to thank Dr. Donatas Mishkinis, a friend and colleague with whom I have shared the passion of creativity and exploration of new research boundaries.

Last but not least, to express my love and to thank my wife, Mar and my daughters, Miriam and Sofia. They have been the daily unconditional generous support along these years. This challenge would have never happened without their sacrifice to allow me completing this thesis.

I want to thank also to Antonio Abad and Manuel Sansegundo from Hispasat for the demonstrator flight opportunity and Ignacio Solozábal from SSL/MDA, for his continuous support in the flight demonstrator operations program. Also, Prof. C.W. Francis Everitt from Stanford University, for his support and encourage completing this dream. 
Finally, I would like to render a tribute to my parents for providing the means, support and education that have brought me here. 


\section{Table of Contents}

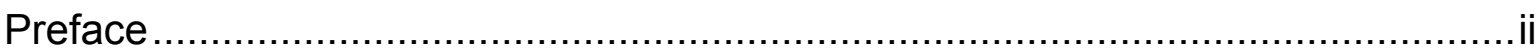

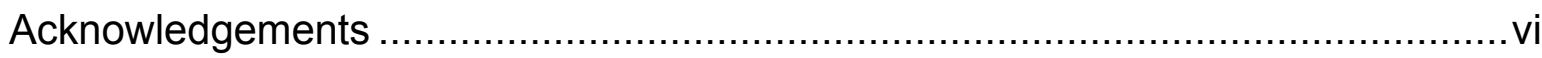

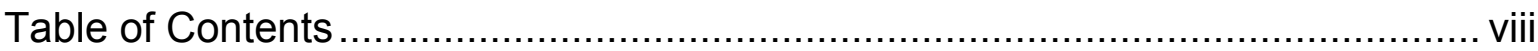

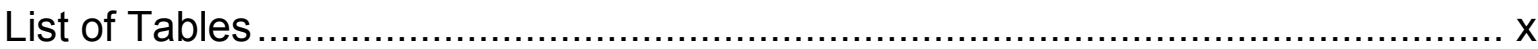

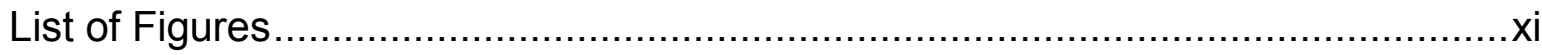

Nomenclature, Acronyms, Symbols and Subscripts.................................. xvii

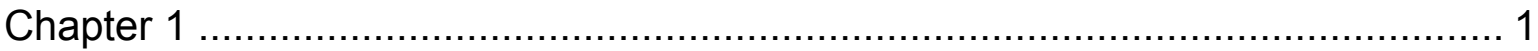

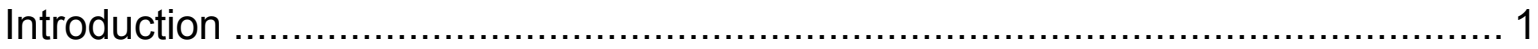

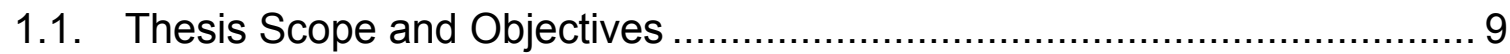

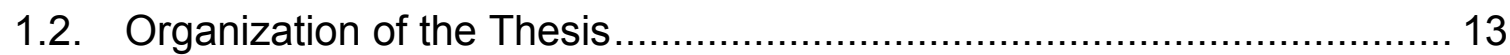

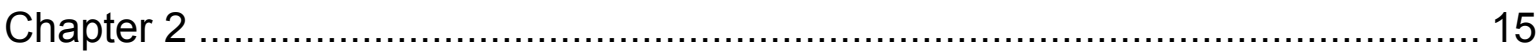

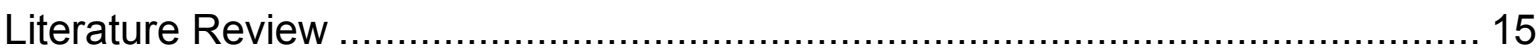

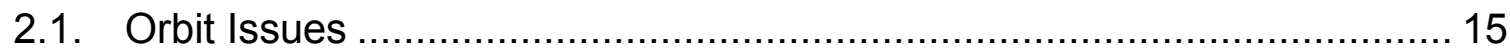

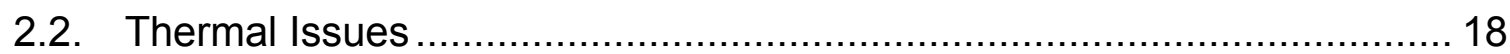

2.3. Common Thermal Architectures ................................................. 18

2.4. Loop Heat Pipes Modeling and Background .................................. 24

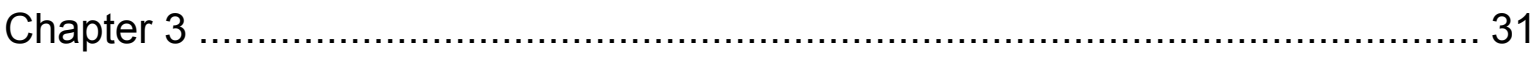

Thermal control of loop heat pipe with pressure regulating valve..................... 31

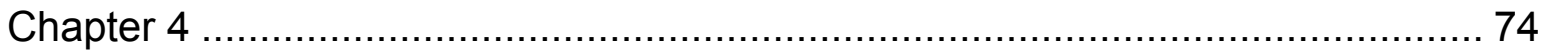

Set point active control of vapor modulated loop heat pipe .......................... 74 
Chapter 5

Mathematical modeling of a new satellite thermal architecture system connecting the east and west radiator panels and flight performance prediction 98

Chapter 6 130

Mathematical model validation of a thermal architecture system connecting east/west radiators by flight data 130

Chapter 7 166

LHP as strategic thermal control element for space and planetary missions 166

Chapter 8 205

Conclusions and recommendations for future work. 205

8.1. Conclusions 205

8.2. Recommendations for future work ............................................ 207

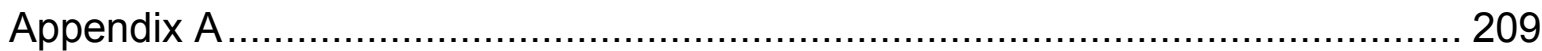

Friction and heat transfer coefficients. Evaporator mathematical equations 209 


\section{List of Tables}

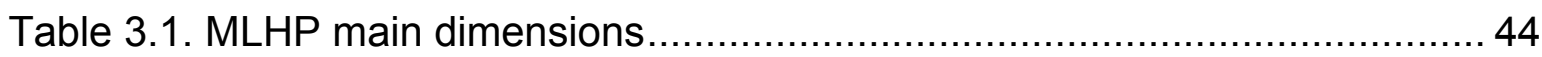

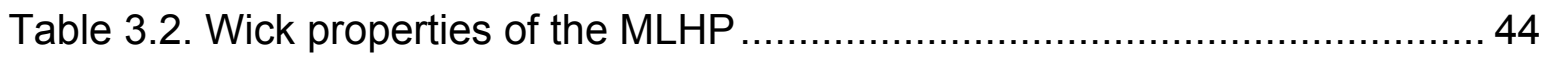

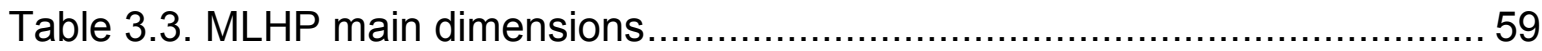

Table 3.4. Design characteristics of the MLHP ........................................ 59

Table 3.5. Comparison of different methods of regulation of LHP operation

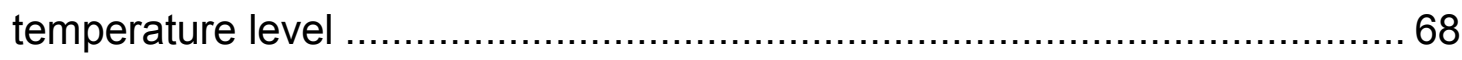

Table 4.1. PRV set point temperature for PRV heating. ............................. 85

Table 4.2. PRV set point temperature for PRV cooling. .............................. 87

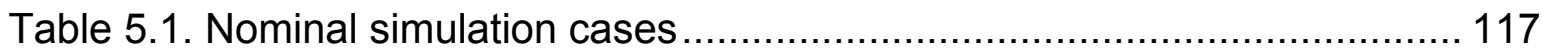

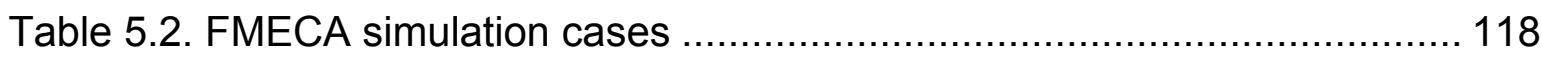

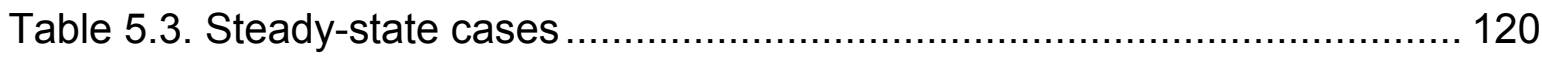

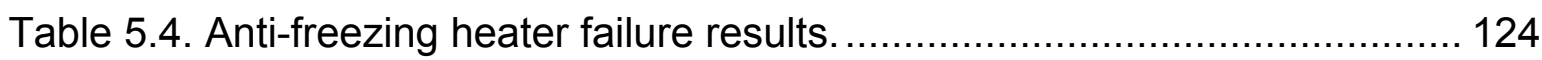

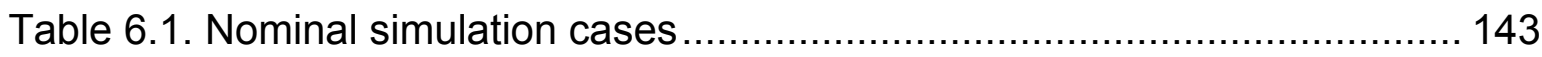

Table 6.2. Coupling matrix for ambient exchange cases ........................... 144

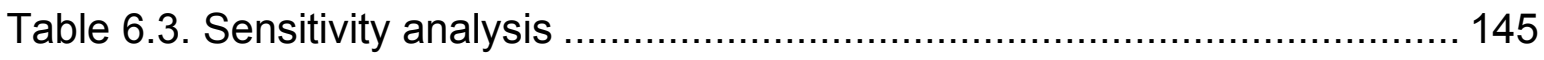

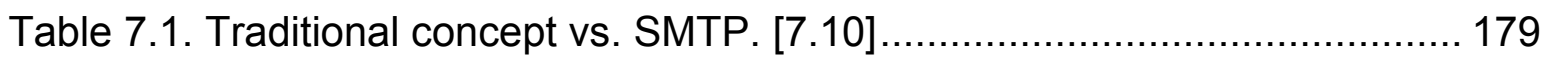

Table 7.2. General overview of the SMTP system. [7.10] ......................... 180

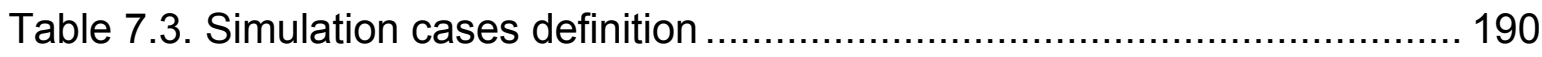




\section{List of Figures}

Figure 1.1. Two-Phase technology classification....................................... 3

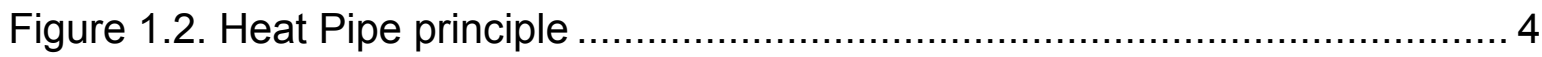

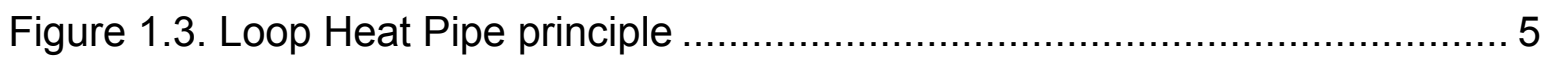

Figure 1.4. Pressure Regulator Valve (PRV) sketch, a) three-way, b) two-way

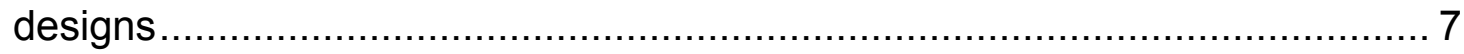

Figure 1.5. General overview of the thermal system architecture.................... 8

Figure 1.6. Thermal system architecture development historical timeline ........... 11

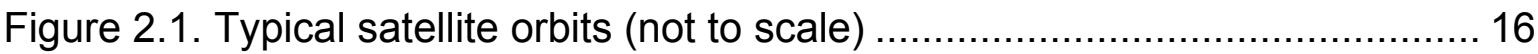

Figure 2.2. Lagrangian Libration Points (not to scale) ................................. 17

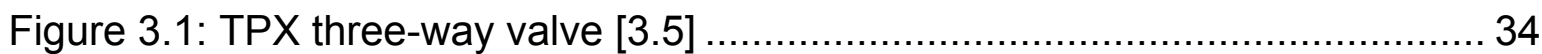

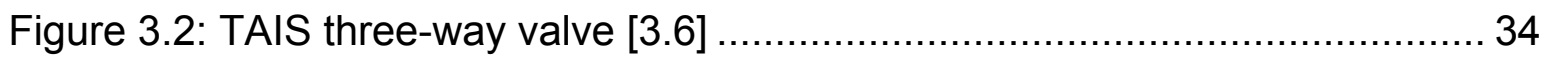

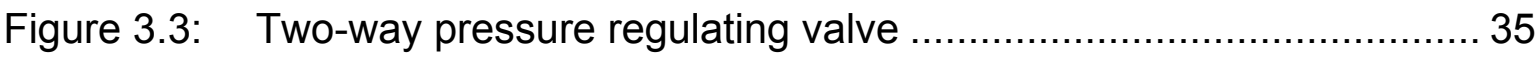

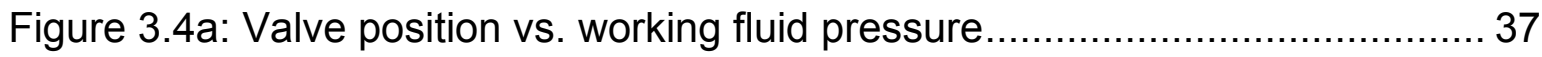

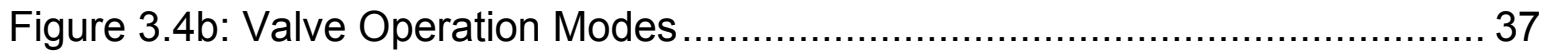

Figure 3.5: Pressure-Temperature diagram of LHP operation ...................... 42

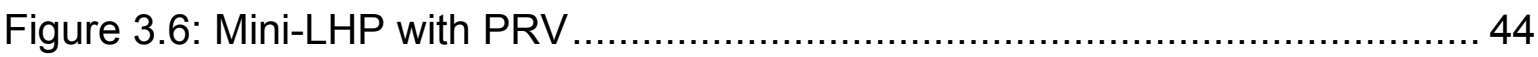

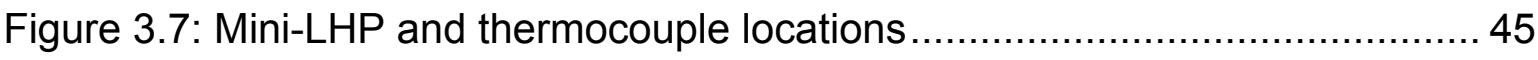

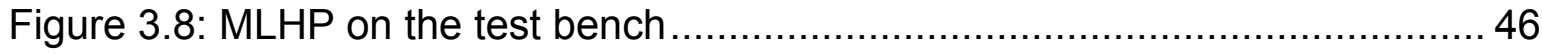

Figure 3.9: Maximum performance test of MLHP with three-way valve. Sink at cold case 48

Figure 3.10: Maximum performance test of MLHP with two-way valve. Sink at cold case 49 
Figure 3.11: Maximum performance test of MLHP without valve. Sink at cold case 50

Figure 3.12: Comparison of operating temperature for MLHP without and with PRV

Figure 3.13: Maximum performance test of MLHP with two-way valve. Sink at cold case. Power 273W is applied constantly. Argon pressure was decreased to decrease valve set point from $4^{\circ} \mathrm{C}$ to $0^{\circ} \mathrm{C}$ (dry-out). 52

Figure 3.14: Maximum performance test of MLHP without valve. Sink at hot case. Sink temperature was reduced at power step $275 \mathrm{~W}$ to permit the LHP reach dry-out within allowable temperature range.

Figure 3.15: Maximum performance test of MLHP with three-way valve. Sink at hot case (Practically the same result was obtained for two-way valve). 54

Figure 3.16: Comparison of maximum heat transfer rate $Q_{\max }$ of MLHP vs. operating temperature 55

Figure 3.17: Mini LHP schematic 59

Figure 3.18: Mini LHP test set up: radiator panel view 59

Figure 3.19: Evaporator block test setup 60

Figure 3.20: Condenser test setup. 60

Figure 3.21: Valve test results - Chamber $\mathrm{T}=-70^{\circ} \mathrm{C}$, power cycling 61

Figure 3.22: Valve test results - Chamber temperature cycling. 62

Figure 3.23: Start up test results - Chamber $\mathrm{T}=-40^{\circ} \mathrm{C}$ 65

Figure 4.1. VMLHP design for European Mars Rover application. 76

Figure 4.2. PRV Scheme: 3-way (a) and 2-way (b) designs. 77

Figure 4.3. Valve Operation Modes 78

Figure 4.4. PRV Back Pressure vs. Temperature. 82 
Figure 4.5. Thermocouples layout.

Figure 4.6. Temperatures for PRV heating (cold conditions) ........................ 84

Figure 4.7. Temperatures for heating the valve (hot conditions) ..................... 85

Figure 4.8. Temperatures for cooling the valve. 86

Figure 4.9. a) LHP evaporator with PRV in vapor line, b) Peltier element attached to PRV. 88

Figure 4.10. Positions of Thermocouples at VMLHP. 89

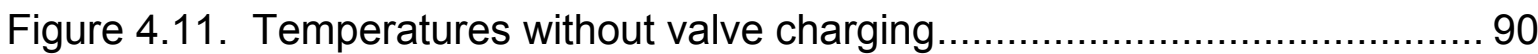

Figure 4.12. Temperatures with PRV charged without temperature control .........91

Figure 4.13. Temperatures with PRV charged and PID controlled .................... 92

Figure 4.14. Temperature control vs. sharp power variations........................ 92

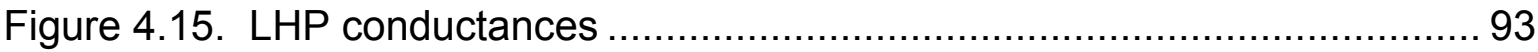

Figure 4.16. Power dependence of CC (upper and lower parts) and PRV temperatures. 94

Figure 4.17. Power dependence of temperature differences between CC and vapor line inlet

Figure 5.1. Pressure Regulator Valves (PRV) sketch. Three way (a), two way (b). 107

Figure 5.2. East radiator (left) and west radiator (right) configurations.............. 108

Figure 5.3. A general overview of the thermal system architecture................. 109

Figure 5.4. 2-D staggered grid control volume representation....................... 111

Figure 5.5. Control volume junction scheme ....................................... 113

Figure 5.6. Numerical model overview. ........................................... 116

Figure 5.7. Incident solar heat load on east and west radiators. .................... 118

Figure 5.8. Complete orbit $24 \mathrm{~h}$ diurnal $\mathrm{BOL}$ cases................................. 121 
Figure 5.9. Complete orbit $24 \mathrm{~h}$ diurnal EOL cases.

Figure 5.10. Support panel temperature versus driving heater power. 125

Figure 5.11. Radiator temperature (condenser temperature) versus percentage of damaged OSR. 126

Figure 6.1. Demonstrator general view. 137

Figure 6.2. Detailed view of demonstrator evaporator area components. 138

Figure 6.3. Detailed view of east radiator components 138

Figure 6.4. Mathematical model overview prior to validation. 141

Figure 6.5. Detailed view of evaporator area thermal couplings. 142

Figure 6.6. Predicted and measured radiator temperature. 147

Figure 6.7. Radiation model refinement. 148

Figure 6.8. Modified numerical model schematics. Circled items were adjusted according to the flight data. 149

Figure 6.9. Radiator temperature comparison between measured flight data and calculations for Summer Solstice. 150

Figure 6.10. Calibrated orifice location. 151

Figure 6.11. Valve operation scenarios as a function of applied payload power and satellite environmental temperature. 153

Figure 6.12. Identification tags and position of the flight thermistors. 154

Figure 6.13. Demonstrator and satellite daily average temperatures from July 2011 to March 2013. 156

Figure 6.14. Demonstrator temperature before and after start-up, July $2011 \ldots . .157$ Figure 6.15. Demonstrator temperature, December 2011 (First winter solstice). 158 Figure 6.16. Demonstrator temperature, March 2012 (Spring equinox). 159 
Figure 6.17. Demonstrator temperature, December 2012 (Second winter solstice). 160

Figure 6.18. Mathematical model and flight data comparison for winter solstice 2011 and 2012

Figure 6.19. Mathematical model and flight data comparison for spring equinox 2012 162

Figure 7.1. Two-Phase technology classification 170

Figure 7.2. Engineering model general overview 184

Figure 7.3. Daily average temperature flight data CREW 186

Figure 7.4. Power sharing flight data CREW. February 2013. 187

Figure 7.5. Numerical model connecting north-south-east-west radiators 189

Figure 7.6. Temperature vs time for a GEO orbit 191

Figure 7.7. Power sharing vs. time for a GEO orbit 192

Figure 7.8. Temperature vs time for a LEO orbit 193

Figure 7.9. Shared power vs. time for a LEO orbit 194

Figure 7.10. Engineering model performed tests definition 195

Figure 7.11. Measured temperatures for north-south radiators at $10^{\circ} \mathrm{C}$ and eastwest varying between $10^{\circ} \mathrm{C}$ and $30^{\circ} \mathrm{C}$ 196

Figure 7.12. Measured shared power values for north-south radiators at $10^{\circ} \mathrm{C}$ and east-west varying between $10^{\circ} \mathrm{C}$ and $30^{\circ} \mathrm{C}$ 196

Figure 7.13. North LHP test data and mathematical model comparison for northsouth radiators at $10^{\circ} \mathrm{C}$ and east-west varying between $10^{\circ} \mathrm{C}$ and $30^{\circ} \mathrm{C}$ 197

Figure 7.14. South LHP test data and mathematical model comparison for northsouth radiators at $10^{\circ} \mathrm{C}$ and east-west varying between $10^{\circ} \mathrm{C}$ and $30^{\circ} \mathrm{C} \ldots . .198$ 
Figure 7.15. East LHP test data and mathematical model comparison for northsouth radiators at $10^{\circ} \mathrm{C}$ and east-west varying between $10^{\circ} \mathrm{C}$ and $30^{\circ} \mathrm{C} \ldots . .198$

Figure 7.16. West LHP test data and mathematical model comparison for northsouth radiators at $10^{\circ} \mathrm{C}$ and east-west varying between $10^{\circ} \mathrm{C}$ and $30^{\circ} \mathrm{C} \ldots . .199$

Figure 7.17. Test data and mathematical model comparison for north-south-eastwest radiators at $-40^{\circ} \mathrm{C}$ 200

Figure 7.18. LHPs temperature test data for north-south radiators at $-25^{\circ} \mathrm{C}$ and east-west varying between $-25^{\circ} \mathrm{C}$ and $30^{\circ} \mathrm{C}$ 201

Figure 7.19. Measured shared power values for north-south radiators at $-25^{\circ} \mathrm{C}$ and east-west varying between $-25^{\circ} \mathrm{C}$ and $30^{\circ} \mathrm{C}$ 202

Figure A.1. Bend pipe parameters 210

Figure A.2. Evaporator cross-section representation 217 


\section{Nomenclature, Acronyms, Symbols and Subscripts}

\section{Nomenclature}

A area $\left(\mathrm{m}^{2}\right)$

$\mathrm{C}_{\mathrm{p}} \quad$ specific heat at constant pressure $\left(\mathrm{J} \mathrm{kg}^{-1} \mathrm{~K}^{-1}\right)$

C heat capacity $\left(\mathrm{J} \mathrm{K}^{-1}\right)$

D diameter $(\mathrm{m})$

f friction factor

$F_{i j} \quad$ view factor

Fa acceleration force $(\mathrm{N})$

$\mathrm{Ff} \quad$ friction force $(\mathrm{N})$

Fg gravitational force (N)

Fp pressure force (N)

g gravitational acceleration $\left(\mathrm{m} \mathrm{s}^{-2}\right)$

$\mathrm{h} \quad$ convection heat transfer coeff. $\left(\mathrm{W} \mathrm{m}^{-2} \mathrm{~K}^{-1}\right)$ and enthalpy $\left(\mathrm{J} \mathrm{kg}^{-1}\right)$

$\mathrm{h}_{\mathrm{fg}} \quad$ latent heat of evaporation $\left(\mathrm{J} \mathrm{kg}^{-1}\right)$

I moment of inertia $\left(\mathrm{kg} \cdot \mathrm{m}^{-2}\right)$

$\mathrm{k} \quad$ thermal conductivity $\left(\mathrm{W} \mathrm{m}^{-1} \mathrm{~K}^{-1}\right)$

$\mathrm{L}, \ell \quad$ length $(\mathrm{m})$

$\dot{m} \quad$ mass flow rate $\left(\mathrm{kg} \mathrm{s}^{-1}\right)$ 


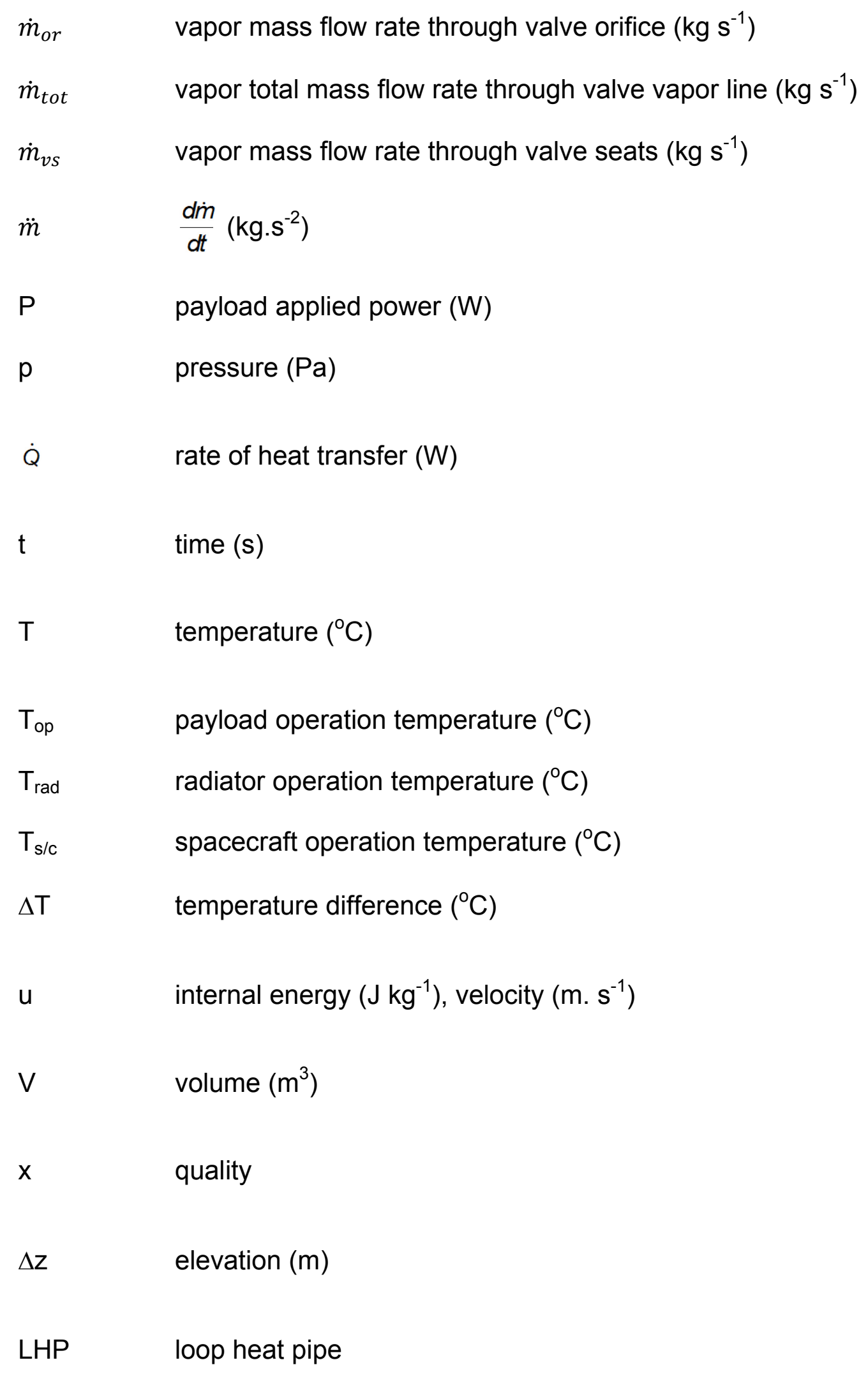

\section{Acronyms}

AGHP Axially Grooved Heat Pipe 

AMS Alpha Magnetic Spectrometer
BLLHP Bypass Line Loop Heat Pipe
BOL Beginning Of Life Conditions
CAB Cryomagnetic Avionic Box
CC Compensation Chamber or Reservoir
CCHP Constant Conductance Heat Pipe
CDL Capillary Driven Loop
C_LHP LHP Conductance
CN Condenser
CPL Capillary Pumped Loop
CREW Coupled Radiator East West
DASSL Differential Algebraic System Solver
DHP Diode Heat Pipe
E East
EO Earth Observation
EOL End Of Life
EQS Spring Equinox
ESA European Space Agency
EV Evaporator
FMECA Failure Mode Effects Criticality Analysis
GEO Geosynchronous Earth Orbit
GPS Global Positioning System
HALO/LPO Lagrangian Point Orbit
HEM Homogeneous Equilibrium Model
HP Heat Pipe 


\begin{tabular}{ll} 
IOT & In-Orbit Test \\
Ka & K-above \\
Ku & Kurz-unten (directly below microwave K-band) \\
LEO & Low Earth Orbit \\
LHP & Loop Heat Pipe \\
LL & Liquid Line \\
LNA & Low Noise Amplifier \\
MEO & Medium Earth Orbit \\
MLI & Multi-Layer Insulation \\
MPDL & Mechanically Pump Driven Loop \\
N & North \\
NASA & National Aeronautics and Space Administration \\
OMUX & \\
OSR & Optical Solar Reflector \\
PCM & Phase Change Material \\
PFM & Proto Flight Model \\
PL & Payload \\
PRV & Pressure Regulating Valve \\
PVTCD & Passive Variable Thermal Conductance Device. \\
RAD & Radiator \\
RHU & Radioisotope Heating Unit \\
S & South \\
SMTP & Spacecraft Modular Thermal Platform \\
SOHO & Solar \& Heliospheric Observatory \\
SS & Stainless Steel \\
\hline
\end{tabular}


TC

Thermocouple

TPL Two-Phase Loop

TPX Two-Phase experiment

TRP Technological Research Program

VCHP Variable Conductance Heat Pipe

VMHP Vapor Modulated Heat Pipe

VMLHP Vapor Modulated Loop Heat Pipe

W West

WS1 Winter Solstice December 2011

WS2 Winter Solstice December 2012

\section{Greek symbols}

$\delta \quad$ flow direction indicator

$\varepsilon_{\text {eff }} \quad$ effective emissivity of insulating blanket

$\xi \quad$ pressure drop coefficient

$\kappa \quad$ permeability $\left(\mathrm{m}^{2}\right)$

$\mu \quad$ viscosity (Pa s)

$\rho \quad$ density $\left(\mathrm{kg} \mathrm{m}^{-3}\right)$

$\sigma \quad$ liquid-vapor surface tension $\left(\mathrm{N} \mathrm{m}^{-1}\right)$ and Stefan-Boltzmann constant

\section{Subscripts}

amb ambient

app applied

ave average

c-g case to groove

C-W $\quad$ case to wick 


\begin{tabular}{|c|c|}
\hline $\mathrm{cb}$ & convective boiling \\
\hline cond & condensation \\
\hline eff & effective \\
\hline evap & evaporation \\
\hline ext & exterior \\
\hline g & groove \\
\hline int & interface and interior \\
\hline I & liquid \\
\hline LHP & loop heat pipe \\
\hline mac & macroscopic \\
\hline $\max$ & maximum \\
\hline mic & microscopic \\
\hline $\bmod$ & model \\
\hline nc & natural convection \\
\hline or & orifice \\
\hline out & outlet \\
\hline op & operation \\
\hline $\mathrm{pd}$ & post dryout \\
\hline PRV & pressure regulating valve \\
\hline rad & radiator \\
\hline sat & saturation \\
\hline$s p$ & single phase \\
\hline $\mathrm{s} / \mathrm{c}$ & spacecraft \\
\hline tot & total \\
\hline $\mathrm{tp}$ & two phase \\
\hline
\end{tabular}


V

VS

w

vapor

valve seats

wick

xxiii 


\section{Chapter 1}

\section{Introduction}

The ever-increasing level of power and integration complexity induced by new electronic technologies characterizes the natural evolution of on-board satellite equipment, antennae and sub-systems. Spacecraft thermal designs are facing limitations to handle the effects of the harsh environment on the design temperatures and heat dissipation of these new electronic units. The limitations are mainly due to two reasons: on one side, the increase in the number of transponders per satellite that telecommunication operators require, in order to make satellites more profitable; on the other side, the incorporation of new types of antennas (highly dissipative), such Ka and Ku bands, that respond to the new telecommunication market demands, such as High Definition TV.

Spacecraft thermal control relies on the global thermal balance between external and internal heat inputs by combining conduction and radiation heat transport phenomena. The heat loads are transported by conduction to dedicated radiators installed on the satellite external surfaces, where they will be rejected to deep space via thermal radiation, acting as thermal sinks.

Given the fact that a satellite volume is restricted to the launcher's fairing envelope and that in telecom sats the equipment is preferably located on the north-south radiator areas, units end up installed close to each other and results in high power density spots. 
This new situation has originated the necessity to improve the heat rejection capability of this type of satellites. Current research focuses on two main areas: one is based on increasing the radiator temperatures, in order to enhance the heat rejection capability. The second one aims to develop architectures that combine two-phase thermal control devices. The main target is to increase the areas to locate equipment and occupy those that traditionally were not used because of their changing external environment, for example the east-west panels.

Although the first one seems to be the easiest one to be implemented, it turns out that it is not feasible today. The main reason resides on the materials used in the electronic equipment and the derating issues (failure rates at large amplitude and number of thermal cycles). New components, based on Gallium-Nitrate technology, are now under space qualification process, but it will take time to have all the required electronics running at temperatures close to $100^{\circ} \mathrm{C}-150^{\circ} \mathrm{C}$. The technology associated to this type of solution is beyond the scope of this thesis.

Second area bases its research on two-phase heat transportation systems. The available technologies and classification associated to two-phase heat transportation systems are presented in Fig. 1.1. 


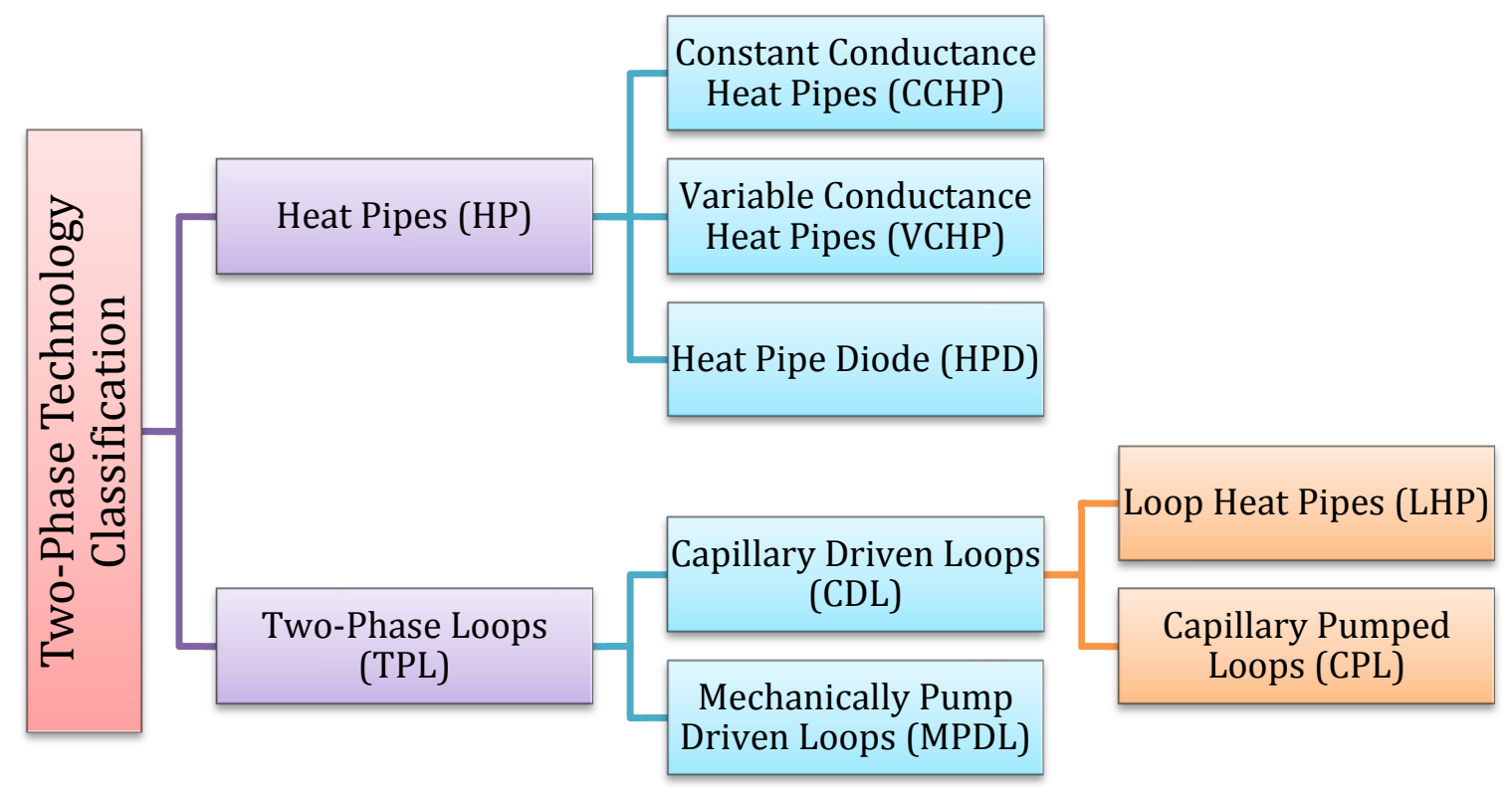

Figure 1.1. Two-Phase technology classification

Heat pipes, Fig. 1.2, are capillary-driven heat transfer devices with the capability to transport large amounts of thermal energy with small temperature gradients. Heat pipes are extremely attractive for space applications where they provide a highly efficient and effective heat transfer and heat spreading tool without the need of external sources. Telecom spacecraft today employ constant conductance heat pipes (CCHP) in large quantities. Heat pipes are also used more and more for Science and Earth Observation missions. Other more specific designs have been or are being developed for dedicated applications; e.g. variable conductance heat pipes (VCHP, allowing temperature control), heat pipe diodes (allowing heat flux switching), low temperature/cryogenic heat pipes, high temperature heat pipes. However, most of these applications are typically dedicated to specific needs. 


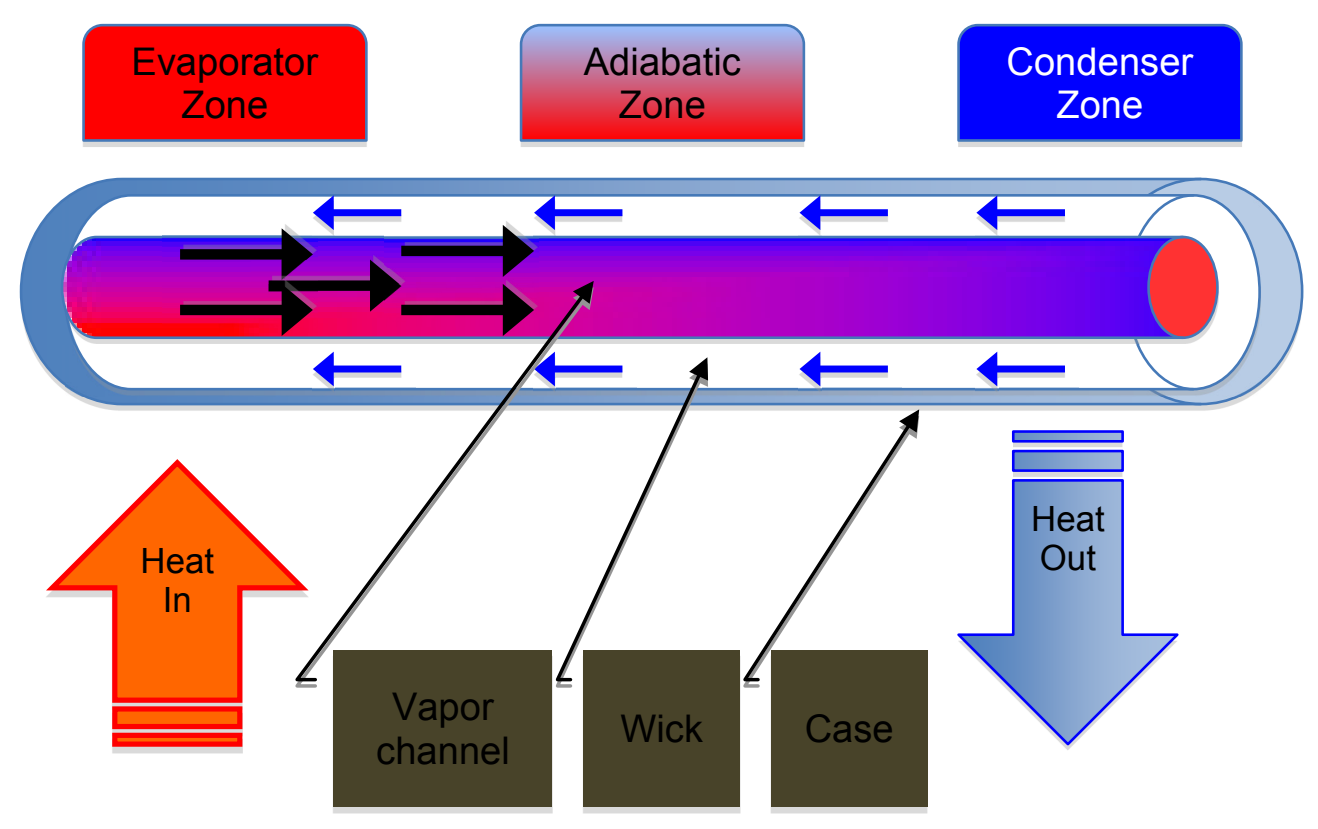

Figure 1.2. Heat Pipe principle

Capillary driven loops (CPL and LHP) provide the means to transport an even larger amount of heat over larger distances (compared to classical heat pipes) and they are also enabling technology for deployable radiators. These devices in smaller sizes, like mini-CPL's or mini-LHP's, can provide highly efficient and flexible thermal control means, for e.g. electronic cooling, sensor cooling or for mini/micro spacecraft thermal control.

The operation principle of an LHP is similar to that of a heat pipe, see Fig. 1.3. In the case of LHP or CPL, the liquid and vapor flow through separated and smooth-walled tubes. The capillary action (pressure) is provided by means of a porous material, the so-called primary wick, inserted in a tube. Altogether, they constitute the evaporator, where the heat is applied. A small type of vessel, named 
reservoir or compensation chamber, is attached (i.e. welded) to the evaporator in LHP's, or placed far from the evaporator through a tube in CPL's. The function of this vessel is to manage the liquid volume changes in the loop that result from variations in the applied heat or in the condenser temperatures. The compensation chamber or reservoir is hydraulically connected by means of a porous structure, the secondary wick, which ensures continuous liquid supply to the primary wick.

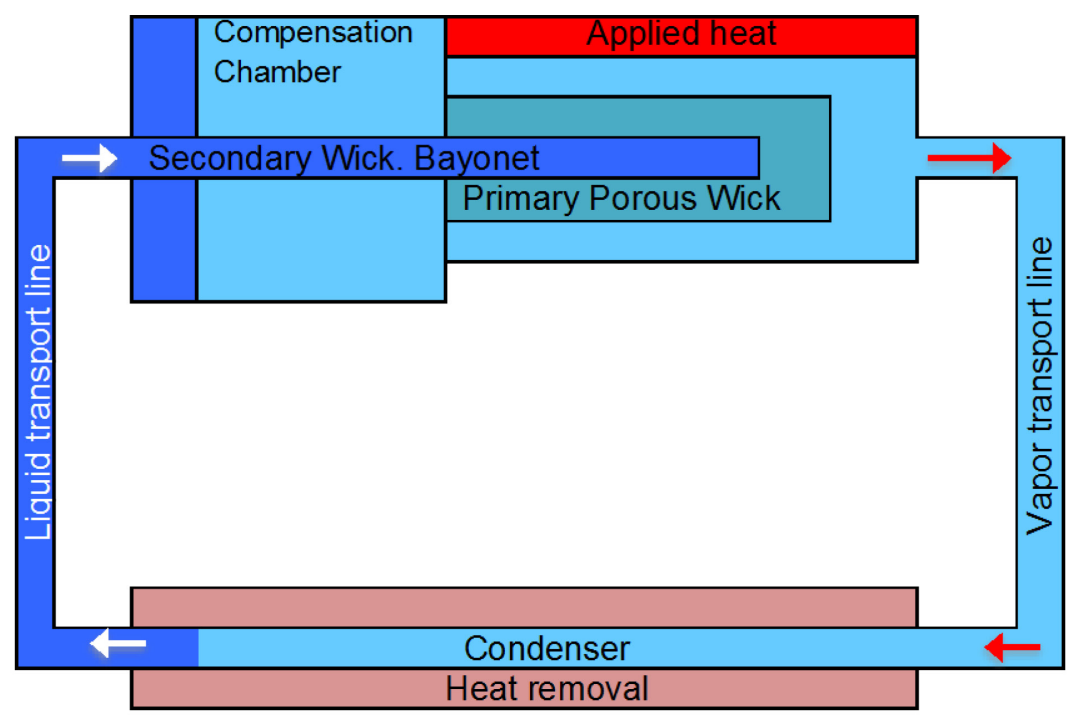

Figure 1.3. Loop Heat Pipe principle

Two-phase Mechanical Pump Driven Loops (MPDL) transport large amounts of heat over long distances using a quasi-isothermal fluid along the loop path. Two main differences exist between a CDL and a two-phase MPDL in terms of driving force and evaporator design. In CDL's fluid circulation is produced by capillary forces. On the other hand, in MPDL's a mechanical pump drives the fluid circulation. With respect to the evaporator, in the CDL it contains a porous material, however, this is not compulsory for a two-phase MPDL evaporator.

Two main types of two-phase MPDL can be identified: mixed and with separated flow. In the mixed type, liquid is pumped at a constant flow rate 
independent from the heat load applied to the evaporator(s) resulting in a liquidvapor mixture at the evaporator outlet with varying ratio as function of the applied heat load. In MPDL's with separated flow, the transport lines between evaporator(s) and condenser(s) only contain vapor. In this case, a flow rate control device or phase separator at the evaporator(s) inlet is required.

This thesis investigates an architecture to maximize the available radiation area on a spacecraft by passively selecting the appropriate radiators with the best environment according to their temperature conditions. The novel solution allows facilitating and potentially increasing the accommodation of electronic equipment within the satellite. Summarizing, this architecture allows:

- Radiating heat from areas located far from heating sources (delocalisation of the radiator).

- $\quad$ Linking the dissipating element to the radiator (low thermal gradient).

- Accommodating radiators in favourable radiative environment.

- Providing a generic heat collector (cold plate) wherever the dissipating unit is located.

- Providing a generic radiator wherever the location of the electronic unit.

- Saving electrical heater power consumption.

Three main building blocks are considered in the proposed architecture:

- Heat collection area: a heat pipe network collects and homogenizes the heat dissipation .

- Heat transportation and regulation system: LHPs transport the heat from the collection area to the rejection area.

- Heat rejection area: radiator panels for heat rejection to space. 
The dissipative equipment is mounted on a heat pipe network to homogenize their temperatures and to collect the entire heat load, providing a common way to reject the waste heat. The LHPs are used to transport the heat collected by the heat pipes network to the radiators. Because of the peculiar behavior of the LHPs, they can only operate if the condenser is colder than the evaporator. Therefore, it will be possible to decouple source and sink if the radiators are at a higher temperature than the heat pipe network (diode effect).

As it was previously stated, the LHP temperatures need to be controlled within the desired range. To accomplish this, a pressure regulator valve (PRV) is used to decouple both sides when the radiators are at very low temperature, see Fig. 1.4. In order to control the equipment temperature, the PRV by-passes vapor to heat the LHP compensation chamber or liquid line.

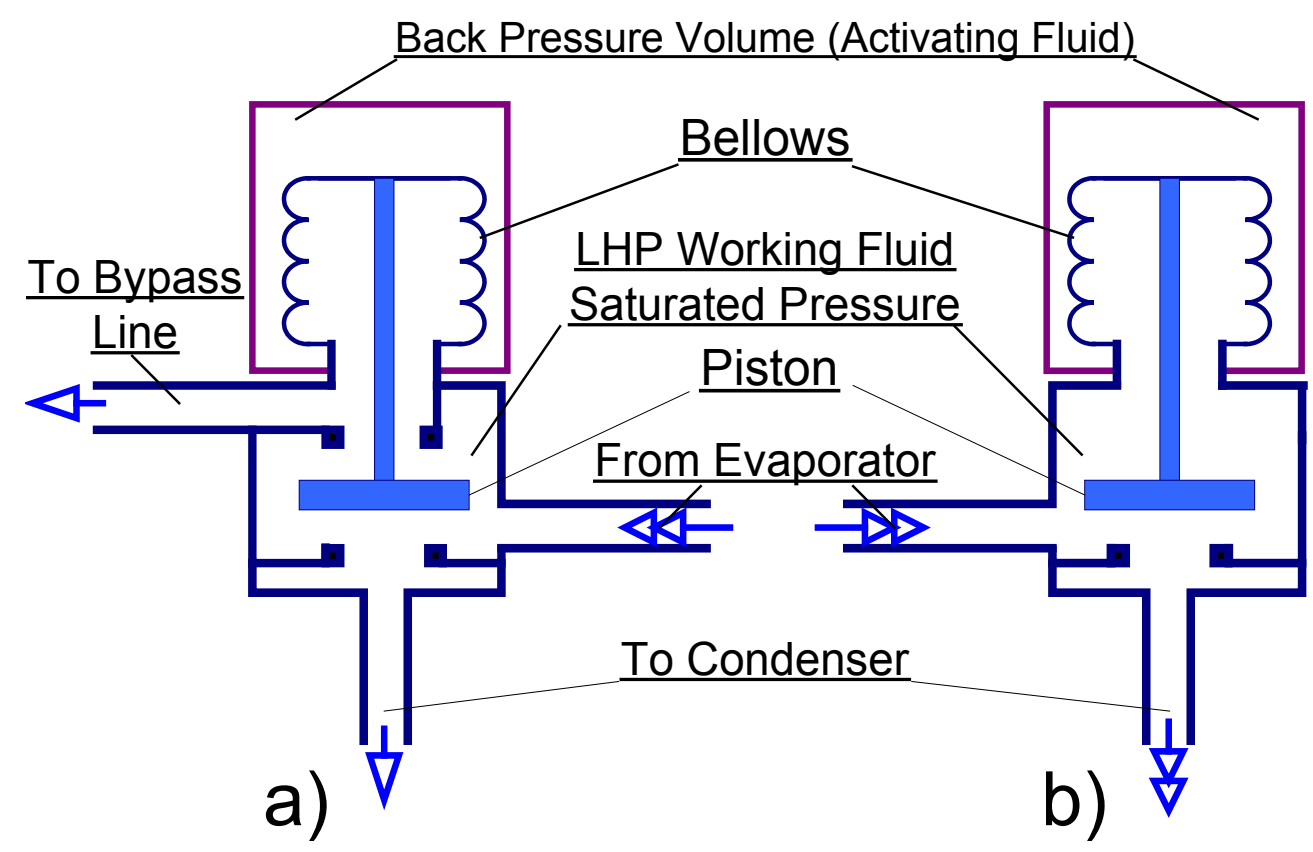

Figure 1.4. Pressure Regulator Valve (PRV) sketch, a) three-way, b) two-way designs 
The transportation system allows allocating the equipment and the radiators at any place in the satellite. Besides, the transportation system based on an LHP can be enabled or disabled.

The rejection system is composed by multiple radiators that can be located at any external area of the spacecraft.

The isolation system will prevent incoming heat input from, typically, sun illumination.

A general conceptual scheme of the complete system is presented in Fig.1.5.

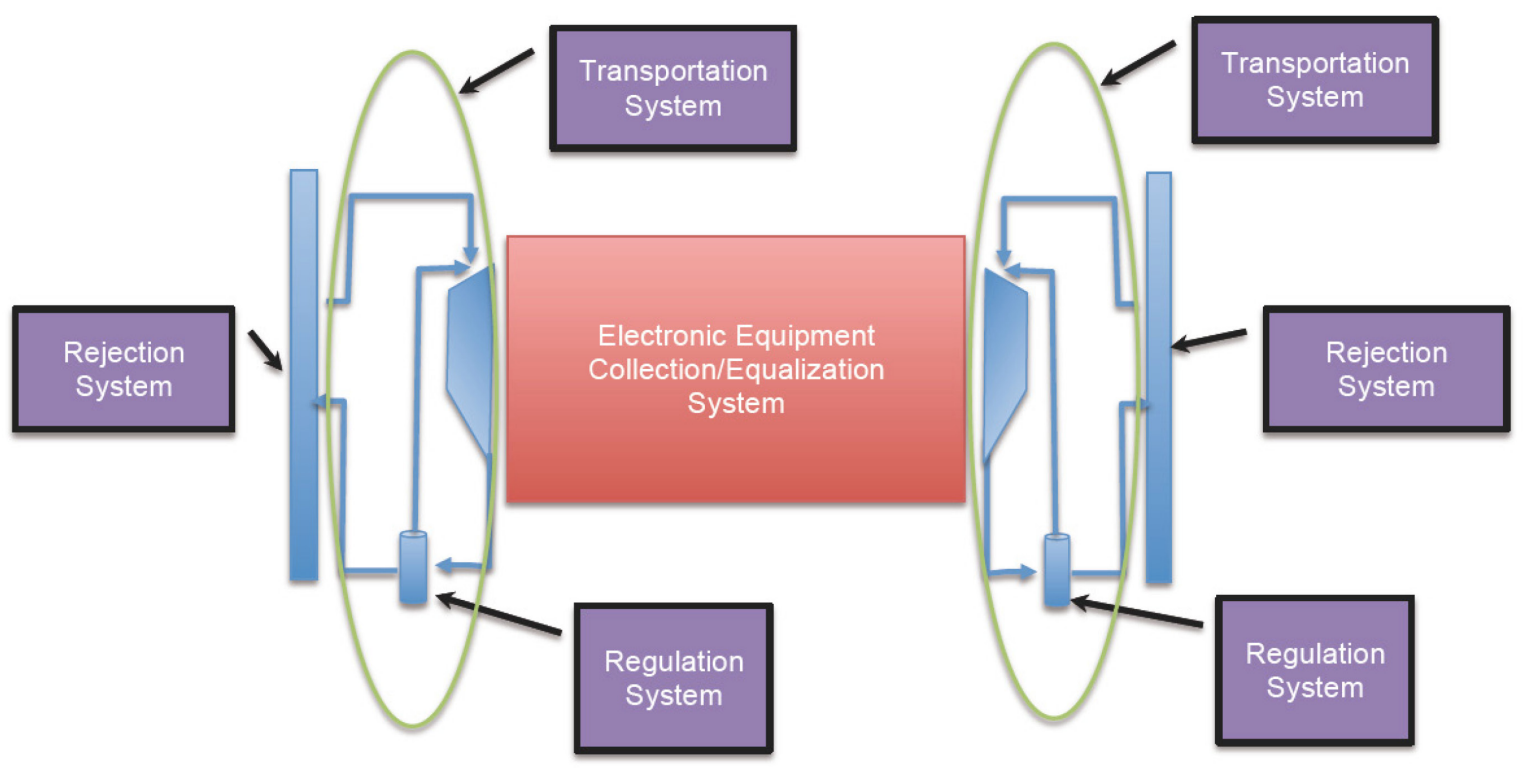

Figure 1.5. General overview of the thermal system architecture

The main features of this concept are: modularity, scalability, self-regulation, independence of satellite orientation in space, and autonomous operation. 
Furthermore, the system provides several advantages:

- Passive. There is no need of ground command.

- Energy efficient. The power budget for the thermal control system is reduced to zero or to the minimum in case survival heaters are needed to avoid working fluid freezing in the radiators.

- Possibility to manage high heat loads.

- Precision temperature control. It depends only on the regulator valve design and characteristics.

- Flexibility in electronic equipment arrangement inside the satellite. The LHP tubing lines have small diameters and it is very easy to make complex routing.

- It can be used for different space missions/orbits.

- Possibility to test the satellite on ground at any orientation. The LHP can operate at any position in the gravity field in contrast to ordinary constant or variable conductance heat pipes.

All the above reduce time, cost and the resources required for the spacecraft manufacturing, integration and testing.

\subsection{Thesis Scope and Objectives}

The main objective of this research is to design a complete thermal architecture based on LHP's with PRV connecting four radiators representing the four sides of a typical telecommunications satellite. The development of a 
numerical model to support the architecture design and its corresponding validation are also a main goal of the thesis.

The work performed prior to the start of this thesis is summarized in Fig. 1.6 to clearly show the connection between the previous work and the research undertaken during this thesis.

In October 2008, a patent application was filed for a thermal architecture concept. In this patent [1-3], general thermal architecture concept was proposed, which uses several radiators in a spacecraft to autonomously reject waste heat to radiators having their best environmental condition.

In February 2009, a flight opportunity to demonstrate the concept in space onboard the telecommunication satellite Hispasat $1 \mathrm{E}$ was approved by the Spanish satellite operator Hispasat. The demonstrator named Couple Radiator East and West (CREW) was a simplified version of the patented novel thermal architecture to prove the general concept.

CREW had a mass of $5 \mathrm{~kg}$ and was designed to handle a 70-W payload power dissipation. The design requirements also included that the system should withstand severe launch mechanical loads and in case of failure no propagation was extended to the Hispasat 1E mission. CREW development was therefore focused on testing the three-manufactured hardware for both thermal and mechanical subsystems, i.e. a qualification model, a proto-flight model and a flight model. The thermal mathematical modeling support was based on some high-level 
analytical models with simple assumptions.

In December 2010, H1E was launched and the In-Orbit Test (IOT) performance verification of CREW was realized. After the three months of these tests, the system was switched off, waiting the approval from Hispasat for operation. Then, the system was switched on in July 2011 and it is currently operational.

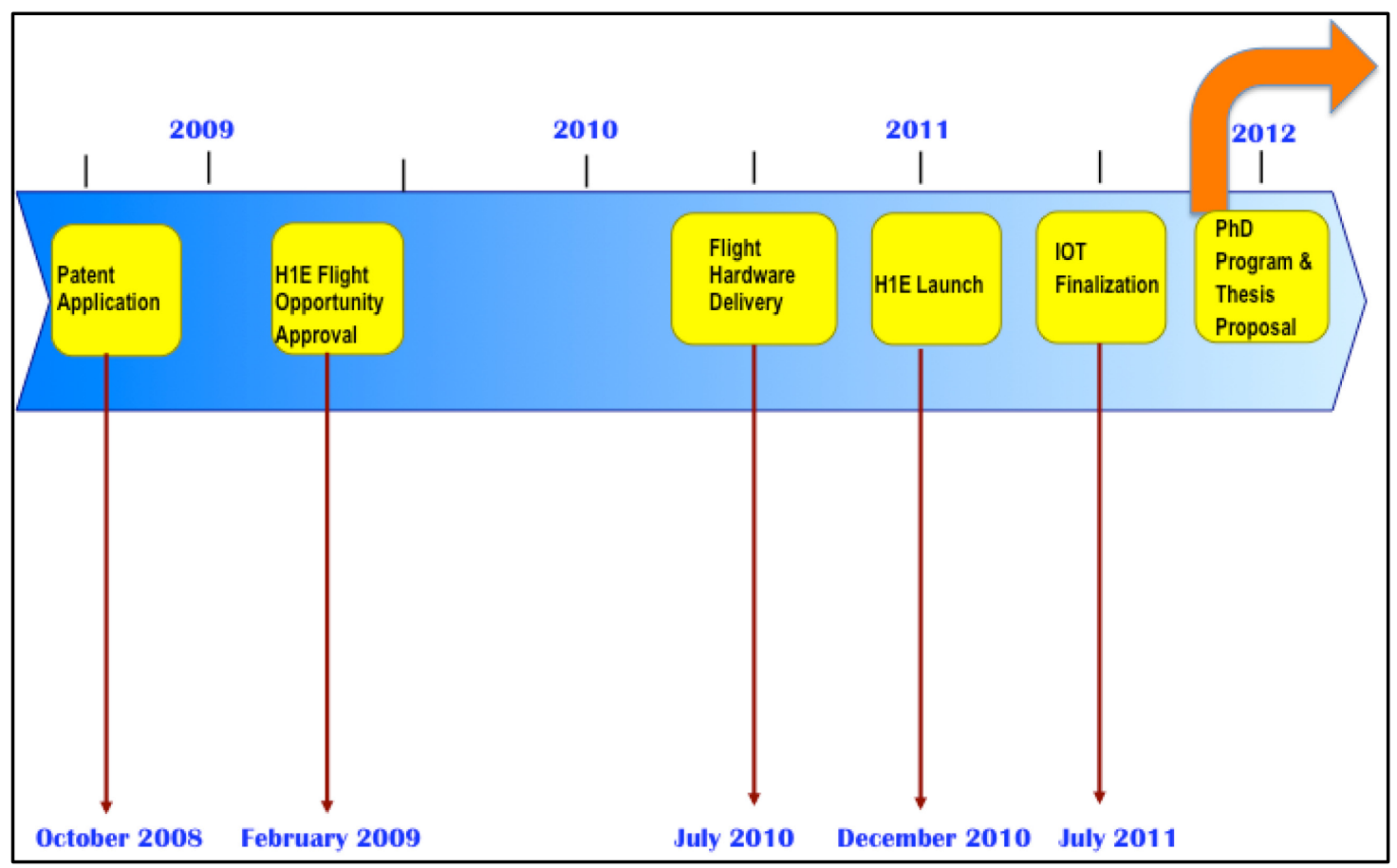

Figure 1.6. Thermal system architecture development historical timeline

The thesis development was structured in four main phases.

1. Phase 1: The first phase was devoted to an extended review of the state-ofthe-art relevant to satellite thermal architectures and LHP modeling.

2. Phase 2: The second phase was dedicated to modify an existing LHP 
numerical model for the purpose of designing the proposed thermal architecture including the modeling of PRV. The compound LHP plus PRV model will constitute the basic building block to develop the complete numerical model of the novel architecture. This phase is reported in manuscripts presented in Chapters 3 and 4 .

3. Phase 3: The third phase was split into two sub-phases. On one hand, efforts were focused to develop the numerical model to simulate the novel thermal architecture at system level and this was reported in manuscript presented in Chapter 5. On the other hand, the resulting model was compared with the data for a mathematical validation campaign. The test data used provided by the telemetry of the in-flight demonstrator on-board of the Hispasat 1E telecommunication satellite, and reported in manuscript presented in Chapter 6 .

4. Phase 4: The last phase used the validated numerical model to design a specimen consisting of four sets of LHPs (including radiator/condensers) plus PRV. The specimen was manufactured and tested according to typical power profiles and temperature variations. The objective of this phase was to verify the capability of the mathematical model to build more complex thermal architectures. This work is reported in manuscript presented in Chapter 7.

The content of this thesis is in manuscript form. Chapter 2 gives a general review of previous work relevant to this study and also some background knowledge. Chapter 3 studies the pressure regulating devices. Chapter 4 investigates the use of pressure regulating valves under active control. Chapter 5 
provides the mathematical model and the design cases analyzed. Chapter 6 shows the mathematical model validation against test flight data. Chapter 7 demonstrates the ability of the developed mathematical model to design a more complex thermal architecture consisting of four complete sets, including the model verification using an engineering model. Chapter 8 provides the general conclusions and recommendations for future work.

\subsection{Organization of the Thesis}

The thesis is a collection of manuscripts that have been reproduced in their published forms and overlaps have been avoided to a maximum extend. The following roadmap shows which chapters are already peer-reviewed and also where unavoidable overlapping materials are located. The reader may choose to skip some of this overlapping material without losing the flow of ideas.

- Chapters 3 and 4 are manuscripts published in Heat Pipe Science and Technology journal and thus have been peer-reviewed.

- Chapters 5 and 6 are manuscripts published in Applied Thermal Engineering journal and thus have been peer-reviewed.

- Chapter 7 is a manuscript that was presented in The International Symposium on Space Technology and Science Conference. This manuscript was invited for publication and it is currently under review in The Special Journal Issue of Transactions for The Japan Society for Aeronautical and Space Sciences, and it is currently under review.

- Overlapping materials are contained in the Chapter 2 (Literature Review) and in the experimental sections of Chapters $3,4,5,6$ and 7. 


\section{References}

[1.1] Spacecraft modular thermal platform. JP patent No: 2011-529586. A. Torres, D. Mishkinis, J. L. Pastor.

[1.2] Spaceship heat module. EP patent No: 2332839 A1. A. Torres, D. Mishkinis, J. L. Pastor. Pending.

[1.3] Spacecraft modular thermal platform. US patent No: 2011/0001,013. A. Torres, D. Mishkinis, J. L. Pastor. Pending. 


\section{Chapter 2}

\section{Literature Review}

\subsection{Orbit Issues}

Most of the spacecraft's components and subsystems operate in restricted temperature ranges. Spacecraft thermal control relies on the global spacecraft thermal balance: the heat loads must be rejected to deep space acting as thermal sink via thermal radiation through dedicated radiators installed on the satellite external surfaces.

The available area for these radiators is limited mainly due to limitations on the launcher's dynamic envelope. Most of the dissipative electronic equipment is located on these radiators, so the density of equipment, and therefore power dissipation density is increasing importantly.

The rationale followed to design a thermal control system starts by identifying the hottest conditions the satellite and on-board equipment will experience during the complete lifetime. The selection of the required radiation areas and their position to ensure comfortable maximum equipment design temperatures is the first step. With the selected radiation area, the coldest scenario is verified to identify whether the equipment still complies with the minimum design temperatures. If not, provision of electrical heaters, with the corresponding power consumption, is evaluated and quantified. This preliminary evaluation is followed 
by more and more design and analysis loops to tune the design so that all satellite parts rest within the prescribed operational requirements.

The design and analysis iterations include the evaluation of the performance to different types of hardware to tailor the thermal design. To name a few we can find, coatings (paints, surface treatments, mirrors), Multi-Layer Insulation (MLI), heaters, thermal washers, louvers, heat pipes, loop heat pipes, capillary pumped loops, mechanically pumped loops (either single or two-phase), etc. Given the variety of thermal requirements and the harsh space environment, these thermal elements must be selected, designed, manufactured, tested and integrated carefully [2.1].

The thermal design strategy is very dependent on the objective of the spacecraft and therefore the requirements imposed to the payload as well as the orbit selected, Fig. 2.1.

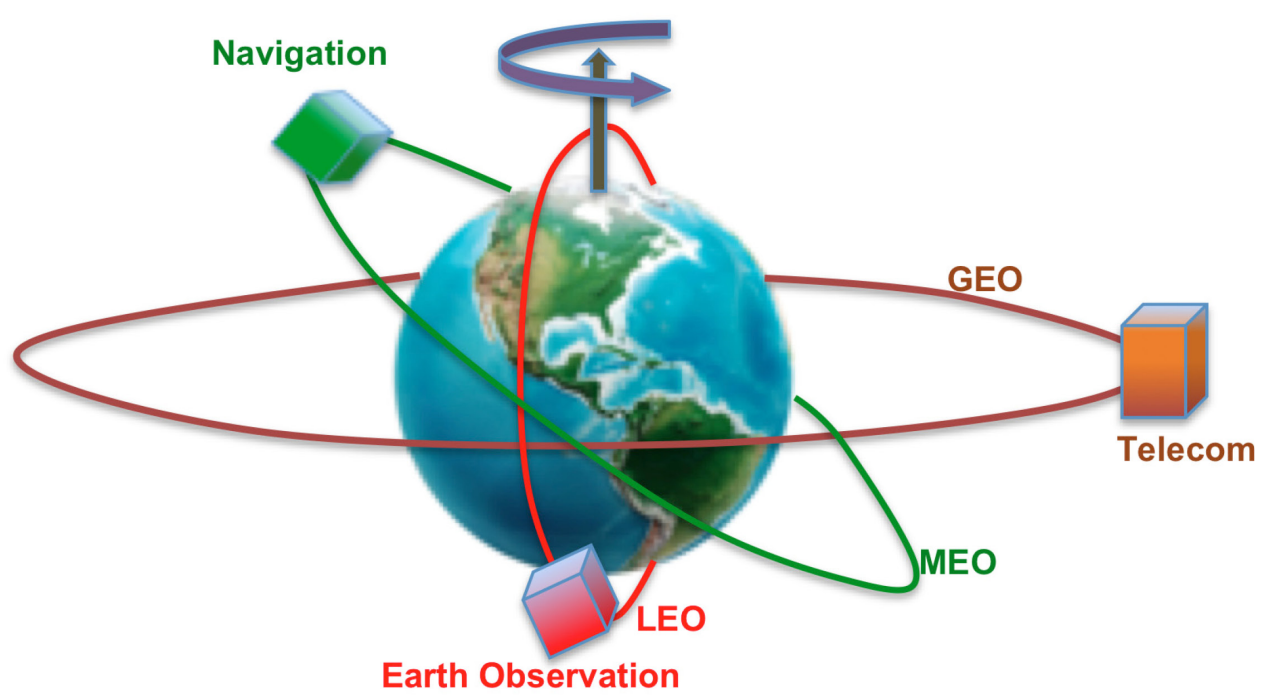

Figure 2.1. Typical satellite orbits (not to scale) 
Low Earth orbits (up to $900 \mathrm{Km}$ altitude), namely LEO, typically used for Earth observation purposes (weather, military, etc) brings a quite varying space environment (solar, albedo and Earth heat fluxes) which demands important electric power consumption to compensate the excursions of sun illumination on the thermal radiators. Thermal masses play also important roles to dump such variations in this type of orbits.

Medium Earth orbits, MEO (up to $22000 \mathrm{~km}$ altitude), as in the case of GPS constellation, have also external environmental excursions but much less, mainly to reduction of albedo factor and Earth radiation.

On contrary, HALO orbits selected to orbit around the Lagrangian Libration Points as shown in Fig. 2.2, provides very stable environmental conditions facilitating the design phases.

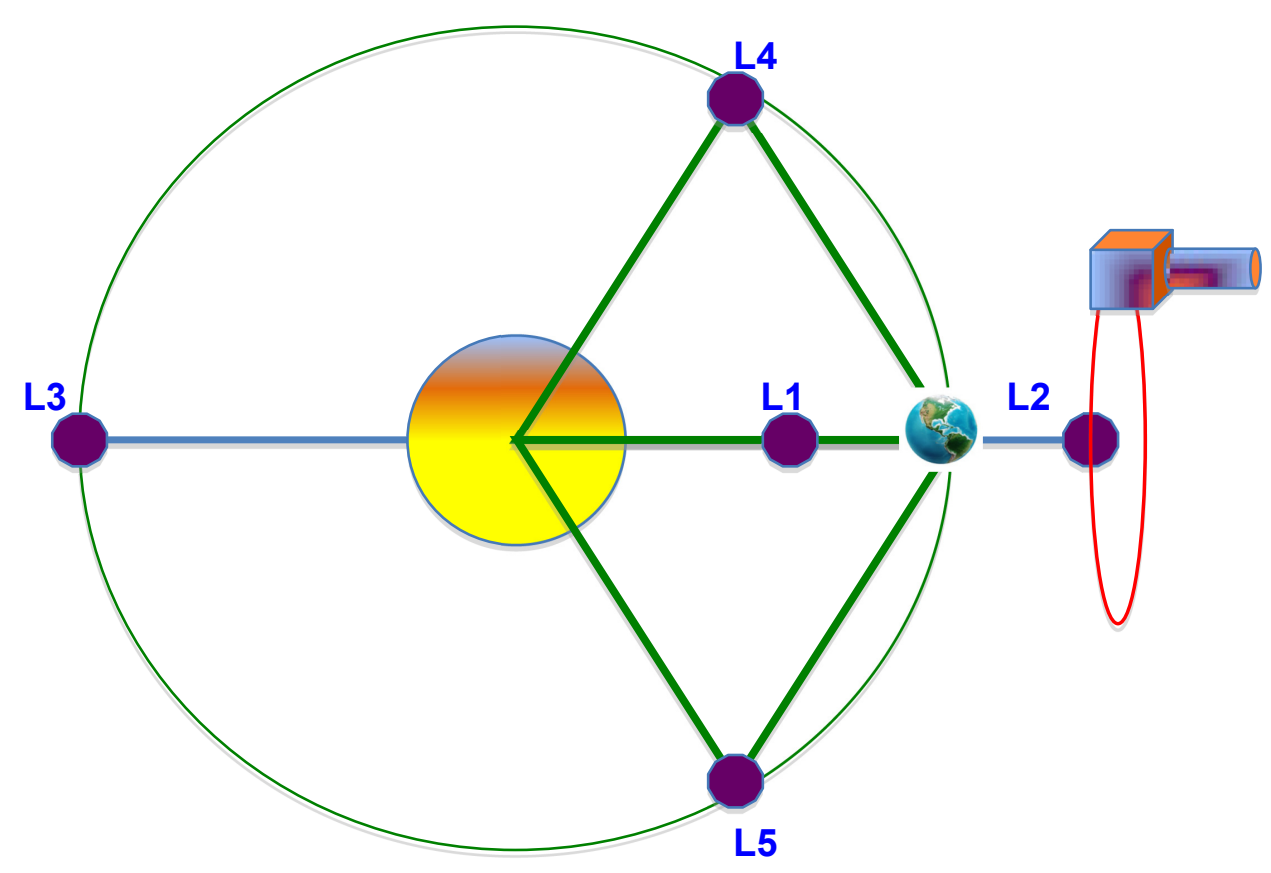

Figure 2.2. Lagrangian Libration Points (not to scale) 
The absence of albedo and Earth radiation in geostationary orbits (GEO up to $38,000 \mathrm{~km}$ altitude) for telecommunications satellites are also a good example on the stability of external environment [2.1].

\subsection{Thermal Issues}

Actual thermal designs are becoming more and more complex bacuse of two main reasons. On one side, to increase the number of transponders per satellite to make each satellite more profitable for the telecommunication operators. On the other side, the incorporation of new type of antennas (highly dissipative), such Ka and $\mathrm{Ku}$ bands, to respond to the new telecommunication market demands such High Definition TV.

Electronic equipment concentration and high power densities are increasing due to limitations imposed by the launcher's fairing envelops and the available north-south radiators area in telecom satellites [2.1].

\subsection{Common Thermal Architectures}

An advanced thermal architectures based on heat pipes was proposed in [2.2]. The purpose of the Thermal Canister Experiment carried by the Space Shuttle STS-3 flight was to determine the ability of a device using controllable heat pipes to maintain simulated instruments at selected temperature levels, in zero gravity and under varying internal and external thermal loads. A total of 11 data points were achieved during the flight, including the control of canister walls, of instrument 
simulators and of temperatures in two different zones, as well as passive thermal control. The set point variation ranged from $5^{\circ} \mathrm{C}$ to $23^{\circ} \mathrm{C}$, with power changes of 165-325 watts. Better fluid distribution in the heat pipes during zero-g operation showed improved performance over ground tests, and a temperature stability of $\pm 2^{\circ} \mathrm{C}$ was demonstrated between orbiter maneuvers in which the cargo bay was shadowed from the sun and those in which full solar exposure of the cargo bay existed.

Another thermal control system for a spacecraft minimizing the generation of vibration and inertia force by eliminating or minimizing rotation of a radiator was presented in [2.3]. The fluid system comprises a radiator panel, a control unit and selector valves. The heat generated inside the spacecraft is radiated into space by switching the selector valves without rotation of the radiator panel, so that generation of inertia force or vibration is prevented.

In 1998, Loral Space Communications Ltd. patented an increased satellite heat rejection system using a radiative surface, which was based on VCHP architecture [2.4]. The radiative surfaces were exposed to direct sunlight on an intermittent basis. The consequences of the direct solar exposure were a large increase in the radiator surface temperatures due to degradation of the absorptance value of the space radiator over the mission lifetime (15 years). This high temperature precludes utilization of these surfaces as radiators for continuously operating electronic equipment, which is normally constrained to a maximum mounting surface temperature of $55^{\circ} \mathrm{C}$. Therefore, these surfaces are only employed for equipment that can withstand high temperatures above $55^{\circ} \mathrm{C}$, or intermittently 
operated equipment, such as $(\mathrm{Ni} / \mathrm{H} 2)$ Batteries.

For a three-axis stabilized geosynchronous satellite in its orbit [2.4], four out of the six usual satellite surfaces is exposed to direct solar illumination on a 24-hour basis. Over a 24-hour orbital day, only north and south faces of the satellite escape direct solar illumination although even these faces are subject to $23.5^{\circ}$ incident angle for solar illumination in solstice, further limiting satellite thermal dissipation capacity. Therefore, with a right prismatic geometry, $67 \%$ of the satellite surface area is unavailable for electronic equipment, which operates continuously at $55^{\circ} \mathrm{C}$. This substantially limits high power capability of satellites and may lead to either multiple satellites for a single mission or larger body size satellites. Both of these solutions add cost. The patent described in [2.4] provides two approaches for continuous utilization of these radiator surfaces.

- Connect the thermal load to a phase change material (PCM), which is in turn connected to an intermittently available radiative surface with variable conduction heat pipe (VCHP) or diode heat pipe (DHP).

- Connect the thermal load to two or more opposed intermittently available radiative surface (east/west or earth/anti-earth) with sets of thermal conductors such as VCHPs or diode heat pipes (DHPs) which will not conduct heat from a hot radiator to the internal equipment.

The system provides a thermal radiator mounted on a face of the satellite for discharging heat from a thermal load to deep space. A heat conductor extends between the thermal load and the thermal radiator. The system also includes 
thermal switches operable for connecting/disconnecting the thermal load to the thermal radiator for cooling/heating when the temperature of the thermal load is above/below a predetermined level. One way of accomplishing this process is the use of VCHP architecture with active temperature control. Heaters are installed on VCHP reservoirs filled by non-condensable gas. Computers govern the heater power as a function of radiator temperatures; and dedicated temperature sensors have to be installed in every radiator. Although this system is based on a passive thermal control device, the complexity of the system in terms of operation is relevant.

In [2.5], a thermal control system controlling spacecraft's internal temperature by changing the reflectivity properties of the satellite walls. A sandwich of two layers made of inner aluminized Mylar composes the system. The sandwich is installed on the satellite walls. In the external layer of the sandwich, thermal control flaps are manufactured. Each flap contains a looped wire to create a magnetic field. Underneath each flap, a permanent magnet is installed under the internal sandwich layer. Both magnetic fields are opposite. A current regulation device similar to a thermostat switch controls (i.e. on/off) the current running on the wire of the flap, and therefore generating a magnetic field. When the satellite is exposed to direct solar radiation, the internal temperature of the spacecraft increases forcing the switch to close and it allows current to flow. This current causes the generation of a magnetic field opposite to the magnetic field generated by the permanent magnets. The repellent force created by the opposite magnetic fields causes the thermal control flaps to rise and exposing the aluminum surface of the internal sandwich layer. 
The patent presented in [2.6] describes a scalable instrument thermal control arrangement. The arrangement comprises one or more active cryo-coolers mounted on the spacecraft far from the instrument location to reduce the impact of cooler-induced mechanical vibrations. The cold side of the cryo-cooler is thermally connected to the instrument focal planes or other assemblies requiring cryogenic cooling. The warm side is connected to the spacecraft radiator panels for waste heat removal. The cooling needs to maintain the required instrument focal plane temperatures can be controlled during the mission by on-board flight software.

Another attempt to develop advanced thermal control system was described in [2.7]. The objective was to provide a system to store heat generated by a battery to reduce the amplitude of a temperature excursion. A heat absorber is thermally coupled to the battery. The heat absorber (HA) consists of high heat capacity heat absorbing material. The HA material is selected to exhibit an endothermic phase change at specified temperature within a range about $50^{\circ} \mathrm{C}$ to $80^{\circ} \mathrm{C}$. A proposed $\mathrm{HA}$ material is paraffin and is selected to have a melting point of about $75^{\circ} \mathrm{C}$, deposited into a fibrous containment mat preferably formed of dielectric fibers, such as Kevlar or fiberglass.

A spacecraft battery thermal management system was presented in [2.8] in which multiple radiator panels are thermally coupled to a battery using heat pipes. The heat pipes allowed the radiator panels to be located far from the battery and positioned on opposite sides of the spacecraft. When the sun illuminates one radiator panel, other radiator panel on the opposite side of the spacecraft 
dissipates excess heat from the battery. In this manner, the radiator panels can be positioned on the east and west facing sides of a spacecraft in a GEO orbit. One of main drawbacks of the system is that when the radiator is too cold the battery falls in temperature. To prevent this, compensation heaters are installed, and therefore satellite power consumption increases. Other important drawback is the limitation of the potential locations of the batteries within the satellite, since the length and number of bends of a heat pipe is limited.

In 2009, Astrium Ltd. patented a non-planar payload module structure, which was configured to support complete payload comprising sufficient closely packed mechanical/thermal modules [2.9]. This concept was developed to avoid the disadvantages of the standard concept for satellite payload configuration, which consisted of attaching the payload equipment on aluminum sandwich panels. A number of such panels make up an assembly called the Communications Module. Thermal dissipation is typically handled by a combination of locating the dissipative units on north and south facing radiator panels. The internal panels were thermally linked to the north and south facing radiators by heat pipes or pumped loops.

The LHP cooling system presented in [2.10] comprises LHP routed from internally facing surfaces of one or more internally located equipment panels to externally located radiator panels. Heat is collected at evaporator ends of each LHP and is transported to their respective condenser ends The LHP used in the cooling system have flexible transport lines, so that they can be routed to multiple radiator panels in order to optimize heat sharing between radiator panels. The total number of LHP used in the cooling system depends on the overall heat load. The 
system also comprises one or more fixed conductance heat pipes mounted to selected internally facing surfaces of the internally located equipment panels. The problem of this system is an impossibility to control the temperature of the equipment since LHP without a control mechanism will be subject to the sink temperature fluctuations.

As a conclusion, during last decade a significant increase of the amount of patents and publications dedicated to provide solutions to new thermal challenges based on two-phase technology and in particular LHPs is evident. An exhaustive description and historical development of such devices are provided by [2.11].

\subsection{Loop Heat Pipes Modeling and Background}

The transient modeling of the LHP systems have been highly difficult. Although there are several transient models published previously, complex architectures have been studied much less by mathematical modeling. Hoang and $\mathrm{Ku}$ [2.12] presented a transient LHP model based on the one-dimensional time-dependent conservation equations, which represent the entire LHP as a mass-spring-damper dynamical system. Although the main features of the transient LHP operation were simulated without the startup phase, the experimental correlations showed that the heat leak at low powers was largely underestimated. It was then proposed that the heat transfer mechanism across the wick differs at low and high powers.

A transient model including the startup transients developed using the thermal analyzer SINDA was presented by Cullimore and Bauman [2.13]. The thermal analyzer SINDA was also used by several authors for the LHP based thermal 
control systems simulation.

A software named EASY based on the lumped parameter method capable of simulating LHP startup under predefined initial conditions and architectures with more than one LHP was presented in [2.14]. The EASY code was later modified to be incorporated into the ESA's Thermal Analyzer (ESATAN) [2.15]. The main objective was to model LHP based spacecraft thermal control systems within the thermal analyzer, which has proven capabilities such as calculation of orbital heat fluxes, satellite level transient analysis etc. This project was later abandoned.

Vlassov and Riehl [2.16] presented a transient model which required experimentally determined values of the thermal conductances between the vaporliquid interface in the evaporator and in the compensation chamber. The comparison of the simulation and experimental results were in agreement within about $5^{\circ} \mathrm{C}$ for a heat load varying from 2 to $60 \mathrm{~W}$.

A comprehensive transient mathematical model was published by Pouzet et al. [2.17]. This work included a model for the interface in the evaporation zone and the variations in the meniscus curvature (curve in the upper surface of a liquid in contact to another object caused by the surface tension). It was demonstrated that the dynamic couplings between the components play an important role in the formation of instabilities following a sudden power change.

Nishikawara et al. [2.18] presented a transient model based on the onedimensional mass, momentum, and energy conservation laws and thermodynamic 
relationships. The model results were confirmed by comparing them with the experimental results obtained from two miniature LHPs. No time lag between the calculated and experimental results was observed when the power was changed, which has been a major problem for the previously published transient models. Some temperature overshoots observed in the simulations was attributed to the large thermal mass used in the experimental setup.

Among the complex architecture simulations, Nadalini and Bodendieck [2.19] developed a mathematical model within the ESATAN software by means of subroutines. The paper describes the thermal control design of a lander vehicle to be used within the Mars Netlander mission. The design includes an LHP circuit to transport the excess heat from the RHU units during hot environments. A breadboard representing the thermal design was built and tested. The LHP characteristics (thermal conductivities and capacitances etc.) were chosen to post fit the experimental results. Although the comparison results proved the approach, the results were not very satisfactory. The authors recommended a more detailed and accurate mathematical formulation without a need to post fit the data so that the model results can be truly verified.

Another example of complex architectures is discussed in [2.20]. The paper presents the system model of the Alpha Magnetic Spectrometer (AMS-02), based on SINDA software package. The LHP parts were modeled by using the pre-built subroutines within SINDA. Boundary conditions for the LHP model were included as time-varying arrays previously calculated from the global thermal mathematical model. Large computational time, i.e. days, were identified by the authors. A 
parametric study showed that the thermal control requirements cannot be met without a bypass valve. In a follow-up study in [2.21], a SINDA based mathematical model was used to support the design phase of the Cryomagnetic Avionic Box (CAB) of AMS-02. Only one of the two LHPs included in the thermal design was modeled to avoid excessive computing time. Through a parametric and sensitivity analysis the authors analyzed some of the LHP parameters and identified an overtemperature problem in the design. No validation of the model predictions was provided.

More recently, [2.22] a numerical thermo-hydraulic model of a complete LHP was presented. The model represents a disk-shape evaporator type LHP, mainly devoted to non-space applications. Although it is a steady-state model, the authors have included a 2-D modeling of the wick and casing to accurate predict heat flux distribution. Also, although already incorporated in other related studies, the model includes transport lines and condenser modeling to investigate their impacts on the LHP operation. The study has been compared with already exiting experimental data. Authors claim a good agreement between model and experimental available data highlighting the importance of the evaporation coefficient and wick conductivity on the LHP operating temperature. Increases of parasitic heat losses through evaporator casing reduces evaporation rate leading to larger operating temperature, especially combined with substantial heat conduction in the evaporator body.

The operational characteristics of the LHPs are not discussed here and a detailed description of the operation of LHP can be found in [2.23] and [2.24]. A 
complete set of equations and assumptions taken into account for the modeling of the LHP as part of the thermal mathematical model of the novel architecture, investigated in this thesis can be found in [2.25].

\section{References}

[2.1] D. G. Gilmore, Spacecraft Thermal Control Handbook. El Segundo, USA, 2002.

[2.2] Thermal control canister. US Patent 4162701. S. Ollendorf, NASA, 1979.

[2.3] Thermal control system for spacecraft. JP Patent 2001315700. S. Kawashaki, MHI, 2001.

[2.4] Sequenced heat rejection for body stabilized geosynchronous satellites. US Patent 6073888. W.S. Gelon, J.C. Hall, C. J. Goodman, Loral Space \& Communications Ltd., 2000.

[2.5] Thermal control system for controlling temperature in spacecraft. US Patent 6511021. N.A. Keramidas, 1998.

[2.6] Scalable thermal control system for spacecraft mounted instrumentation. US Patent 7270302. H. Wong, N. Goodzeit, LMM, 2007.

[2.7] Method and apparatus for amplitude limiting battery temperature spikes. US Patent 7893659. H. Tsukamoto, D. Skinlo, C. Kishiyama, J. Dodd, Quallion LLC, 2008.

[2.8] Spacecraft battery thermal management system. US Patent 7967256. $\mathrm{H}$. Wong, LMM, 2007.

[2.9] Payload modules. US Patent 8096512. A. G. Russell, Astrium Ltd. 2012.

[2.10] Spacecraft multiple loop heat pipe thermal system for internal equipment panel application. US Patent 6478258. E. M. Yee, SS/L Inc. 2002.

[2.11] D. Mishkinis, G. Wang, D. Nikanpour, E. MacDonald, T. Kaya,. Advances in two phase loop with capillary pump technology and space applications, International Conference on Environmental Systems, Rome, Paper no. 2005-012883, 2005. 
[2.12] T. Hoang, J. Ku, Transient modeling of loop heat pipes, International Energy Conversion Engineering Conference, Portsmouth, Virginia, Paper no. AIAA-20036082, 2003.

[2.13] B. Cullimore, J. Baumann, Steady state and transient loop heat pipe modeling, International Conference on Environmental Systems, Toulouse, Paper no. 2000-01-2316, 2000.

[2.14] K. Goncharov, O. Golovin, V. Kolesnikov, Loop heat pipe with several evaporators, International Conference on Environmental Systems, Toulouse, Paper no. 2000-01-2407, 2000.

[2.15] R. Schlitt, D. Labuhn, V. Vlassov, J. Ochterbeck, O. Pin, ALGOCAP: Assessment of thermo-hydraulic algorithms for CPLs and LHPs, $16^{\text {th }}$ European Thermal \& ECLS Software Workshop, Noordwijk, The Netherlands, October 22-23, 2002.

[2.16] V. Vlassov, R. Riehl, Mathematical model of a loop heat pipe with cylindrical evaporator and integrated reservoir, Applied Thermal Engineering, Vol. 28, Nos. 89, pp. 942-954. 2008.

[2.17] E. Pouzet, J.L. Joly, V. Platel, J.Y. Grandpeix, C. Butto, Dynamic response of a capillary pumped loop subjected to various heat load transients, International Journal of Heat and Mass Transfer (47) 2293-2316. 2004.

[2.18] M. Nishikawara, H. Nagano, T. Kaya, Transient thermo-fluid modeling of loop heat pipes and experimental validation, AIAA Journal of Thermophysics and Heat Transfer, Vol. 27, No.4, October-December 2013, pp. 641-647. 2013.

[2.19] R. Nadalini, F. Bodendieck, The thermal control system for a network mission on Mars: the experience of the Netlander mission, Acta Astronautica 58 pp. 564-575. 2006.

[2.20] G. Xin, L. Cheng, W. Du, T. Luan, Y. Qu, S. Zinna, M. Marengo, M. Molina, J. Burger, Modeling of a real LHP and integration in a system level analysis, International Conference on Environmental Systems, Norfolk, Virginia, Paper no. 2006-01-2228, 2006.

[2.21] M. Marengo, S. Zinna, M. Molina, Numerical model of the LHP for the thermal control of the cryomagnet avionic box (CAB) mounted on the AMS-02 
experiment, VII Minsk International Seminar "Heat Pipes, Heat Pumps, Refrigerators, Power Sources", Minsk, Belarus, September 8-11, 2008.

[2.22] B. Siedel, V. Sartre, F. Lefèvre, Numerical investigation of the thermohydraulic behaviour of a complete loop heat pipe, Applied Thermal Engineering 61 pp. 541-553. 2013.

[2.23] J. Ku, Operating characteristics of loop heat pipes, $29^{\text {th }}$ International Conference of Environmental System, Denver, Colorado, Paper No: 1999-01-2007, 1999.

[2.24] Yu. F. Maydanik, Review loop heat pipes, Applied Thermal Engineering 25 pp. 635-657. 2005.

[2.25] T. Kaya, R. Perez, C. Gregori, A. Torres, Numerical simulation of transient operation of loop heat pipes, Applied Thermal Engineering 28 pp. 967-974. 2008. 


\title{
Chapter 3
}

\section{Thermal control of loop heat pipe with pressure regulating valve}

(Manuscript published in Heat Pipe Science and Technology, Vol. 3(2-4), pp. 263280, 2012. DOI: 10.1615/HeatPipeScieTech.2013006631)

\begin{abstract}
An innovative approach to regulate operation temperature of a loop heat pipe (LHP) with two-way valve is discussed. Comparison with a traditional three-way bypass valve is presented. It is found that a two-way valve design provides better thermal control than a traditional three-way design and has significant advantages. Some examples of two-way valve application are presented. Heat transfer limitation of an LHP with pressure regulating valve is verified. Both modes of pressure regulating valve (PRV) application demonstrated practically the same maximum heat transfer rate. It is also found that the maximum heat transfer capacity of an LHP with a PRV is higher than an LHP without a valve. Start-up ability of an LHP with and without PRV is also compared. It is observed that the PRV can facilitate the LHP start up.
\end{abstract}




\section{Key words}

Loop Heat Pipe, Pressure Regulating Valve, Two-way Regulation Mode, Spacecraft Thermal Control

\subsection{Introduction}

Loop heat pipes (LHP) are widely used for thermal control of spacecraft electronic equipment. For a number of satellite operational scenarios the temperature of LHP condenser can decrease significantly. That causes the lowering of LHP evaporator temperature and therefore temperature of the LHP controlled equipment. Thus, onboard equipment temperature can decrease below an acceptable value. To prevent the equipment overcooling the pressure regulating valve (PRV) can be used. Other fields of PRV applications are precise temperature control of satellite equipment and "thermal switch" for Lunar and Mars rovers [3.1]. PRV has feedback from vapor temperature of LHP and can keep the temperature of the equipment at required level. This method of temperature control has a number of advantages in comparison with other techniques [3.2].

\subsection{Two-way and three-way pressure regulating valve design and operation principle comparison}

Usually the three-way valves are used for an LHP to redistribute vapor flow between the main LHP loop where the PRV links condenser, vapor line and compensation chamber. The incorporation of a three-way regulating valve in vapor 
line was proposed in the process of an ESA Two-Phase experiment (In-orbit Technology Demonstration Program aboard Space Shuttle STS-60, February 1994, [3.3]) TPX is a scaled-down capillary pumped two-phase ammonia system with multichannel condensers, vapor quality sensors (VQS) and a controllable three-way valve (Fig. 3.1). One of TPX objectives was the in-orbit calibration of the vapor quality sensors, by adjusting the three-way controllable valve, mixing the bypassed vapor with liquid leaving the condenser.

The idea to use by-passed vapor for heating of the LHP compensation chamber or liquid line and finally, for the control of equipment temperature with the help of a three-way pressure regulated valve (Fig. 3.2), was proposed by Lavochkin/TAIS and successfully realized in a number of onboard thermal control systems, including Russian Mars Rover application [3.4-3.6]. The same approach (three-way valve) was originally pre-selected for European Mars Exploration Program and a prototype has been extensively tested [3.7-3.9]. It was found that for certain combinations of condenser temperature and input power, the temperature oscillations (in the range of several degrees) are possible due to the gravity effect. It has a minor influence on the LHP thermal switch functional performance. Detailed explanation of this phenomenon has been presented in [3.10]. However, in case of regulation temperature being very low (below $-20^{\circ} \mathrm{C}$ ) the oscillation amplitudes can reach 10 degrees and even higher. 


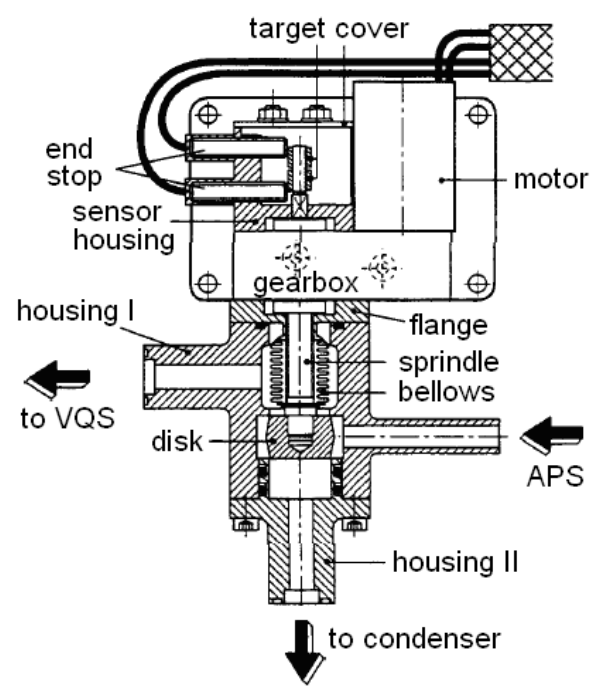

Figure 3.1: TPX three-way valve [3.5] Figure 3.2: TAIS three-way valve [3.6]

The main drawback of the three-way regulating valve is the following: in case of even a very small vapor flow leakage into the bypass line, the performance (conductance) of the LHP will degrade, particularly for the operational regimes when the bypass line is closed and the two-phase loop is working as a regular LHP without the valve. It means that possibility of heat source overheating above an acceptable limit exists, since temperature difference between the evaporator and the condenser increases. It is difficult to avoid the leakage since the typical material for evaporator capillary structures is metallic powder and the particles of the powder can appear and migrate inside the loop during the LHP operation. These particles can deposit on the valve stem and seats and cause the vapor leak into the bypass line. Actually, the leakage in the bypass line produces the same effect as a parasitic heat leak from the evaporator into the compensation chamber: difficult start-up, low LHP thermal conductance, instabilities at transient regimes, etc. 
To overcome the above noted drawbacks of the three-way regulating valve, a new method of evaporator temperature control is proposed [3.11]. In fact, this approach simplifies the current design of the three-way regulating valve up to a two-way regulating valve and eliminates the necessity of the bypass line (Figs. 3.1, 3.2). The two-way valve has only one input and one output (Fig. 3.3). Other elements are the same as the three-way valve.

However, the law of valve regulation is different. Since the LHP is an evaporating- condensing heat transfer device, it operates around vapor-liquid saturation line. The increase of pressure drop of the external loop of LHP (the drop between vapor and liquid

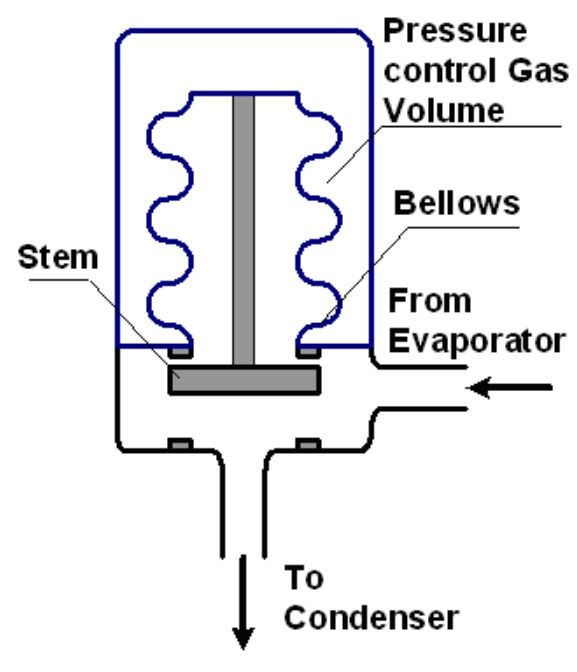

Figure 3.3: Two-way pressure regulating valve

sides of evaporator porous structure) leads to the corresponding increase of temperature difference between evaporator and condenser. This effect is used in case of the two-way regulating valve LHP. 


\subsection{Three-way and two-way valve operation comparison}

\subsubsection{Three-way PRV operation description}

A scheme of the three-way valve is given in Fig. 3.2 above. The operation description is provided in $[3,10]$ and reproduced here to easy the reader.

The bellows separates the back pressure reservoir from the working fluid. The back pressure is provided normally by argon although other gases can be used.

The valve piston is subjected to the back pressure, the working fluid pressure and the bellows force. The bellows behaves as a spring with an elastic coefficient.

Once the valve is charged with the back pressure, if there is a very low working fluid pressure coming from the evaporator inlet, the valve piston is pressed in the bottom position (in accordance with Fig. 3.4a), closing the radiator path. In this configuration the flow is completely diverted to the bypass line. For increasing working fluid pressure, the piston keeps this position until a first characteristic pressure is reached (called set point pressure) for which the piston starts to take off from the seat (see Fig. 3.4b). This set point pressure is a function of the back pressure and the bellows preload. 

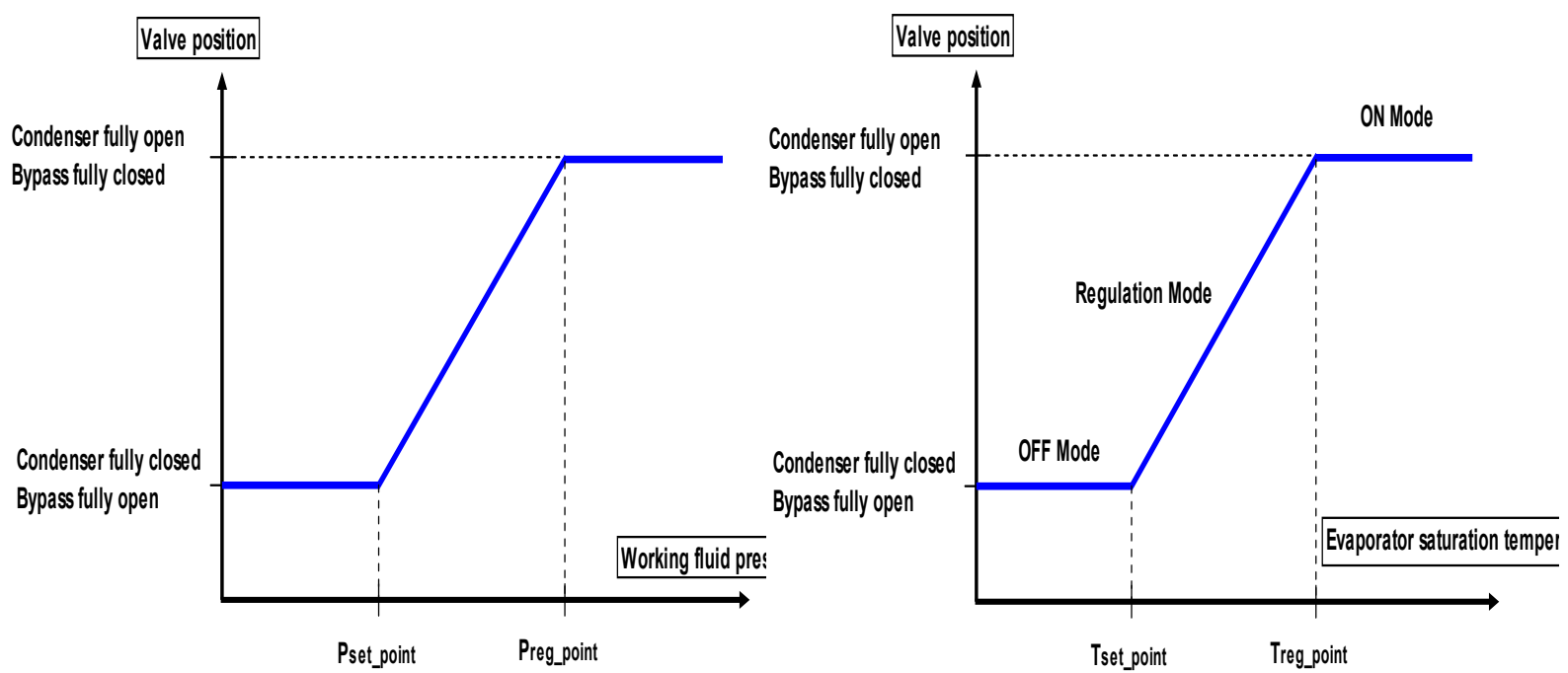

Figure 3.4a: Valve position vs. working Figure 3.4b: Valve Operation Modes fluid pressure

For further pressure increase, the piston runs the distance between the bottom and the top seat. Under this configuration, the flow is split between the bypass line and the condenser paths. This situation is kept until the piston reaches the upper seat for another characteristic pressure knows as regulation point pressure. In this position, the condenser path is totally open and the bypass path fully closed. This second pressure is a function of the back pressure, the bellows preload and the valve stroke. For increasing working fluid pressure, the piston keeps in this position.

The pressures mentioned for Fig. 3.4a translate into temperatures in accordance with the saturation line of the working fluid. These temperatures are the LHP evaporator saturation temperatures. The evaporator saturation temperature cannot usually be measured. The temperature measured in the evaporator takes into account the thermal resistance of the evaporator case and saddle, and the vapor line temperature is normally superheated. In any case, the difference between the saturated and measured temperatures is small and the measured evaporator 
temperature is used as the related saturated one. The nearest saturated temperature that can be measured is the reservoir one. Therefore, the temperature of valve regulation corresponds first of all to the measured temperature of compensation chamber. This temperature is slightly lower than the evaporator one.

The pressure difference between the set and regulation points is only a function of the bellows spring coefficient and the valve stroke, and it is usually in the range 1 -2 bar. For a specific valve, it is a constant parameter. However, it provides variable temperature differences between the mentioned set and regulation points. Effectively, the same pressure difference translates in different temperature differences in accordance with the valve set point established and the related $\mathrm{dP} / \mathrm{dT}$ derivative of the saturation line. For low set points, the derivative is small and the temperature difference is more important than for high set points. This temperature difference is often referred as the valve transition range.

When Fig. 3.4a is translated in temperatures, Fig. $3.4 \mathrm{~b}$ is obtained. We can distinguish 3 zones on this figure. For temperatures below the set point, the flow is completely diverted to the bypass line. This operation mode is called OFF mode because no power removal is performed.

For temperatures between the set and regulation points the flow is split between the condenser and the bypass line. This regime is called regulation mode. For temperatures above the regulation point, the working fluid is fully directed to the condenser, the LHP behaves as a regular LHP without valve and this regime is called ON mode. 
When there is heat load applied to the LHP evaporator and the LHP has startedup, the OFF mode cannot be maintained steadily since no power removal is performed and the evaporator increases its temperature. As soon as the evaporator reaches the set point temperature, the condenser circuit starts to be open and power removal can be carried out. The valve will then operate in regulation or ON mode.

For a given regular LHP (without valve), the operating temperature (evaporator) is determined by the thermal power, the sink temperature and ambient conditions. $A$ valve introduced in this LHP has the ability to increase the operating temperature as long as the regulation point is set above it. This effect is obtained because the "conductance degradation" provided by the bypassed hot vapor injected in the reservoir or liquid line. It is somehow equivalent to the working temperature raising brought by the operation of a heater on the compensation chamber.

It is obvious this regulation capacity of the valve is confined to the combinations of thermal power/sink conditions for which the LHP regular operating temperature is below the regulation point of the valve.

When the LHP with valve is working, the evaporator temperature cannot be below the set point. Effectively, if it were below the set point, the flow circulation would be established only in bypass mode. Under this circumstance, no power removal would be performed and the evaporator temperature should increase until the condenser path is to some extent open. Therefore, the set point is defined as the minimum possible evaporator temperature when the LHP is in operation. 
The question now is to what extent the condenser path will open. The answer is clear if one considers that the thermal load shall be removed in the condenser. This power removal is mainly performed by condensation. If the most part of the vapor is not sent to the condenser, the power still to be rejected after vapor condensation would require a very high liquid sub-cooling that could not be produced by the existing sink conditions. Therefore, the actual valve operating conditions is with the condenser almost totally open and just a small bypassed vapor flow. This configuration corresponds to a working fluid pressure near the regulation point. The resulting evaporator temperature is then very close to the regulation point (hence the origin of this name). However, for low thermal powers and high sink temperatures (where the bypass path can provide some cooling capacity) or in the presence of gravity assistance effect (thermo-syphon configuration), the operating point can sometimes drift towards the set point.

\subsubsection{Two-way PRV operation description}

In case the PRV is operated as a two-way valve, the evaporator temperature is not close to the regulation temperature but close to the set point temperature. Effectively, since there is not bypass flow, the degradation of the conductance is obtained by introduction of pressure drop in the vapour line and this is achieved by the piston positioning very close to condenser totally close (set point).

To explain the principle of a two-way regulating valve LHP operation the general functional P-T diagram of LHP (Fig. 3.5) will be used. 
Since LHP is an evaporating- condensing heat transfer device, it operates around vapor-liquid saturation line SL. Two cycles are shown on the Fig. 3.5: blue (solid) and red (dashed) lines. We will use the blue line to explain the cycle diagram. At the position 1, liquid evaporates from the porous structure and moves to the evaporator outlet 2 (some vapor overheating can take place).On the way to the vapor line (path 2-3), the temperature is practically constant but the pressure is reduced. In the condenser (path 3-4-5-6), the vapor cools down up to the saturation state (3-4), condenses (4-5), and the condensed liquid is subcooled (56). Pressure is reduced while the liquid is on the way to the evaporator (6-7) due to the friction losses in the conduit. In the compensation chamber of LHP, the vapor phase is usually present and the liquid is in equilibrium with vapor (7-8). Liquid is superheated and pressure is further reduced during the filtration through the porous structure (8-9). The cycle is closed at vapor-liquid interface - meniscus where evaporation takes place (9-1). Point 9 corresponds to the liquid phase just under the meniscus and point 1 corresponds to the vapor phase just above the meniscus. Detailed description of the LHP functional diagram can be found in [3.11].

As it is clear from diagram, the increase of pressure drop of the external loop of LHP (the drop between vapor and liquid sides of evaporator's porous structure) from DPext to DPext' leads to the corresponding increase of temperature difference between the evaporator (Top) and the condenser (from Tc to Tc'). This effect is used in case of two-way regulating valve LHP. 
For instance, at given conditions of heat sink and input power, the LHP operates according to the blue solid line. The reducing of heat sink temperature has to lead to the reduction of operational temperature Top (and the corresponding operational pressure Pop) but, in the presence of a two-way regulating valve in the loop, it is impossible. If the operational pressure in the LHP is less than the valve's backpressure of inert gas in the upper chamber, the valve stem will close the vapor line and circulation will be totally stopped. In real situation, the valve stem will go down and close part of the outlet cross section of the valve. It means that the pressure drop in the vapor line will rise (from 2-3-blue solid line to 2-3'- red dashed line), consequently, the total pressure drop will also increase (from 1-9 to 1-9'). It will force the conductance of LHP to degrade and the temperature control of the LHP will be achieved: the change of heat sink temperature does not cause the reducing of evaporator temperature.

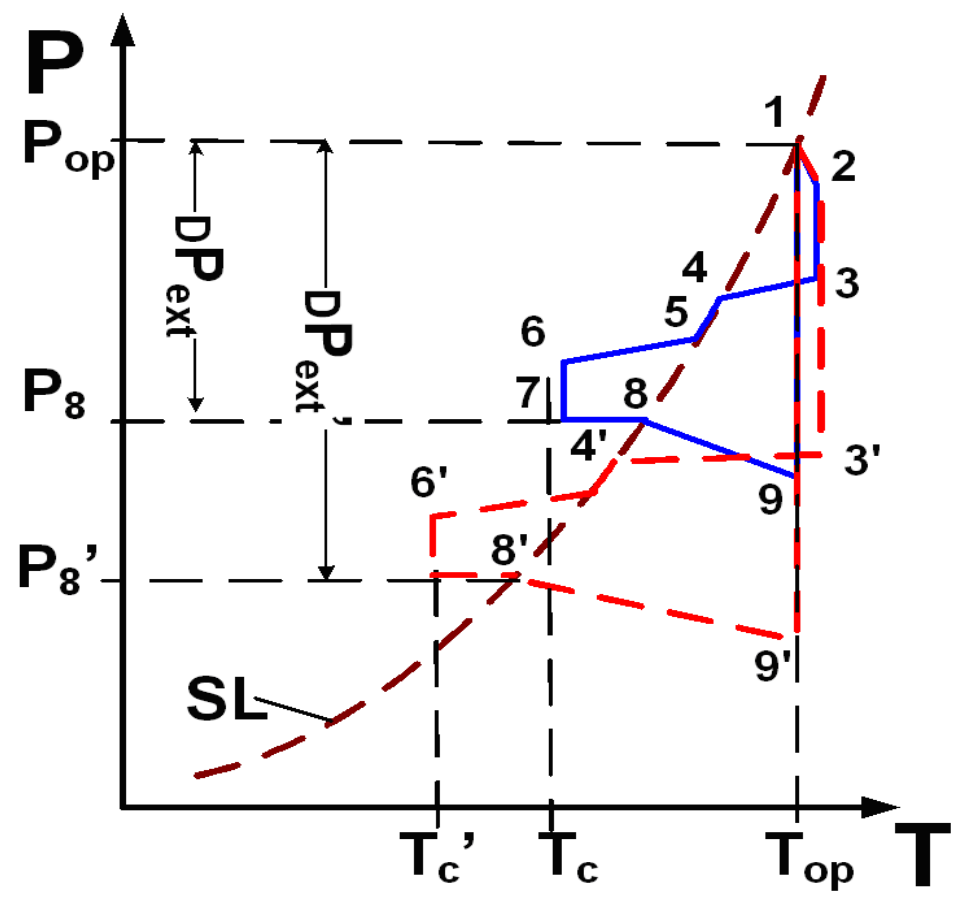

Figure 3.5: Pressure-Temperature diagram of LHP operation 
It has to be mentioned, that an introduction of an additional hydraulic resistance into the vapor line finally leads to the increase of the parasitic heat leak from the external vapor part of the capillary structure to the internal part of the structure (to the compensation chamber).

The two-way valve is able to adjust automatically the hydraulic resistance of the circuit by adjusting the hydraulic resistance of the vapor transport line. The twoway regulating valve acts on the hydraulic resistance of the vapor line by means of acting on the fluid flow through it, by changing the cross section of the line, thus varying the LHP external pressure difference. In this way, the temperature of the evaporator is maintained close to constant and is independent of the condenser temperature.

\subsubsection{Experimental LHP description}

A miniature LHP (MLHP) equipped with pressure regulating valve was designed, manufactured and tested [3.12] to characterize the LHP performance. Special investigation was performed with objectives to compare and verify operation of LHP with the three-way and two-way valves and to find limitations of LHP operated with the two different regulating valves. This LHP is shown in Fig. 3.6. The PRV is installed on top of the evaporator saddle.

Main dimensions are shown in Table 3.1. Wick properties of the MLHP are presented in Table 3.2. PRV set point is $4^{\circ} \mathrm{C}$ and regulation point $12^{\circ} \mathrm{C}$. 


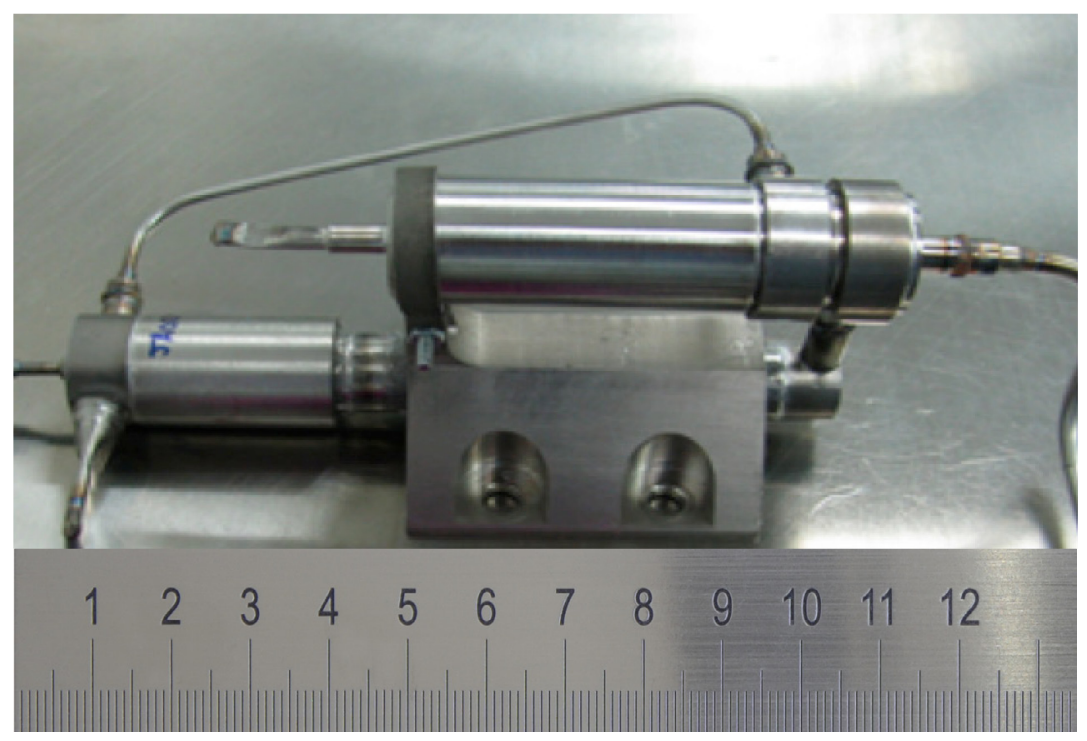

Figure 3.6: Mini-LHP with PRV

Table 3.1. MLHP main dimensions

\begin{tabular}{|l|l|l|}
\hline Component & $\begin{array}{l}\text { Length } \\
(\mathrm{mm})\end{array}$ & $\begin{array}{l}\text { Diameter } \\
(\mathrm{mm})\end{array}$ \\
\hline Evaporator & 55 & 12 \\
\hline Condenser & 300 & 2 \\
\hline Reservoir & 30 & 16 \\
\hline Vapor Line & 700 & 3 \\
\hline Liquid Line & 700 & 2 \\
\hline
\end{tabular}

Table 3.2. Wick properties of the MLHP

\begin{tabular}{|l|l|}
\hline Characteristics & LHP-SS \\
\hline Wick Material & $\begin{array}{l}\text { Stainless } \\
\text { Steel }\end{array}$ \\
\hline Porous diameter $(\mu \mathrm{m})$ & 3.5 \\
\hline Porosity $(\%)$ & 70 \\
\hline
\end{tabular}




\begin{tabular}{|l|l|}
\hline Permeability $\left(\mathrm{m}^{2}\right)$ & $6.5 \mathrm{E}-13$ \\
\hline
\end{tabular}

\subsubsection{Test description}

The thermocouple locations for the MLHP are shown in Fig. 3.7.

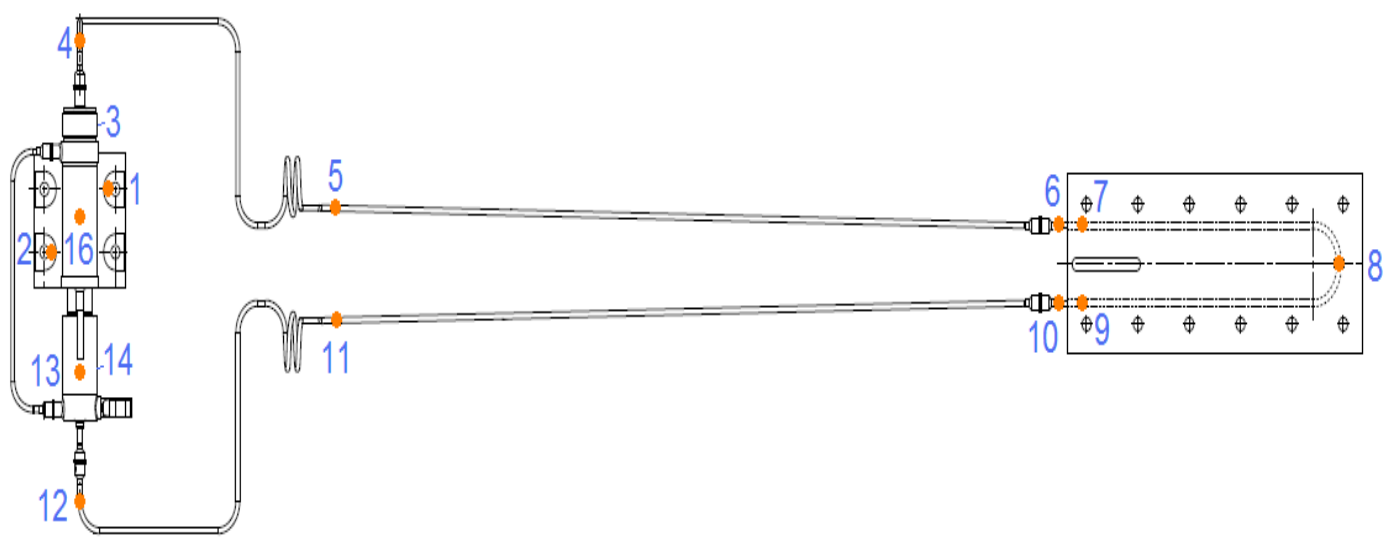

Figure 3.7: Mini-LHP and thermocouple locations 


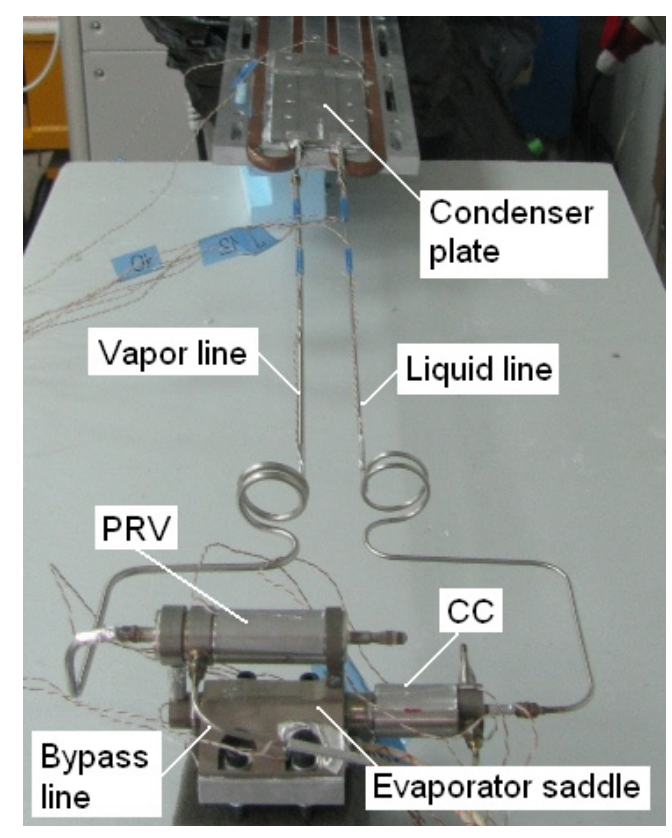

Figure 3.8: MLHP on the test bench

The condenser plate was set in contact with the cold plate of the chiller. The evaporator saddle was attached to the saddle of the cartridge heater (which provides the power dissipated by the MLHP). During ambient tests, the MLHP was thermally isolated. T-type thermocouples were used to monitor of MLHP temperatures. A photograph of the MLHP on test bench can be seen in Fig. 3.8.

Performance tests were carried out for different LHP configurations. Initially, the MLHP was tested as it was manufactured with a three-way valve. Then, the bypass line was pinched to change mode of operation to the two-way valve. Pressure of argon inside the valve remained the same that led to moving of temperature of regulation to set point temperature. To verify influence of temperature of the PRV on the maximum heat transfer capability, several tests were performed. Argon reservoir of the PRV was connected to an argon tank with ability to regulate the 
argon pressure. Finally, argon was completely removed from the valve to have the MLHP operated like a LHP without valve.

The PRV can operate only when natural operation temperature (which the LHP could have without the PRV) is less than the temperature of regulation. We will consider such conditions as cold case. Conditions when the PRV is beyond regulation can be considered as hot case.

During tests, the cold plate temperature was maintained constant with stepwise increments of power.

\subsubsection{Test results}

During the tests, chiller was set to the minimum allowable temperature to verify operation of the regulating valve. The LHP regulation by the PRV continued up to the LHP dryout.

The MLHP with the three-way valve mode and with the two-way valve mode sustained practically the same power: up to about $300 \mathrm{~W}$ (Figs. 3.9 and 3.10). As it was expected the temperature of regulation for the two-way valve (Set point) was less than that for three-way valve (Regulation point). Because of chiller cooling capability was not enough, an increase of temperature at 1,25 hours was observed. The MLHP demonstrated same conductance during the cold case tests. 
MLHP with3-way valve maximum performance. Cold case.

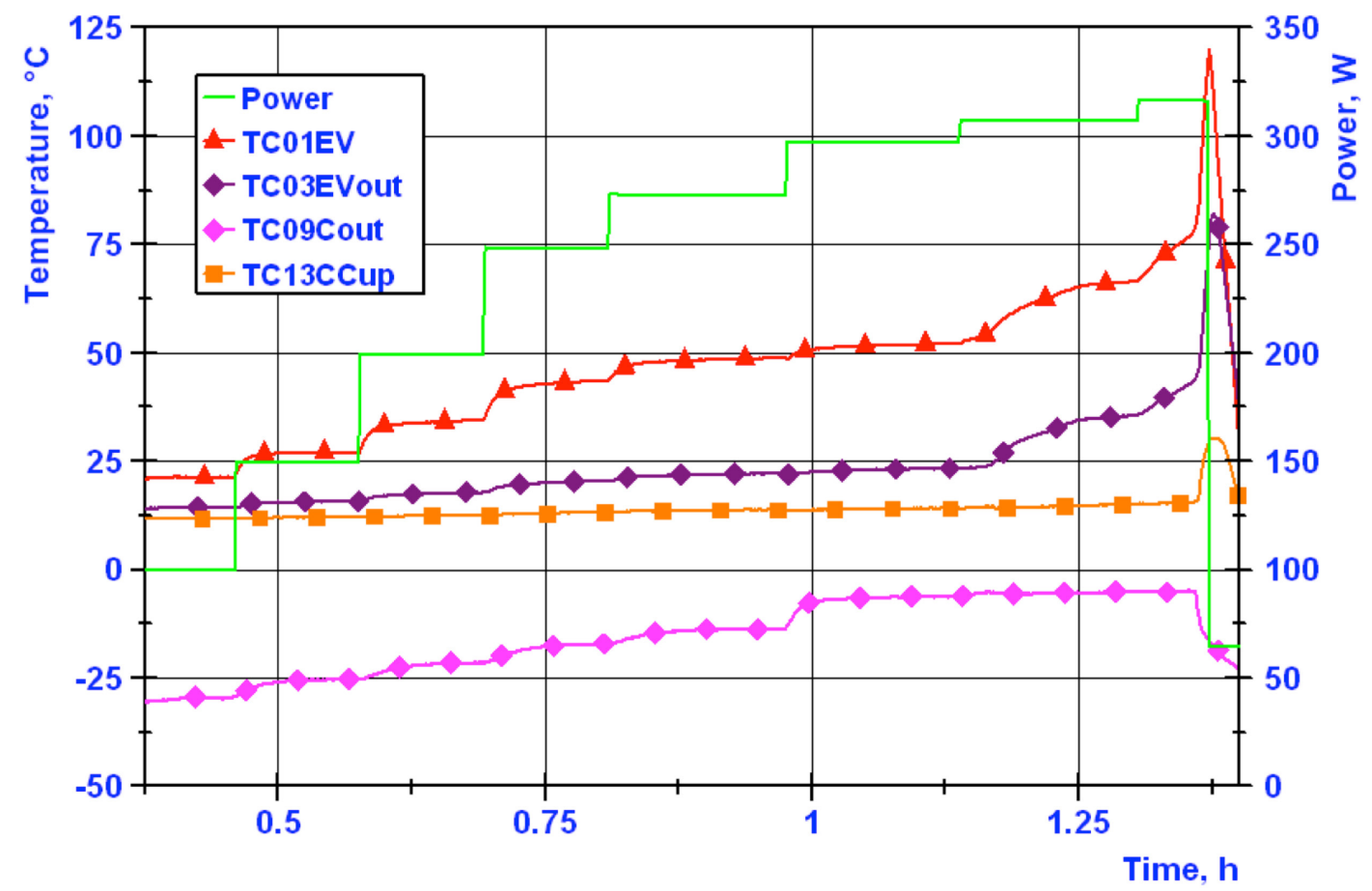

Figure 3.9: Maximum performance test of MLHP with three-way valve. Sink at cold case 
MLHP with 2-way valve maximum performance. Cold case.

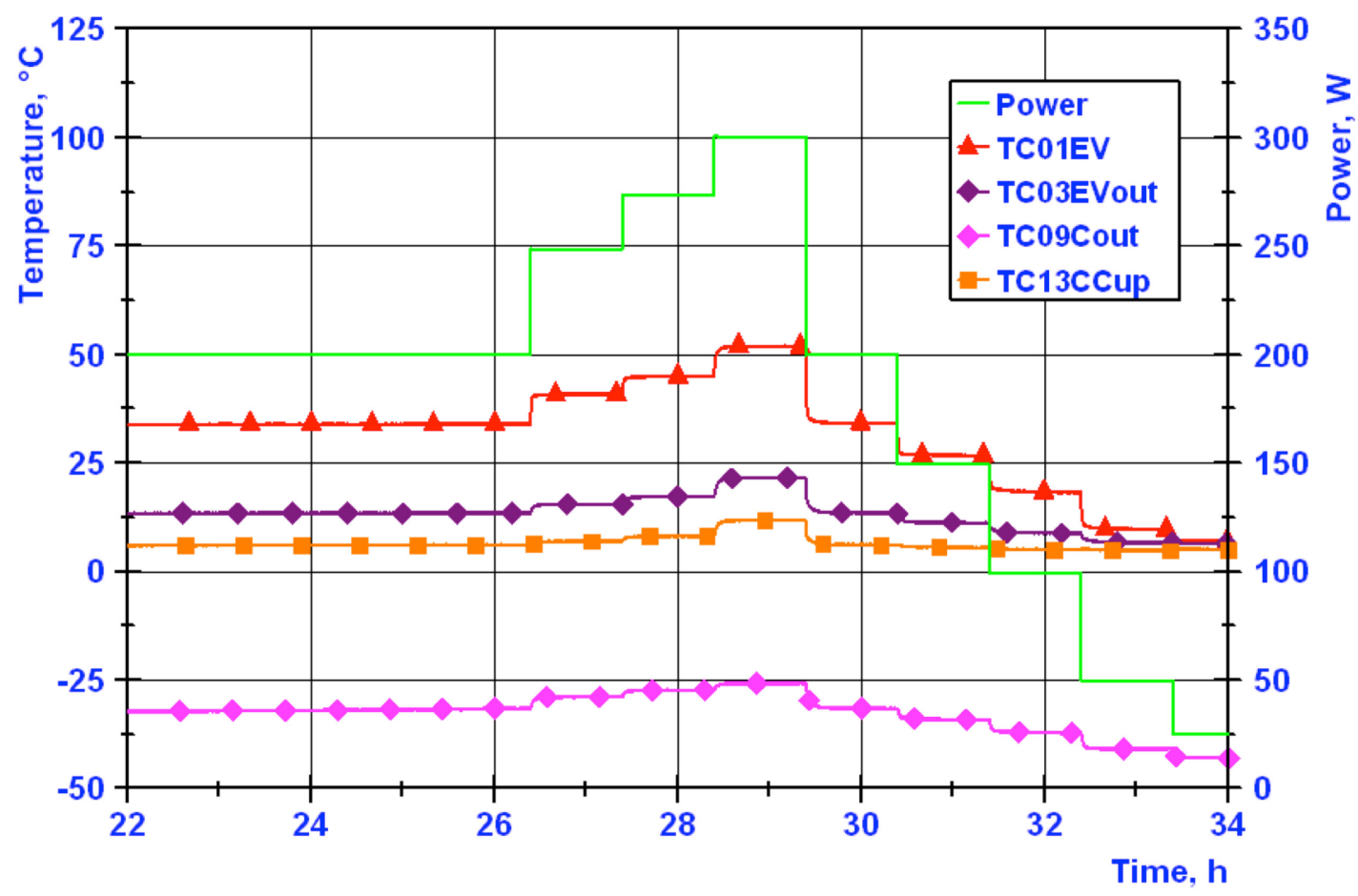

Figure 3.10: Maximum performance test of MLHP with two-way valve. Sink at cold case

For comparison purposes the MLHP was tested without the valve control (when argon was removed). In this case the MLHP operated as a usual LHP without any regulation. The tests showed that maximum heat transfer capability was reduced significantly for the same sink conditions (Fig. 3.11). The MLHP could transfer only $200 \mathrm{~W}$ due to the decreasing of operating temperature despite the absence of the PRV operation, which introduces additional hydraulic resistance to the loop. This phenomenon is discussed also hereafter in the paper. 
MLHP without valve maximum performance. Cold case.

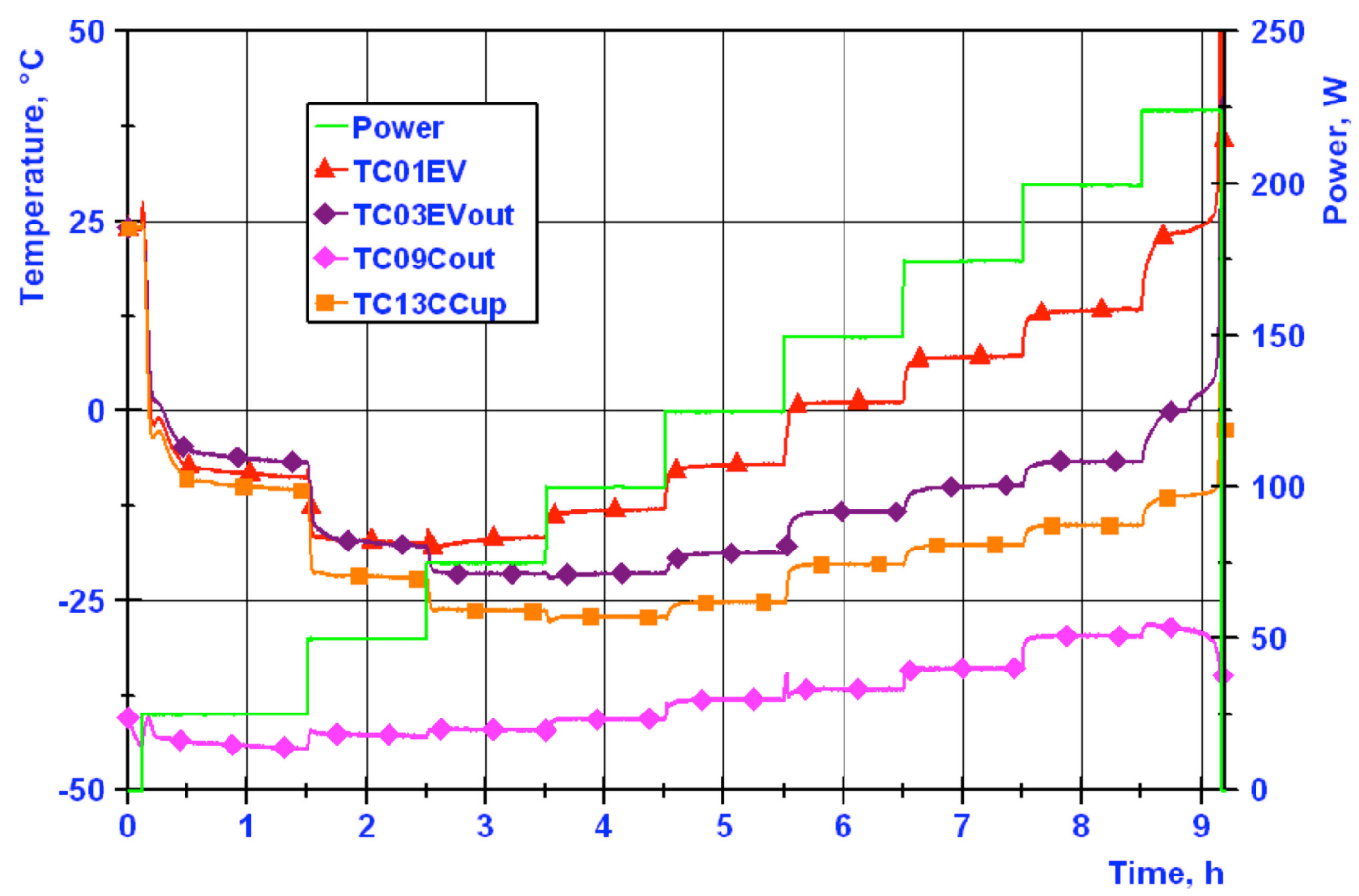

Figure 3.11: Maximum performance test of MLHP without valve. Sink at cold case

\section{MLHP Operating Temperature}

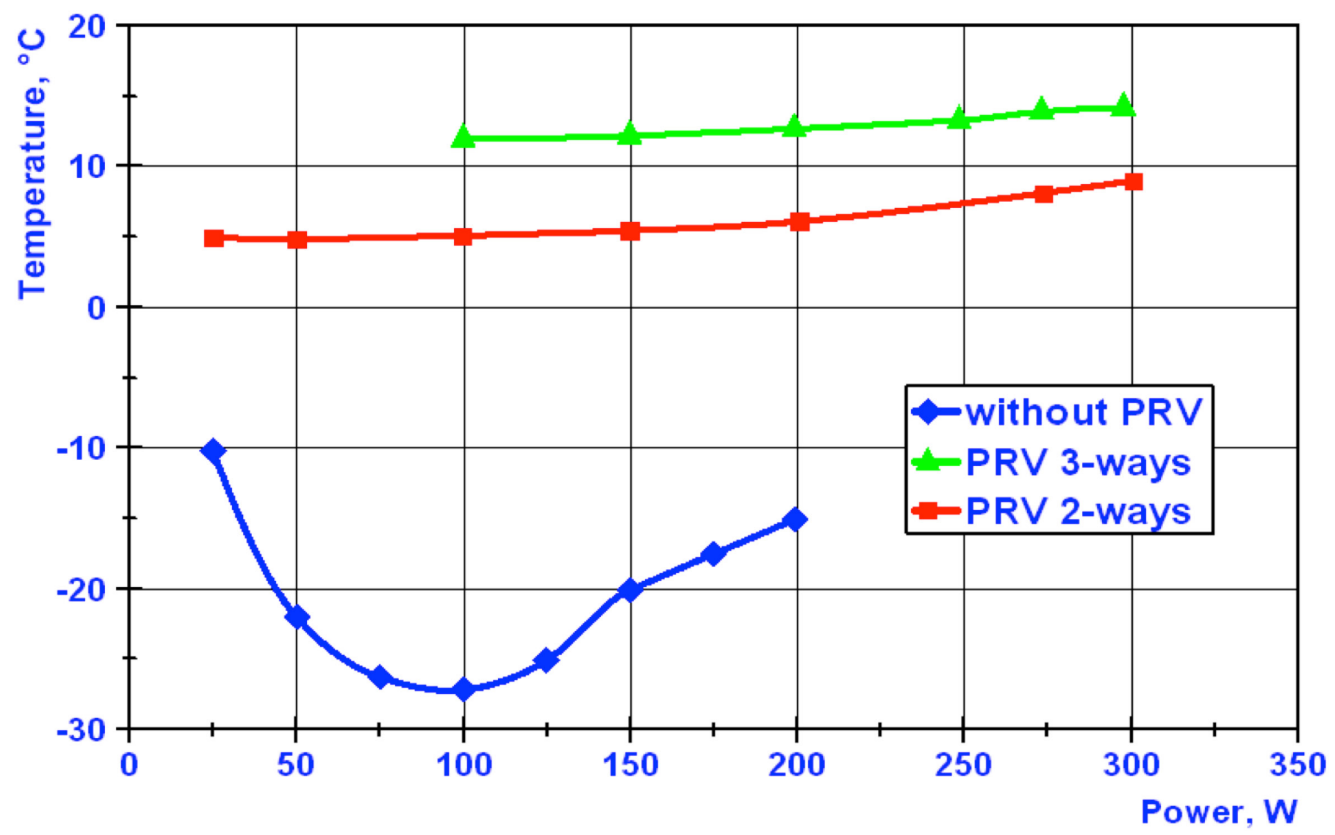

Figure 3.12: Comparison of operating temperature for MLHP without and with PRV 
Comparison of the operating temperature for different modes of LHP operation is shown in Fig. 3.12. Decreasing of the maximum capability of the MLHP without valve becomes logical taking into account that operational temperature of the MLHP decreased. On the other hand, there is no significant difference between the two PRV designs from the point of view of the maximum heat transfer capacity of LHP. Difference between them is that if three-way valve controls temperature at the regulation point, corresponded to upper position of stem inside the valve, the two-way valve regulates it at the set point, corresponded to lower position of the stem (for the same pressure of argon). This difference is several degrees of Celsius and for real applications can be adjusted on the step of charging of the PRV with inert back pressure gas (argon).

A different type of maximum performance test is shown in Fig. 3.13. It was conducted at constant applied power (273 W) with decreasing of argon pressure inside the valve. For this test the charging tube of PRV was open and back pressure gas reservoir of the PRV was connected through pressure regulator to the argon tank. The MLHP could transfer heat up to decreasing of operating temperature till $0{ }^{\circ} \mathrm{C}$ that showed again the general tendency of decreasing of the transferred heat with decreasing of the operation temperature. The typical curve "maximum heat transfer versus operating temperature" has a maximum around $45^{\circ} \mathrm{C}$ for ammonia LHPs, and all the tests, which were performed, correspond to the left hand side of the curve. 
MLHP with 2-valve maximum performance. Cold case.

Setpoint decrease.

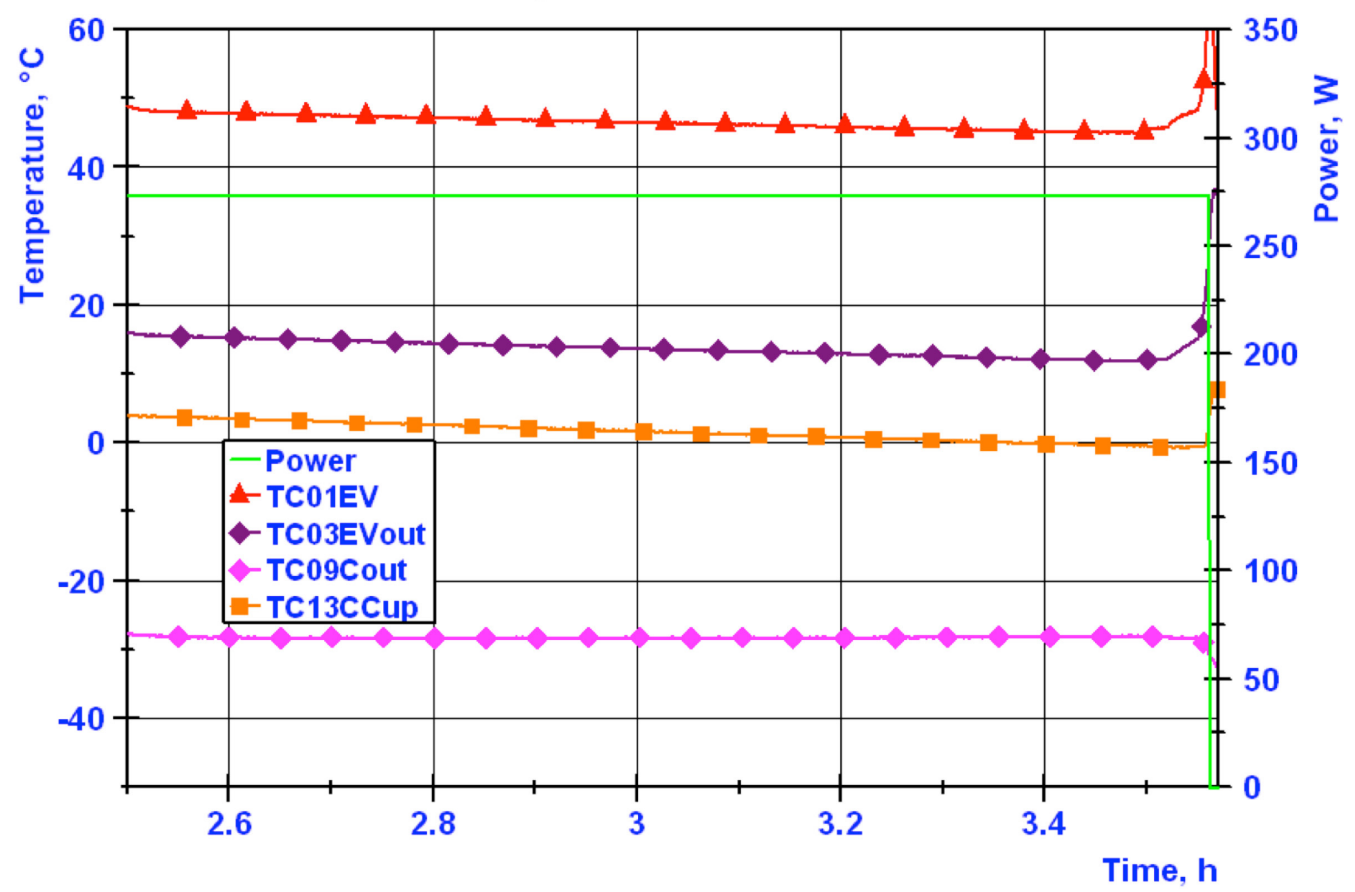

Figure 3.13: Maximum performance test of MLHP with two-way valve. Sink at cold case. Power $273 \mathrm{~W}$ is applied constantly. Argon pressure was decreased to decrease valve set point from $4^{\circ} \mathrm{C}$ to $0^{\circ} \mathrm{C}$ (dry-out) 
MLHP without valve maximum performance. Hot case.

Sink temperature decrease.

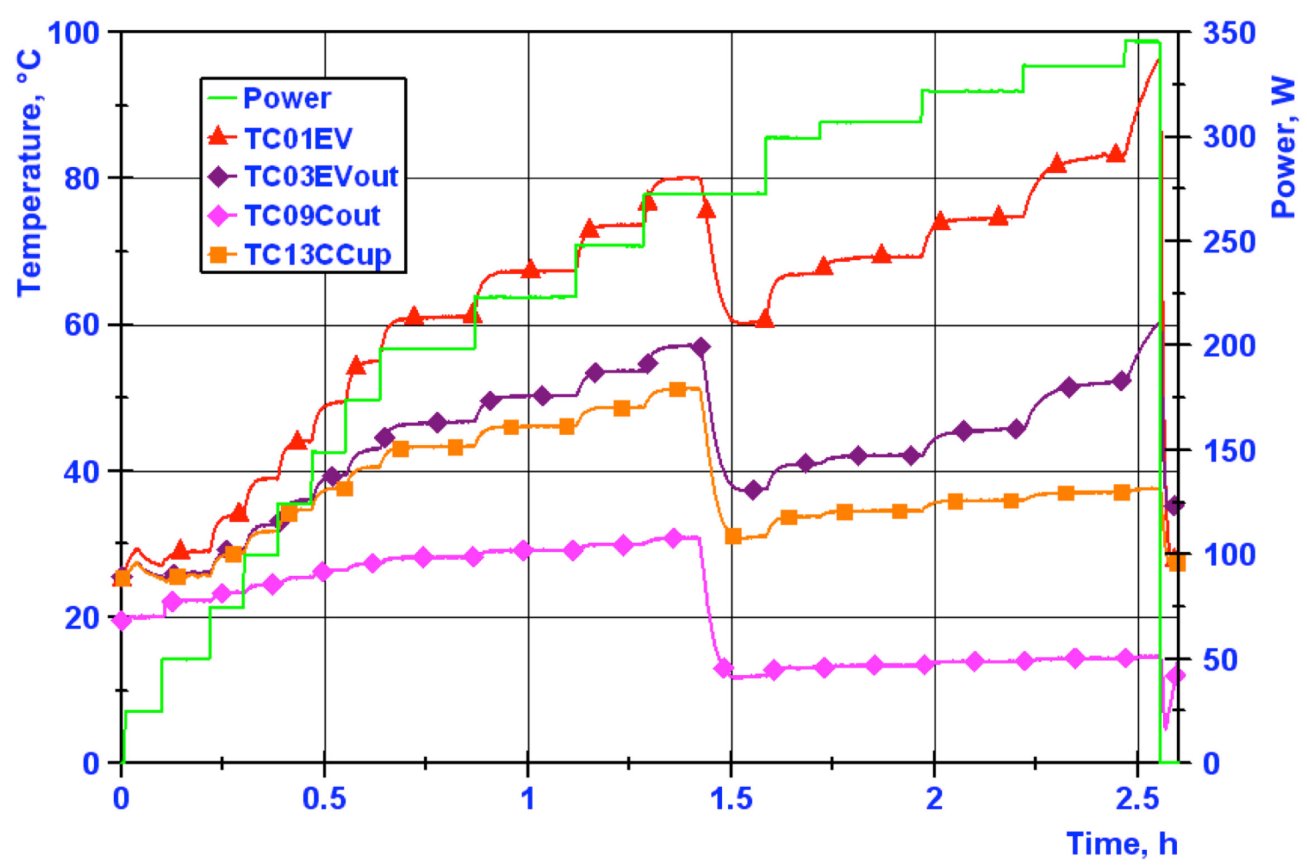

Figure 3.14: Maximum performance test of MLHP without valve. Sink at hot case. Sink temperature was reduced at power step $275 \mathrm{~W}$ to permit the LHP reach dry-out within allowable temperature range

In Figs. 3.14 and 3.15, the maximum performance tests for "hot case" without and with a valve are shown. The LHP demonstrated similar performance for both cases because at hot case the valve does not operate for the PRV set point. 
MLHP with 3-way valve maximum performance. Hot case.

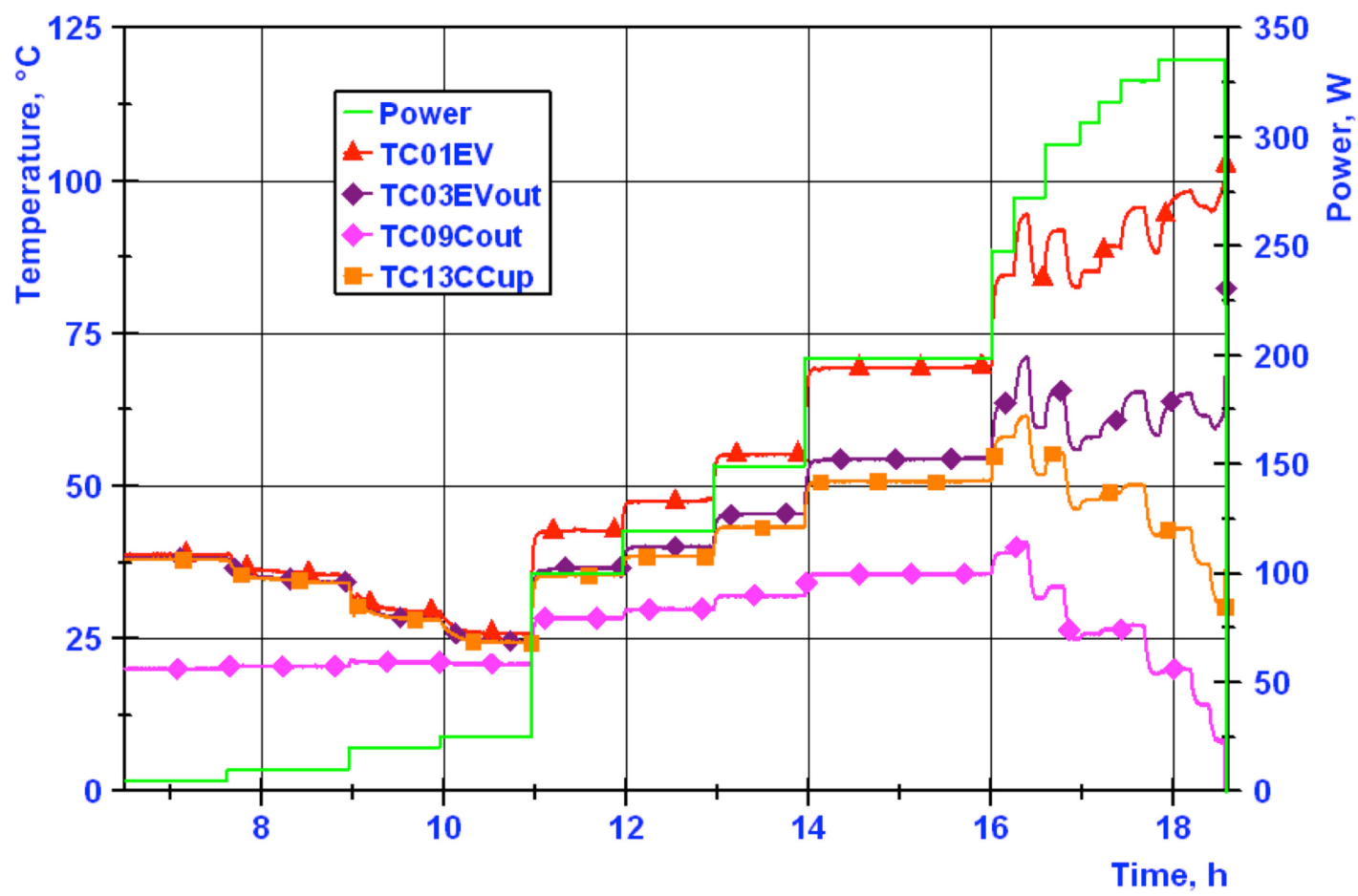

Figure 3.15: Maximum performance test of MLHP with three-way valve. Sink at hot case (Practically the same result was obtained for two-way valve) 
Maximum heat transfer rate $\mathbf{Q}_{\max }$ LHP

vs. operating temperature

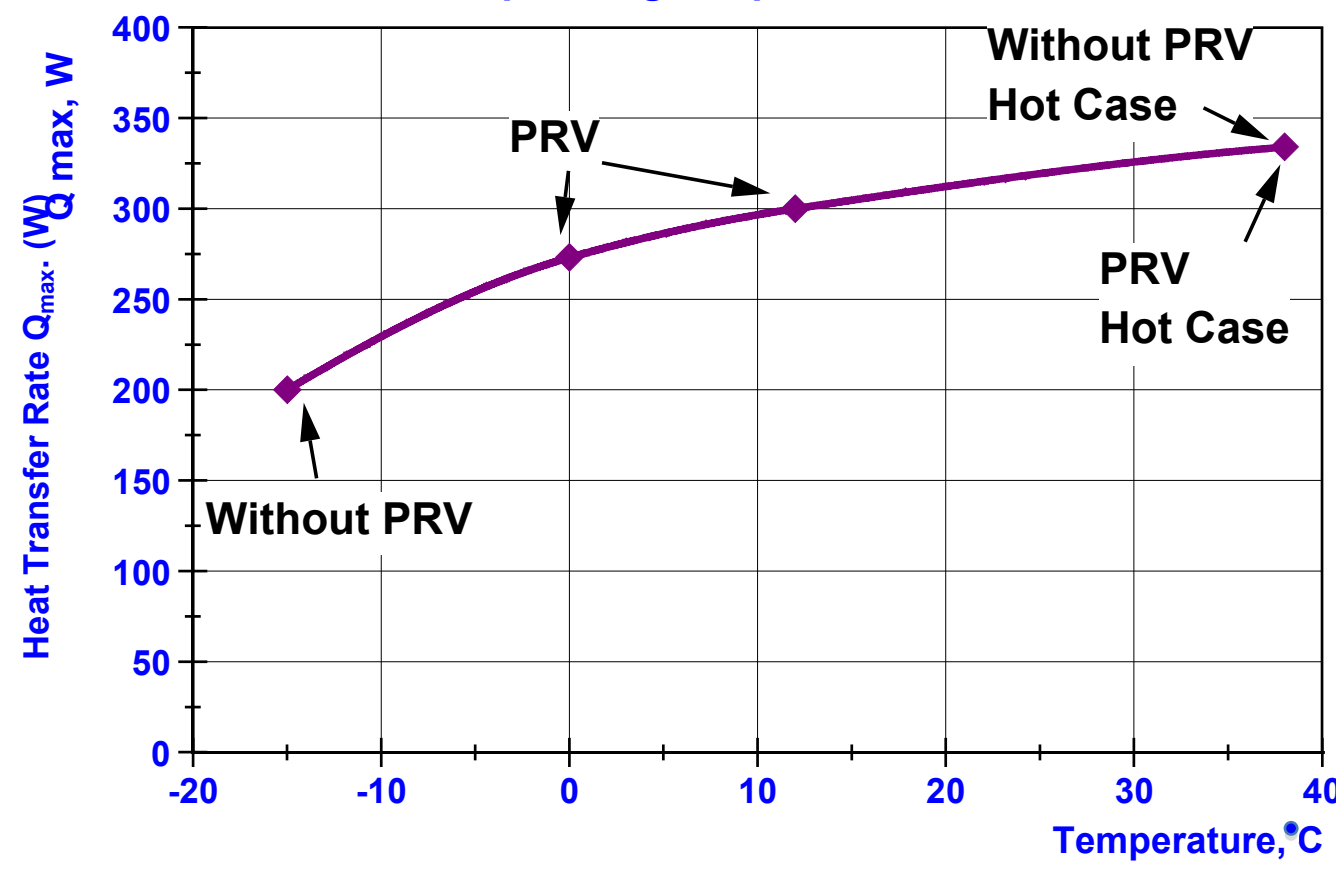

Figure 3.16: Comparison of maximum heat transfer rate $Q_{\max }$ of MLHP vs. operating temperature

In Fig. 3.16, a summary of performed tests is represented. Similar data was obtained for the MLHP with a PRV, both the three or two-way type. For the highest temperatures of tests similar data was obtained for LHP with and without PRV because at this temperature level PRV is beyond regulation and operates like the LHP without a valve.

From point of view of the maximum value of $Q_{\max }$, an optimal set point of the PRV exists. This is logical taking into account the figure of merit, which has a maximum for every working fluid and $Q_{\max }$ is increased up to the certain level with increasing of the set point and operation temperature and then it is decreased.

Taking into account the obtained test results, we can conclude that the maximum heat transfer rate of the LHP depends on the operation temperature which, in turn, influences the pressure drop along the LHP and does not depend on 
the nature of the drop. It can be a "natural" pressure drop in an LHP without valve, pressure drop introduced by the PRV or caused by the hydrostatic height or even by non-condensable gas presence. A thermal and hydraulic balance exists in the compensation chamber because the operation cycle of the LHP is near the saturation curve of working fluid. The balance finally determines the overall temperature drop of the LHP. Both internal and external heat flows between outer and inner surfaces of the wick influence the thermal balance: along main contour of the LHP and across the wick. Thus, the heat leak across the wick (and conditions in the evaporator core and compensation chamber) is proportional to external pressure drop $\Delta \mathrm{P}_{\mathrm{LHP}}+\Delta \mathrm{P}_{\mathrm{PRV}}+\rho g h$.

Therefore, the mechanism of the PRV operation in three-way and two-way modes can be considered as similar. In the same operation conditions (temperatures of condenser and evaporator are the same), LHP should be in the same hydro-mechanical and thermal equilibrium. LHP is a device, operating temperature of which is driven by the temperature of compensation chamber. Due to the operation of the valve, LHP has the same pressure drop and thermal state of the compensation chamber. The difference between the two PRV designs is in character of adjusting of compensation chamber state. In case of the three-way valve direct vapor flow exists through the bypass line to the compensation chamber. For the two-way valve, the increased heat leak from the evaporator core to the compensation chamber plays the same role: the pressure drop along the LHP had been increased the heat leak from the evaporator core to the compensation chamber to adjust the LHP operation temperature level. We can conclude that the heat flow through the bypass line and the heat leak from the 
evaporator core are practically the same (when the argon pressure is adjusted to have the same temperature of regulation). Therefore, it can be considered that from the point of view of the thermo- and hydrodynamics, the LHP operates in the same regime for both modes.

\subsection{LHP with a two-way valve for planetary rovers}

Because of their characteristics, the LHPs are particularly suitable to control the temperature of the electronics and equipment inside the rovers, which are designed for planetary exploration missions and they operate in gravity fields $[3.1,3.13]$. The temperature control of the rovers is rather challenging because of the extreme environmental conditions. Usually, to control the temperatures of the equipment, it is enough to remove some power to keep the temperatures below a maximum allowable limit. However, in these applications, the night temperatures can be very low and it is necessary to prevent the electronics from overcooling. Such temperature control can be organized by different methods [3.13]. Specifically for the rover missions the passive control techniques are preferable since during the night only battery power is available. Therefore, a PRV was integrated in the LHP design to provide the device a thermal switch function. This element does not require any power and allows dissipating the heat from the rover electronic equipment through the radiators in nominal conditions, but also thermally decoupling the electronics from the outside cold temperatures when needed.

A propylene MLHP equipped with a regulating valve has been designed for the Mars Rover applications in the frame of the ExoMars project [3.14]. This breadboard is based on a previous prototype developed for the ESA TRP "Passive 
Variable Thermal-Conductance Device (PVTCD) for Mars Rover Applications" [3.7]. Nevertheless, in the current application the thermal requirements have been modified according to the updated ExoMars needs, and there are important differences in terms of dissipated power and temperature control set point. The new power range is from $5 \mathrm{~W}$ to $25 \mathrm{~W}$ and the required set point has been decreased up to $-30^{\circ} \mathrm{C}$. To provide an accurate temperature control for these new conditions, a two-way pressure-regulating valve has been proposed. This novel design has demonstrated its precise temperature control as well as its capability to avoid oscillations and back flow at low power regimes.

\subsubsection{LHP with a Two-way Valve Design}

A general view of one of the mini LHPs developed for the Rover applications is provided in Fig. 3.17. It consists of one evaporator, one compensation chamber, one condenser, two transport lines and one two-way PRV located in the vapor line. The selected working fluid is propylene to avoid the freezing in the condenser during the Mars night cold temperatures (according to the specification the radiator temperature can reach $-120^{\circ} \mathrm{C}$ ). The main characteristics of the design are shown in Tables 3.3 and 3.4 . 


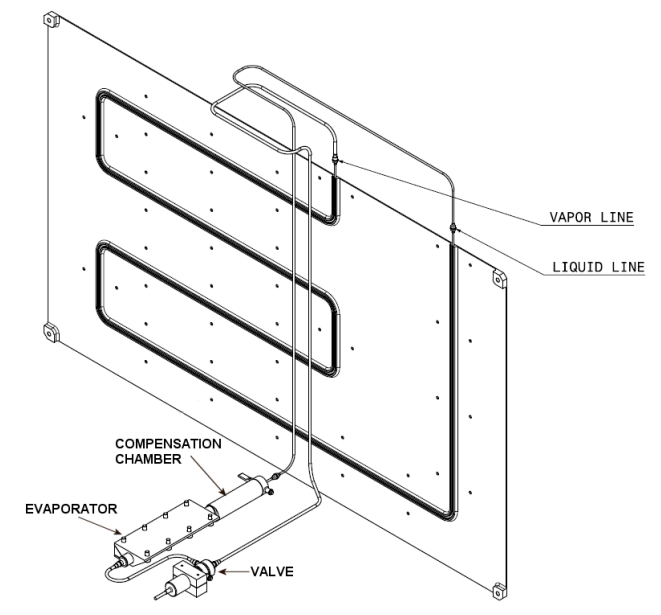

Figure 3.17: Mini LHP schematic

Table 3.3. MLHP main dimensions

\begin{tabular}{|l|l|l|}
\hline Component & $\begin{array}{l}\text { Length } \\
(\mathrm{mm})\end{array}$ & $\begin{array}{l}\text { Diameter } \\
(\mathrm{mm})\end{array}$ \\
\hline Evaporator & 130 & 12 \\
\hline Condenser & 2340 & 2 \\
\hline Reservoir & 75 & 19 \\
\hline Vapor Line & 1160 & 3 \\
\hline Liquid Line & 970 & 2 \\
\hline
\end{tabular}

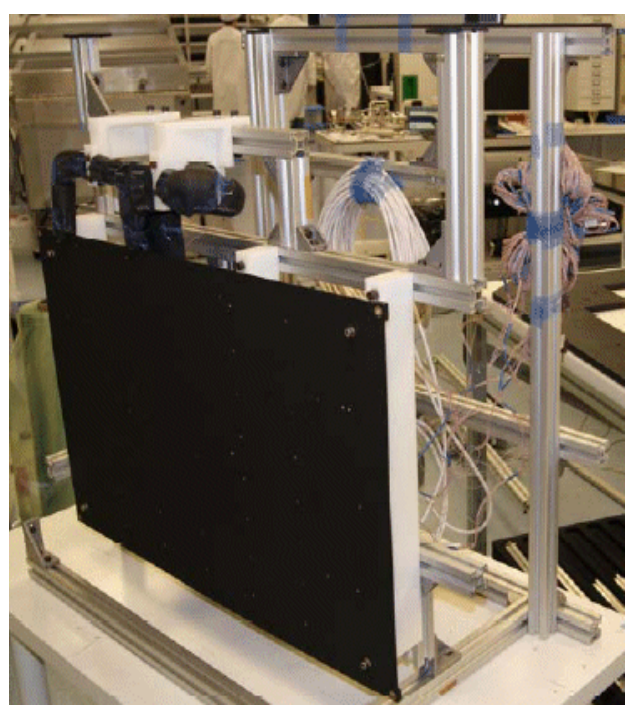

Figure 3.18: Mini LHP test set up: radiator panel view

Table 3.4. Design characteristics of the

\begin{tabular}{|l|l|}
\multicolumn{2}{c}{ MLHP } \\
\hline Characteristics & LHP-SS \\
\hline Wick Material & $\begin{array}{l}\text { Stainless } \\
\text { Steel }\end{array}$ \\
\hline Porous diameter $(\mu \mathrm{m})$ & 3.4 \\
\hline Porosity $(\%)$ & 65 \\
\hline Valve set point & $-30^{\circ} \mathrm{C}$ \\
\hline
\end{tabular}

\subsubsection{LHP with a Two-way Valve Test Set Up}

The LHP is tested in nominal orientation as it is presented in Fig. 3.18. The evaporator saddle is bolted to the saddle of the cartridge heater, which provides the power to be dissipated by the LHP. Additionally, a start up heater is glued to 
the evaporator saddle to provide extra power to facilitate the start up. Then, the LHP is instrumented with type-T thermocouples according to the schematics shown in Figs. 3.19 and 3.20.

To reduce the heat exchanged with the environment and between the different components, each LHP component (excepting the condenser plate) is isolated separately by Armaflex elastomeric foam. Additionally, to reduce the influence of the forced convection of the climatic chamber, the subassembly evaporator, compensation chamber and valve is covered by plastic, closing the possible inlets. The photo of the set-up can be found in Fig. 3.18. Finally, the LHP is introduced in the climatic chamber.
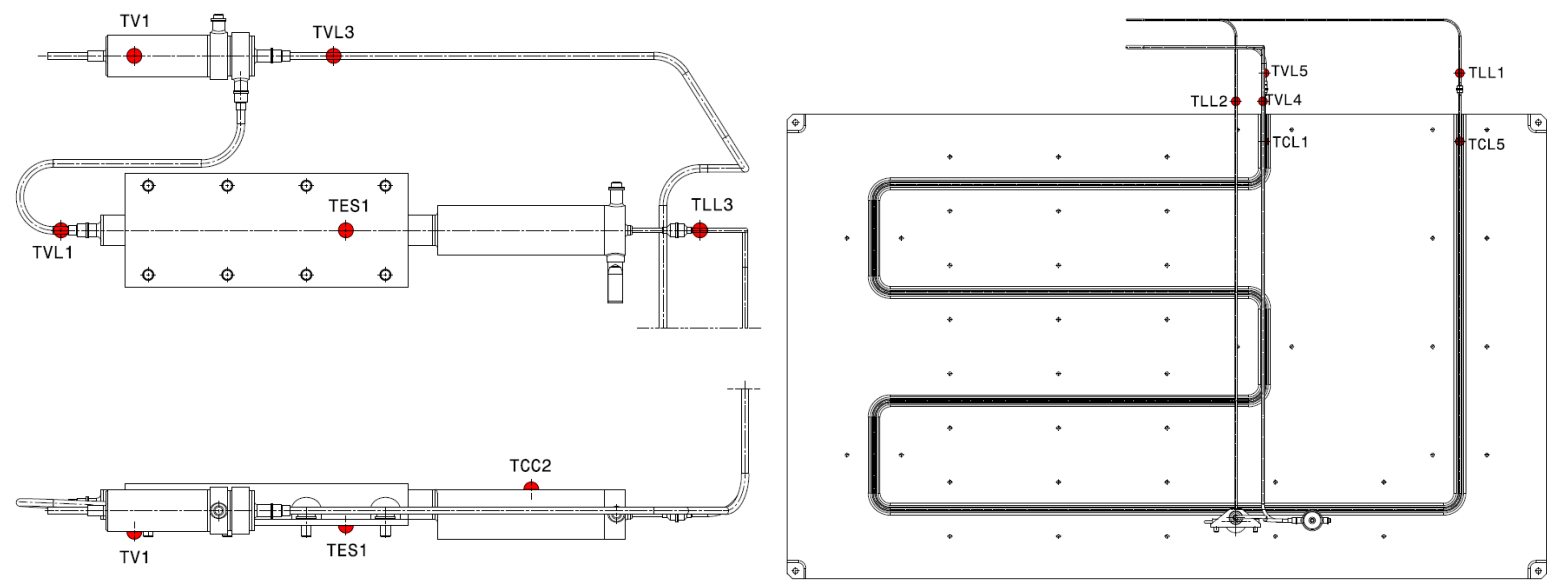

Figure 3.19: Evaporator block test setup

Figure 3.20: Condenser test setup 


\subsection{Thermal switch temperature control: results \& discussion}

\subsubsection{Valve Tests}

The objective of these tests is to verify the valve behavior and to check the LHP regulation capability. In this way, two different kinds of tests have been carried out. In the first ones, the chamber temperature is fixed and the applied power on the cartridge heater is cycled. In the second kind of tests, the power is fixed and the chamber temperature is cycled. The results obtained in these conditions are presented below:

LHP with 2-way valve performance.

Chamber temperature $-70^{\circ} \mathrm{C}$. Power cycling.

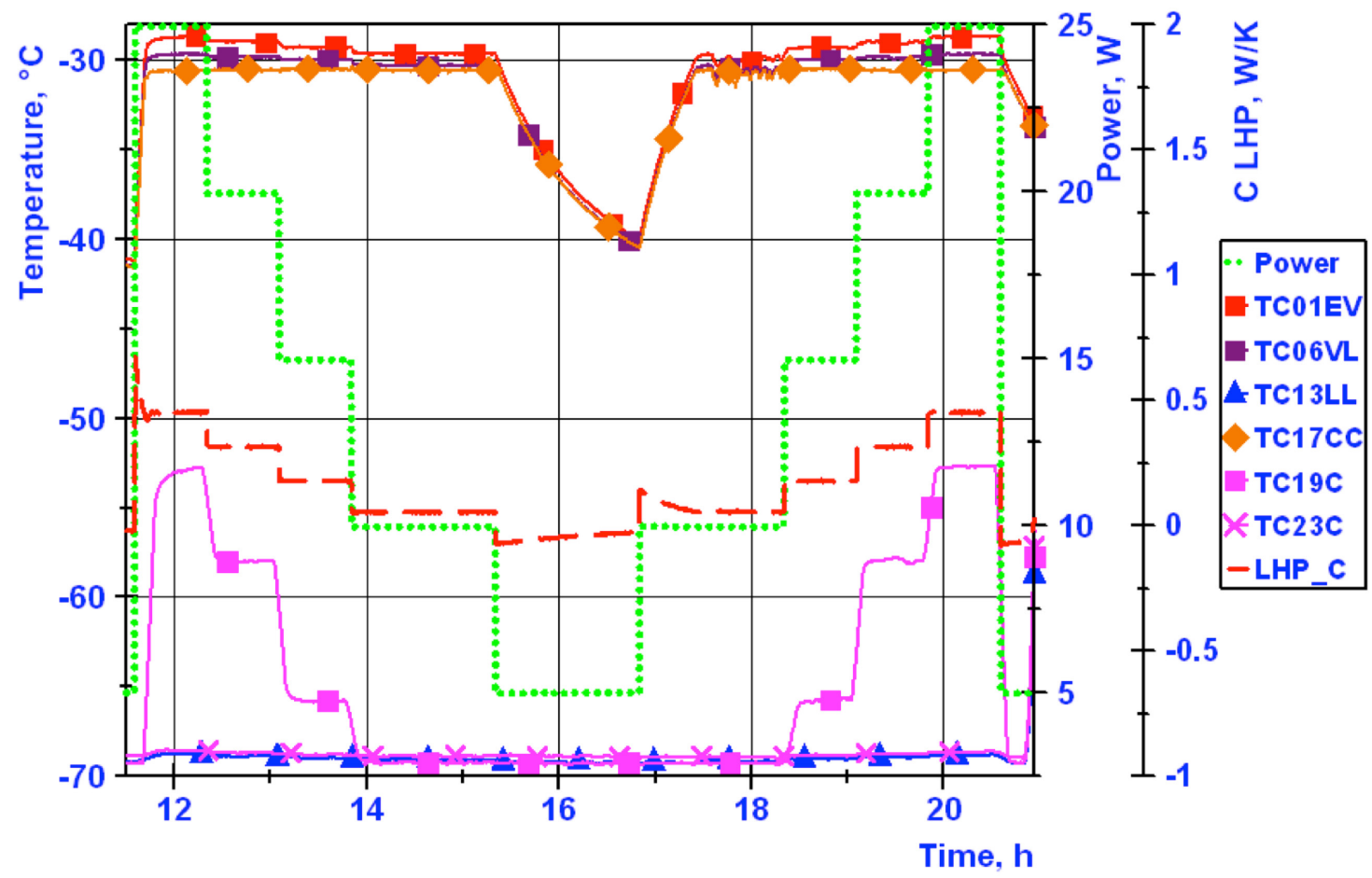

Figure 3.21: Valve test results - Chamber $\mathrm{T}=-70^{\circ} \mathrm{C}$, power cycling 
LHP with 2-way valve performance.

Chamber temperature cycling. Input power 25W.

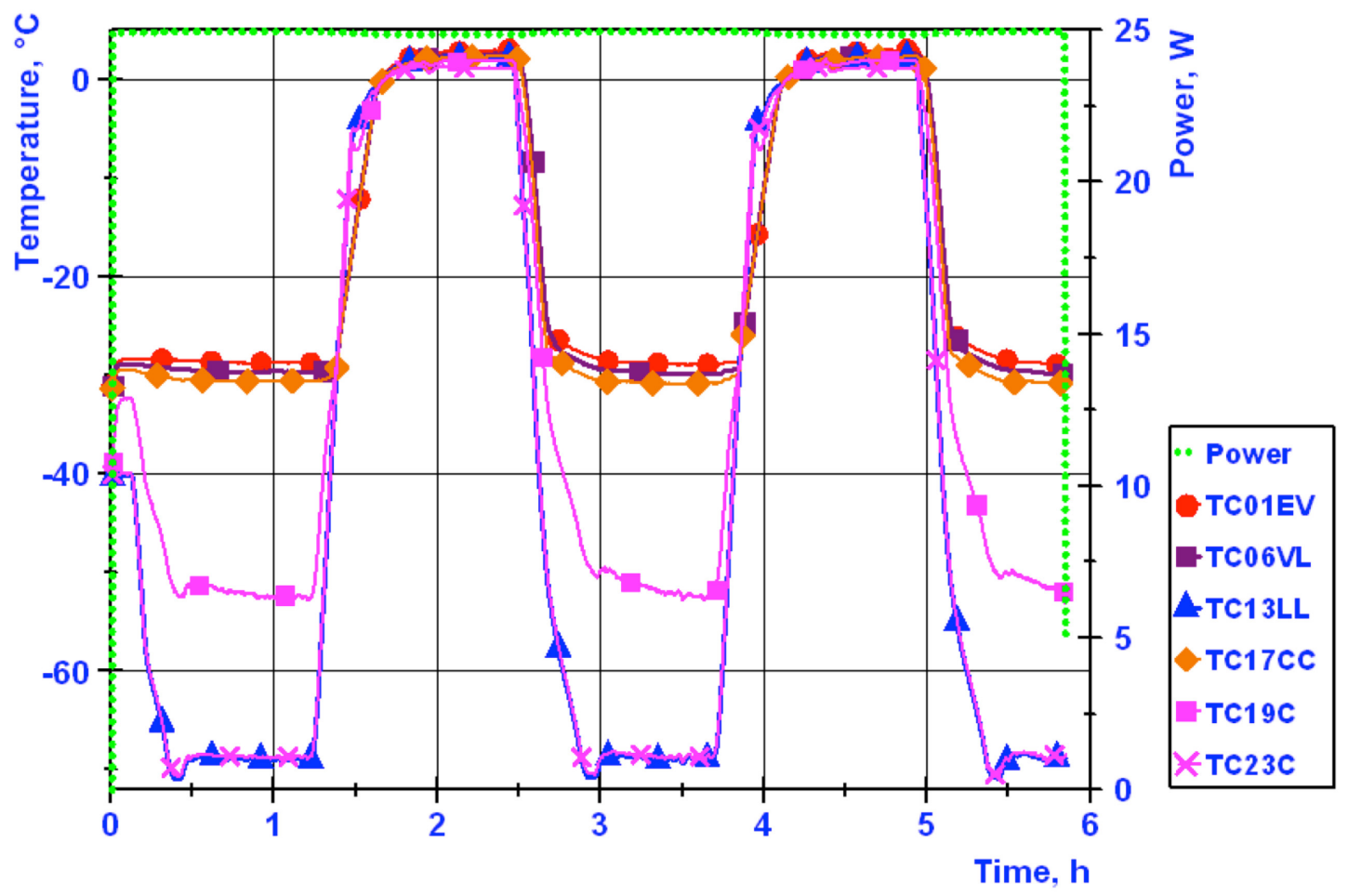

Figure 3.22: Valve test results - Chamber temperature cycling

For a chamber temperature of $-70{ }^{\circ} \mathrm{C}$ (Fig. 3.21), the LHP temperature regulation worked as desired, very close to the required set point for almost all the power levels. In fact, the compensation chamber temperature is regulated around $31^{\circ} \mathrm{C}$ for powers higher or equal to $10 \mathrm{~W}$. When the power applied is $5 \mathrm{~W}$, practically all the power is leaked to the ambient and the net power introduced in the LHP is not enough to keep the LHP operational. Therefore, the LHP shuts down and the temperatures decrease due to the leakages to the ambient. The big number of cycles tested demonstrates the repeatability of the results and the proper behavior of the LHP as a temperature control device.

In these conditions, when the valve is regulating the temperatures, the obtained values of the LHP thermal conductance vary from $0.05 \mathrm{~W} / \mathrm{K}$ to $0.45 \mathrm{~W} / \mathrm{K}$ depending 
on the power applied. When the LHP is stopped for a power of $5 \mathrm{~W}$, the power applied was dissipated to the surroundings.

Then the chamber temperature is increased and set to $-40{ }^{\circ} \mathrm{C}$. The LHP is regulating at the specified set point $\left(-30^{\circ} \mathrm{C}\right)$ for the whole power range and the good repeatability of the results is demonstrated.

When the valve is controlling the temperature of LHP, the path to the condenser is not completely closed, and a small flow is still circulating through the LHP. Since the operational conditions for this chamber temperature are more favorable than in the previous test, the obtained LHP thermal conductances are higher, and they are within $2.25 \mathrm{~W} / \mathrm{K}$ and $0.25 \mathrm{~W} / \mathrm{K}$.

Afterwards, the power is fixed and the chamber temperature is cycled between $0{ }^{\circ} \mathrm{C}$ and $-70{ }^{\circ} \mathrm{C}$. To test the LHP behavior in the whole power range, two extreme power levels are analyzed: $25 \mathrm{~W}$ and $5 \mathrm{~W}$.

As shown by the results presented in Fig. 3.22, for a fixed power of $25 \mathrm{~W}$, the LHP operates as expected without regulation for a chamber temperature of $0{ }^{\circ} \mathrm{C}$. For a chamber temperature of $-70^{\circ} \mathrm{C}$, the valve controls the temperature around the required set point (the compensation chamber temperature is about $-31^{\circ} \mathrm{C}$ ).

For an applied power of $5 \mathrm{~W}$, practically all the power is leaked to the ambient when the chamber temperature is $-70^{\circ} \mathrm{C}$. In these conditions, the LHP stops and the temperatures are cooled due to the heat exchanged with the ambient. When 
the chamber temperature is increased to $0{ }^{\circ} \mathrm{C}$, the condenser temperatures increase quicker than the evaporator ones. Therefore, the time needed to reach a start up is large and this event is achieved at the very end of the power step.

The thermal conductances calculated in steady conditions for a power of $25 \mathrm{~W}$ is $0.5 \mathrm{~W} / \mathrm{K}$ for $-70^{\circ} \mathrm{C}$. The obtained value is low when the valve is regulating and decoupling the evaporator from the condenser. Additionally, the value calculated when the LHP is working without regulation is $16 \mathrm{~W} / \mathrm{K}$, which is a high value considering the low power applied.

When the applied power is $5 \mathrm{~W}$, the LHP stops because all the applied power is leaked to the ambient. Since there is not enough time to reach steady conditions for a chamber temperature of $0{ }^{\circ} \mathrm{C}$, the thermal conductance could not be estimated.

\subsubsection{Start Up Tests}

The main objective of these tests was to determine what is the minimum power needed to reach a successful start up in cold conditions. Since the LHP is not perfectly insulated and there are some thermal leaks to the ambient, the estimated coupling of $0.2 \mathrm{~W} / \mathrm{K}$ is considered to calculate the net power introduced in the LHP and, consequently, to 
LHP with 2-way valve start up from cold conditions.

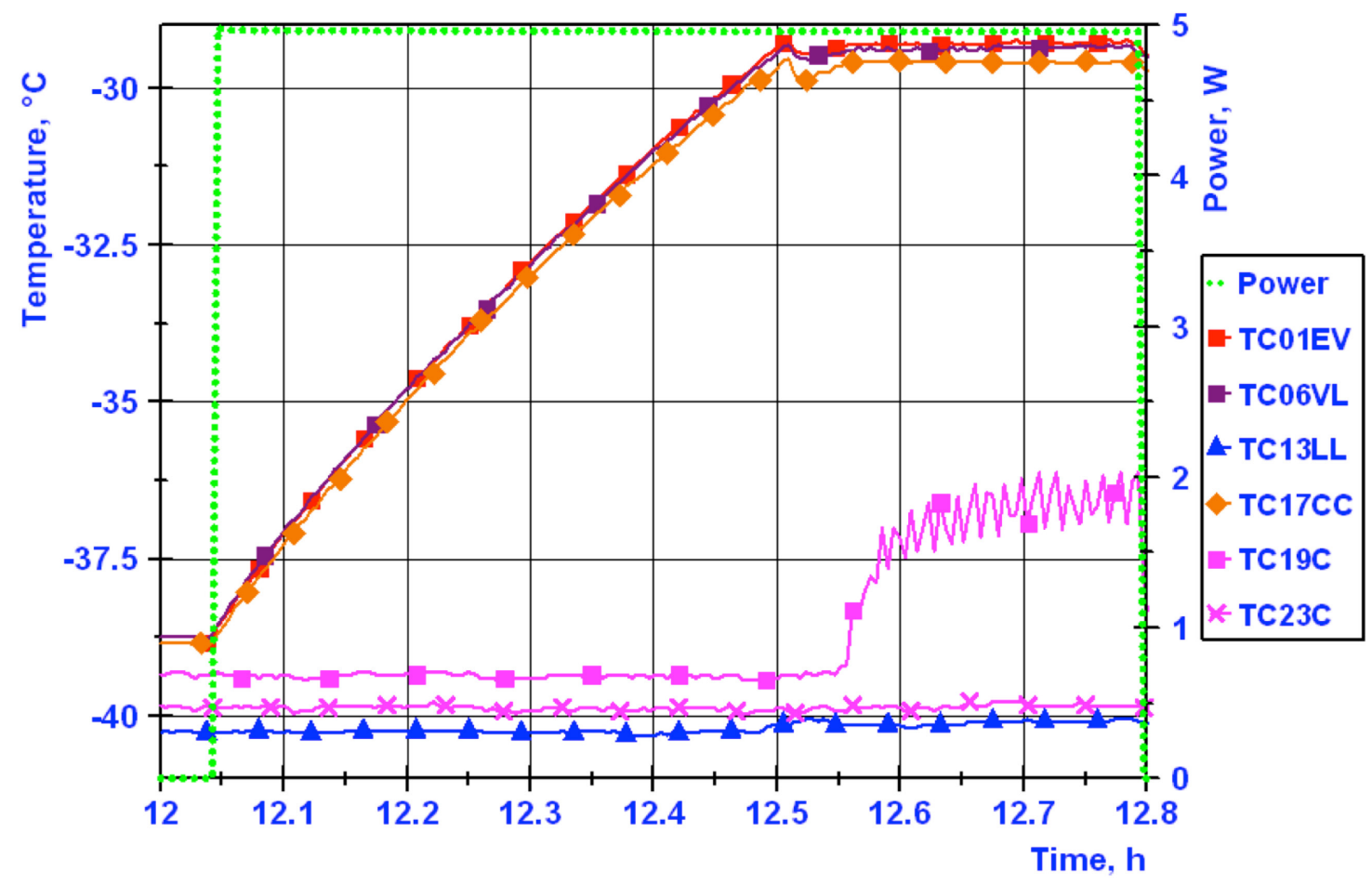

Figure 3.23: Start up test results - Chamber $\mathrm{T}=-40^{\circ} \mathrm{C}$

establish the minimum start up power. The power is applied on the start up heater and the chamber temperature is set to two different values: $-40{ }^{\circ} \mathrm{C}$ and $-70{ }^{\circ} \mathrm{C}$. Moreover, several attempts are performed to demonstrate a minimum of three consecutive successful start ups.

For a chamber temperature of $-40^{\circ} \mathrm{C}$, the heat loss to ambient is about $2 \mathrm{~W}$. Therefore, a total power of $5 \mathrm{~W}$ is applied to the start up heater to demonstrate that the LHP is able to start up with only $3 \mathrm{~W}$.

Five consecutive successful start ups have been achieved in these conditions. As it is shown in the detailed graph (Fig. 3.23), as soon as the temperatures cross the valve set point $\left(-30^{\circ} \mathrm{C}\right)$, a successful start up is reached and a no overshoot is 
observed. Moreover, the results demonstrate a reliable and repeatable behavior of the LHP. Regarding to the LHP thermal conductance, the calculated values are around $0.3 \mathrm{~W} / \mathrm{K}$ for steady conditions when the LHP is operating.

Then, the chamber temperature is decreased to $-70^{\circ} \mathrm{C}$. In this case, the heat loss to ambient is around $8 \mathrm{~W}$. A total power of $10 \mathrm{~W}$ is applied to the evaporator saddle to check if there is a successful start up with a minimum power of $2 \mathrm{~W}$ in this worse scenario.

According to the results, four consecutive successful start ups have been achieved in these conditions. In the first two attempts, the time with the power applied is not enough to verify the steady conditions. For this reason, in the next steps this application time has been increased significantly. As it can be verified in the detailed plot of the third attempt, as soon as the temperatures cross the valve set point $\left(-30^{\circ} \mathrm{C}\right)$, a successful start up is reached and a no overshoot is observed. Again, the test results demonstrate a reliable and repeatable behavior of the LHP even for this worst case. Finally, the LHP thermal conductance calculated in these conditions is about $0.1 \mathrm{~W} / \mathrm{K}$. It has to be mentioned that a two-way valve facilitates the start up from cold conditions since vapor is generating in the vapor line entrance before the start up event and all the vapor removing grooves are filled by vapor and "waiting" the opening of the valve.

Ambient performance test shows a high thermal conductance of the LHP for the low power range typical of the electronics inside Mars/Lunar rovers [3.14]. 
One more particularity of the LHP with a two-way valve was observed: pressure oscillations appeared in the LHP with three-way valve due to gravity effect was not seen for the two-way valve. This oscillatory behavior has been found in a LHP with PRV designed and manufactured for a Mars rover application by IberEspacio and discussed in [3.7-3.10].

Additional information regarding the LHP testing can be found in [3.14].

\subsection{Overall comparison of different methods of regulation of LHP}

In general, the LHP with a two-way valve has demonstrated outstanding performance and excellent capability of temperature control. The new design of pressure regulating valve allows eliminating such undesirable effects as gravity caused temperature oscillations, instability of start up and operation at low power regimes. It also increases the system reliability and precision of temperature control. Comparison of this method of LHP control with the traditional and more commonly used three-way valve and a heater on compensation chamber is presented in Table 3.5 . 
Table 3.5. Comparison of different methods of regulation of LHP operation temperature level

\begin{tabular}{|c|c|c|c|}
\hline $\begin{array}{l}\text { Method of } \\
\text { control }\end{array}$ & $\begin{array}{l}\text { two-way } \\
\text { valve }\end{array}$ & three-way valve & $\begin{array}{c}\text { Heater on compensation } \\
\text { chamber }\end{array}$ \\
\hline Reliability & excellent & very good & excellent \\
\hline $\begin{array}{l}\text { Necessity of } \\
\text { active control }\end{array}$ & No & No & Yes \\
\hline $\begin{array}{c}\text { Power } \\
\text { consumption }\end{array}$ & No & No & Yes \\
\hline $\begin{array}{c}\text { Simplicity of } \\
\text { design }\end{array}$ & excellent & very good & $\begin{array}{c}\text { good } \\
\text { (Electronic device for } \\
\text { control is needed) }\end{array}$ \\
\hline Redundancy & Yes $^{*}$ & No & Yes \\
\hline Remarks & & $\begin{array}{l}\text { Temperature oscillations in } \\
\text { gravity. } \\
\text { Instability of start up and } \\
\text { operation at low power and } \\
\text { low temperature regimes }\end{array}$ & $\begin{array}{c}\text { Complex algorithm of } \\
\text { regulation } \\
\text { Sensitivity to transients }{ }^{* *} \\
{[3.15]}\end{array}$ \\
\hline
\end{tabular}

${ }^{*}$ Additional valve can be installed in the loop to increase system reliability.

** According to [3.15], it is not easy to provide a reliable algorithm for the temperature control of the compensation chamber. A LHP can stop operation if the rate of change of control power is higher than the rate of change of evaporator power. The control heater power level should be low enough to avoid an undesirable shut down of LHP, and on the other hand it should be high enough to be able compensate sub-cooling if returning fluid is relatively cold. 


\subsection{Conclusion}

A mini LHP equipped with a PRV was designed, manufactured and tested to compare the two-way and three-way valve designs and verify the LHP heat transfer limitations. To investigate characteristics of the two-way valve operation, especially at low temperature of regulation, an extensive test campaign has been performed on the propylene mini LHP developed for rover applications.

The new concept of two-way PRV allows performing precise temperature control at low power and low temperature levels, to increase reliability and temperature stability of the system, and to eliminate the drawbacks of three-way valves such as temperature oscillations caused by gravity.

Both types of PRV design demonstrated practically the same maximum heat transfer rate of the LHP. Moreover, it was found that the heat transfer capability of LHP with PRV becomes higher than "natural operated" LHP without PRV. An optimal temperature set point of PRV exists, providing the maximum heat transfer performance.

A valve performance verification test campaign has been carried out to demonstrate the regulation capability of the LHP at a set point of $-30^{\circ} \mathrm{C}$. For all the conditions the valve regulates correctly the temperature around the set point value. Additionally, when the net power applied directly to the LHP is too small to keep 
the LHP operating, the LHP shuts down and the evaporator and the condenser are completely thermally decoupled.

Moreover, several start-up tests have been performed considering the worst environmental scenarios. Even in these conditions, the LHP start up capability has been demonstrated for a power so small as $2 \mathrm{~W}$. Therefore, we can conclude that the presence of this two-way valve facilitates the start up in cold conditions.

The ambient performances test shows a high thermal conductance of the LHP for the low power range, typical of the electronics inside Mars/Lunar rovers.

The results obtained from these tests prove the suitability of the propylene mini LHP with novel two-way valve to the requirements of the planetary exploration programs, and demonstrates the capability of these devices to control the temperature of the equipment and electronics.

\section{Nomenclature}

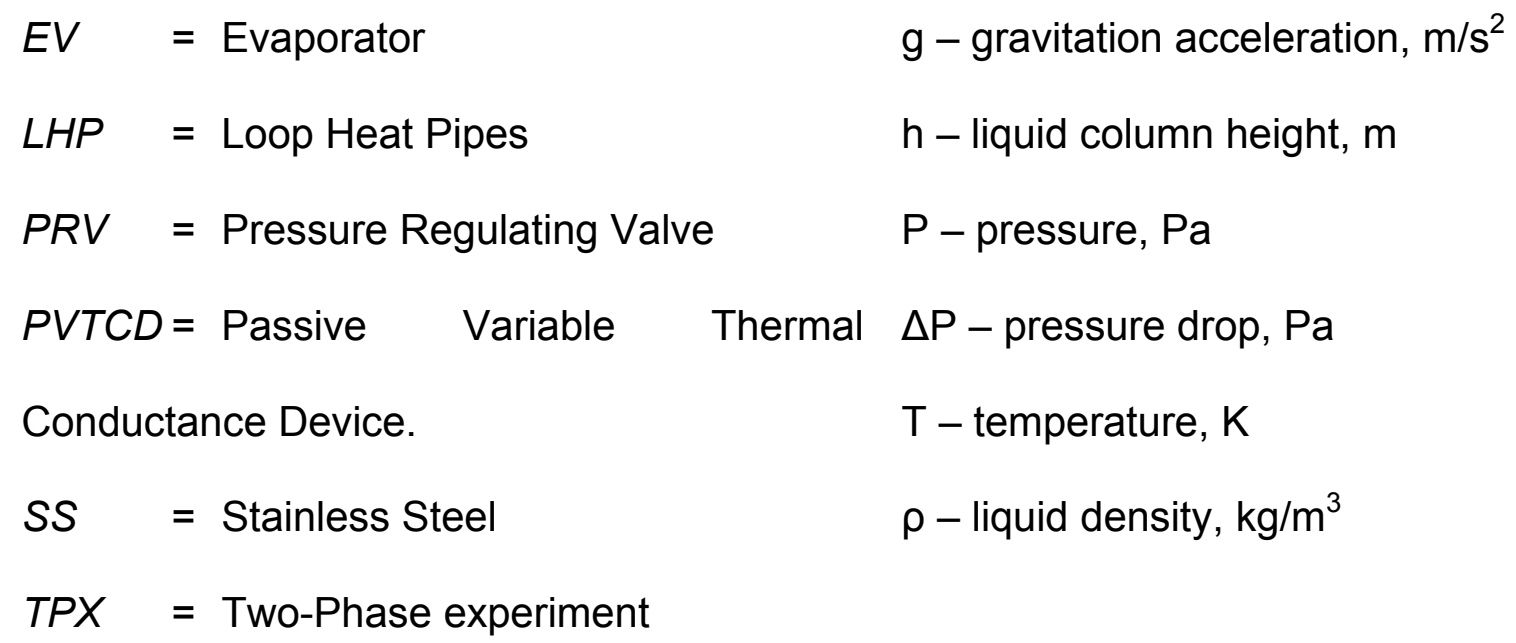


$T R P=$ Technological Research Program

Indexes

PRV - pressure regulating valve,

LHP - loop heat pipe,

w - wick

max - maximum,

\section{References}

[3.1] Anderson W.G., Hartenstine J.R., Walker K.L. and Farmer J. T. Variable Thermal Conductance Link for Lunar Landers and Rovers, IECEC 2010, 8th Annual International Energy Conversion Engineering Conference, Nashville, Tennessee, USA, 2010.

[3.2] Kaya T. and Mishkinis D. Accurate Temperature Control Using Heat Pipes. International Review of Mechanical Engineering (I.R.E.M.E.). Vol. 1. no. 1. 2008.

[3.3] Delil A.A.M., Dubois M. and Supper W. The European Two-Phase eXperiments TPX I \& II, Proceedings of the $X^{\text {th }}$ International Heat Pipe Conference, Stuttgart, Germany, 1997.

[3.4] Goncharov K., Kochetkov A., Buz V. Development of Loop Heat Pipe with Pressure Regulator, Intl. Two-Phase Thermal Control Technology Workshop, Los Angeles, USA, 2005.

[3.5] Goncharov K.A., Kozmine D.E., Smirnov F.Yu., Nikitkin M.N., Fershtater Yu.G., Maidanik Yu.F. Loop Heat Pipes for Space Mission Mars 96, Proceedings of International Seminar and Workshop "Heat Pipes, Heat Pumps, Refrigerators", Minsk, Belarus,1995. 
[3.6] Goncharov K. Orlov A., Tarabrin A., M. Gottero, V. Perotto, S. TaveraG. P. Zoppo. 1500 W Deployable Radiator with Loop Heat Pipe, Proceedings of the $31^{\text {th }}$ International Conference on Environmental Systems, SAE Paper 01ICES-68, Orlando, Florida, USA, 2001.

[3.7] Mishkinis D., Gregori C., Romera F. and Torres A. Development of Propylene LHP for European Mars Rover Applications, Heat Pipe Science and Technology International Journal. Vol. 1, Issue 1. Pp. 19-46. 2010.

[3.8] Molina M., Franzoso A., Bursi A., Romera F., and Barbagallo G. A Heat Switch for European Mars Rover, Proceedings of the $38^{\text {th }}$ International Conference on Environmental Systems, SAE Paper 2008-01-2153, San Francisco, 2008.

[3.9] Molina M., Franzoso A., Romera F., and Barbagallo G. Thermal Testing of a Heat Switch for European Mars Rover, Proccedings of the $39^{\text {th }}$ International Conference on Environmental Systems, SAE Paper 2009-01-2573, Savannah, USA, 2009.

[3.10] Romera F., Mishkinis D., Kulakov A., Torres A. Control of LHP operation temperature by a pressure regulating valve, 15th International Heat Pipe Conference, Clemson, USA, 2010.

[3.11] Thermal control device regulated by pressure. Patent application EP 2631183 A1., Mishkinis D., Torres A., 2010. Pending.

[3.12] Mishkinis D., Kulakov A., Turrion E., Radkov A., Torres A. Application of Peltier Element in Loop Heat Pipes, 40th International Conference on Environmental Systems, AIAA paper 2010-6004. Barcelona, Spain, 2010.

[3.13] Bugby D. C., Farmer J. T., O'Connor B. F., Wirzburge M. J., Abel E. D., and Stouffer C. J., Two-Phase Thermal Switching System for a Small, Extended Duration Lunar Surface Science Platform, SPESIF Conference, 2010. 
[3.14] Mishkinis D., Gregori C., Huidobro D., and Torres A. Low Power and Low Temperature LHP for Thermal Control of Rovers, 41th International Conference on Environmental Systems, Portland, Oregon, USA, 2011.

[3.15] Kaya T., Baker Ch., Ku J. Comparison of Thermal Performance Characteristics of Ammonia and Propylene Loop Heat Pipes, SAE paper 2000-012406, International Conference On Environmental Systems, Toulouse, France, 2000 


\title{
Chapter 4
}

\section{Set point active control of vapor modulated loop heat pipe}

(Manuscript published in Heat Pipe Science and Technology, Vol. 3(2-4), pp. 263280, 2012. DOI: 10.1615/HeatPipeScieTech.2013006631)

\begin{abstract}
Novel advanced active temperature control method, based on variable conductance vapor modulated Loop Heat Pipe (VMLHP) technology, is presented and discussed. Pressure regulating valve (PRV) is a key element of the VMLHP. The back pressure reservoir of the PRV has been charged by actuating fluid to provide the system thermal regulation by means of pressure control inside of the VLMHP. Argon and ammonia (single- and two-phase fluids) have been investigated as PRV actuating agents. The active control of the VMLHP is achieved by the PRV actuating fluid pressure adjustment provided by the PRV temperature conditioning. A miniature heater and Peltier element have been attached to the PRV body for this purpose.
\end{abstract}

For argon, the results show that the temperature set point can be modified up to $5^{\circ} \mathrm{C}$ without exceeding the hardware temperature limitations with very little heater/Peltier (thermoelectric cooler) element power. A ratio of about $1^{\circ} \mathrm{C}$ set point increase per $10^{\circ} \mathrm{C}$ argon temperature increase is obtained. 
Regarding ammonia, the test goal was to keep evaporator temperature constant whatever the power applied to VMLHP (up to 170W), by means of a controller. In this case, again very few control power was needed (less than $4 \mathrm{~W}$ ) to achieve a precise temperature control. A simple PID control was used to avoid complex control algorithms. The tuning of the PID gains was performed by trial and error.

A possible application of this active control is to counterbalance the heat fluxes, which can reach the PRV, back pressure reservoir from a hot/cold environment or from the superheated vapor of the working fluid. This is very important when high temperature control precision (less than $0.1^{\circ} \mathrm{C}$ ) is required.

Keywords: Two-phase heat transfer, Thermal control, Pressure regulating valve, Active control, Loop heat pipe, Vapor modulation.

\subsection{Introduction}

A variable conductance LHP with a pressure regulating valve (PRV) is able to passively regulate the working temperature of the evaporator. This regulation is quite precise: a few degrees for the complete power range and sink thermal conditions. For the majority of the applications this passive regulation is precise enough [4.3]. However, there are some applications, which may require a narrower temperature regulation, or different temperature set points for thermally controlled equipment. For that purpose, an active control can be introduced onto the PRV. It consists on the active heating or cooling of the valve actuating fluid reservoir. With 
very few power, the set point can be increased (heating) or decreased (cooling), providing a high precision temperature control.

PRV can be used as a 2-way or 3-way valve configuration, depending whether the bypass outlet is closed or connected to the compensation chamber (or liquid line), respectively. Variable conductance LHP with 3-way PRV is called Bypass Line LHP (BLLHP) and LHP with 2-way PRV is named as Vapor Modulated LHP (VMLHP) by analogy with Variable conductance Heat Pipes with PRV (Vapor Modulated Heat Pipe - VMHP) proposed in [4.2]. Figure 4.1 shows VMLHP design for European Mars Rover application.

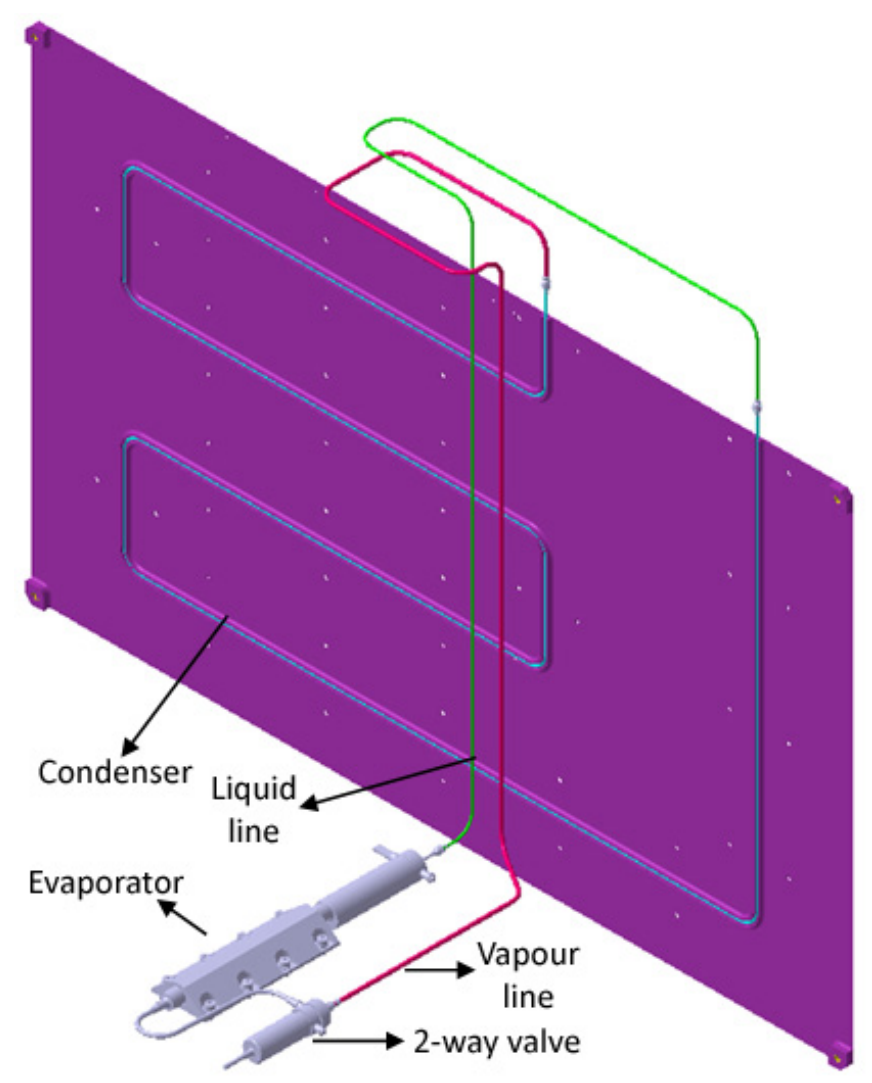

Figure 4.1. VMLHP design for European Mars Rover application. 


\subsubsection{PRV general working principles}

Scheme of the 2-way and 3-way PRVs is given in Figure 4.2. The back pressure and the LHP working fluid are separated by the bellow. The valve piston position depends on the back pressure of activating fluid, the working fluid pressure and bellows force.

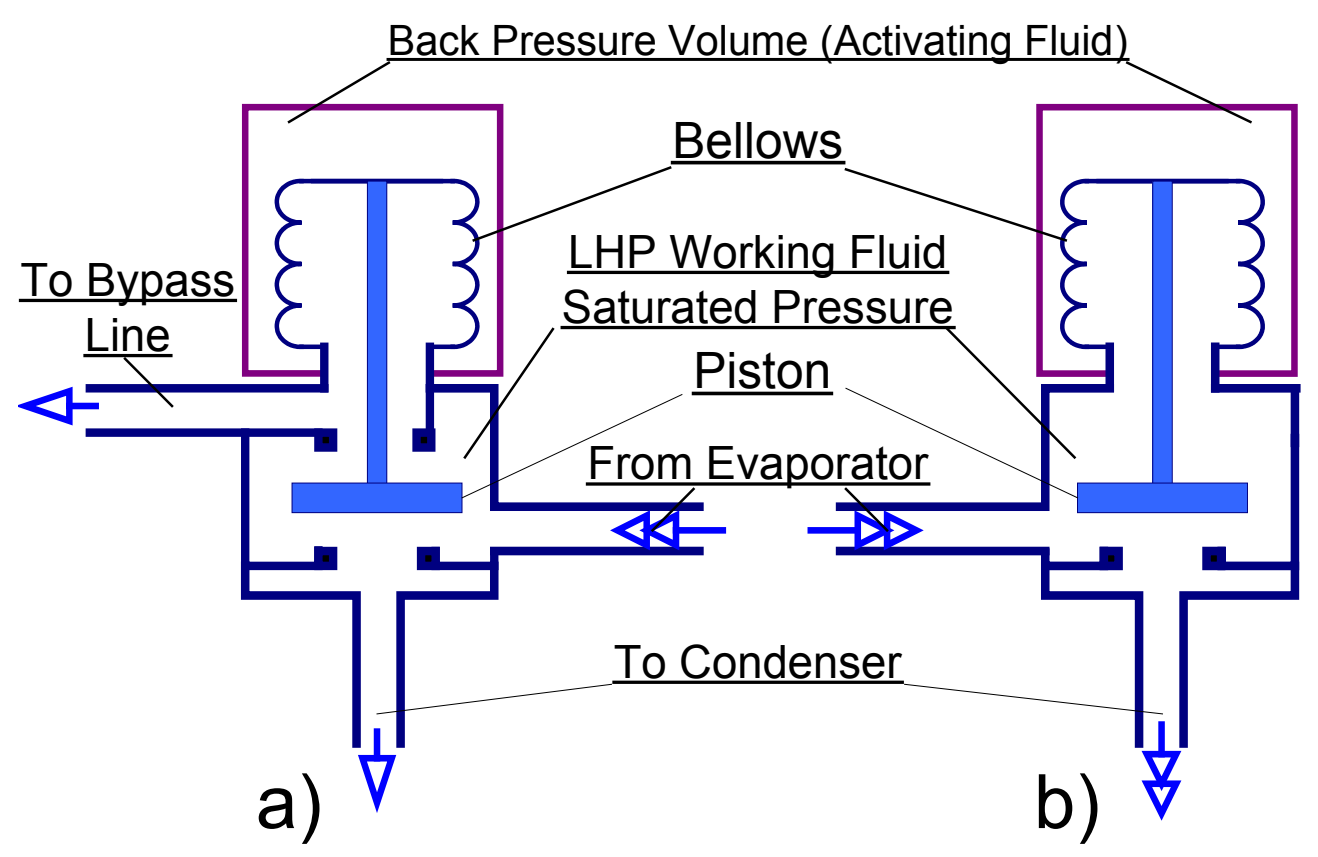

Figure 4.2. PRV Scheme: 3-way (a) and 2-way (b) designs.

Figure 4.3 shows valve piston position as a function of the saturation pressure (or working fluid temperature) for 2-way and 3-way PRVs. Once the valve is charged with the back pressure, if there is a small working fluid pressure, the valve piston remains pressed in the bottom position (in accordance with Figure 4.2), closing the condenser path. With increasing working fluid pressure, the piston keeps this position until a set 
point pressure is reached. At this point, the piston starts to take off from the seat. This set point pressure is a function of the back pressure and bellows preload.

With further pressure increase, the piston runs the distance between the bottom and the top seat until the piston reaches the upper seat at a determined pressure. For 3-way valve design this pressure is known as regulation point pressure and it depends on the back pressure, the bellows preload and the valve stroke. With increasing working fluid pressure, the piston keeps in this position and path to the condenser is fully open. For 2-way valve design set point and regulation pressures have the same value and path to the condenser is fully open after set point pressure is reached.

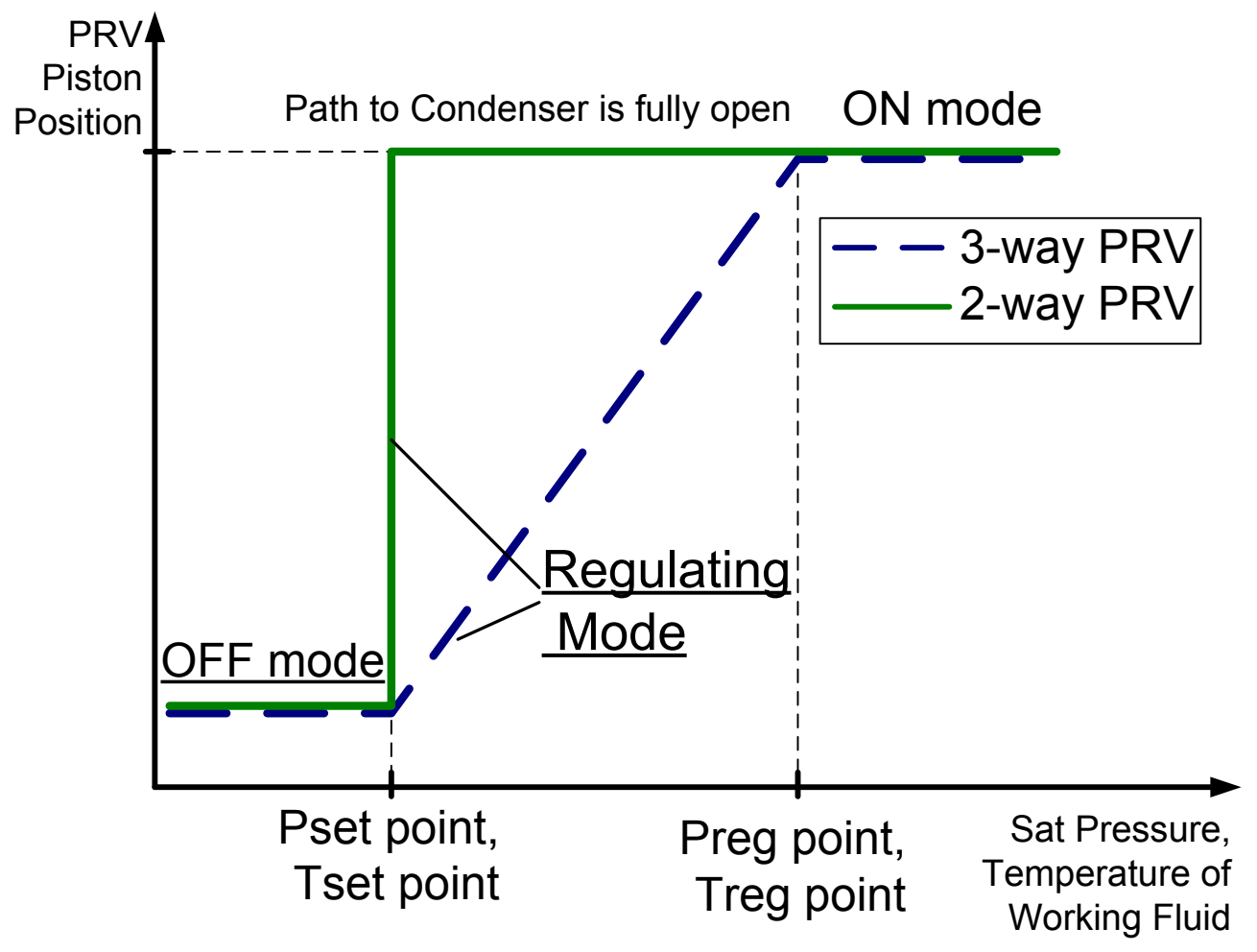

Figure 4.3. Valve Operation Modes

The pressures mentioned in Figure 4.3 translate into temperatures in accordance with the saturation line of the LHP working fluid. These temperatures are the LHP 
evaporator saturation temperatures. Since it is difficult to measure evaporator saturation temperature, the nearest saturated temperature that can be referenced is the reservoir one.

For temperatures between set and regulation points the flow is split between the condenser and the bypass line (BLLHP) or an important pressure drop is introduced in the vapour line (VMLHP). This regime is called regulation mode. For temperatures above the regulation point, the LHP behaves as a regular LHP without valve and this regime is called ON mode.

\subsubsection{Comparison VMLHP vs. BLLHP}

The input thermal power and the sink temperature mainly determine the evaporator operating temperature of an LHP. A valve introduced in this LHP has the ability to increase this operating temperature as long as the regulation point is set above it. This effect is obtained because the "conductance degradation" provided by PRV.

In the case of a BLLHP, the conductance degradation is obtained by the bypassed hot vapor mass flow, injected directly into the reservoir or liquid line. More subcooling is required for liquid, which is returned from condenser, to counterbalance this heat injection in the compensation chamber. For power and pressure drop conservation considerations [4.5], the LHP operating temperature is normally obtained near the regulation point. 
For a VMLHP configuration, the additional pressure drop introduced in the vapor line provides the conductance degradation. This pressure drop makes the primary wick to provide more capillary pressure and therefore to work under a higher temperature gradient. Under this circumstance the back conduction is increased [4.4]. For high power (high working fluid mass flow) and/or low sink conditions, the required pressure drop to reach the necessary back conduction may come close to the pumping capability of the wick. In this condition, the wick provides the maximum pumping capability and the evaporation front in the wick recedes toward the evaporator core. This produces a higher heat leakage through the wick even if the gradient between the evaporator and reservoir temperatures is not very important. This is distinguishing difference in operation between VMLHP and VMHP. VMLHP continues to operate when VMHP dries out in similar conditions due to capillary limit. VMLHP is robust self-regulated system with variable back heat leak into LHP compensation chamber.

Thus, the 2-way PRV is only able to introduce a high pressure drop when the piston is in the position near the set point (condenser passage section almost choked) and this is therefore the operating temperature for VMLHP configuration.

For a BLLHP configuration, a small leakage through the bypass can prevent the start-up event because it makes difficult to obtain a proper temperature gradient between evaporator and reservoir. Besides, this configuration can promote temperature oscillations under gravity due to a coupling phenomenon between the bypass line pressure drop (introduced by the PRV) and liquid column static pressure variations in the condenser (variation of the condensation front position) [4.5]. 
In a VMLHP layout, start-up is easier than in a BLLHP, mainly if it is triggered from an evaporator temperature below the valve set point (condenser closed). Moreover, there are no undesirable temperature oscillations between set and regulation points due to gravity effects because only one pressure (with corresponding temperature) point can be realized for VMLHP. Detailed analysis and experimental investigation of VMLHP and BLLHP operation were performed in [4.6].

\subsubsection{PRV set point migration}

For the PRV operation description it has been assumed that the back pressure is constant. This means that the actuating fluid temperature is constant. However, it can vary due to ambient and LHP working fluid temperature changes. Figure 4.4 shows back pressure as a function of Ar and ammonia temperature. Since the argon is not in saturated state its pressure evolution with temperature is not as important as for a saturated fluid. For argon high temperature variations are needed to get moderate pressure changes, especially for low valve set points. The pressure variations shown in Figure 4.4 translate directly in set point migration in accordance with the saturation line of the related LHP working fluid. 


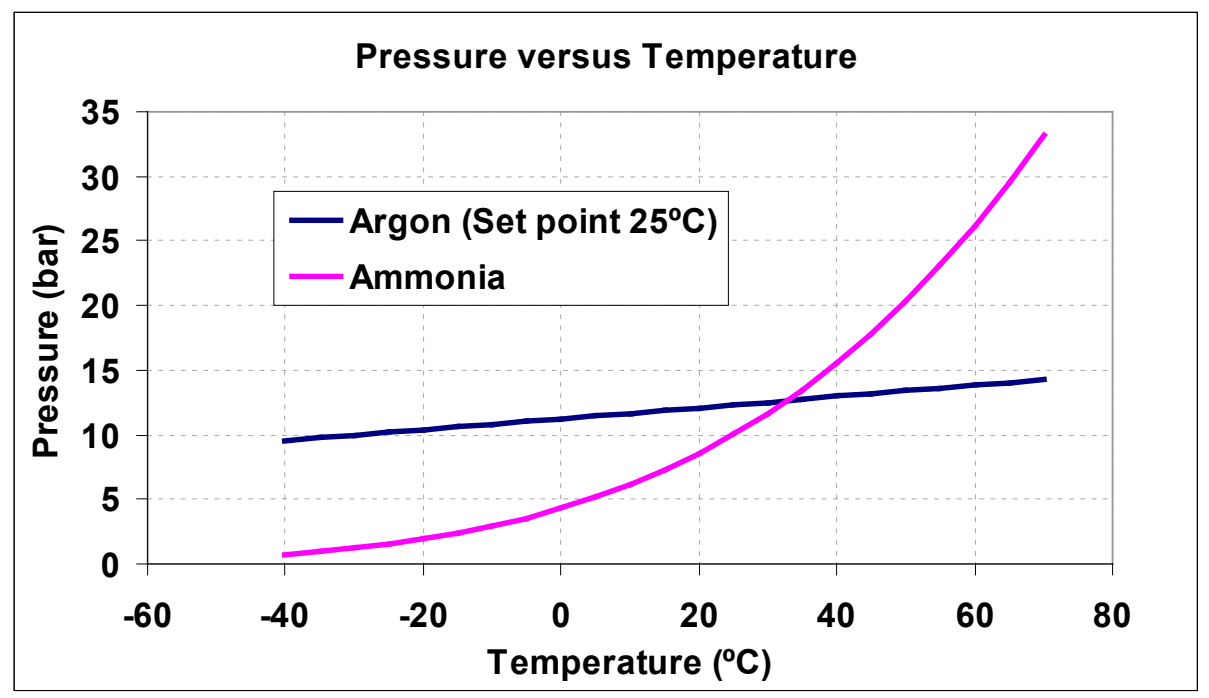

Figure 4.4. PRV Back Pressure vs. Temperature

\subsection{PRV set point active control}

\subsubsection{Argon charged valve}

This back pressure evolution with the argon temperature can be of interest in case an active control of the set point is desirable. It is the case of applications requiring a very precise temperature regulation, for which, even the small set point drifts caused by environmental thermal influence is wanted to be counterbalanced.

It is important to remark that the precise temperature control is not usually required for the PRV set point itself but for the saddle temperature. Between these two temperatures there is a gradient, which depends on the thermal coupling between the saddle and the evaporator saturation temperature, and the heat being transferred by the LHP. The active control discussed here can also be applied to correct this gradient and make the saddle temperature to be really independent of the LHP power level and sink conditions. Small temperature variations and precise set point control can be obtained with relatively small power. 
A VMLHP including a heater and a Peltier element is tested in vacuum and in climatic chamber. Valve was connected to the cold face of the Peltier through an aluminum block. Hot face of the Peltier was cooled by air natural convection through aluminum heat sink (finned plate). This VMLHP has been developed for the temperature control of a spacecraft communication system. Hot and cold sink conditions are investigated. Thermocouples layout is shown in Figure 4.5. Main LHP characteristics are the following:

- Evaporator: $140 \mathrm{~mm}$; outer diameter $15 \mathrm{~mm}$

- Compensation chamber: $60 \mathrm{~mm}$, outer diameter $30 \mathrm{~mm}$

- Titanium sintered wick: $\sim 2.5 \mu \mathrm{m}$ pore size, $\sim 50 \%$ porosity

- Vapor line: $1.3 \mathrm{~m}$, outer diameter $3 \mathrm{~mm}$

- Liquid line: $1.0 \mathrm{~m}$, outer diameter $3 \mathrm{~mm}$

- Condenser: $2.5 \mathrm{~m}$, outer diameter $3 \mathrm{~mm}$

- Ammonia charging: $27 \mathrm{~g}$

- Valve set point: $25-27^{\circ} \mathrm{C}$ (12 bar of argon pressure in ambient)

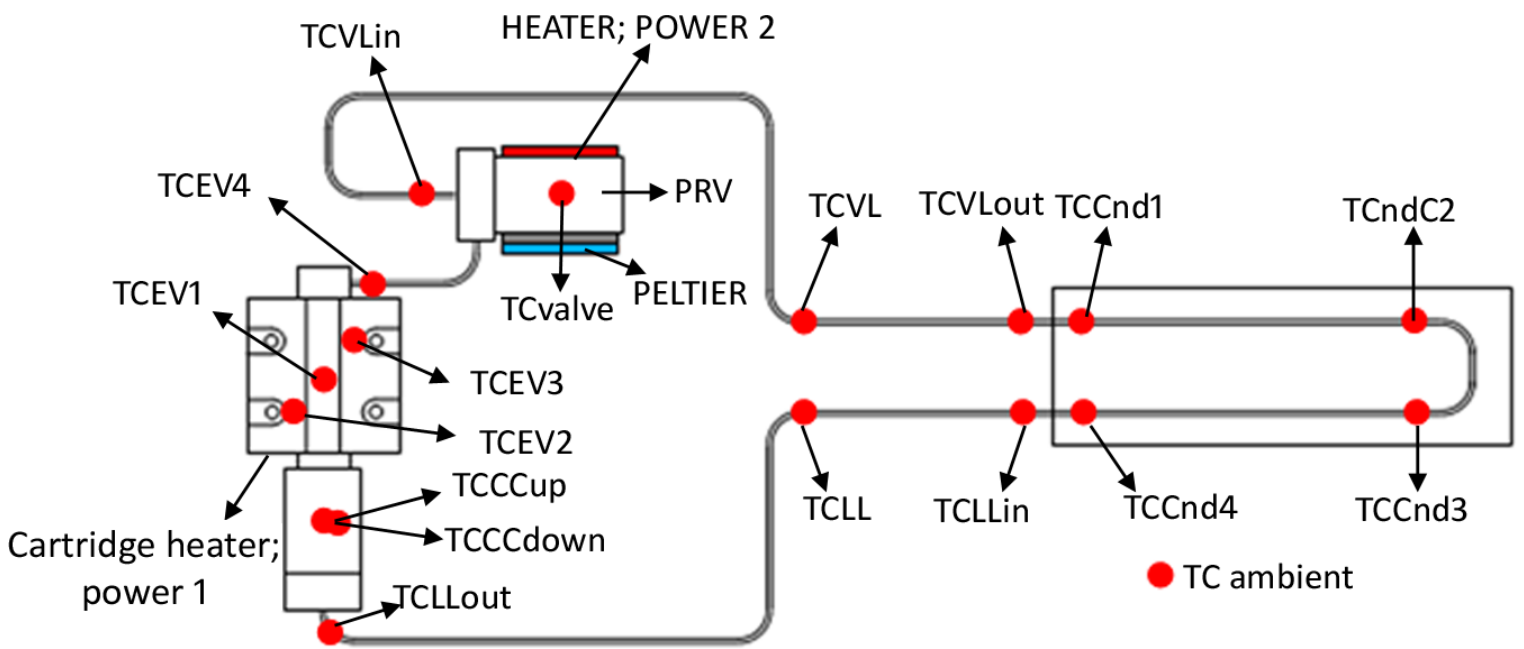

Figure 4.5. Thermocouples layout. 
In Figure 4.6, the increase of the set point obtained by heating the valve body is shown. It refers to a cold sink case $\left(-60^{\circ} \mathrm{C}\right)$ test performed in vacuum chamber. Three saddle temperatures (TCEV1, TCEV2 and TCEV3) and the top and bottom compensation chamber temperatures (TCCCup and TCCCdown) are shown. Green line power is the VMLHP power (35W) and Power 2 is the power applied to the heater installed on the valve case. First part of the graph with temperature peak at $28^{\circ} \mathrm{C}$ corresponds to LHP start-up event. As soon as start-up is happened passive set point $26^{\circ} \mathrm{C}$ at the compensation chamber has been reached. There is a set point increase of $1^{\circ} \mathrm{C}$ per every $0.4 \mathrm{~W}$ valve heating. Valve body temperature variation is from $26^{\circ} \mathrm{C}$ to $36^{\circ} \mathrm{C}$ for $0.4 \mathrm{~W}$, and up to $45^{\circ} \mathrm{C}$ for $0.8 \mathrm{~W}$. These results are listed in Table 4.1.

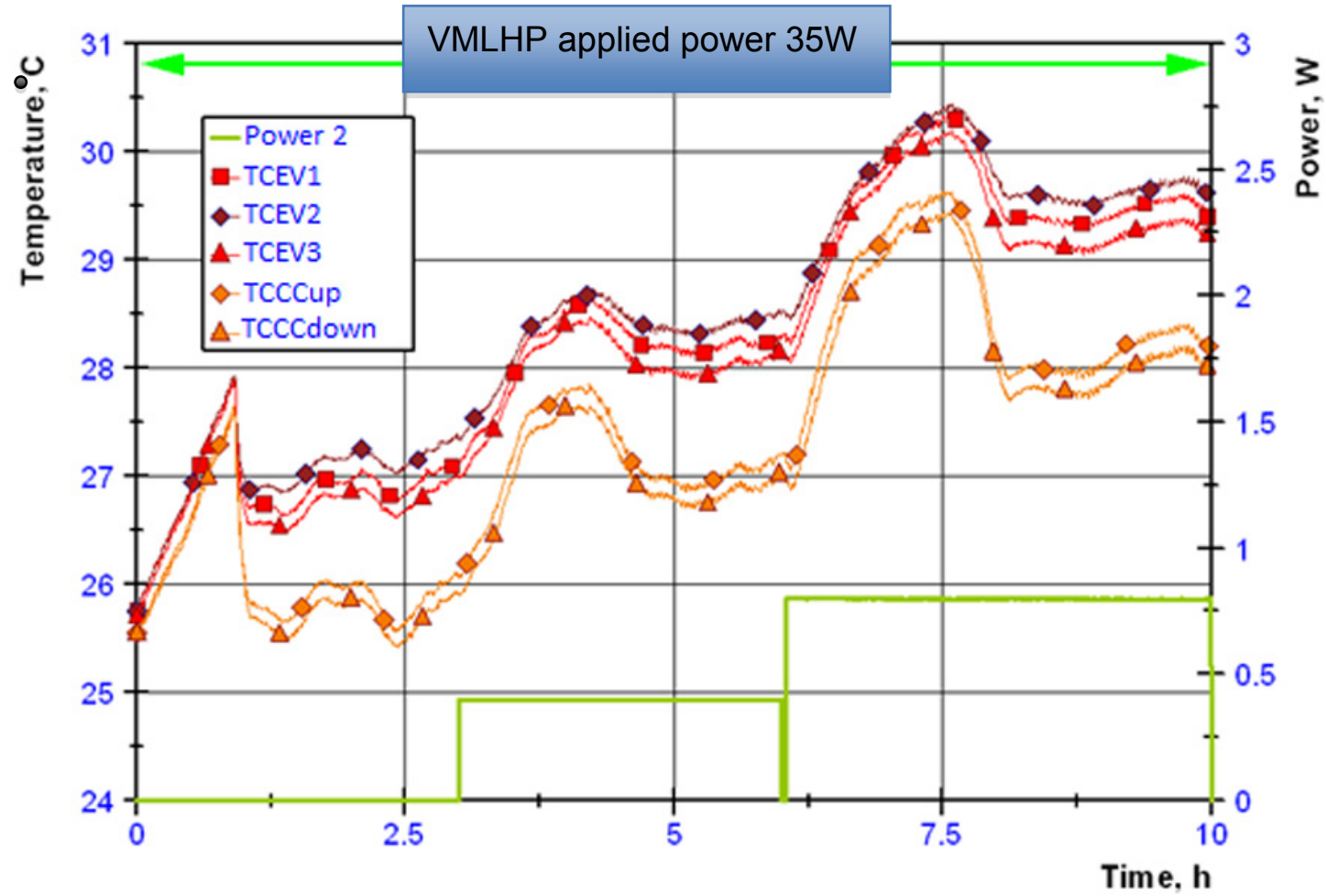

Figure 4.6. Temperatures for PRV heating (cold conditions). 
Table 4.1. PRV set point temperature for PRV heating.

\begin{tabular}{|c|c|c|}
\hline $\begin{array}{c}\text { Control Power } \\
(\mathrm{W})\end{array}$ & $\begin{array}{c}\text { PRV } \\
\text { Temperature } \\
\left({ }^{\circ} \mathrm{C}\right)\end{array}$ & $\begin{array}{c}\text { PRV Set Point } \\
\left({ }^{\circ} \mathrm{C}\right)\end{array}$ \\
\hline 0 & 26 & 26 \\
\hline 0.4 & 36 & 27 \\
\hline 0.8 & 45 & 28 \\
\hline
\end{tabular}

In Figure 4.7, a similar test performed for hot sink conditions $\left(25^{\circ} \mathrm{C}\right)$ is presented. The same conclusions can be drawn.

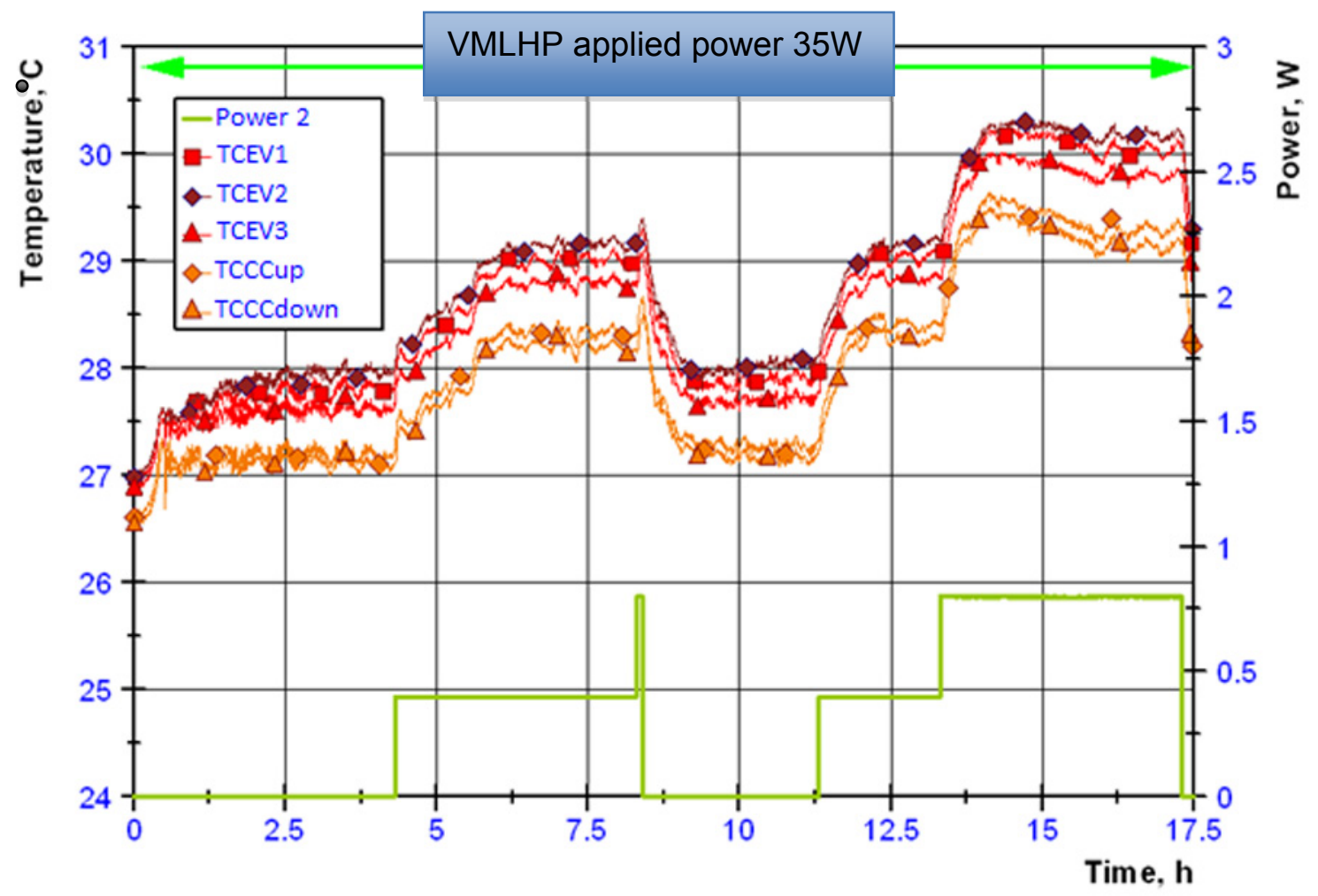

Figure 4.7. Temperatures for heating the valve (hot conditions)

It is important to remark that control power is dependant of the power being transported by the VMLHP because the thermal link between the argon reservoir and the circulating working fluid mass flow. The higher the VMLHP power, the 
higher the working fluid mass flow and higher the needed PRV heating power to reach the same argon temperature level.

Additionally, some tests in climatic chamber are performed by using a Peltier element in the valve body. Temperature profiles are shown in Figure 4.8. The possibility to decrease the set point by cooling down the valve is verified. VMLHP power is now higher $(100 \mathrm{~W})$. Active control results for PRV cooling are shown in Table 4.2. Electrical power applied to the Peltier element during the experiment is shown in Figure 4.8.

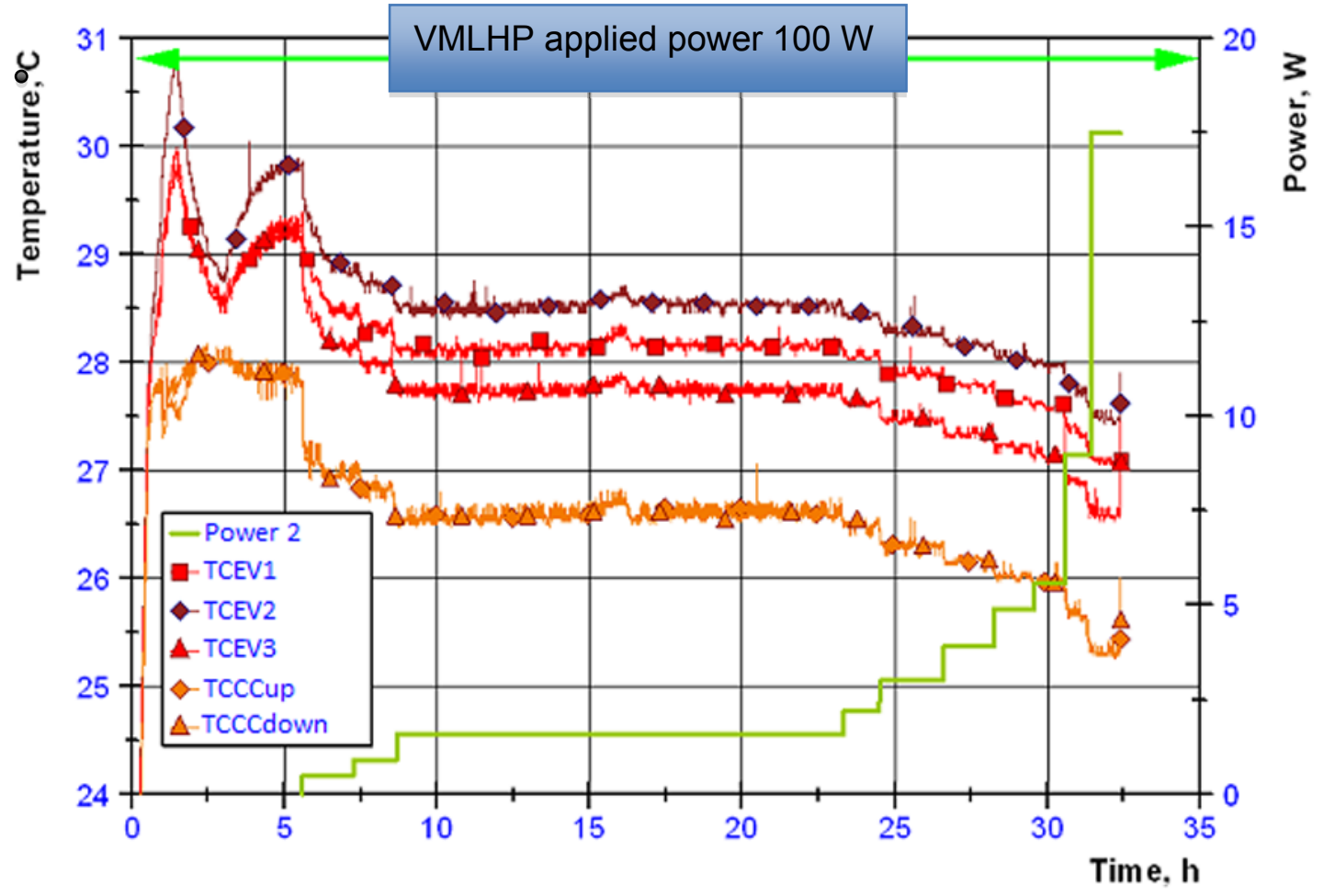

Figure 4.8. Temperatures for cooling the valve. 
Table 4.2. PRV set point temperature for PRV cooling.

\begin{tabular}{|c|c|c|}
\hline $\begin{array}{c}\text { Control Power } \\
(\mathrm{W})\end{array}$ & $\begin{array}{c}\text { PRV } \\
\text { Temperature } \\
\left({ }^{\circ} \mathrm{C}\right)\end{array}$ & $\begin{array}{c}\text { PRV Set Point } \\
\left({ }^{\circ} \mathrm{C}\right)\end{array}$ \\
\hline 0 & 26.5 & 26.5 \\
\hline 1.5 & 12 & 25.5 \\
\hline
\end{tabular}

\subsubsection{Ammonia charged valve}

As mentioned previously, when a saturated fluid is used to provide the valve back pressure, higher set point variation can be provided by heating or cooling the valve reservoir [4.1]. This charging possibility is also of interest for applications requiring a very precise thermal control, including direct control of equipment (evaporator) temperature and/or different temperature set points in wide range are needed.

A VMLHP including a Peltier element and a heater attached to PRV is tested in ambient. Pictures of the Evaporator and 2-way PRV with attached heater and Peltier element can be seen in Figure 4.9. Valve was connected to the cold face of the Peltier through an aluminum block. Hot face of the Peltier was cooled by air natural convection through aluminum heat sink (finned plate). Only cold sink conditions were investigated: temperature of the chiller cold plate, attached to the LHP condenser has been fixed at $-50^{\circ} \mathrm{C}$. The LHP has following characteristics:

- Evaporator: $55 \mathrm{~mm}$; outer diameter $12 \mathrm{~mm}$

- Compensation chamber: $30 \mathrm{~mm}$, outer diameter $16 \mathrm{~mm}$

- Stainless steel sintered wick: $\sim 3.5 \mu \mathrm{m}$ pore size, $\sim 65 \%$ porosity 
- Vapor line: $0.8 \mathrm{~m}$, outer diameter $3 \mathrm{~mm}$

- Liquid line: $0.7 \mathrm{~m}$, outer diameter $2 \mathrm{~mm}$

- Condenser: $0.3 \mathrm{~m}$, outer diameter $2 \mathrm{~mm}$

- Ammonia charging: $6 \mathrm{~g}$

- Valve ammonia charging $0.5 \mathrm{~g}$

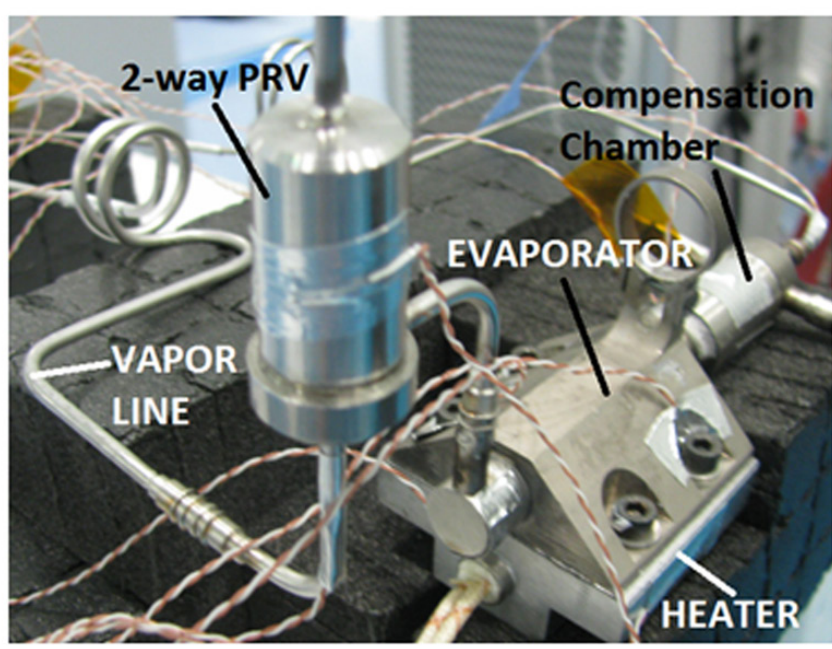

a)

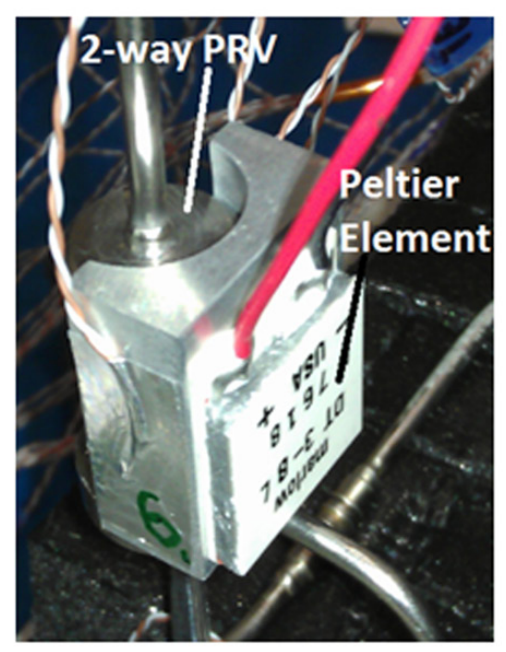

b)

Figure 4.9. a) LHP evaporator with PRV in vapor line, b) Peltier element attached to PRV

For the PRV charged with ammonia, it is not possible to maintain a constant back PRV pressure for different ambient conditions, as it is in the PRV charged by argon, because pressure is related to temperature in accordance with the saturation line. Three set of tests have been performed:

- Without PRV ammonia charging (this case corresponds to regular LHP without PRV)

- With PRV ammonia charging but without temperature control

- With ammonia charging and with temperature control. 
VMLHP has been equipped with 20 thermocouples as it is shown in Figure 4.10. Measuring uncertainties are power $\pm 5 \%$, Temperatures: $\pm 0.5{ }^{\circ} \mathrm{C}$ and stabilization slope $\left({ }^{\circ} \mathrm{C} / \mathrm{h}\right)<1$, measured over 15 minutes time.

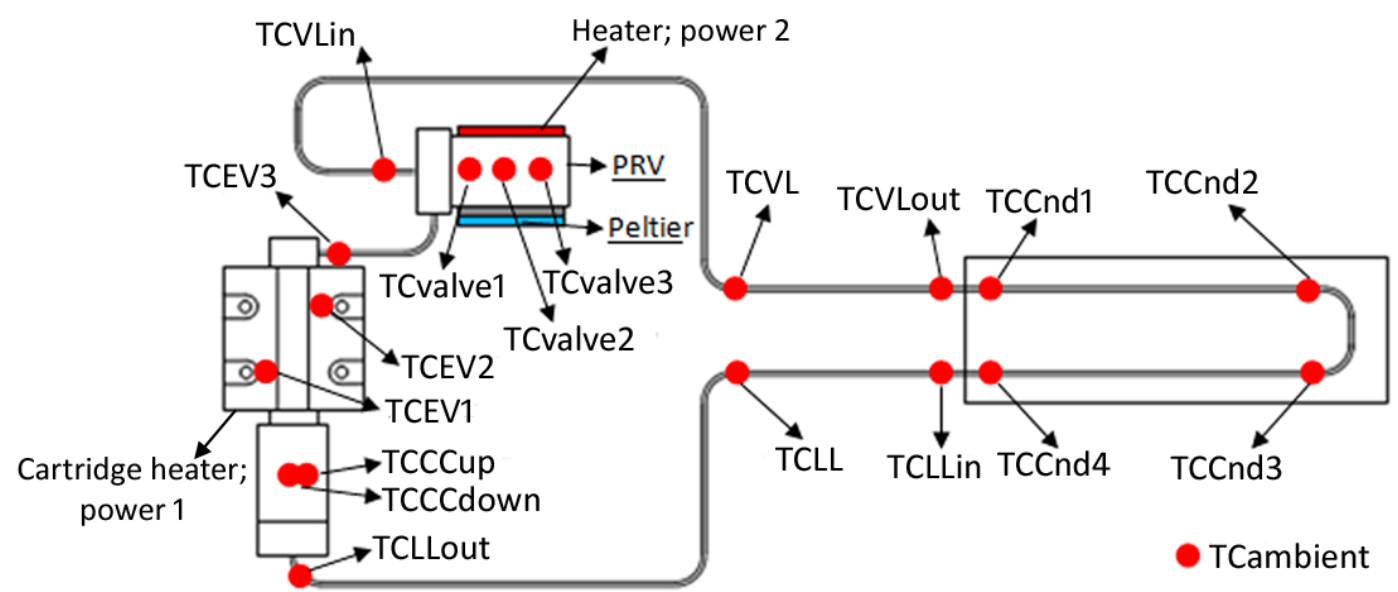

Figure 4.10. Positions of Thermocouples at VMLHP.

Figure 4.11 shows the temperature profiles versus power for a $-50^{\circ} \mathrm{C}$ sink temperature when the PRV has no ammonia. This performance is typical of a regular LHP. Evaporator temperature parts from the sink temperature according to the LHP conductance for each power. Ambient temperature has important influence on LHP performance, since temperature of heat sink is very low. That is why, practically in all power range LHP operates in variable conductance mode: ambient air is heating liquid line and compensation chamber. Also, the evaporator temperature is in a couple of degrees lower than vapor line temperature at powers before $100 \mathrm{~W}$ due to the same effect: vapor line heating by ambient. It is worth noting how the working fluid temperature affects the (empty) PRV temperature. The valve temperature follows the vapor line temperature and this is more visible when the power is high (more mass flow crosses the valve). 


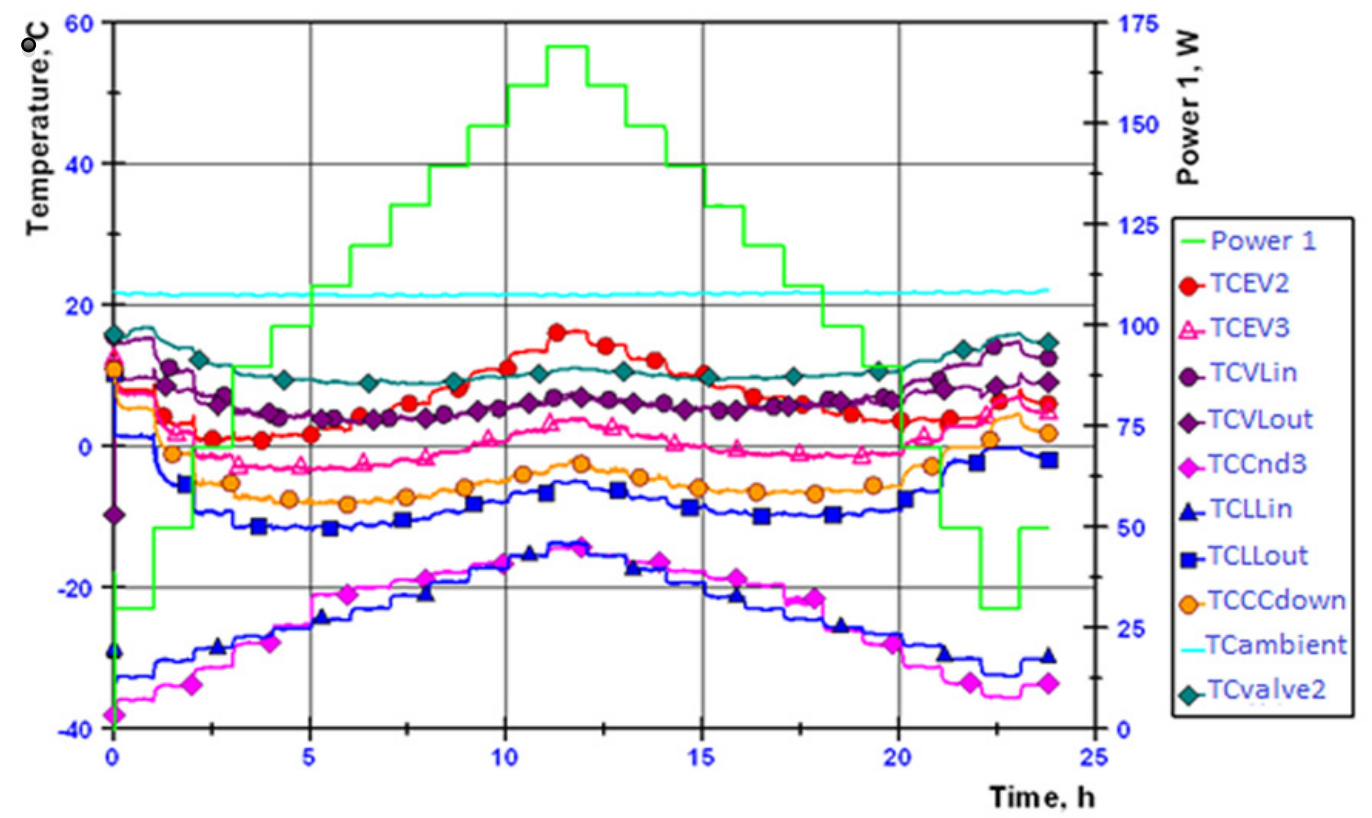

Figure 4.11. Temperatures without valve charging

When the PRV is charged by ammonia and no control is performed on its temperature, the back pressure is the saturation pressure corresponding to the valve temperature. Figure 4.12 shows temperature profiles.

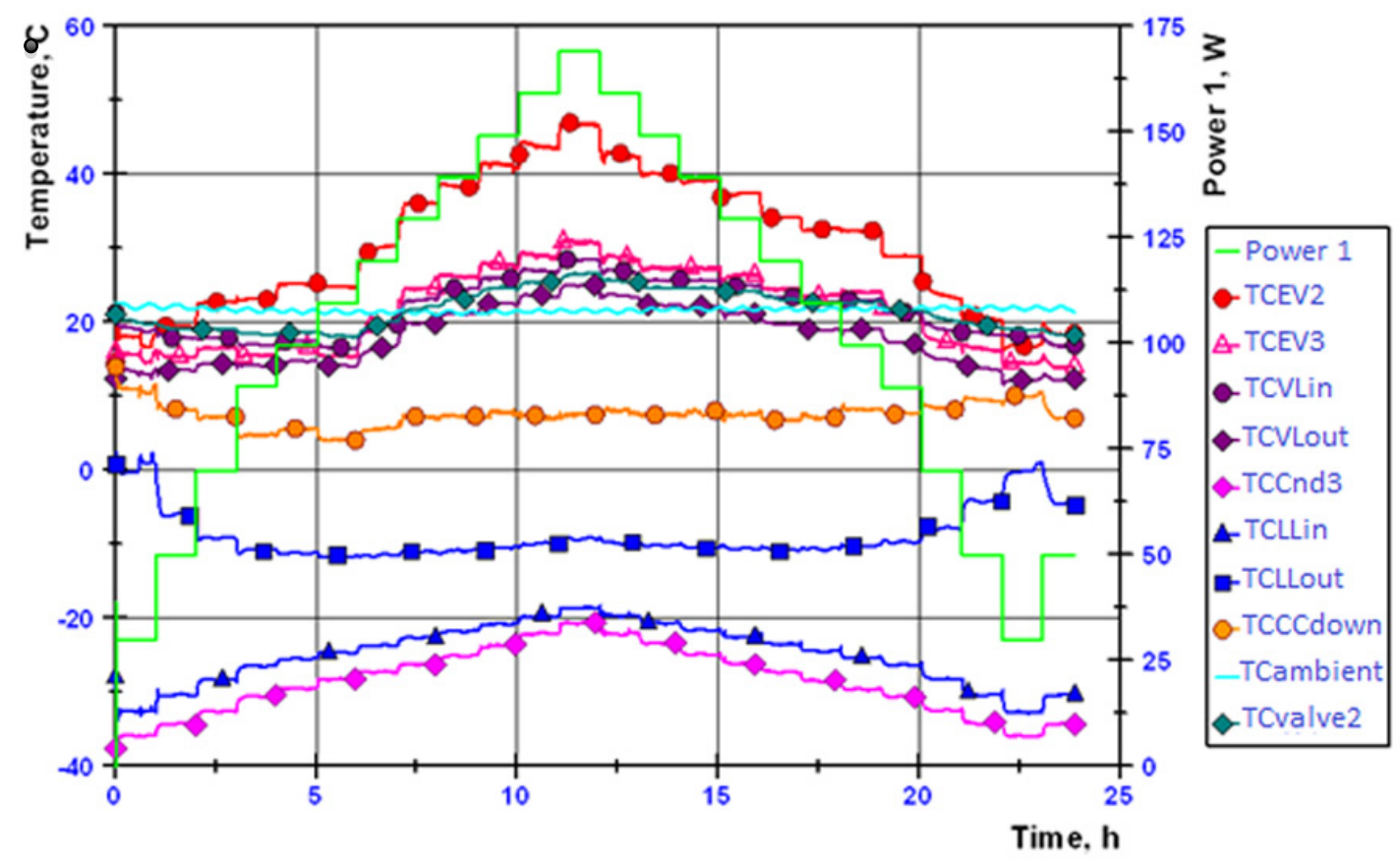


Figure 4.12. Temperatures with PRV charged without temperature control

For a valve temperature around $20^{\circ} \mathrm{C}$, the backpressure is about 8.5 bars.

Taking into account the valve bellows preload and the valve stroke, this pressure corresponds to a set point of around $10^{\circ} \mathrm{C}$, which can be observed in the compensation chamber temperature.

As a general conclusion, when there is no control, the PRV ammonia charging will prevent that the evaporator cools down below PRV (evaporator) ambient temperature.

Figure 4.13 shows the VMLHP performance when a PID controller is introduced. The objective of this PID controller is to keep an evaporator temperature of $21^{\circ} \mathrm{C}$. The heater or Peltier element is operated to accomplish this goal. It can be seen that the objective is very precisely fulfilled for almost the complete power range. For low power $(<70 \mathrm{~W})$, the PRV needs to be heated and a too small amount of power is used for this purpose $(2 \mathrm{~W}$ was maximum heater power). For higher powers, there is a need to cool down the PRV. The set point (again it can be seen in the compensation chamber temperature) decreases for increasing powers so that evaporator temperature keeps constant. Valve temperature (TCvalve2) fluctuations are due to the PID control of the valve. The valve is heated or cooled by the heater or Peltier in order to maintain the set point during the whole test.

An additional test has been carried out to check the behaviour of this controller in front of sharp power transients. The result is shown in Figure 4.14 and the conclusion is that the temperature controllability is rather good. 


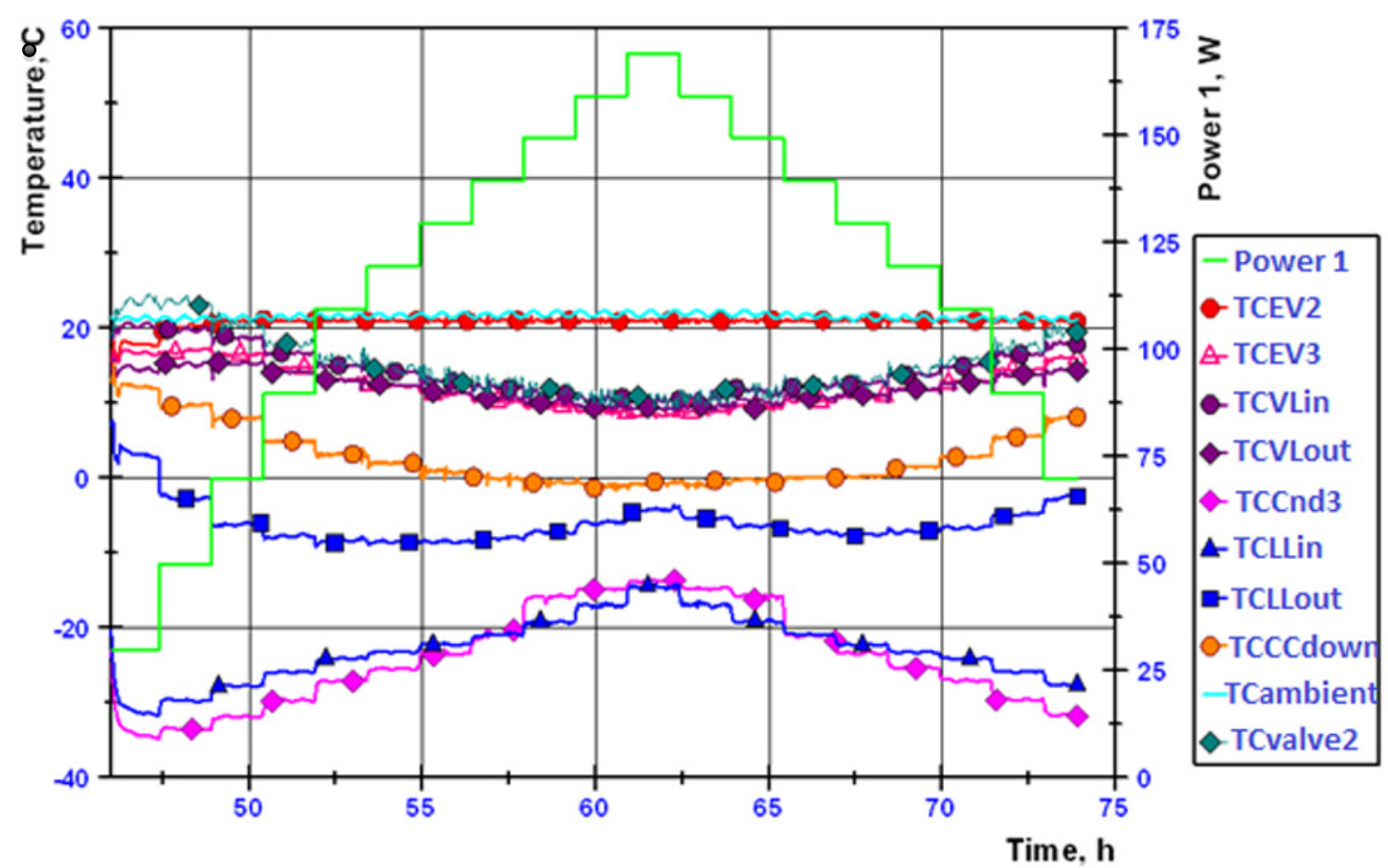

Figure 4.13. Temperatures with PRV charged and PID controlled

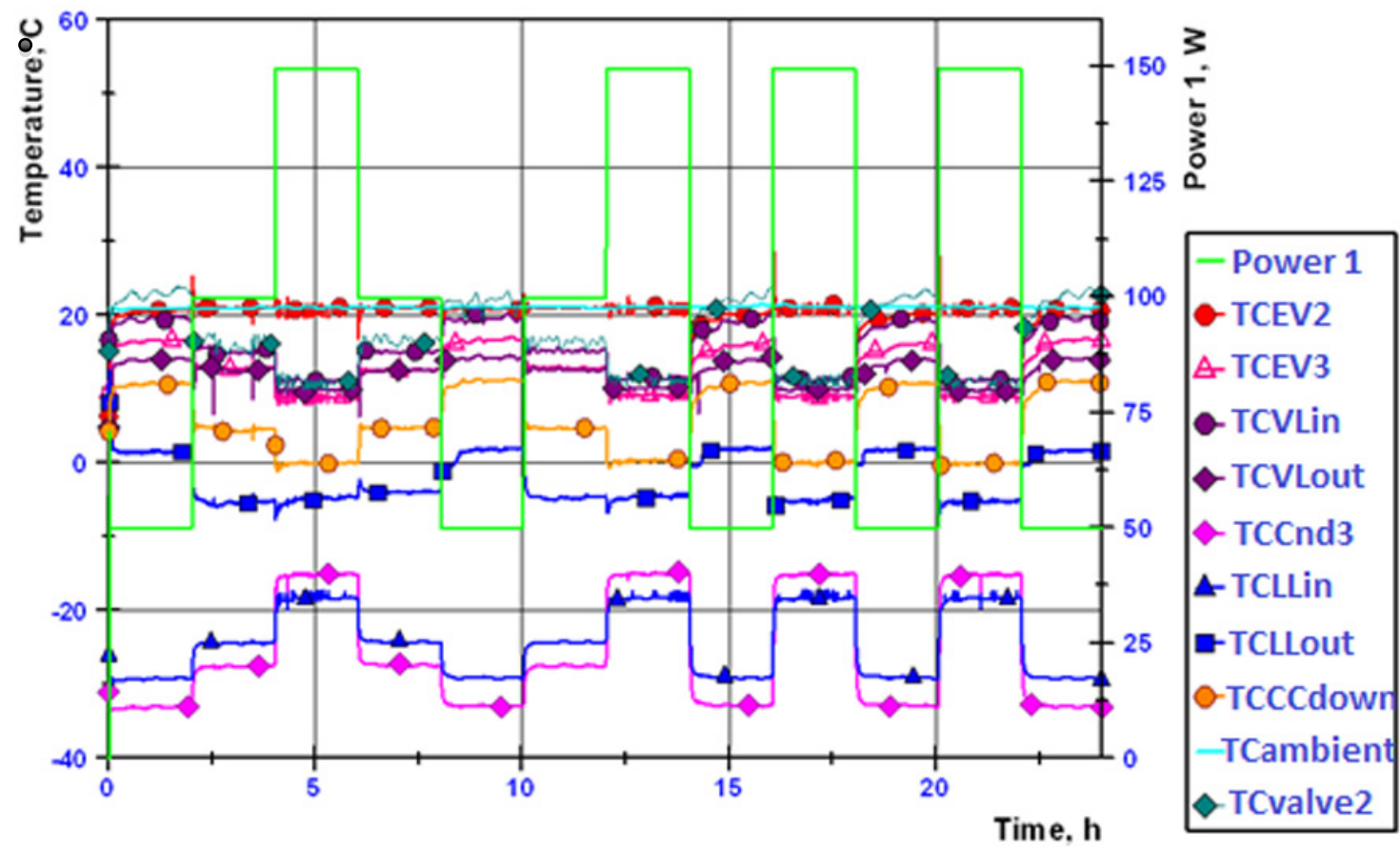

Figure 4.14. Temperature control vs. sharp power variations 
LHP conductance (C_LHP) has been calculated as follows:

C_LHP= Power/(T_Ev-T_CN )

Where Power is heat load $(\mathrm{W}), \mathrm{T}_{-} \mathrm{EV}(\mathrm{K})$ is the average temperature of evaporator and $T_{-} \mathrm{CN}(\mathrm{K})$ is the average temperature of condenser $(\mathrm{K})$.

Figure 4.15 shows the LHP conductance evolution without valve (no ammonia in PRV) and how this conductance is degraded and modulated by the valve in order to reach the evaporator temperature objective.

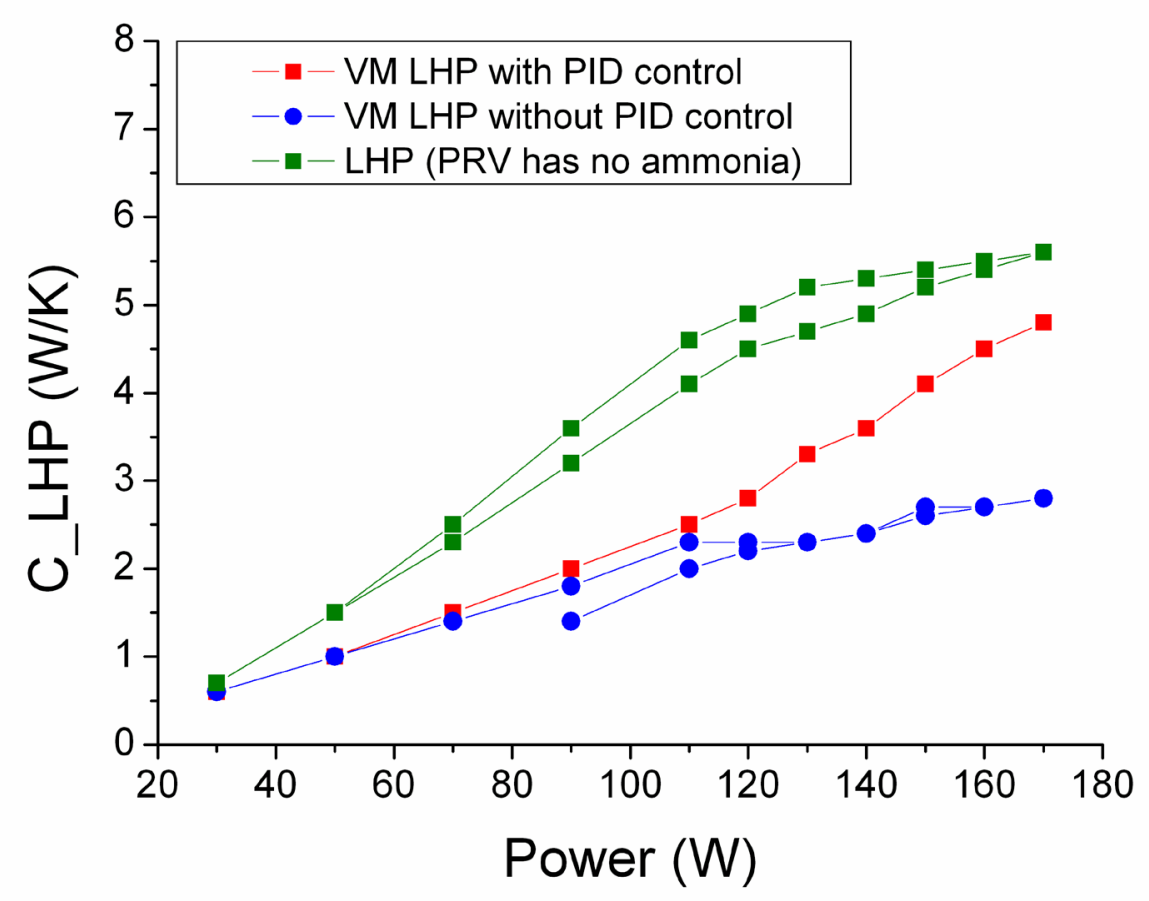

Figure 4.15. LHP conductances

The VMLHP operation, in contrast with normal LHP, is characterized by temperature difference between upper and lower parts of CC (Figure 4.16). This implies that subcooled liquid layer is normally presented on the bottom of the chamber. Furthermore, from the analysis of Figure 4.16, it is clear that in the mode of VMLHP without PID control (blue lines) certain change in the operational 
performance takes place at $\sim 110 \mathrm{~W}$ : sudden increase of CC and PRV temperatures. Our opinion is that the increase is associated with rapid amplification of heat leak into CC. The hydraulic resistance of PRV is getting so high that capillary pump can barely support the flow circulation; however the LHP continues to operate properly without any evidence or even any sign of dryout. The vapor front in the capillary pump goes deeply into the wick. This deepening leads to superheating of the vapor at the evaporator exit, to increase temperature change between evaporator and CC (see Figure 4.17) and, finally, leading to a higher heat leak to CC. Thus, the mechanism of variable heat leak is responsible for the robust operation and highly efficient temperature control provided by the VMLHP.

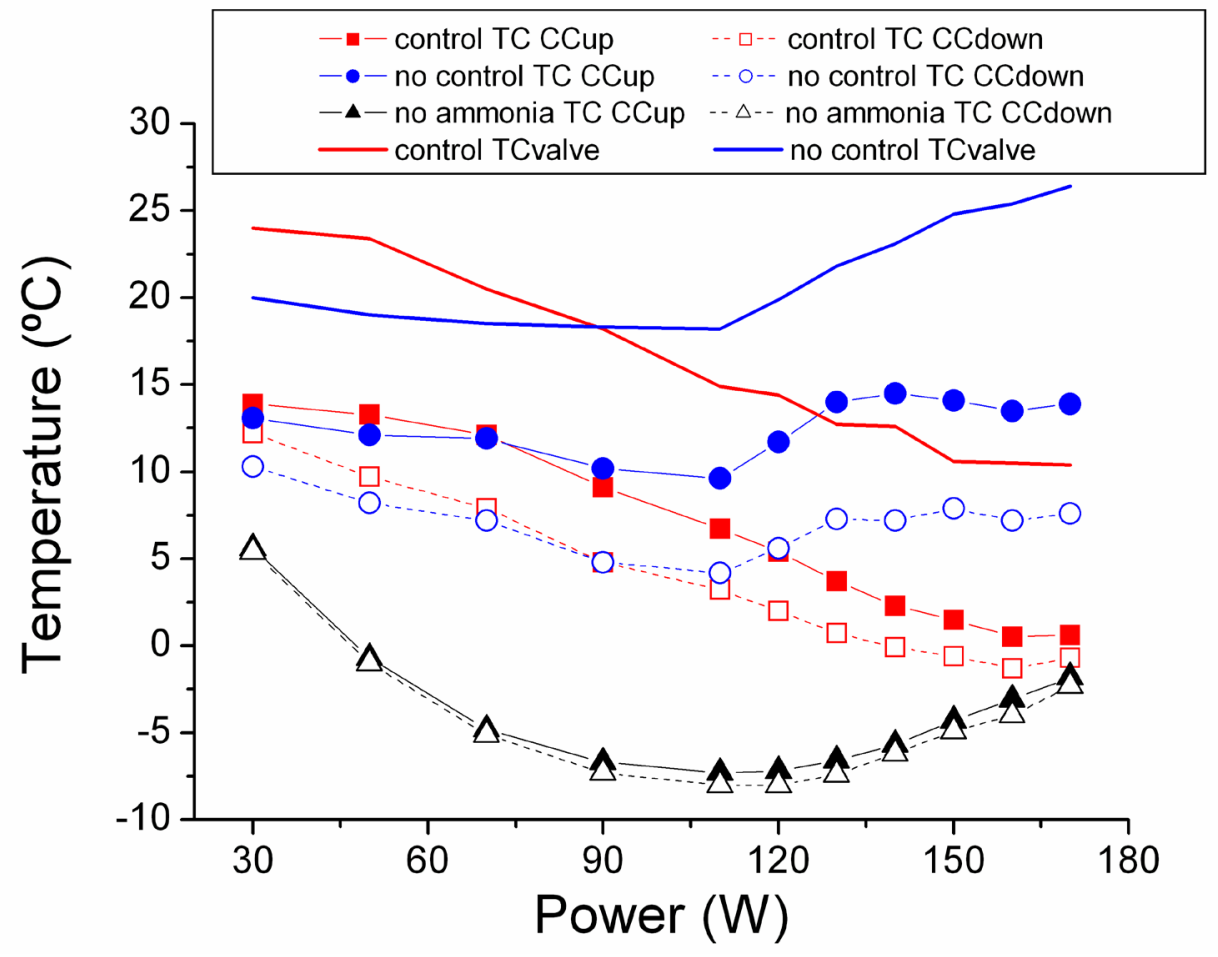

Figure 4.16. Power dependence of CC (upper and lower parts) and PRV temperatures 


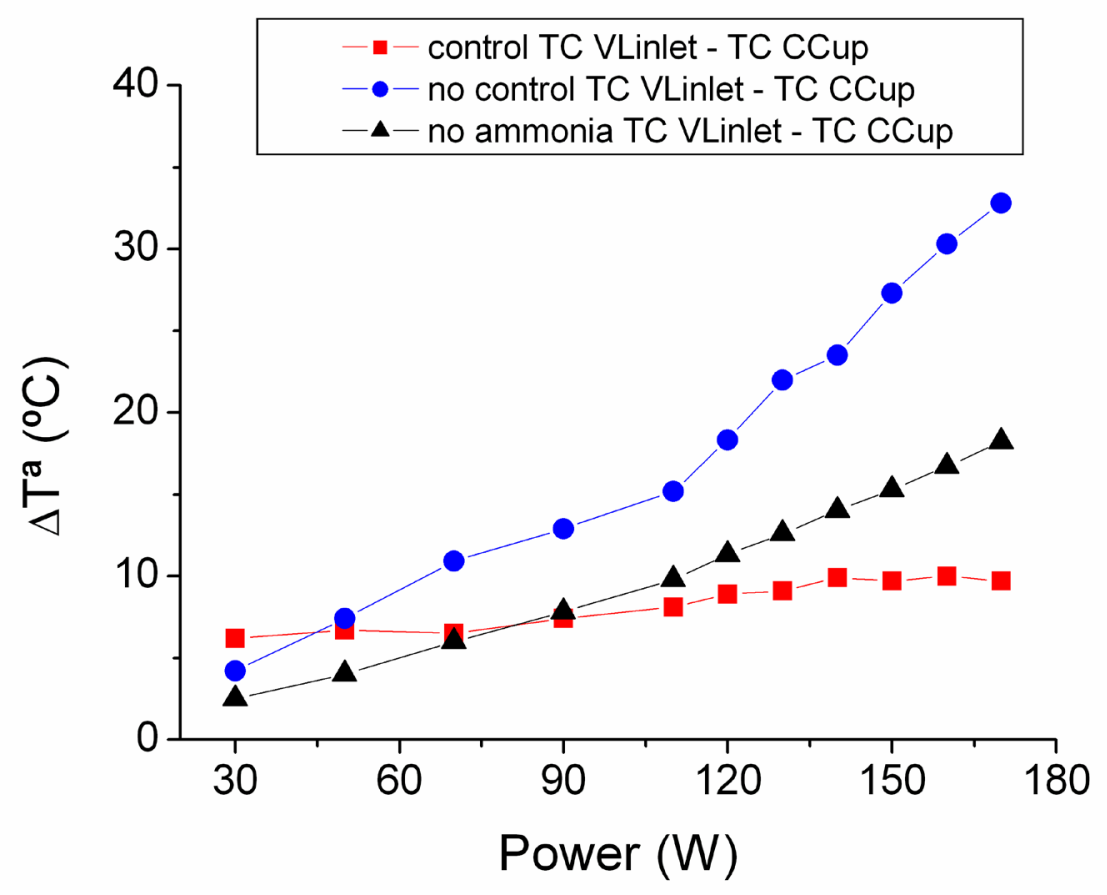

Figure 4.17. Power dependence of temperature differences between CC and vapor line inlet

\subsection{Conclusions}

Although the passive temperature regulation provided by a variable conductance LHP with a pressure regulating valve (PRV) is quite precise, it can be further improved by introducing an active control on the PRV. This consists of the valve body cooling or heating to modify the temperature of the PRV reservoir and hence the back pressure (set point).

Two VMLHPs provided with a heater and Peltier elements on the 2-way PRV have been tested for that purpose. Argon and ammonia have been used as the activating fluids in the PRV. 
For argon, the results show that it is possible to slightly increase or decrease the set point by a few degrees using a small control power. For heating, a ratio of $0.5 \mathrm{~W}$ for every set point degree of variation has been obtained when the VMLHP power was set to $34 \mathrm{~W}$. Regarding the valve cooling, such a ratio is more difficult to establish because of the Peltier element efficiency. In all the cases, a ratio of about $10^{\circ} \mathrm{C}$ valve temperature variations is needed to produce a $1^{\circ} \mathrm{C}$ set point change.

When PRV was charged with ammonia, a very precise evaporator temperature control was established, which was highly robust even for the sudden and large power variations.

\section{Acronyms}

$$
\begin{array}{ll}
B L L H P & =\text { Bypass Line Loop Heat Pipe } \\
C C & =\text { Compensation Chamber } \\
C N & =\text { Condenser } \\
C \_L H P & =\text { LHP Conductance } \\
d & =\text { Derivative } \\
E V & =\text { Evaporator } \\
L H P & =\text { Loop Heat Pipe } \\
P & =\text { Pressure, Pa } \\
P R V & =\text { Pressure Regulating Valve } \\
T & =\text { Temperature, }{ }^{\circ} \mathrm{C} \\
T C & =\text { Thermocouple } \\
V M H P & =\text { Vapor Modulated Heat Pipe } \\
V M L H P & =\text { Vapor Modulated Loop Heat Pipe }
\end{array}
$$




\section{References}

[4.1] Goncharov, K., Schlitt R., Hildebrand U., Loop Heat Pipe For High-Precision Satellite Thermal Control Intl. Two-Phase Thermal Control Technology Workshop, Los Angeles, USA, 2005.

[4.2] Marcus B.D., Edwards D.K., Anderson W.T., Variable Conductance Heat Pipe Technology, Research Report No. 4, 1973.

[4.3] Mishkinis, D., Kulakov, A., Romera, F., Gregori, C., Torres, A., Thermal Control of Loop Heat Pipe with Pressure Regulating Valve, VIII Minsk International Seminar "Heat Pipes, Heat Pumps, Refrigerators, Power Sources", Minsk, Belarus, 2011.

[4.4] Mishkinis, D., Gregori, C., Huidobro, D., Torres, A., (2011) Low Power and Low Temperature LHP for Thermal Control of Rovers, 41st International Conference on Environmental Systems, Portland, USA. 2011.

[4.5] Romera, F., Mishkinis, D., Kulakov, A., Torres, A., Control of LHP operation temperature by a pressure regulating valve, 15th International Heat Pipe Conference, Clemson, USA, 2010.

[4.6] Torres, A., Mishkinis, D., Kulakov, A., Romera, F., Gregori, C., Kaya, T., Thermal Control of Loop Heat Pipe with Pressure Regulating Valve, Heat Pipe Science and Technology, An International Journal, Vol. 3(2-4), pp. 263-280, 2012. DOI: 10.1615/HeatPipeScieTech. 


\section{Chapter 5}

\section{Mathematical modeling of a new satellite thermal architecture system connecting the east and west radiator panels and flight performance prediction}

(Manuscript accepted for publication in Applied Thermal Engineering, Vol. 65, pp. 623-632, 2014, DOI: 10.1016/j. applthermaleng.2013.11.040)

\section{Abstract}

An entirely novel satellite thermal architecture, connecting the east and west radiators of a geostationary telecommunications satellite via loop heat pipes (LHPs), is proposed. The LHP operating temperature is regulated by using pressure regulating valves (PRVs). A transient numerical model is developed to simulate the thermal dynamic behavior of the proposed system. The details of the proposed architecture and mathematical model are presented. The model is used to analyze a set of critical design cases to identify potential failure modes prior to the qualification and in-orbit tests. The mathematical model results for critical cases are presented and discussed. The model results demonstrated the robustness and versatility of the proposed architecture under the predicted worst-case conditions. 


\section{Nomenclature}

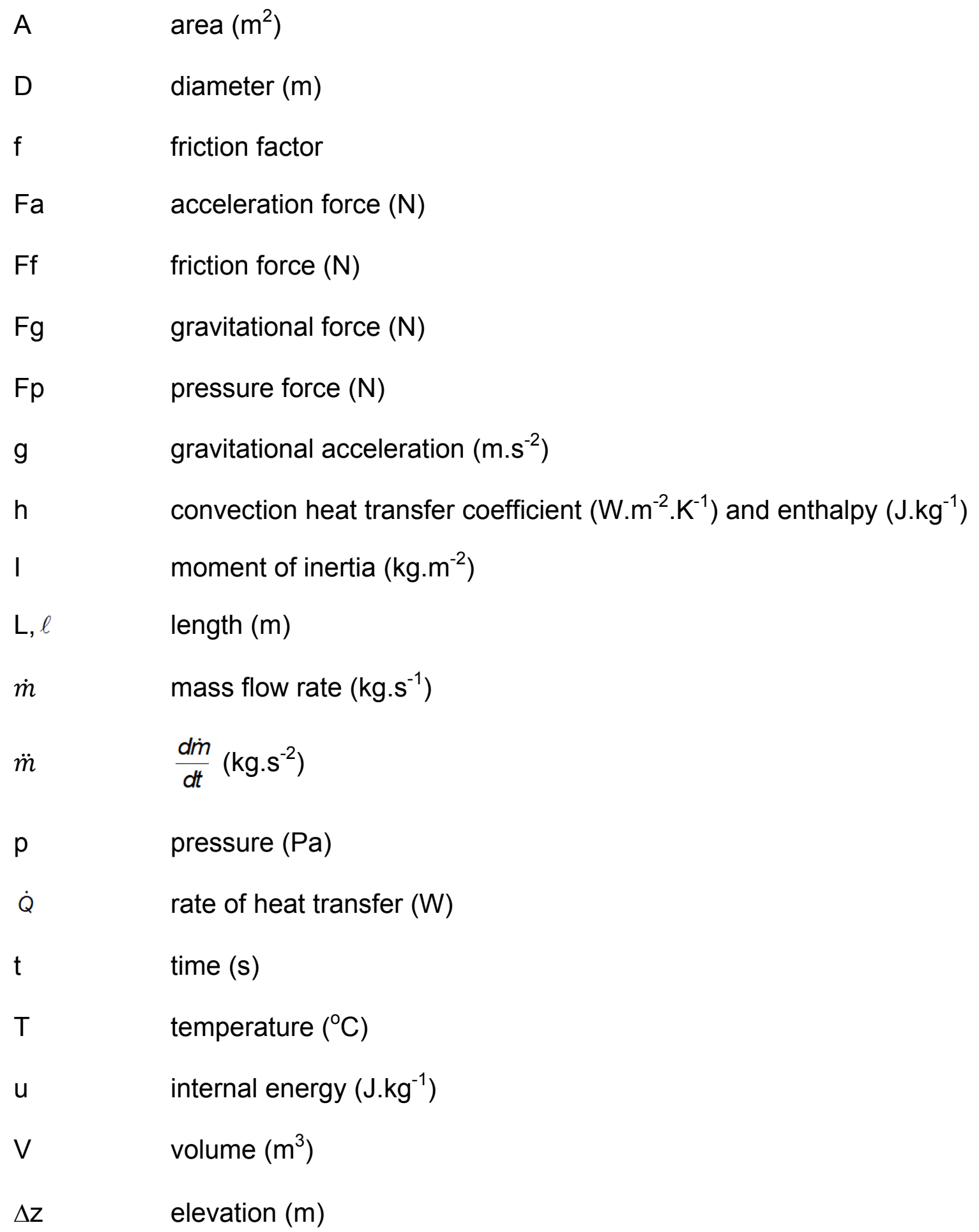




\section{Greek symbols}

$\begin{array}{ll}\delta & \text { flow direction indicator } \\ \xi & \text { pressure drop coefficient } \\ \mu & \text { viscosity (Pa.s) } \\ \rho & \left.\text { density (kg. } \mathrm{m}^{-3}\right)\end{array}$

\section{Acronyms}

$\begin{array}{ll}\text { AMS } & \text { Alpha Magnetic Spectrometer } \\ \text { BOL } & \text { Beginning Of Life Conditions } \\ \text { CAB } & \text { Cryomagnetic Avionic Box } \\ \text { DASSL } & \text { Differential Algebraic System Solver } \\ \text { EOL } & \text { End Of Life Conditions } \\ \text { ESA } & \text { European Space Agency } \\ \text { FMECA } & \text { Failure Mode Effects Criticality Analysis } \\ \text { LHP } & \text { Loop Heat Pipe } \\ \text { MLI } & \text { Multi-Layer Insulation } \\ \text { OSR } & \text { Optical Solar Radiator } \\ \text { PFM } & \text { Proto Flight Model } \\ \text { PRV } & \text { Pressure Regulating Valve } \\ \text { RHU } & \text { Radioisotope Heating Unit }\end{array}$




\subsection{Introduction}

The ever-increasing level of power and integration complexity induced by new electronic technologies characterizes the natural evolution of on-board satellite equipment, antennas and sub-systems. Spacecraft thermal designs are facing limitations to handle the effects of the harsh environment on the design temperatures of the electronics. The limitations are mainly due to two reasons: On one side, to increase the number of transponders per satellite to make a satellite more profitable for the telecommunication operators; on the other side, the incorporation of new type of antennas (highly dissipative), such Ka and Ku bands, to respond to the new telecommunication market demands, such as High Definition TV. This new situation has originated the necessity to improve the heat rejection capability of this type of satellites.

In December $29^{\text {th }}, 2010$ the telecommunication satellite Hispasat $1 \mathrm{E}$ was launched to a geostationary orbit. Besides the commercial payload, the satellite authority provided the opportunity to flight-test a demonstrator to provide novel thermal control architecture to maximize the available radiation areas by passively selecting the appropriate radiators with the best environmental condition according to their temperature conditions. The proposed solution will allow facilitating and potentially increasing the accommodation of electronic equipment within the satellite. The flight demonstrator connects the east and west radiators via a set of loop heat pipes (LHPs) together with the pressure regulating valves (PRVs). 
The demonstrator was designed to comply with the general design and interface requirements along with others specifically imposed by the spacecraft client in terms of operation and interfaces. The most important of these requirements were: the demonstrator should be designed to be mounted and dismounted in four hours. It should not have any functional responsibility and/or interference with the satellite thermal system. In case of malfunction, the demonstrator should be disabled such that failure propagation does not occur. An overall demonstrator mass of $5 \mathrm{~kg}$ and a total power of $70 \mathrm{~W}$ were allocated.

The flight has provided a unique opportunity to test the novel thermal architecture connecting two sides of a typical geostationary telecommunication satellite for potential use as radiators. Additionally, the flight has also provided the opportunity to demonstrate the well functioning of a new hardware for at least three years in space requested by most of the satellite operators.

The design of the demonstrator was performed using simplified mathematical models to size the radiators and obtain the corresponding linear and radiative conductors to be integrated into the global satellite thermal model. The main objective of these earlier simplified models was to prove that under any orbital condition the demonstrator would not risk the mission. A more detailed numerical model was developed later to simulate the actual orbital conditions and to proceed with the validation of such model by comparing model predictions and flight data provided by the satellite. In this paper, the detailed mathematical model together with the analysis of a set of expected critical conditions are presented. The 
validation of the mathematical model results against orbit nominal operation data will be presented in a subsequent paper [5.1].

An extensive mechanical and thermal vacuum tests was also performed on the proto-flight model (PFM) [5.2]. The results obtained from these tests demonstrated the capability of the system to adapt to the changing environmental and operational conditions by rejecting the heat through the most favourable radiator.

The transient modeling of the LHP systems have been highly difficult. Although there are several transient models published previously, complex architectures have been studied much less by mathematical modeling. Hoang and Ku [5.3] presented a transient LHP model based on the one-dimensional time-dependent conservation equations, which represent the entire LHP as a mass-spring-damper dynamical system. Although the main features of the transient LHP operation were simulated without the startup phase, the experimental correlations showed that the heat leak at low powers was largely underestimated. It was then proposed that the heat transfer mechanism across the wick differs at low and high powers. A transient model including the startup transients developed using the thermal analyzer SINDA was presented by Cullimore and Bauman [5.4]. The thermal analyzer SINDA was also used by several authors for the LHP based thermal control systems simulation. A software named EASY based on the lumped parameter method capable of simulating LHP start-up under predefined initial conditions and architectures with more than one LHP was presented in [5.5]. The EASY code was later modified to be incorporated into the ESA's Thermal Analyzer (ESATAN) [5.6]. The main objective was to model LHP based spacecraft thermal 
control systems within the thermal analyzer, which has proven capabilities such as calculation of orbital heat fluxes, satellite level transient analysis etc. This project was later abandoned. Vlassov and Riehl [5.7] presented a transient model which required experimentally determined values of the thermal conductances between the vapor-liquid interface in the evaporator and in the compensation chamber. The comparison of the simulation and experimental results were in agreement within about $5^{\circ} \mathrm{C}$ for a heat load varying from 2 to $60 \mathrm{~W}$.

A comprehensive transient mathematical model was published by Pouzet et al. [5.8]. This work included a model for the interface in the evaporation zone and the variations in the meniscus curvature. It was demonstrated that the dynamic couplings between the components play an important role in the formation of instabilities following a sudden power change. More recently, Nishikawara et al. [5.9] presented a transient model based on the one-dimensional mass, momentum, and energy conservation laws and thermodynamic relationships. The model results were confirmed by comparing them with the experimental results obtained from two miniature LHPs. No time lag between the calculated and experimental results was observed when the power was changed, which has been a major problem for the previously published transient models. Some temperature overshoots observed in the simulations was attributed to the large thermal mass used in the experimental setup.

Among the complex architecture simulations, Nadalini and Bodendieck [5.10] developed a mathematical model within the ESATAN software by means of subroutines. The paper describes the thermal control design of a lander vehicle to 
be used within the Mars Netlander mission. The design includes an LHP circuit to transport the excess heat from the RHU units during hot environments. A breadboard representing the thermal design was built and tested. The LHP characteristics (thermal conductivities and capacitances etc.) were chosen to post fit the experimental results. Although the comparison results proved the approach, the results were not very satisfactory. The authors recommended a more detailed and accurate mathematical formulation without a need to post fit the data so that the model results can be truly verified.

Another example of complex architectures is discussed in [5.11]. The paper presents the system model of the Alpha Magnetic Spectrometer (AMS-02), based on SINDA software package. The LHP parts were modeled by using the pre-built subroutines within SINDA. Boundary conditions for the LHP model were included as time-varying arrays previously calculated from the global thermal mathematical model. Large computational time, i.e. days, were identified by the authors. A parametric study showed that the thermal control requirements cannot be met without a bypass valve. In a follow-up study in [5.12], a SINDA based mathematical model was used to support the design phase of the Cryomagnetic Avionic Box $(\mathrm{CAB})$ of AMS-02. Only one of the two LHPs included in the thermal design was modeled to avoid excessive computing time. Through a parametric and sensitivity analysis the authors analyzed some of the LHP parameters and identified an overtemperature problem in the design. No validation of the model predictions was provided. 
In the following chapters, the details of the system components modeling and the selected design simulation cases will be first provided. Then, the results will be presented and analyzed.

\subsection{Associated hardware and their functions}

There are three main architecture building blocks:

1. Heat collection area: Heat pipe networks collect the power dissipation from electronic equipment and homogenize their temperature. Driving heaters or payload provides the power dissipation.

2. Heat transportation and regulation system: LHPs transport the heat from the collection area to the rejection area. A set of PRVs regulates the access to the radiators and therefore the payload operation temperature.

3. Heat rejection area: Two radiator panels are responsible for rejecting the transported heat to space.

The LHP temperatures need to be controlled at a desired range. To accomplish this, a PRV per LHP was used as shown in Fig. 5. 1. The operational characteristics of the LHPs are not discussed here and a detailed description of the operation of LHP can be found in [5.13] and [5.14]. The PRV allows decoupling evaporator and radiator when the radiators are at a very low temperature than desired. The function of the PRV is to by-pass vapor from the evaporator to the LHP compensation chamber or liquid line to control the equipment temperature. The bellows in the PRV separate the backpressure reservoir from the working fluid. 
The valve piston is subjected to a backpressure: the working fluid pressure and the bellows force. The set point of the valve can be adjusted, case-by-case, to the specific minimum temperature required for the equipment. Once the backpressure is chosen, the piston position depends on the pressure of the working fluid. A more extended description and functioning of such types of valves are presented in [5.15].

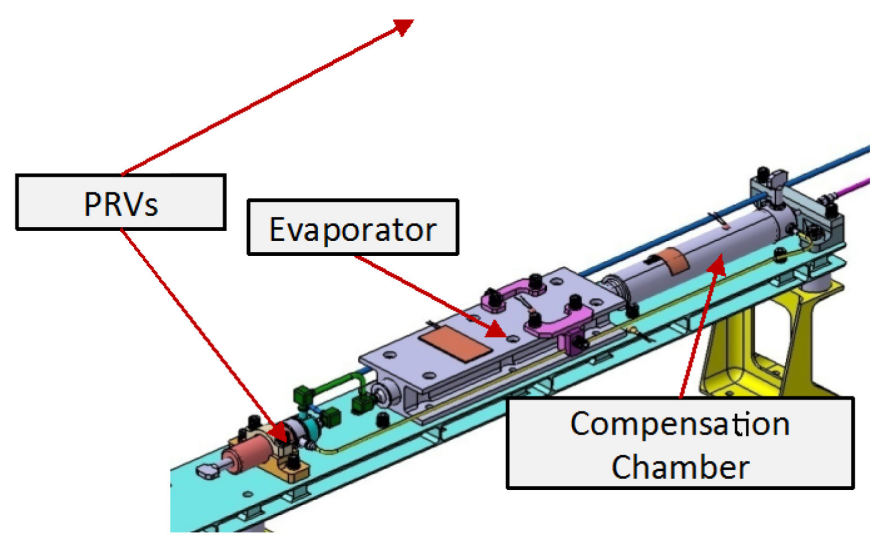

Figure 5.1. Pressure Regulator Valves (PRV) sketch. Three way (a), two way (b).

Because of its flexibility, the thermal control system allows placing the equipment in any location inside the satellite box. The radiator surfaces can also be changed. In addition, a transportation system based on the LHPs can be enabled or disabled by choice.

There were two different radiators in the architecture. One was located on the east and the other on the west sides of the satellite. Both were made out of 
aluminum honeycomb with aluminum skins as shown in Fig. 5. 2. For the east panel, the east LHP condenser was bolted to the panel with dry interface filler. This configuration was called indirect condensation radiator. For the west panel, the west LHP condenser was embedded into the honeycomb panel. This configuration was referred to as direct condensation radiator. The external coating of both of the radiator panels was Optical Solar Reflectors (OSRs). The thermal mass of each radiator is $730 \mathrm{~J} /{ }^{\circ} \mathrm{C}$.
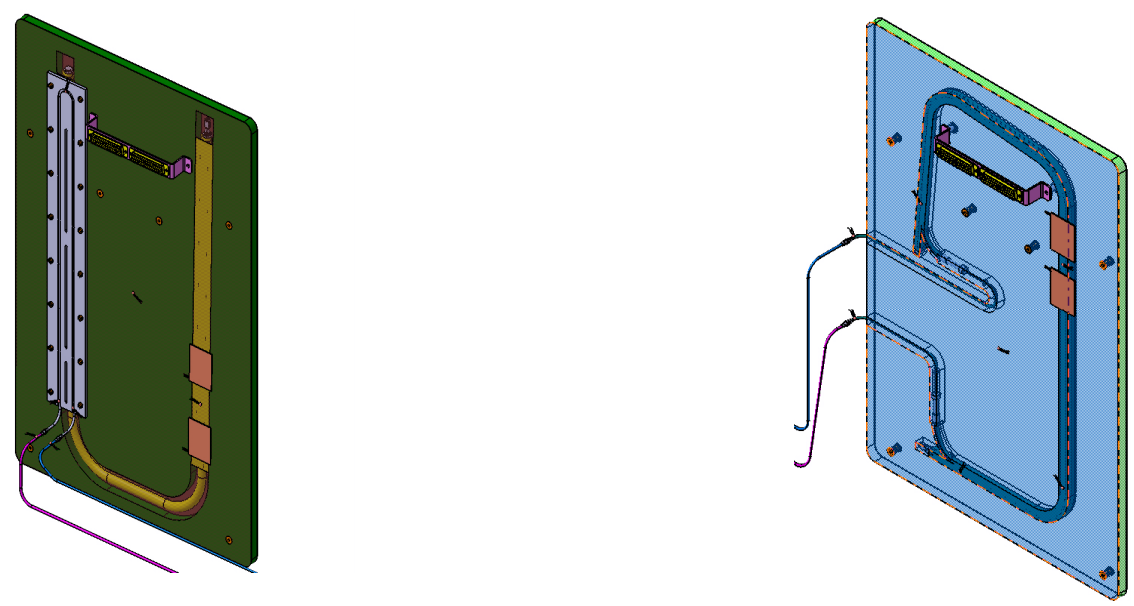

Figure 5.2. East radiator (left) and west radiator (right) configurations.

A multi-layer insulation (MLI) was used in certain areas to prevent incoming heat inputs (typically, sun illumination) from heating the system. A general conceptual scheme of the complete system is presented in Fig. 5. 3. 


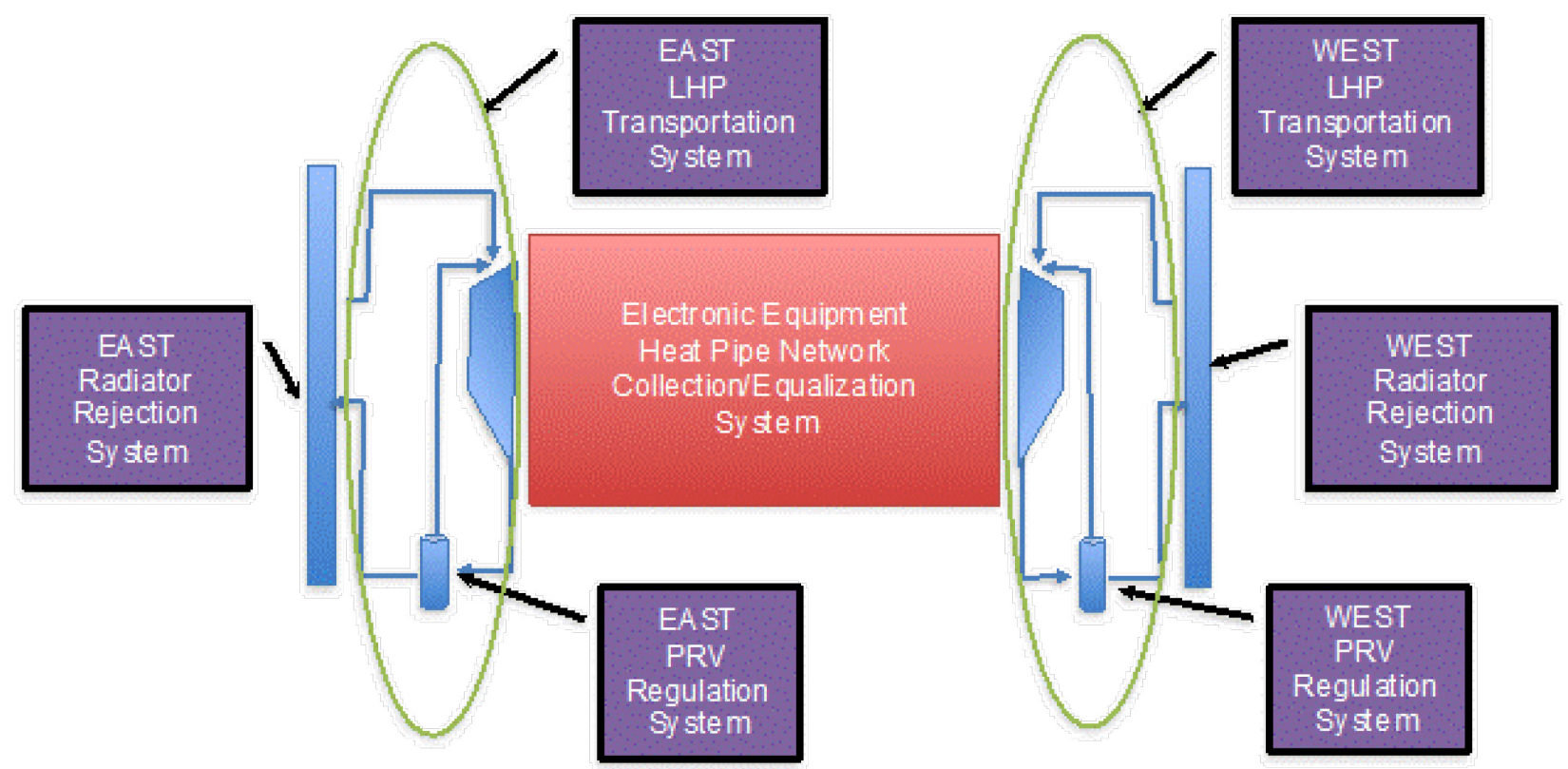

Figure 5.3. A general overview of the thermal system architecture.

\subsection{Mathematical formulation}

Each of the LHP components (evaporator, compensation chamber, liquid and vapor lines, condenser and pressure regulator valve) were modeled and linked to generate a system level mathematical model. Other hardware components such as heaters, thermistors and the corresponding algorithm control to command ON/OFF of the heaters, MLI, thermal washers, heat pipes, etc. were also modeled. The conduction and radiation links, with the corresponding environment, complete the model.

A more detailed discussion of the transient LHP mathematical model can be found in [5.16]. Only the main assumptions and governing equations will be 
provided in this paper to avoid repetition. The summary of the considered assumptions is provided here after:

1. The fluid is Newtonian and compressible.

2. The model is based on the one-dimensional and time dependent conservation equations (mass, momentum and energy) applied to control volumes. The fluid part of each LHP component is sub-divided into individual control volumes.

3. The homogeneous equilibrium model (HEM) is assumed [5.17]. This is, the one-dimensional conservation equations are established for the twophase mixture and the amount of vapor and liquid is taken into account in terms of quality. It is considered that the two phases are in equilibrium assuming equal phase velocities, temperatures and pressures.

4. The calculated thermodynamic properties correspond to the two-phase mixture. In case of saturation conditions, the thermodynamic properties are calculated separately for vapor and liquid phases. The thermodynamic properties are obtained by interpolation using the tables built from NIST routines.

5. The viscous effects are taken into account through the pressure drop calculations. The pressure drop calculations use the built-in specific functions for different elements. These include empirical correlations for the pressure drop in a porous media.

6. The external (convection model during ambient ground test) and internal heat transfer coefficients are calculated by using the single-phase and twophase correlations depending on the flow regime. 
7. Gravity effects due to the different orientations of the LHPs have been taken into account in the formulation.

The model was based on a staggered grid method. A typical 2-D staggered mesh arrangement distinguishes between the main cell or control volume and the staggered cell or control volume [5.18]. The pressure was stored at centroids of the main cells as shown in Fig. 5. 4. The velocity components were stored on the faces of the main cells and were associated with the staggered cells. The $\boldsymbol{u}$ velocity was stored on the $\boldsymbol{E}$ and $\boldsymbol{W}$ faces and the $\boldsymbol{v}$ velocity was stored on the $\boldsymbol{N}$ and $\boldsymbol{S}$ faces. Scalars such as enthalpy or species mass fraction were stored at the centroids of the cell $P$ as shown in Fig. 5. 4. The present reported model, being 1-D only makes use of $\boldsymbol{u}$ velocity component, and therefore the $\boldsymbol{E}$ and $\boldsymbol{W}$ faces.

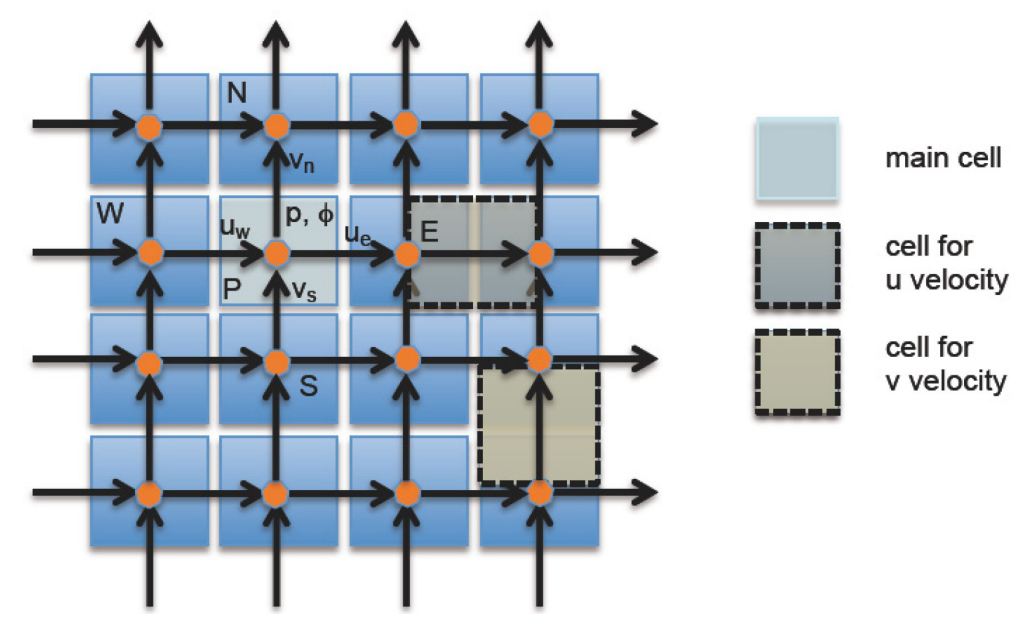

Figure 5.4. 2-D staggered grid control volume representation.

The LHP model considers the set of equations for the different physical components: vapor and liquid transport lines, evaporator and condenser. Both transport lines and the compensation chamber (as part of the evaporator) were 
discretized into several centered control volumes (nodes), sharing the conditions at the junction between adjacent control volumes. Therefore, mass and energy equations were solved for each control volume. Details of pressure losses and heat transfer coefficients can be found in [5.16].

The mass balance is stated as follows:

$$
\left\lfloor v \frac{d \rho}{d t}\right\rfloor_{n}=\dot{m}_{j}-\dot{m}_{j+1}
$$

Where $V$ is the volume, $\rho$ is the density of the two-phase mixture and $\dot{m}_{j}$ and $\dot{m}_{j+1}$ are the mass flow corresponding to the mixture at the entrance and exit of the control volume respectively.

The energy balance is stated as follows:

$$
\left[V\left(\frac{d u}{d t} \rho+u \frac{d \rho}{d t}\right)\right]_{n}=\dot{m}_{j} h_{j}-\dot{m}_{j+1} h_{j+1}+\dot{Q}_{n}
$$

Where $\dot{Q}_{n}$ represents the rate of heat exchanged between the volume element and external walls, and $u$ the internal energy. The variables at a junction such as $h_{j}$ are calculated by using the properties of the nearby nodes as follows:

$$
\tilde{h}_{j}=\delta h_{n}+(1-\delta) h_{n-1}
$$

Where $\delta$ is given by the direction of the flow:

$$
\delta= \begin{cases}0 & \dot{m}_{j} \geq 0 \\ 1 & \dot{m}_{j}<0\end{cases}
$$


The momentum conservation equation is stated in the $\mathrm{J}$-Control Volume as shown in Fig. 5. 5.

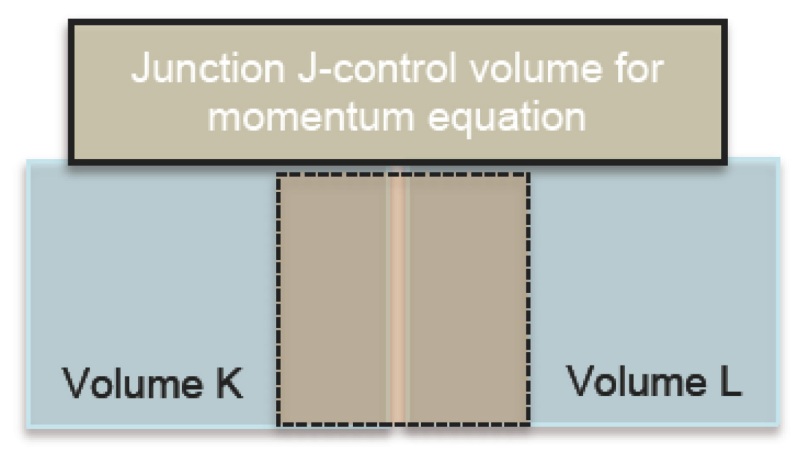

Figure 5.5. Control volume junction scheme

The momentum balance in the control volume is formulated as follows:

$$
\frac{d l}{d t}=F_{a}+F_{p}+F_{f}+F_{g}
$$

$I$ is the total momentum in the volume. The forces that take part in the previous equation are the acceleration force, the pressure force, the friction force and the gravitational force. Developing the terms corresponding to the different forces, the following momentum balance equation was used in the model:

$$
p_{n+1}-p_{n}=\left[\frac{\ell}{A} \ddot{m}+\frac{\xi}{2 \rho}\left(\frac{\dot{m}}{A}\right)^{2}-\rho g \Delta z\right]_{j+1}
$$

Where $\xi$ is the pressure loss coefficient and it is calculated as follows:

$$
\xi=\xi_{\text {misc }}+\xi_{\text {bends }}+f \frac{L}{D}
$$


For the PRVs, the mass and energy conservation equations were applied for the fluid contained in the valve main chamber in order to obtain the density and the internal energy at any time. To fix the valve set point, the model requires an input temperature value $\left(T_{\text {open }}\right)$. The saturation pressure corresponding to this temperature $\left(\mathrm{P}_{\mathrm{open}}\right)$ was obtained by interpolation using the tables from NIST and it represents the point where the valve opens completely the by-pass path and; consequently, the radiator path is completely closed. Taking into account the properties of the valve bellows, a new pressure $\left(P_{\text {close }}\right)$ was calculated to define the point where the valve starts to close. Then, part of the heat (mass flow) goes through the radiator and the remaining part of the heat goes to the compensation chamber. Both PVRs used in the flight model were two-way valve type with a set point of $29^{\circ} \mathrm{C}$.

Both radiators were modeled by discretization into several nodes. Each radiator was made out of aluminum (core and skins) with a radiator area (covered by OSR) of $562 \times 361 \mathrm{~mm}^{2}$. The east radiator (indirect condensation) was divided in square nodes of $20 \mathrm{~mm}$ side ( $28 \times 18$ nodes) having two levels to characterize the transversal gradients. The west radiator (direct condensation) was divided in square nodes of $10 \mathrm{~mm}$ side ( $56 \times 36$ nodes). To characterize the gradients, two levels across the panel have been modeled. There were also one node to represent each heat pipe, one node for the condenser and one node for the outer space (sink).

The compensation chamber sizing and the fluid inventory were determined according to following conditions: 
1. For the coldest case some liquid is left in the compensation chamber when the rest of the LHP is flooded.

2. For the hottest case, some space for vapor is available in the compensation chamber.

Once the parameters have been fixed, the maximum liquid volume corresponding to this fluid inventory was calculated for the maximum non-operating temperature. Some of the temperature values of the LHP are as follows:

- Maximum Operating Temperature: $44^{\circ} \mathrm{C}$

- Maximum Non-Operating Temperature: $72^{\circ} \mathrm{C}$

- Minimum Startup Temperature for the Capillary Pump: $-40^{\circ} \mathrm{C}$

- Minimum Non-Operating Temperature for the Liquid and Vapor Line: $-40{ }^{\circ} \mathrm{C}$

The final values of charged ammonia were: $29.4 \mathrm{~g}$ for the east LHP and $27.2 \mathrm{~g}$ for the west LHP (Note that the west LHP fluid inventory was less because of the shorter transport lines).

\subsection{Numerical model and simulation cases}

The resulting differential-algebraic equations were solved by using a multistep and implicit solver (DASSL) previously developed within a commercially available software tool, EcosimPro. This software provides the capability to model each component individually. This modular approach allows integrating the separate 
model blocks in a similar fashion as the typical hardware integration. The overview of the numerical model is presented in Fig. 5. 6 .

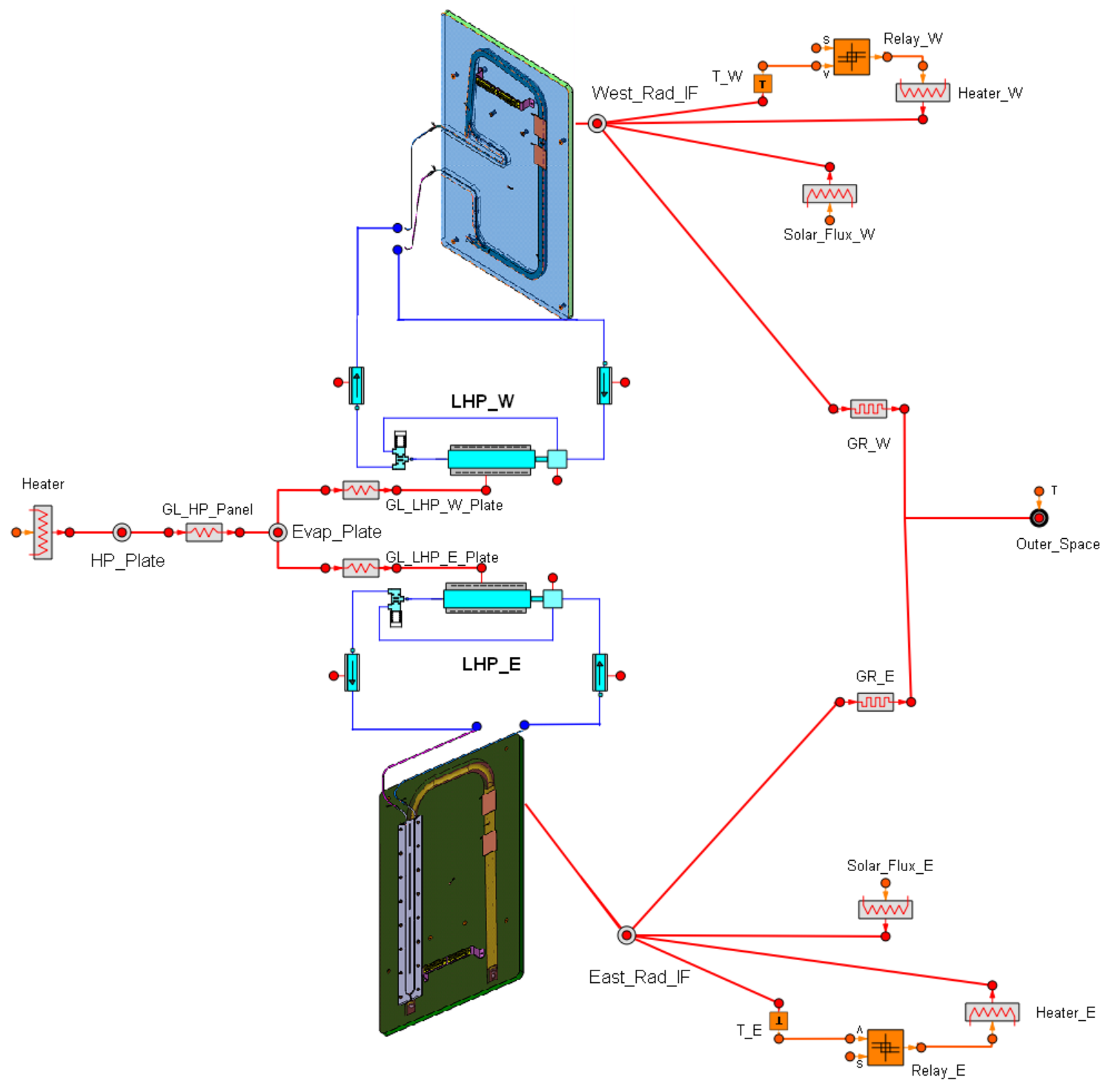

Figure 5.6. Numerical model overview.

The selected nominal cases presented in Table 5.1, cover all possible nominal operational scenarios the demonstrator could be performing during the orbital operation and were used to size the system. Besides the nominal cases, a set of failure modes has also been analyzed. The objective of these failure cases is to demonstrate that under the potential failure conditions satellite mission will not be 
compromised and to support the Failure Mode Effects and Criticality Analysis (FMECA) as shown in Table 5.2.

Table 5.1. Nominal simulation cases

\begin{tabular}{|c|c|c|c|c|}
\hline Case \# ID. Description & $\begin{array}{l}\text { Simulation } \\
\text { Type }\end{array}$ & $\begin{array}{c}\text { Radiator Incident Heat } \\
\text { Flux } \\
\text { Direct (west)/Indirect } \\
\text { (east) } \\
\left(\mathrm{W} / \mathrm{m}^{2}\right)\end{array}$ & $\begin{array}{l}\text { Absorptivity } \\
3 \text { years }\end{array}$ & $\begin{array}{l}\text { Power } \\
\text { Applied } \\
\text { (W) }\end{array}$ \\
\hline $\begin{array}{l}\text { \#1. Hot Maximum A (2 } \\
\text { LHP operating) }\end{array}$ & Steady & $0 / 1410$ & 0.17 & 70 \\
\hline $\begin{array}{l}\text { \#2. Hot Maximum A (1 } \\
\text { LHP operating) }\end{array}$ & $\begin{array}{c}\text { Steady } \\
\text { See note } 1\end{array}$ & $0 / 1410$ & 0.17 & 10 \\
\hline $\begin{array}{l}\text { \#3. Hot Minimum A (2 } \\
\text { LHP operating) }\end{array}$ & Steady & $0 / 1410$ & 0.17 & 20 \\
\hline $\begin{array}{l}\text { \#4. Cold Maximum A (2 } \\
\text { LHP operating) }\end{array}$ & Steady & $0 / 0$ & 0.17 & 70 \\
\hline $\begin{array}{l}\text { \#5. Cold Maximum A (1 } \\
\text { LHP operating) }\end{array}$ & $\begin{array}{c}\text { Steady } \\
\text { See Note } 1\end{array}$ & $0 / 0$ & 0.17 & 40 \\
\hline $\begin{array}{l}\text { \#6. Cold Minimum A (2 } \\
\text { LHP operating) }\end{array}$ & Steady & $0 / 0$ & 0.17 & 20 \\
\hline \# 7. 24 BOL Diurnal A & Transient & See Note 2 & 0.17 & $\begin{array}{l}20,40, \\
60,70\end{array}$ \\
\hline \# 8. 24 EOL Diurnal B & Transient & See Note 2 & $\begin{array}{c}0.27 \\
\text { (15 years) }\end{array}$ & 20,70 \\
\hline
\end{tabular}

Note 1: The east LHP has been selected for the cases simulating only 1 LHP operating

Note 2: The incident heat fluxes of the east and west radiators for the complete orbit simulation in both $\mathrm{BOL}$ and EOL environmental conditions are provided in Fig.

5. 7. 


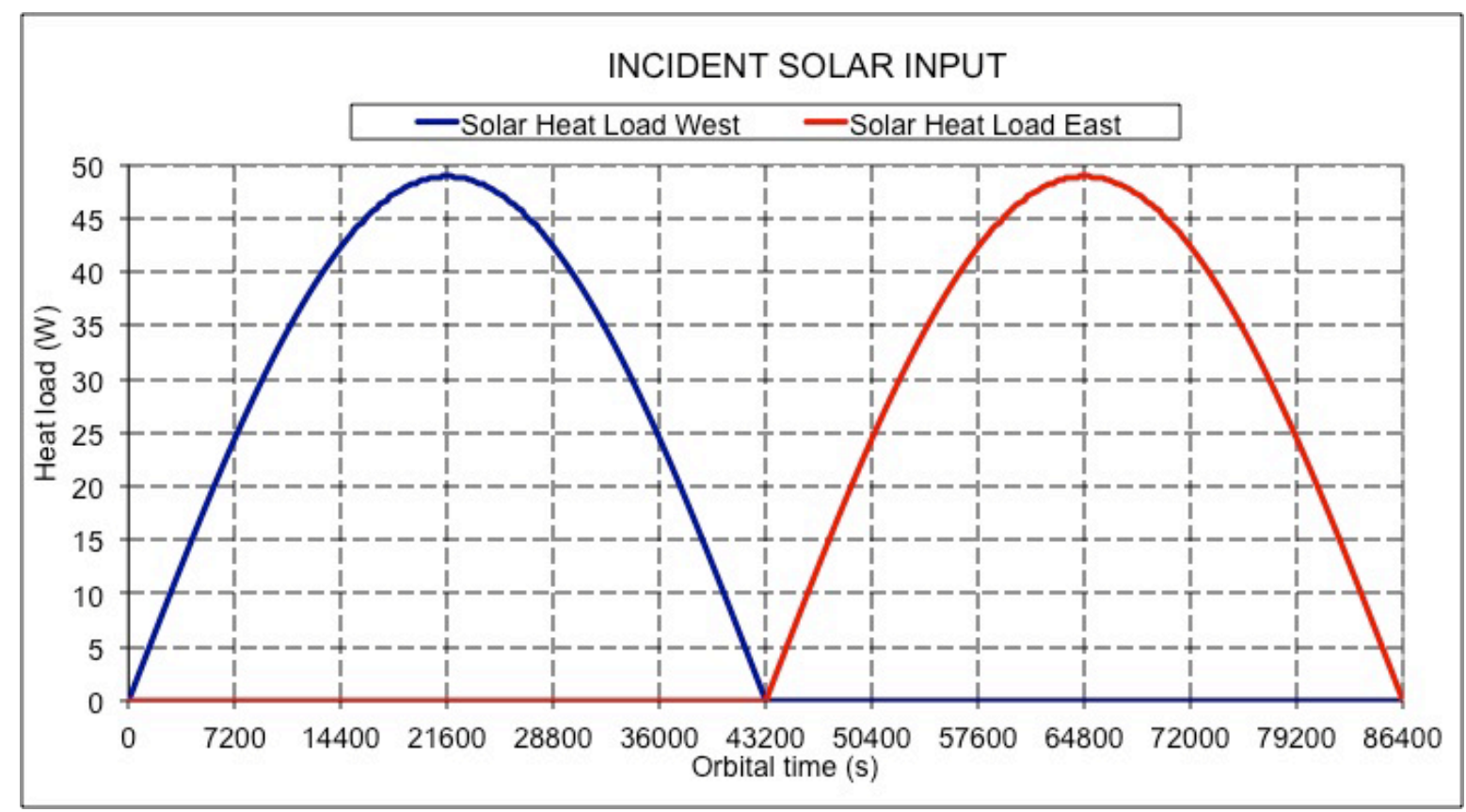

Figure 5.7. Incident solar heat load on east and west radiators.

Table 5.2. FMECA simulation cases

\begin{tabular}{|c|c|c|}
\hline Case \# ID. Description & $\begin{array}{c}\text { Simulation } \\
\text { Type }\end{array}$ & Objective \\
\hline $\begin{array}{c}\text { \#9. Anti-Freezing heater } \\
\text { failure }\end{array}$ & $\begin{array}{c}\text { Steady } \\
\text { See Note 1 }\end{array}$ & $\begin{array}{c}\text { To determine the maximum driving } \\
\text { heater or payload power to be } \\
\text { applied when the anti-freezing } \\
\text { heaters are continuously ON to } \\
\text { stay below LHP proof pressure } \\
\text { level }\end{array}$ \\
\hline $\begin{array}{c}\text { \#10. Driving heater } \\
\text { failure }\end{array}$ & Steady & $\begin{array}{c}\text { To determine the maximum driving } \\
\text { heater or payload power to be } \\
\text { applied in case the heaters are } \\
\text { continuously ON to stay below } \\
\text { LHP burst pressure level }\end{array}$ \\
\hline \#11. OSR launch & Steady & $\begin{array}{c}\text { To determine the maximum of } \\
\text { damaged OSR compatible with } \\
\text { total anti-freezing heaters power } \\
\text { (53 W) continuously ON to stay } \\
\text { below LHP burst pressure level }\end{array}$ \\
\hline
\end{tabular}

Note 1:

- Anti-Freezing Heaters continuously ON.

- East (indirect) radiator efficiency 0.87 at $45^{\circ} \mathrm{C}$.

- East (indirect) incident heat fluxes $1410 \mathrm{~W} / \mathrm{m}^{2}$. 
- West (direct) radiator efficiency 0.9 at $45^{\circ} \mathrm{C}$.

- West (direct) radiator incident heat flux $0 \mathrm{~W} / \mathrm{m}^{2}$.

- West LHP operating, east LHP disabled.

\subsection{Discussion of results}

The steady simulation results are presented in Table 5.3. The transient cases simulating the orbital conditions as well as the corresponding power sharing between the two LHPs are shown in Fig. 5.8 for the BOL conditions and in Fig. 5.9 for the EOL conditions. Finally, FMECA results are presented in Table 5.4 and in Figs. 5.10 and 5.11

\subsubsection{Results of the steady nominal cases}

It can be seen in Table 5.3 that for the cases with only one enabled LHP (east LHP), cases \#2 and \#5, the west radiator anti-freezing heaters are needed to keep temperatures above $-40^{\circ} \mathrm{C}$ as specified. Similar condition occurs when the applied power is not enough. In case \#3 in hot conditions, the west radiator has the antifreezing heaters activated; while in case \#6 both radiators need the anti-freezing heaters.

In all cases the maximum LHP temperatures are below the maximum specified required temperature set at $39^{\circ} \mathrm{C}$. 
Table 5.3. Steady-state cases

\begin{tabular}{|c|c|c|c|c|c|c|c|c|}
\hline Case \# ID. Description & $\begin{array}{c}\text { Total } \\
\text { applied } \\
\text { power } \\
(\mathrm{W})\end{array}$ & $\begin{array}{c}\text { East } \\
\text { LHP } \\
\text { shared } \\
\text { power } \\
(\mathrm{W})\end{array}$ & $\begin{array}{c}\text { West } \\
\text { LHP } \\
\text { shared } \\
\text { power } \\
(\mathrm{W})\end{array}$ & $\begin{array}{c}\text { Paylo } \\
\text { ad } \\
\text { temp. } \\
\left({ }^{\circ} \mathrm{C}\right)\end{array}$ & $\begin{array}{c}\text { East } \\
\text { evap. } \\
\text { temp. } \\
\left({ }^{\circ} \mathrm{C}\right)\end{array}$ & $\begin{array}{c}\text { West } \\
\text { evap. } \\
\text { temp. } \\
\left({ }^{\circ} \mathrm{C}\right)\end{array}$ & $\begin{array}{c}\text { East } \\
\text { rad. } \\
\text { temp. } \\
\left({ }^{\circ} \mathrm{C}\right)\end{array}$ & $\begin{array}{c}\text { West } \\
\text { rad. } \\
\text { temp. } \\
\left({ }^{\circ} \mathrm{C}\right)\end{array}$ \\
\hline $\begin{array}{c}\text { \#1. Hot Maximum A (2 } \\
\text { LHP operating) }\end{array}$ & 70 & 13.7 & 56.3 & 36.0 & 35.1 & 32.3 & 31.2 & 24.9 \\
\hline $\begin{array}{c}\text { \#2. Hot Maximum A (1 } \\
\text { LHP operating) }\end{array}$ & 10 & 10.0 & 0 & 30.5 & 29.9 & 30.5 & 25.2 & -38.2 \\
\hline $\begin{array}{c}\text { \#3. Hot Minimum A (2 } \\
\text { LHP operating) }\end{array}$ & 20 & 9.2 & 10.8 & 30.5 & 29.8 & 29.7 & 27.0 & -38.6 \\
\hline $\begin{array}{c}\text { \#4. Cold Maximum A (2 } \\
\text { LHP operating) }\end{array}$ & 70 & 34.79 & 35.21 & 33.3 & 31.0 & 31.0 & -11.5 & -12.2 \\
\hline $\begin{array}{c}\text { \#5. Cold Maximum A (1 } \\
\text { LHP operating) }\end{array}$ & 40 & 40.0 & 0 & 34.0 & 31.3 & 34.0 & -2.3 & -37.9 \\
\hline $\begin{array}{c}\text { \#6. Cold Minimum A (2 } \\
\text { LHP operating) }\end{array}$ & 20 & 9.76 & 10.24 & 30.4 & 29.7 & 29.7 & -38.3 & -39.4 \\
\hline
\end{tabular}

\subsubsection{Results of the transient nominal cases}

The temperatures and power distribution sharing results for a complete orbit simulation at $\mathrm{BOL}$ and $\mathrm{EOL}$ environmental conditions at different applied powers are given in Figs. 5.8 and 5.9, respectively. 


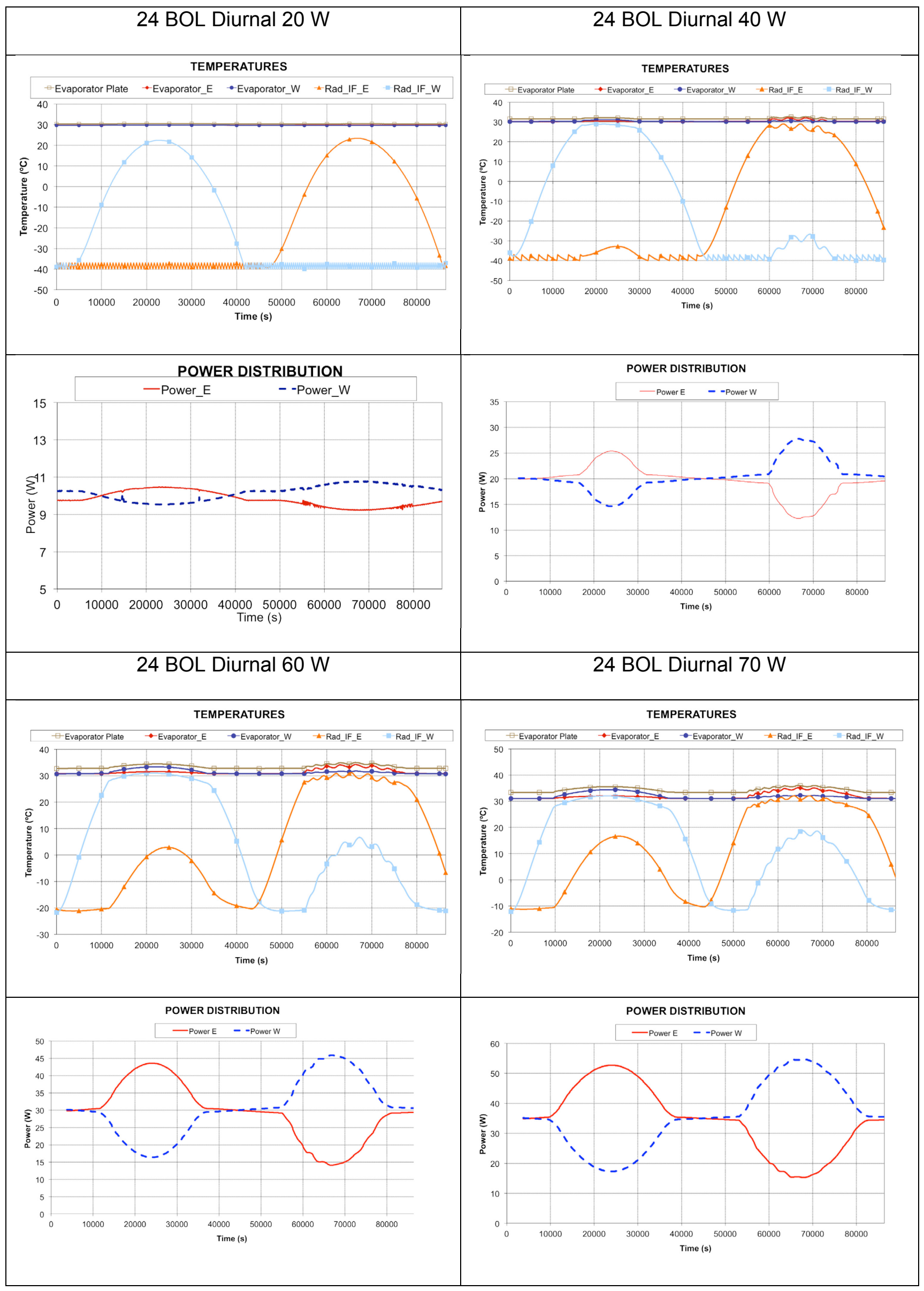

Figure 5.8. Complete orbit 24 h diurnal BOL cases. 


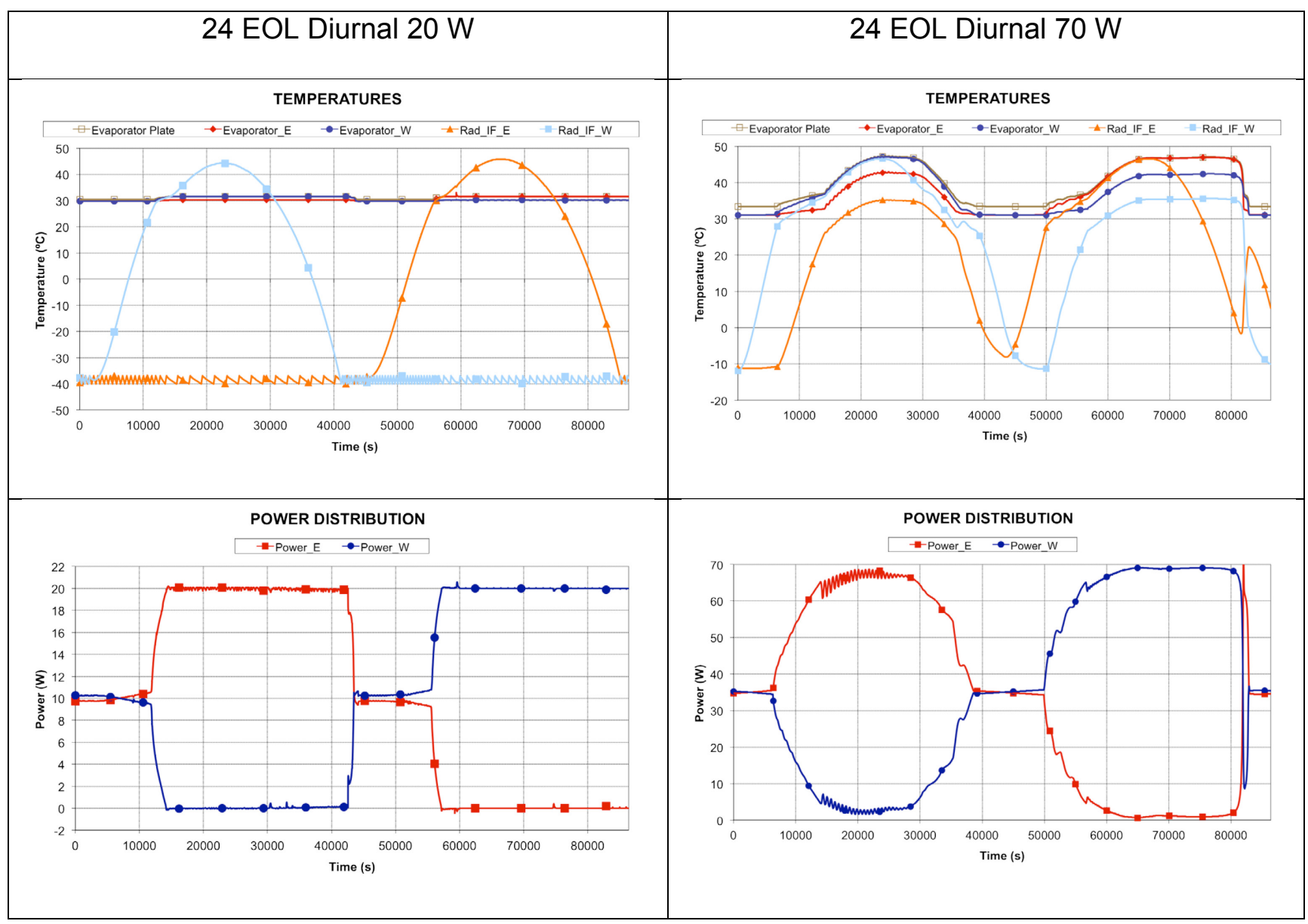

Figure 5.9. Complete orbit 24 h diurnal EOL cases.

For the BOL cases, it can be seen in Fig. 5.8 that the anti-freezing heaters are cycling between -37 and $-40^{\circ} \mathrm{C}$ (threshold levels for anti-freezing system) to maintain the radiator temperature above the ammonia freezing point. This situation occurs when there is no sun illumination and the power transported by the LHP to the radiator is too low (cases BOL $20 \mathrm{~W}$ and $\mathrm{BOL} 40 \mathrm{~W}$ ).

The power sharing is calculated as the temperature difference between each evaporator and the plate multiplied by the conductance between them. Although both radiators have the same area and coating, they differ from each other in the 
condensation type (direct vs. indirect). This matter is important when considering the global conductance of each east and west branches. The east branch has an additional thermal resistance through the interface filler of the indirect condenser. Also, the east branch has longer transport lines than that of the west. Therefore, the east LHP conductance is lower than the west LHP conductance. The global conductance considers all conductance terms from the heat source to the external skin of each radiator. As a result, the east branch has lower conductance than the west branch.

For all cases, the power sharing shows that in the first half of the orbit, when the west radiator is sun illuminated, the east branch is transporting the largest part of the dissipated power. In the second part of the orbit, the west branch is carrying the most of the power. As it was discussed above, the amount of power transported by the west branch is higher since it has higher conductance (direct condenser). This is especially noticeable for the cases of 40,60 and $70 \mathrm{~W}$. This explains why the power sharing is not symmetrical along the orbit in a 24-hour simulation.

Similar observations can be made for the EOL cases. In Fig. 5.9, the radiators are at a higher temperature because of the higher external heat inputs due to the increased solar absorptivity. In these conditions, the branch with its radiator at maximum temperature transports almost no power. For the power of $20 \mathrm{~W}$, only one radiator can handle the dissipated power without an increase in the payload temperature above the PRV set point. This forces the second LHP to stop operating ( $0 \mathrm{~W}$ transported power) when the temperature of the corresponding 
radiator is above the PRV set point. For the power of $70 \mathrm{~W}$, both radiators are utilized to dissipate the total power during the first half of the orbit although the amount transported by the west is around $3 \mathrm{~W}$ only. In the second half of the orbit, the east LHP stops operating since radiator temperature is the same as its evaporator (from 60,000 to 65,000 s). This situation remains until the east radiator reaches a temperature of around $0^{\circ} \mathrm{C}$, allowing the LHP to restart. This can be clearly seen in Fig. 5.9 at approximately $82,000 \mathrm{~s}$.

\subsubsection{Anti-freezing heater failure results}

The model results showed that the maximum payload power compatible with an anti-freezing heater failure is $50 \mathrm{~W}$. Under these conditions, the temperature results for the whole system are presented in Table 5.4.

Table 5.4. Anti-freezing heater failure results.

\begin{tabular}{|c|c|c|c|c|c|c|}
\hline $\begin{array}{c}\text { Case \# ID. } \\
\text { Description }\end{array}$ & $\begin{array}{c}\text { Total } \\
\text { applied } \\
\text { power } \\
(\mathrm{W})\end{array}$ & $\begin{array}{c}\text { Payload } \\
\text { temp. } \\
\left({ }^{\circ} \mathrm{C}\right)\end{array}$ & $\begin{array}{c}\text { East } \\
\text { evap. } \\
\text { temp. } \\
\left({ }^{\circ} \mathrm{C}\right)\end{array}$ & $\begin{array}{c}\text { West } \\
\text { evap. } \\
\text { temp. } \\
\left({ }^{\circ} \mathrm{C}\right)\end{array}$ & $\begin{array}{c}\text { East } \\
\text { rad. } \\
\text { temp. } \\
\left({ }^{\circ} \mathrm{C}\right)\end{array}$ & $\begin{array}{c}\text { West } \\
\text { rad. } \\
\text { temp. } \\
\left({ }^{\circ} \mathrm{C}\right)\end{array}$ \\
\hline $\begin{array}{c}\text { \#9. Anti-freezing } \\
\text { heater failure }\end{array}$ & 50 & 35.2 & 35.2 & 31.9 & 47.4 & 14.4 \\
\hline
\end{tabular}

\subsubsection{Driving heater failure}

The model predicts that the maximum achieved temperature for the maximum driving heater power $(70 \mathrm{~W})$ is approximately $135^{\circ} \mathrm{C}$. This value is under the LHP burst temperature level $\left(170^{\circ} \mathrm{C}\right)$. The temperature at the payload plate versus driving heater power is presented in Fig. 5.10. 


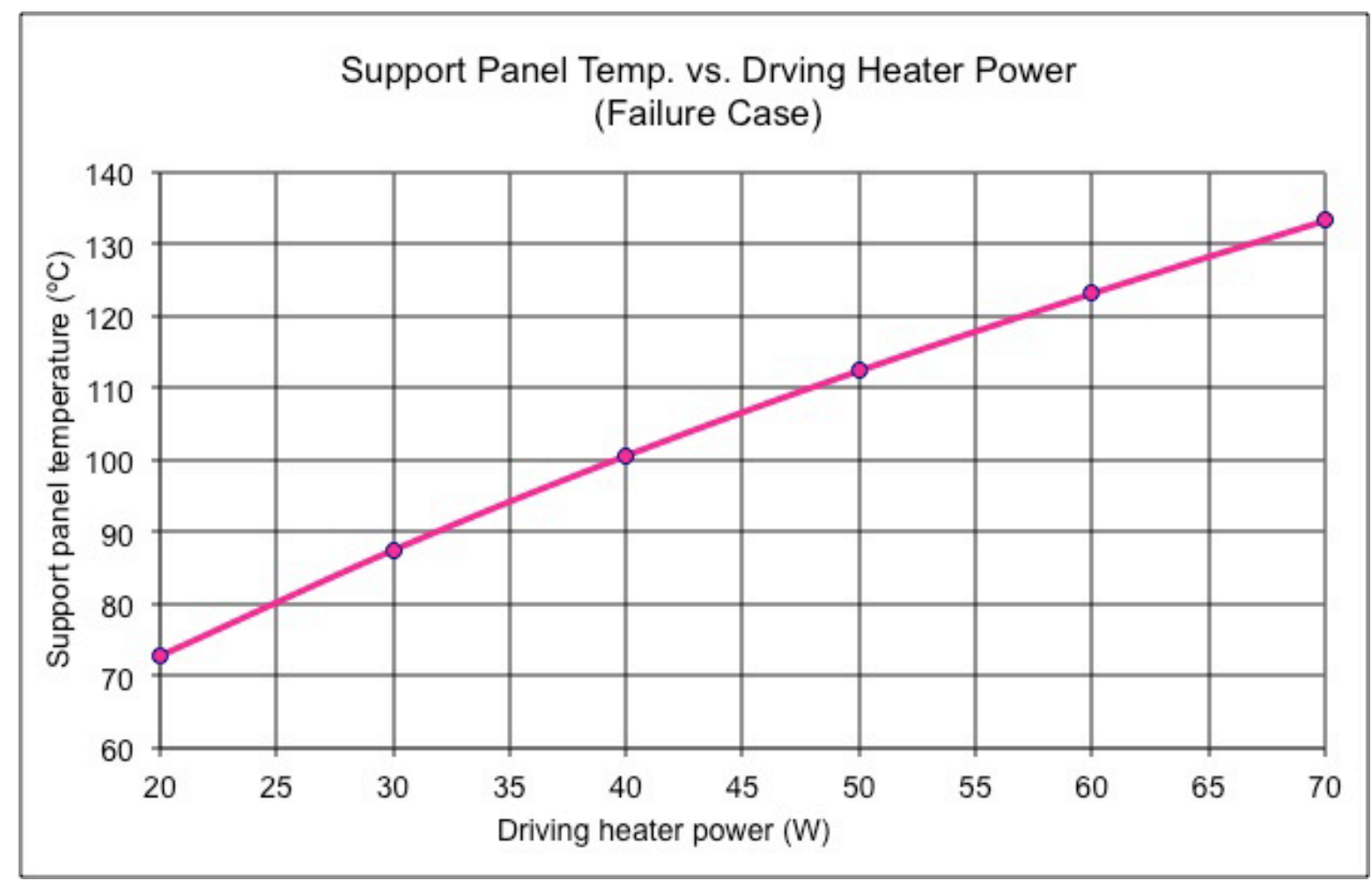

Figure 5.10. Support panel temperature versus driving heater power.

\subsubsection{OSR damage}

The results for this FMECA case are presented in Fig. 5.11. The results indicate that to reach the LHP burst temperature of $170^{\circ} \mathrm{C}$, a minimum of $68 \%$ of the OSR damage or de-bonding should occur during the launch. It is almost impossible to experience such a severe damage in the radiators during the launch. Therefore, it is safe to assume that there is no risk as a result of a potential OSR damage. 


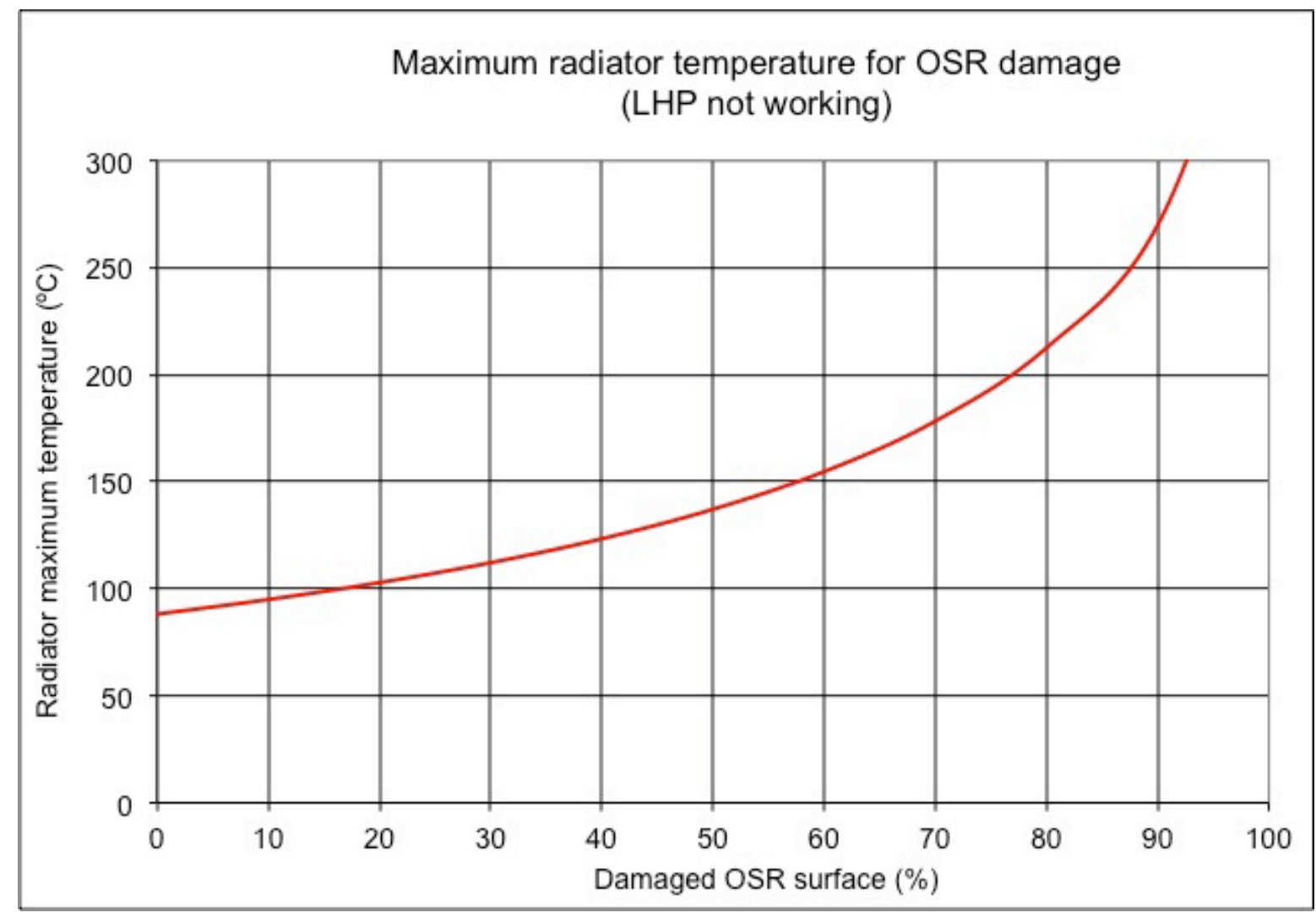

Figure 5.11. Radiator temperature (condenser temperature) versus percentage of damaged OSR.

\subsection{Conclusions}

A mathematical model for the numerical simulation of a novel spacecraft thermal control architecture is presented. The proposed architecture connects the east-west radiators of a geosynchronous telecommunications satellite through LHPs. The mathematical model has been used to size the system and verify its performance as well as to provide the corresponding flight temperature predictions. Several transient cases simulating payload power and time-dependent sun heat input on the radiators have been analyzed to demonstrate the robustness of the proposed architecture. The mathematical model successfully simulated the heat load sharing between the east and west LHPs. This is a unique feature of the design that each LHP is able to passively transport the heat to the radiator with the 
most favorable temperature condition. The FMECA cases analyzed showed that no failure propagation is expected, which could risk the mission. The mathematical model proposed here can be used to design and analyze the LHP based complex thermal control architectures and simulate several critical conditions anticipated in orbit to identify possible failure modes. The model validation against the in-flight test data will be presented in a following paper.

\section{References}

[5.1] A. Torres, D. Mishkinis, T. Kaya, Mathematical model validation of a thermal architecture system connecting east/west radiators by flight data, Applied Thermal Engineering 66/1-2 (2014), pp. 1-14, DOI:10.1016/j.applthermaleng.2014.01.050

[5.2] J.A. Romera, J.L. Pastor, J. Alvarez, J.M. Boix, A. Torres, Demonstrator for connecting the east and west panels of a typical telecommunications satellite via loop heat pipes, International Conference on Environmental Systems, Barcelona, Vol.1, (2010) 421-432.

[5.3] T. Hoang, J. Ku, Transient modeling of loop heat pipes, International Energy Conversion Engineering Conference, Portsmouth, Virginia, Paper no. AIAA-20036082, 2003.

[5.4] B. Cullimore, J. Baumann, Steady state and transient loop heat pipe modeling, International Conference on Environmental Systems, Toulouse, Paper no. 2000-01-2316, 2000.

[5.5] K. Goncharov, O. Golovin, V. Kolesnikov, Loop heat pipe with several evaporators, International Conference on Environmental Systems, Toulouse, Paper no. 2000-01-2407, 2000.

[5.6] R. Schlitt, D. Labuhn, V. Vlassov, J. Ochterbeck, O. Pin, ALGOCAP: Assessment of thermo-hydraulic algorithms for CPLs and LHPs, $16^{\text {th }}$ European 
Thermal \& ECLS Software Workshop, Noordwijk, The Netherlands, October 22-23, 2002.

[5.7] V. Vlassov, R. Riehl, Mathematical model of a loop heat pipe with cylindrical evaporator and integrated reservoir, Applied Thermal Engineering, Vol. 28, Nos. 89, 2008, pp. 942-954.

[5.8] E. Pouzet, J.L. Joly, V. Platel, J.Y. Grandpeix, C. Butto, Dynamic response of a capillary pumped loop subjected to various heat load transients, International Journal of Heat and Mass Transfer (47) (2004) 2293-2316.

[5.9] M. Nishikawara, H. Nagano, T. Kaya, Transient thermo-fluid modeling of loop heat pipes and experimental validation, AIAA Journal of Thermophysics and Heat Transfer, Vol. 27, No.4, October-December 2013, pp. 641-647.

[5.10] R. Nadalini, F. Bodendieck, The thermal control system for a network mission on Mars: the experience of the Netlander mission, Acta Astronautica 58 (2006) 564-575.

[5.11] G. Xin, L. Cheng, W. Du, T. Luan, Y. Qu, S. Zinna, M. Marengo, M. Molina, J. Burger, Modeling of a real LHP and integration in a system level analysis, International Conference on Environmental Systems, Norfolk, Virginia, Paper no. 2006-01-2228, 2006.

[5.12] M. Marengo, S. Zinna, M. Molina, Numerical model of the LHP for the thermal control of the cryomagnet avionic box (CAB) mounted on the AMS-02 experiment, VII Minsk International Seminar "Heat Pipes, Heat Pumps, Refrigerators, Power Sources", Minsk, Belarus, September 8-11, 2008.

[5.13] J. Ku, Operating characteristics of loop heat pipes, $29^{\text {th }}$ International Conference of Environmental System, Denver, Colorado, Paper No: 1999-01-2007, 1999.

[5.14] Yu. F. Maydanik, Review loop heat pipes, Applied Thermal Engineering 25 (2005) 635-657.

[5.15] A. Torres, D. Mishkinis, A. Kulakov, F. Romera, C. Gregori, T. Kaya, Thermal control of loop heat pipe with pressure regulating valve, Heat Pipe Science and Technology Journal 1-4 (2010) 329-357. 
[5.16] T. Kaya, R. Perez, C. Gregori, A. Torres, Numerical simulation of transient operation of loop heat pipes, Applied Thermal Engineering 28 (2008) 967-974.

[5.17] R. S. Lagumbay, O. V. Vasilyev, A. Haselbacher, Homogeneous equilibrium mixture model for simulation of multiphase/multicomponent flows, International Journal for Numerical Methods in Fluids 1-6 (2007).

[5.18] J. Y. Murthy, Numerical Methods in heat, mass, and momentum transfer, School of Mechanical Engineering, Purdue University, USA, 2002. 


\section{Chapter 6}

\section{Mathematical model validation of a thermal architecture system connecting east/west radiators by flight data}

(Manuscript published in Applied Thermal Engineering Vol. 66, pp. 1-14, 2014. DOI:10.1016/j.applthermaleng.2014.01.050)

\section{Abstract}

A novel satellite thermal architecture connecting the east and west radiators of a geostationary telecommunication satellite via loop heat pipes (LHPs) is flight tested on board the satellite Hispasat 1E. The LHP operating temperature is regulated by using pressure regulating valves (PRVs). The flight data demonstrated the successful operation of the proposed concept. A transient numerical model specifically developed for the design of this system satisfactorily simulated the flight data. The validated mathematical model can be used to design and analyze the thermal behavior of more complex architectures.

\section{Nomenclature}

$$
\begin{array}{ll}
\dot{m}_{o r} & \text { vapor mass flow rate through valve orifice }\left(\mathrm{kg} \mathrm{s}^{-1}\right) \\
\dot{m}_{t o t} & \text { vapor total mass flow rate through valve vapor line }\left(\mathrm{kg} \mathrm{s}^{-1}\right) \\
\dot{m}_{v s} & \text { vapor mass flow rate through valve seats }\left(\mathrm{kg} \mathrm{s}^{-1}\right) \\
\mathrm{P} & \text { payload applied power }(\mathrm{W})
\end{array}
$$


$\mathrm{T}_{\mathrm{op}} \quad$ payload operation temperature $\left({ }^{\circ} \mathrm{C}\right)$

$\mathrm{T}_{\mathrm{rad}} \quad$ radiator operation temperature $\left({ }^{\circ} \mathrm{C}\right)$

$\mathrm{T}_{\mathrm{s} / \mathrm{c}} \quad$ spacecraft operation temperature $\left({ }^{\circ} \mathrm{C}\right)$

$\Delta \mathrm{T} \quad$ temperature difference $\left({ }^{\circ} \mathrm{C}\right)$

\section{Subscripts}

$\begin{array}{ll}\text { mod } & \text { model } \\ \text { or } & \text { orifice } \\ \text { out } & \text { outlet } \\ \text { op } & \text { operation } \\ \text { rad } & \text { radiator } \\ \text { s/c } & \text { spacecraft } \\ \text { tot } & \text { total } \\ \text { vs } & \text { valve seats }\end{array}$

\section{Acronyms}

AGHP Axially Grooved Heat Pipe

BOL Beginning Of Life Conditions

CC Compensation Chamber or Reservoir

CREW Coupled Radiator East West

E East

EOL End Of Life

EQS $\quad$ Spring Equinox 


$\begin{array}{ll}\text { EV } & \text { Evaporator } \\ \text { FMECA } & \text { Failure Mode Effects Criticality Analysis } \\ \text { HP } & \text { Heat Pipe } \\ \text { IOT } & \text { In-Orbit Test } \\ \text { LHP } & \text { Loop Heat Pipe } \\ \text { LL } & \text { Liquid Line } \\ \text { LNA } & \text { Low Noise Amplifier } \\ \text { MLI } & \text { Multi-Layer Insulation } \\ \text { OSR } & \text { Optical Solar Reflector } \\ \text { PRV } & \text { Pressure Regulating Valve } \\ \text { RAD } & \text { Radiator } \\ \text { VMLHP } & \text { Vapor Modulated Loop Heat Pipe } \\ \text { W } & \text { West } \\ \text { WS1 } & \text { Winter Solstice December 2011 } \\ \text { WS2 } & \text { Winter Solstice December 2012 }\end{array}$

\subsection{Introduction}

With the increasing power levels of the modern telecommunications satellites, innovative thermal control methods are needed to remove the excess power. Currently, one of the biggest limitations of the satellite thermal control is the available radiator area due to the constraints on the dynamic envelope of the launchers. A novel spacecraft thermal control architecture connecting the east/west radiators is presented in this paper. In this architecture, the radiators are connected 
by loop heat pipes (LHPs) and the LHP operating temperature is regulated by using pressure regulating valves (PRVs).

There are several advantages when using an LHP with PRV instead of a regular heat pipe $(\mathrm{HP})$ :

1. System accommodation: The HP length, number of bends and shape (i.e. 2D or 3D) limit system accommodation. The regular HP used in telecommunication satellites are typically non-flexible and its stiffness can be an important issue for certain equipment, for example Low Noise Amplifiers (LNA). LHP does not have this limitation since transport line routing can be very complex as the lines are flexible.

2. On-ground testability: Depending of the HP orientation and satellite ground test position with respect to gravity vector, some pipes can be either working in reflux mode or not working (evaporator above condenser). However, the LHP will work against gravity, so limitations are minimum.

3. Payload equipment temperature control and satellite power consumption saving: The diode effect of the LHP prevents overheating of payload equipment when a radiator is sun illuminated. In the cases where the radiator is not sun illuminated, the $\mathrm{PRV}$ closes the fluid path to the radiator preventing payload equipment temperature to fall beyond minimum qualification temperatures. Therefore, no compensation heaters are needed and an important satellite power saving is achieved.

4. Power transport capability: The LHP can handle larger heat loads than heat pipes.

5. Radiator size and mass reduction: The LHP allows the use of a direct condensation condenser (condenser embedded into the radiator). Thus, the 
required interfaces and temperature drop between the payload equipment and radiator are minimized, leading to a radiator of smaller size.

A flight demonstrator using this new architecture was launched in December $29^{\text {th }}, 2010$ on board the telecommunication satellite Hispasat $1 \mathrm{E}$. After two year of data collection, a complete validation of the numerical model has been performed. The available data includes In-Orbit Test (IOT) sequences carried out during the first month of the mission after launch, as well as retrieved data corresponding to the orbital seasons, namely summer solstice, winter solstice and equinox.

The main objectives of the IOT campaign were to verify the correct functioning of the demonstrator and to verify that no adverse interference with the satellite thermal control system was occurring. To prove both extends, on one side several start-ups and shuts down of the LHPs were commanded in different orbit locations to demonstrate that in case of an eventual need to power on or off the system, no restriction were imposed on ground operations. On the other side, several power profiles were tested from $70 \mathrm{~W}$ down to as less as $20 \mathrm{~W}$ (total applied to the system) to verify the operation temperature extremes and the potential effect on the satellite thermal control. Some of the results of the IOT campaign were presented in [6.1].

As the behavior of the system was very satisfactory, an extra activity was planned to check the ability of the system to self-start after a self-shut-down due to minimum power dissipation to the system. The total power applied was $10 \mathrm{~W}$. One of the LHPs was shut down while the other transferred alone the 10-W power load 
during the unfavorable radiator orbital positions maintaining the required temperature level of the payload. Once the radiators were in a better thermal condition, a self-start of the other LHP occurred.

This extra phase was very useful for two reasons. First, it demonstrated the ability of the LHPs to start and shut down in orbit. Second, it demonstrated that the proposed thermal architecture can be used for thermally challenging payloads such as Low Noise Amplifiers (LNA) requiring stringent orbit temperature stability and level (near $0^{\circ} \mathrm{C}$ ). For this type of payloads, securing the sufficient radiator area and identifying a proper location have always been a difficult task.

After the IOT activities were concluded, the demonstrator was set to $50 \mathrm{~W}$ payload power. The system has been operating without any problem as of the submittal of this paper.

There have been a small number of publications on the flight data of the LHPbased thermal control systems and its LHP mathematical model validation. In most cases, the mathematical models are proprietary and the model details were not published. In [6.2], the authors reported the stable operation of the 7.5 year flight performance of a thermal system developed to control $\mathrm{Ni}-\mathrm{H}$ storage batteries. Similar conclusions are provided in MAXI/SCC reported in [6.3]. The thermal control system composed of a combination of Peltier coolers and a LHP started as expected after launch. The authors did not present comparison between a mathematical model and flight data, and they concluded that the thermal system behaved as expected as the instrument provided the required performances. 
Although no mathematical model validation has been reported, Baker et al. [6.4] provided a very good example of analysis of flight data and in particular a flight anomaly of LHP. GLAS instrument was equipped with two independent LHPs for controlling the tight temperature requirements of the on-board lasers. During the 6 years of operation, only one anomaly related to the inadequate cooling capacity was observed. The authors have identified possible causes of this anomaly and the specific orbit tests were conducted. The authors concluded that a possible workmanship fault during the secondary wick manufacturing was the most probable reason of the observed anomaly.

Another example of flight anomaly was discussed in [6.5] for an LHP-based cooling system of the COMMx payload on-board TacSat 4 spacecraft. Although no direct mathematical model validation was provided in the paper, the authors have used modeling support along with flight data to analyze the anomaly. According to author's opinions an LHP failure was experienced during the flight.

In $[6.6,6.7]$ the flight data obtained from the six LHPs on-board a telecommunication satellite were presented. An expected and normal behavior of the LHPs was reported after the flight data analysis. No mathematical validation was presented. In [6.8], the flight data were discussed for a deployable radiator based on LHP on the Japanese Kiku-8 satellite.

The main objective of this paper is to present the flight data of the LHP-based thermal architecture system to demonstrate the successful in orbit operation of a 
new concept. The data obtained during the test campaign is also compared against a transient mathematical model results. The flight performance of the system and comparison of the flight data and calculations are found to be very satisfactory. It should be noted that, to our best knowledge, there has been no prior publication where the flight data and corresponding mathematical model validation were presented for an LHP-based thermal control system during its lifetime in flight.

\subsection{Demonstrator hardware description}

The complete demonstrator has an overall mass of $5 \mathrm{~kg}$. An overall view is presented in Fig. 6. 1. Details of the evaporator area and east radiator are presented in Figs. 6.2 and 6.3, respectively.

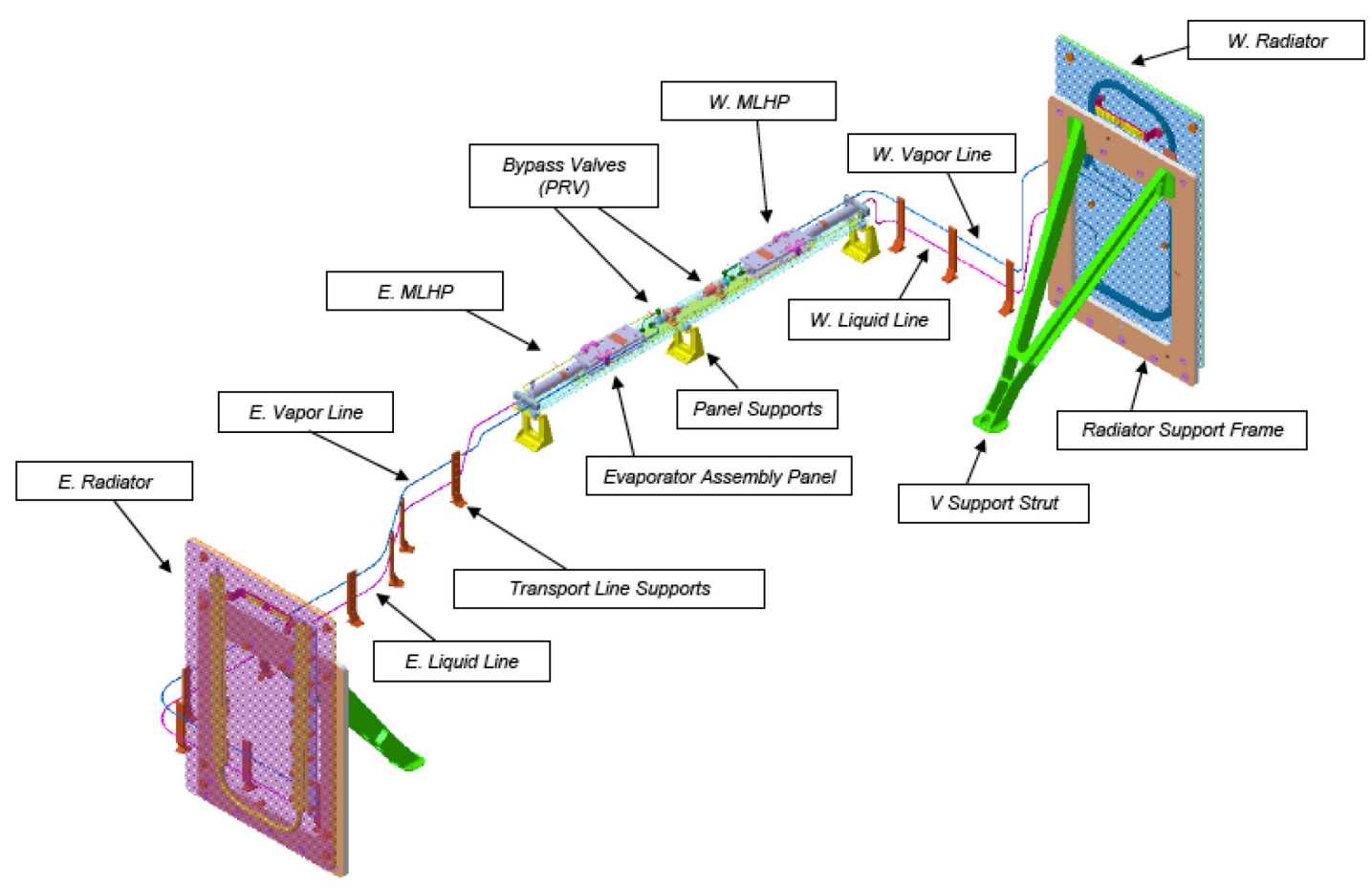

Figure 6.1. Demonstrator general view. 


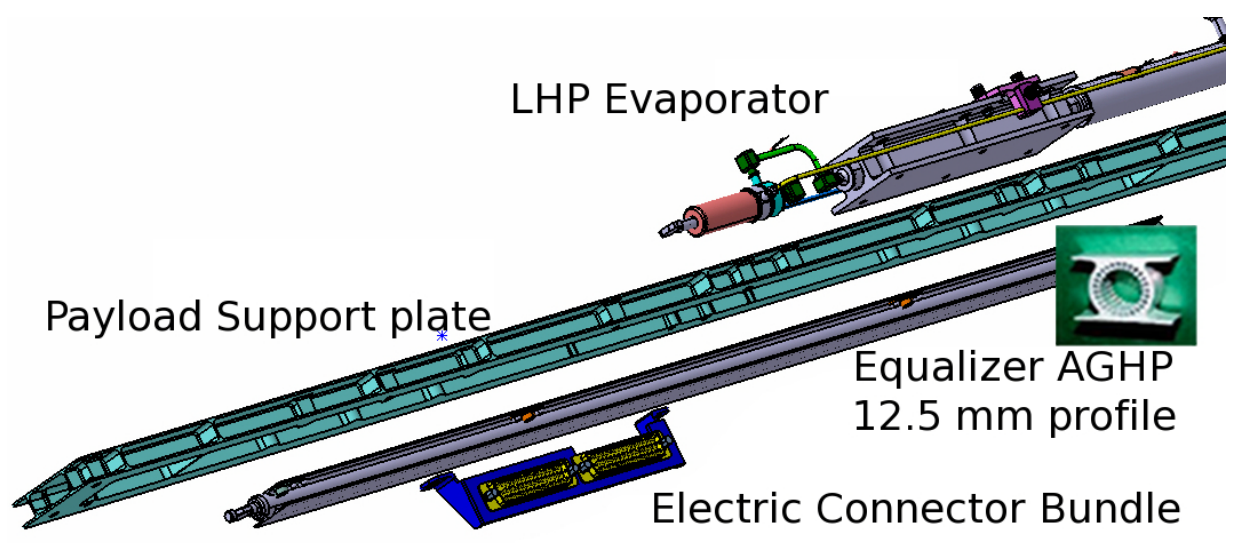

Figure 6.2. Detailed view of demonstrator evaporator area components.

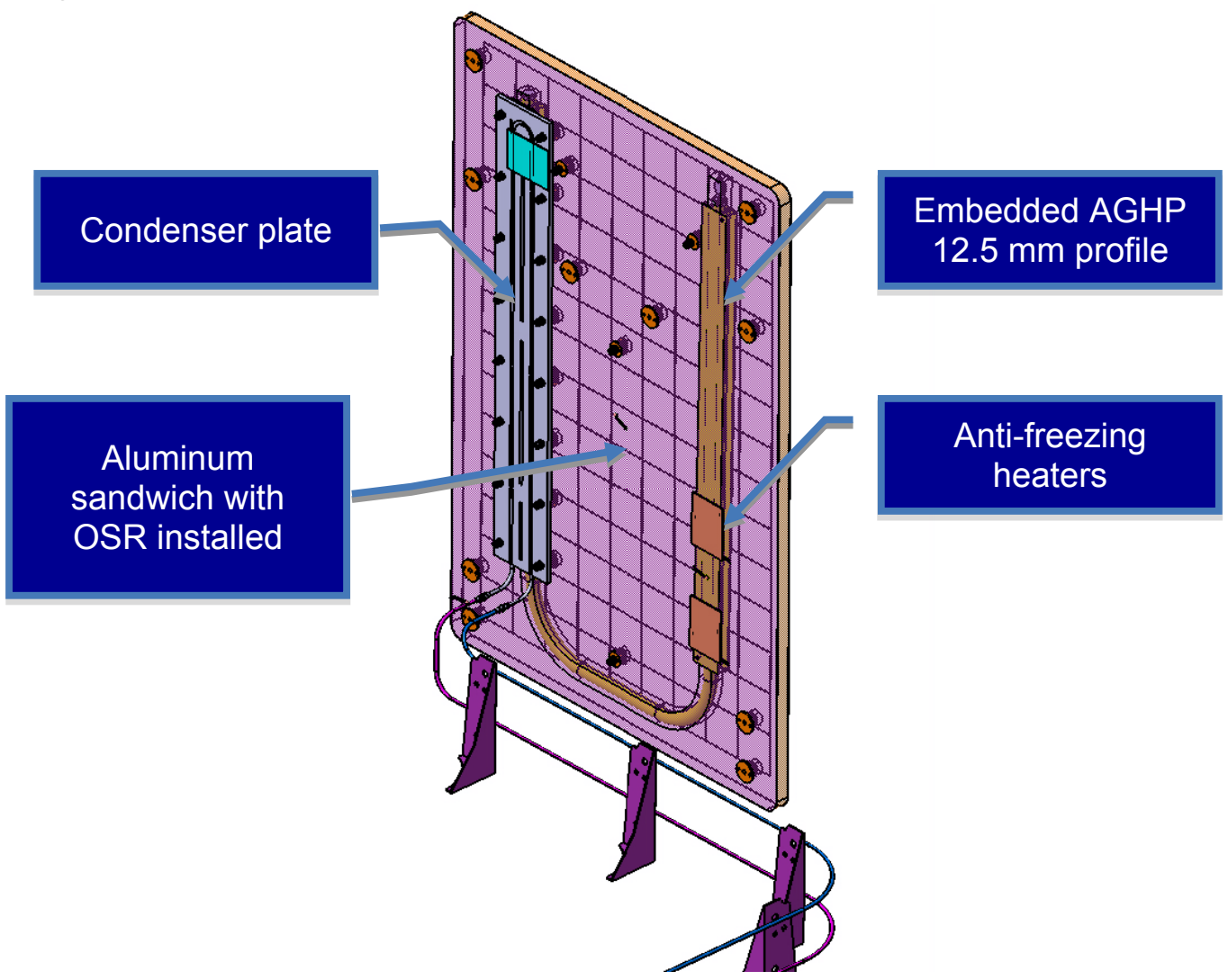

Figure 6.3. Detailed view of east radiator components.

The hardware is split into three main architecture blocks: 
- Heat collection area: Composed by an axially grooved heat pipe (AGHP) 12.5-mm diameter and 1-m length. The AGHP is attached underneath of an aluminium plate. The plate is attached to the satellite by means of brackets and it supports the evaporator and pressure regulation valves (PRVs). The AGHP collects the power from several driving heaters and homogenize their temperature.

- Heat transportation and regulation system: Composed by two LHPs, each one equipped with a PRV. Both LHPs have identical evaporators. Transport lines (vapor and liquid) differ having the east LHP 1.5 times the total transport line length of the west LHP. This was due to satellite accommodation requirements. The east LHP condenser plate is attached to the radiator, so that the type of condensation is indirect in the sense that heat goes through contact interfaces. The west LHP condenser, on the contrary, is directly embedded into the radiator. This time the condensation is direct. A set of PRVs regulates the access to the radiators. Both of the PRVs have two-way valve design. The description of the functioning of the PRVs is reported in [6.9].

- Heat rejection area: The two radiator panels reject the excess heat to space. The radiators are made out of aluminum sandwich externally covered by optical solar reflectors (OSR) as shown in Figs. 6.1 and 6.3.

Isolation hardware, such as multi-layer insulation (MLI), was used in certain areas to prevent incoming heat input from, typically, sun illumination. 
One of the most important aspects to be considered to embark LHP based thermal designs into telecommunication satellites is the operation robustness and flexibility to accommodate this type of thermal hardware without restrictions in satellite integration, test and flight operation. Therefore, demonstrator has incorporated alternative design solutions to prove that all these different options will operate successfully regardless of the restrictions mentioned above. The demonstrator incorporates the following features:

- Short transport lines (West branch) vs. long transport lines (East branch).

- Direct condensation in west radiator (embedded condenser) vs. indirect condensation in the east radiator (bolted condenser plate on the radiator).

- Applied payload power on the evaporator plate difference in both branches (30 $\mathrm{W}$ on the west side and 40W on the east side).

- Compensation chambers of the LHPs are mounted above the evaporator plate to see the parasitic heating effect of this panel on the operation.

To demonstrate that the LHPs can successfully operate at low powers, they have been sized to transport up to $500 \mathrm{~W}$ each although they are expected to experience a maximum power of $70 \mathrm{~W}$ per LHP in-orbit.

\subsection{Numerical model}

The details of the numerical model were presented in [6.10]. In this model, the transient governing equations of the heat and fluid flow were solved using a staggered grid approach. The resulting equations were solved using the 
EcosimPro software. This software provides the capability to model each component individually such that the entire system can be built by a modular approach.

The specific application of this mathematical model to the proposed architecture with the required additions was presented in [6.11]. Therefore, the details of the model will not be discussed in this paper. The overview of the model prior validation is presented in Fig. 6. 4. Details of the linear and radiative couplings at evaporator area are shown in Fig. 6. 5.

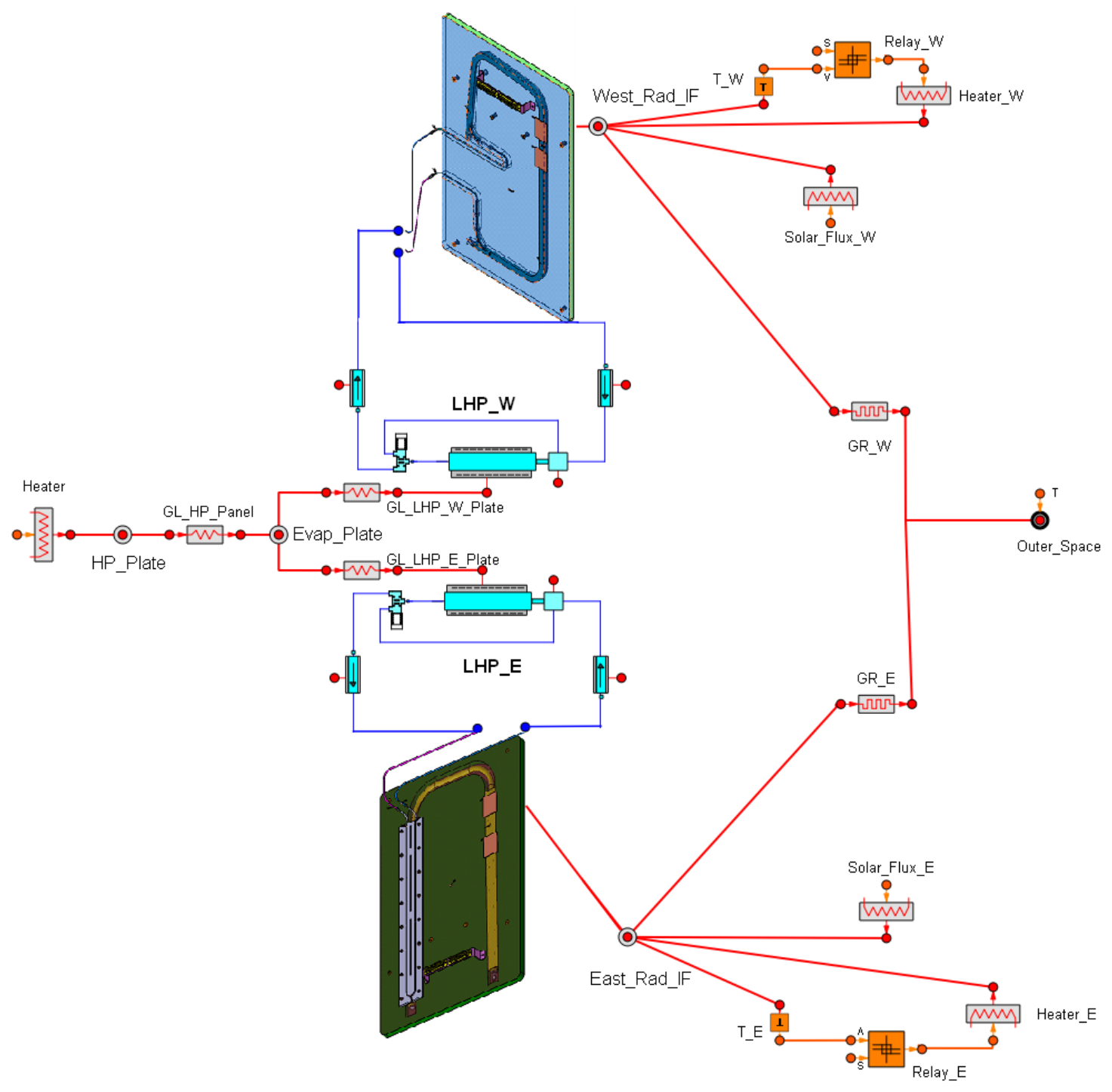

Figure 6.4. Mathematical model overview prior to validation. 


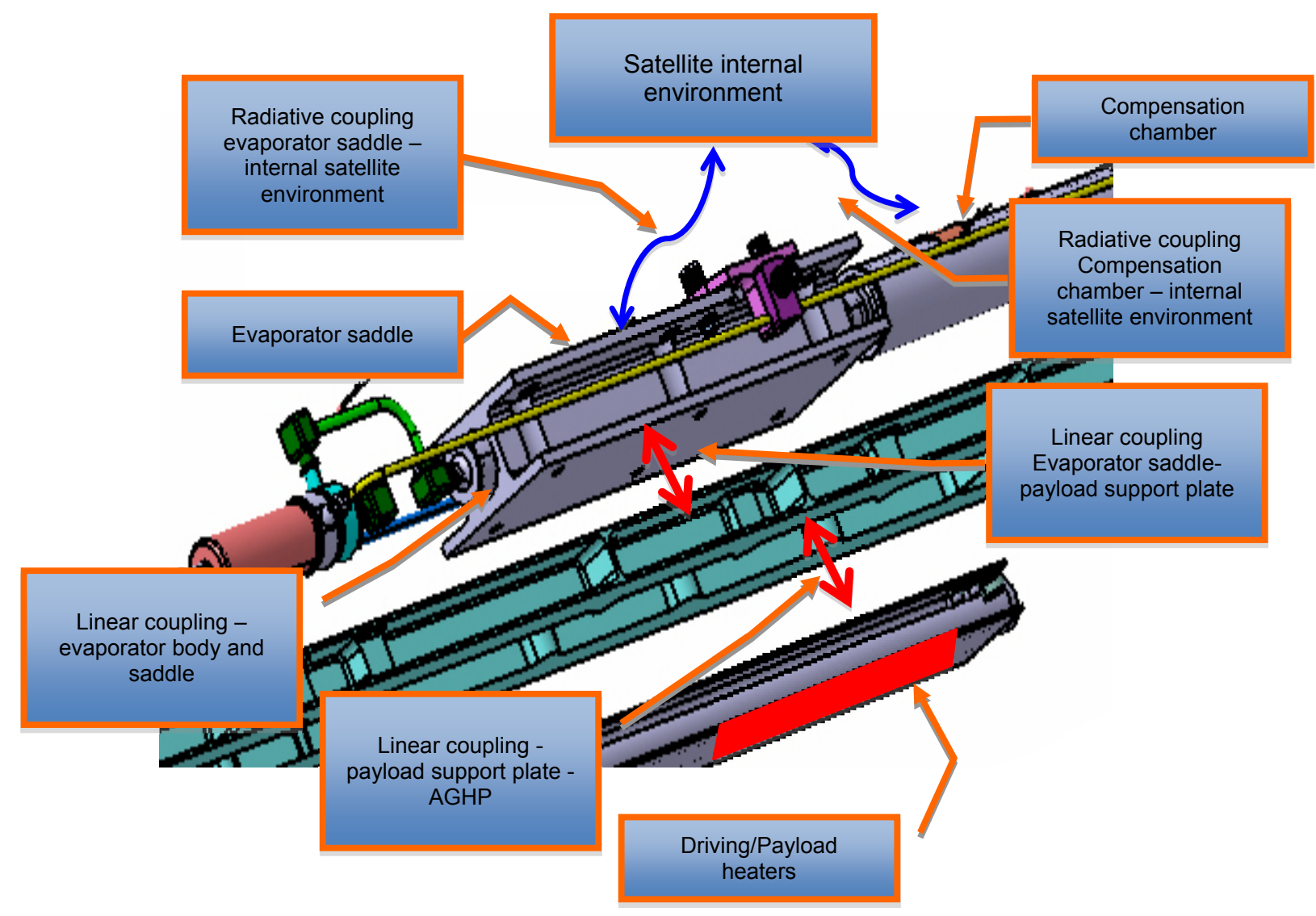

Figure 6.5. Detailed view of evaporator area thermal couplings.

\subsection{Model validation cases}

\subsubsection{Nominal orbital cases}

The following simulations, presented in Table 6.1 , have been run. The selected nominal cases cover all possible nominal operational scenarios that the demonstrator could be performing during the orbital operation. Besides the nominal cases, a set of failure mode cases has also been run. The objective of these failure cases is to demonstrate that under such potential failure conditions satellite mission is not compromised and to support the Failure Mode, Effects, and Criticality Analysis (FMECA). 
Table 6.1. Nominal simulation cases

\begin{tabular}{|c|c|c|c|c|}
\hline Case Description & $\begin{array}{c}\text { Simulation } \\
\text { Type }\end{array}$ & $\begin{array}{l}\text { Absorptivity } \\
\text { (3 years) }\end{array}$ & $\begin{array}{c}\text { Satellite } \\
\text { internal } \\
\text { environment }\end{array}$ & $\begin{array}{c}\text { Power } \\
\text { Applied } \\
\text { (W) }\end{array}$ \\
\hline Winter Solstice 2011 & Transient & 0.17 & Cold & 50 \\
\hline Winter Solstice 2012 & Transient & 0.17 & Hot & 50 \\
\hline Spring Equinox 2012 & Transient & 0.17 & Cold & 50 \\
\hline
\end{tabular}

\subsubsection{Sensitivity analysis}

Prior to the comparison of the flight data and predictions, a sensitivity analysis of important system parameters has been analyzed. The details of the thermal couplings used for the sensitivity analysis is shown in Fig. 6. 5. A set of numerical simulations has been run to determine the influence of the variation of such parameters. For the analysis, the hot maximum case and cold minimum case with both LHPs working has been selected to implement the corresponding variations to the nominal values. The parameters, their values and the corresponding case identification numbers are as follows:

- Thermal contact conductance variation between the evaporator saddle and the evaporator body ( $\pm 20 \%)$. Case $1(+20 \%)$, Case $2(-20 \%)$

- Thermal contact conductance variation at the evaporator side (saddlepayload plate) $( \pm 50 \%)$. Case $3(+50 \%)$, Case $4(-50 \%)$

- Heater dissipation: $\pm 10 \%$ of variation. Case 5 (+10\%), Case $6(-10 \%)$

- Heat exchange with ambient (satellite internal environment): To verify the 
ambient influence, the LHP components will be connected to its ambient by means of thermal couplings. These thermal couplings have been calculated taking into account the components area and the corresponding emissivity. The values that are introduced in the model are summarized in Table 6.2. Case 7 (plus values), Case 8 (minus values).

Table 6.2. Coupling matrix for ambient exchange cases

\begin{tabular}{|c|c|c|c|c|}
\hline & $\begin{array}{c}\text { LHP } \\
\text { Evaporator }\end{array}$ & $\begin{array}{c}\text { Compensation } \\
\text { Chamber }\end{array}$ & $\begin{array}{c}\text { Evaporator } \\
\text { Plate }\end{array}$ & $\begin{array}{c}\text { Satellite } \\
\text { Internal } \\
\text { environment }\end{array}$ \\
\hline $\begin{array}{c}\text { LHP } \\
\text { Evaporator }\end{array}$ & - & $1.14 \mathrm{E}-5 \mathrm{~m}^{2}$ & $2.26 \mathrm{E}-5 \mathrm{~m}^{2}$ & $2.29 \mathrm{E}-3 \mathrm{~m}^{2}$ \\
\hline $\begin{array}{c}\text { Compensation } \\
\text { Chamber }\end{array}$ & $1.14 \mathrm{E}-5 \mathrm{~m}^{2}$ & - & $9.34 \mathrm{E}-5 \mathrm{~m}^{2}$ & $1.11 \mathrm{E}-3 \mathrm{~m}^{2}$ \\
\hline $\begin{array}{c}\text { Evaporator } \\
\text { Plate }\end{array}$ & $2.26 \mathrm{E}-5 \mathrm{~m}^{2}$ & $9.34 \mathrm{E}-5 \mathrm{~m}^{2}$ & - & $1.61 \mathrm{E}-2 \mathrm{~m}^{2}$ \\
\hline $\begin{array}{c}\text { Satellite } \\
\text { Internal } \\
\text { environment }\end{array}$ & $2.29 \mathrm{E}-3 \mathrm{~m}^{2}$ & $1.11 \mathrm{E}-3 \mathrm{~m}^{2}$ & $1.61 \mathrm{E}-2 \mathrm{~m}^{2}$ & - \\
\hline
\end{tabular}

The sensitivity analysis results are presented in Table 6.3: 
Table 6.3. Sensitivity analysis

\begin{tabular}{|c|c|c|c|c|c|c|c|c|c|c|}
\hline $\begin{array}{c}\text { Case ID } \\
\quad \#\end{array}$ & $\begin{array}{l}\text { Evap. } \\
\text { Plate } \\
\text { Temp. } \\
\left({ }^{\circ} \mathrm{C}\right)\end{array}$ & $\begin{array}{l}\Delta \mathrm{T} \\
\left({ }^{\circ} \mathrm{C}\right)\end{array}$ & $\begin{array}{l}\text { East } \\
\text { Evap. } \\
\text { Temp. } \\
\left({ }^{\circ} \mathrm{C}\right)\end{array}$ & $\begin{array}{l}\Delta \mathrm{T} \\
\left({ }^{\circ} \mathrm{C}\right)\end{array}$ & $\begin{array}{l}\text { West } \\
\text { Evap. } \\
\text { Temp. } \\
\left({ }^{\circ} \mathrm{C}\right)\end{array}$ & $\begin{array}{l}\Delta \mathrm{T} \\
\left({ }^{\circ} \mathrm{C}\right)\end{array}$ & $\begin{array}{l}\text { East } \\
\text { Rad. } \\
\text { Temp. } \\
\left({ }^{\circ} \mathrm{C}\right)\end{array}$ & $\begin{array}{l}\Delta \mathrm{T} \\
\left({ }^{\circ} \mathrm{C}\right)\end{array}$ & $\begin{array}{l}\text { West } \\
\text { Rad. } \\
\text { Temp. } \\
\left({ }^{\circ} \mathrm{C}\right)\end{array}$ & $\begin{array}{l}\Delta \mathrm{T} \\
\left({ }^{\circ} \mathrm{C}\right)\end{array}$ \\
\hline Ref. Hot & 36.02 & - & 35.11 & - & 32.25 & - & 31.24 & - & 24.93 & - \\
\hline Ref. Cold & 30.39 & - & 29.74 & - & 29.70 & - & -38.32 & - & -39.45 & - \\
\hline 1 & 36.39 & 0.37 & 35.48 & 0.36 & 32.64 & 0.39 & 32.79 & 1.54 & 22.99 & 1.94 \\
\hline 2 & 30.34 & $\begin{array}{c}- \\
0.05\end{array}$ & 29.69 & $\begin{array}{c}- \\
0.05\end{array}$ & 29.65 & $\begin{array}{c}- \\
0.05\end{array}$ & -38.37 & 0.05 & -39.37 & 0.08 \\
\hline 3 & 39.42 & 3.40 & 37.38 & 2.27 & 32.14 & 0.12 & 34.72 & 3.48 & 20.86 & $\begin{array}{c}- \\
4.07\end{array}$ \\
\hline 4 & 30.16 & $\begin{array}{c}- \\
0.22\end{array}$ & 29.73 & 0.00 & 29.71 & 0.00 & -38.49 & $\begin{array}{c}- \\
0.17\end{array}$ & -39.12 & 0.32 \\
\hline 5 & 39.26 & 3.24 & 38.19 & 3.08 & 35.19 & 2.94 & 35.50 & 4.25 & 29.05 & 4.12 \\
\hline 6 & 30.27 & 0.12 & 29.69 & 0.05 & 29.66 & 0.05 & -37.88 & 0.44 & -38.26 & 1.19 \\
\hline 7 & 39.85 & 3.83 & 39.15 & 4.04 & 35.81 & 3.56 & 29.50 & 1.74 & 29.28 & 4.35 \\
\hline 8 & 30.58 & 0.19 & 29.86 & 0.12 & 29.82 & 0.11 & -37.70 & 0.62 & -38.31 & 1.13 \\
\hline $\begin{array}{c}\text { Maximum } \\
\Delta \mathrm{T}\end{array}$ & - & 3.83 & - & 4.04 & - & 3.56 & - & 4.25 & - & 4.35 \\
\hline $\begin{array}{c}\text { Minimum } \\
\Delta \mathrm{T}\end{array}$ & - & $\begin{array}{c}- \\
0.22\end{array}$ & & $\begin{array}{c}- \\
0.05\end{array}$ & & $\begin{array}{c}- \\
0.12\end{array}$ & & $\begin{array}{c}- \\
1.74\end{array}$ & & $\begin{array}{c}- \\
4.07\end{array}$ \\
\hline
\end{tabular}


As it can be seen from Table 6.3, the influences of the selected parameters do not provide significant deviations with respect to the nominal cases. These parameters could be considered if a fine refinement of the model is required. The specified correlation criterion considers a mathematical error of around $4^{\circ} \mathrm{C}$ and the resulting deviations shown in Table 6.3 were therefore judged acceptable.

\subsubsection{Model refinement}

The analysis of the first set of the flight data during the IOT campaign indicated a large difference between the mathematical model results at radiator level and flight data. This discrepancy was also observed during the orbits prior to switching on the demonstrator in July 2011. Fig. 6. 6 shows the predicted and measured temperature profiles. After the investigations, it was concluded that the reflector antennas located, two on the west side and one on the east side, were the reason. In particular, two different effects were identified. First, the antenna arms were shadowing the demonstrator radiator in certain orbital positions, leading to a modification of the view factors to space and to the antenna. Second, an increase of the heat input to the radiator was detected due to diffuse/specular reflection of the sun on the reflector and a resulting increase of infrared heat input from the reflector and arms. 


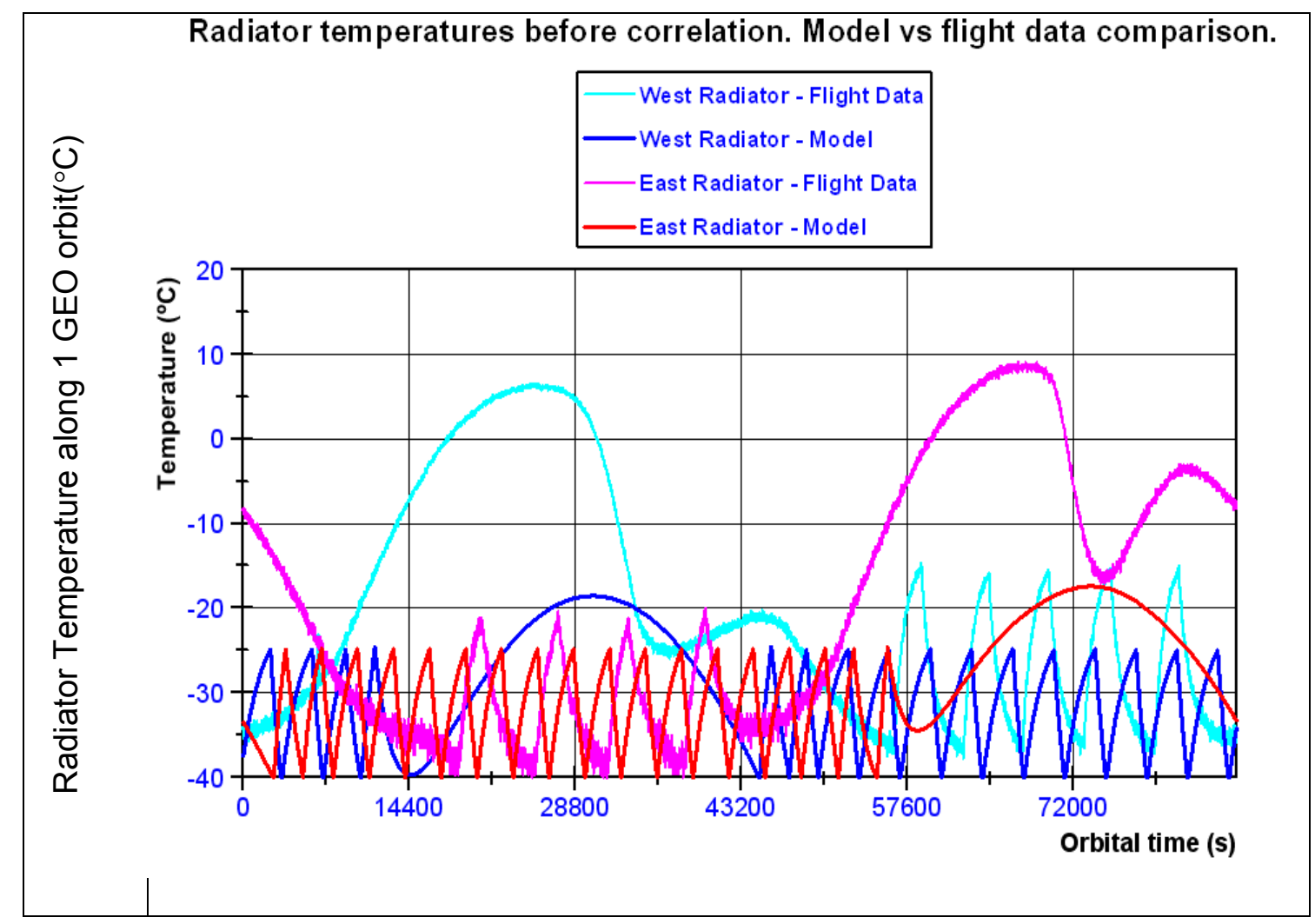

Figure 6.6. Predicted and measured radiator temperature.

The radiation model has been modified to incorporate the antenna reflectors and arms located at the east and west sides of the satellite as shown in Fig. 6. 7. A fine discretization was used to compute more accurately the view factors as well as the eventual shadows of antennas on the corresponding radiators. The radiation model has been run for the corresponding orbital environmental cases. 


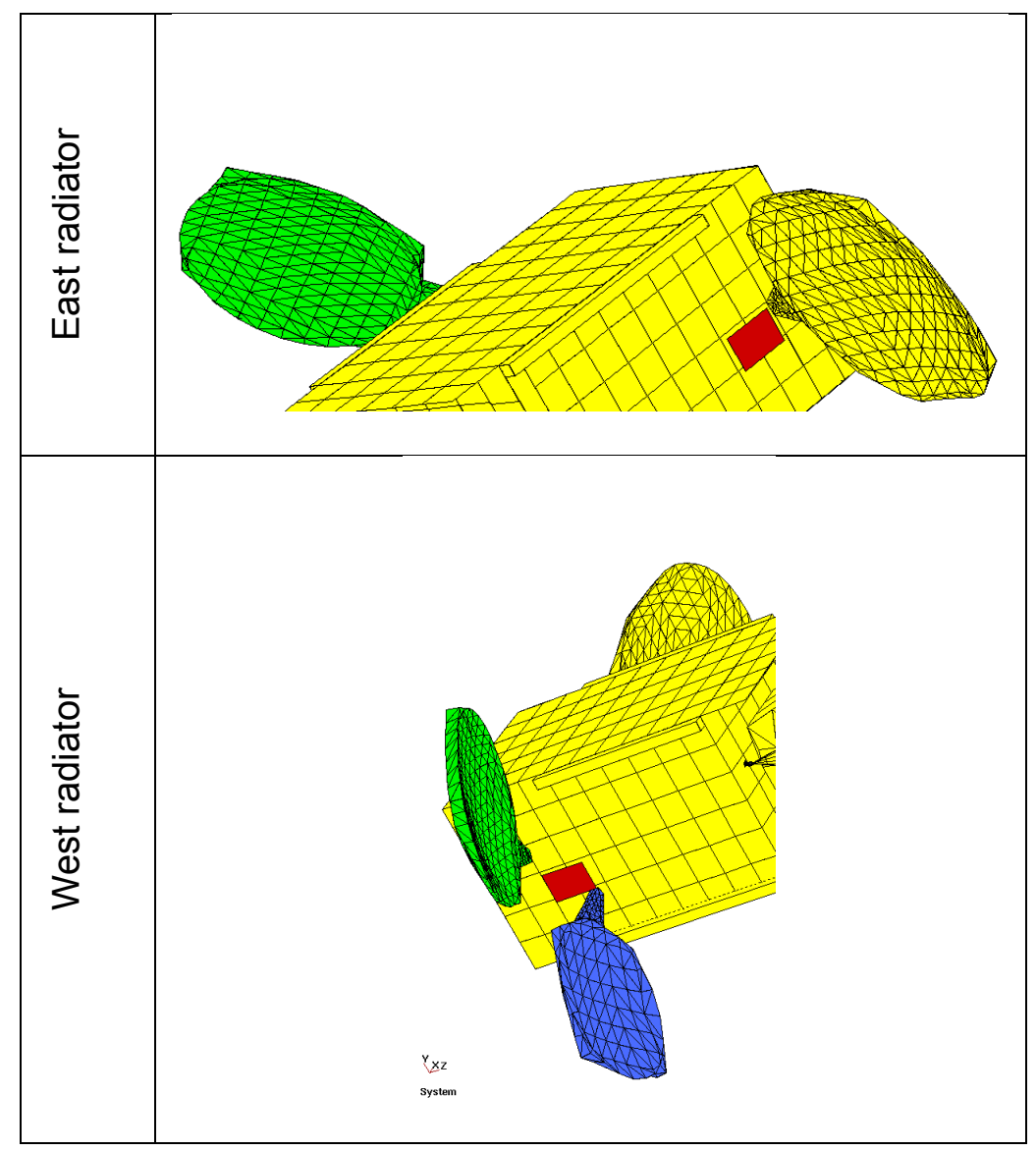

Figure 6.7. Radiation model refinement.

The completed numerical model was modified to accommodate the shadowing effect of the antennas as well as the new calculated external heat inputs on each radiator. Fig. 6.8 presents the modified numerical model schematic that was used to simulate the selected validation cases. 


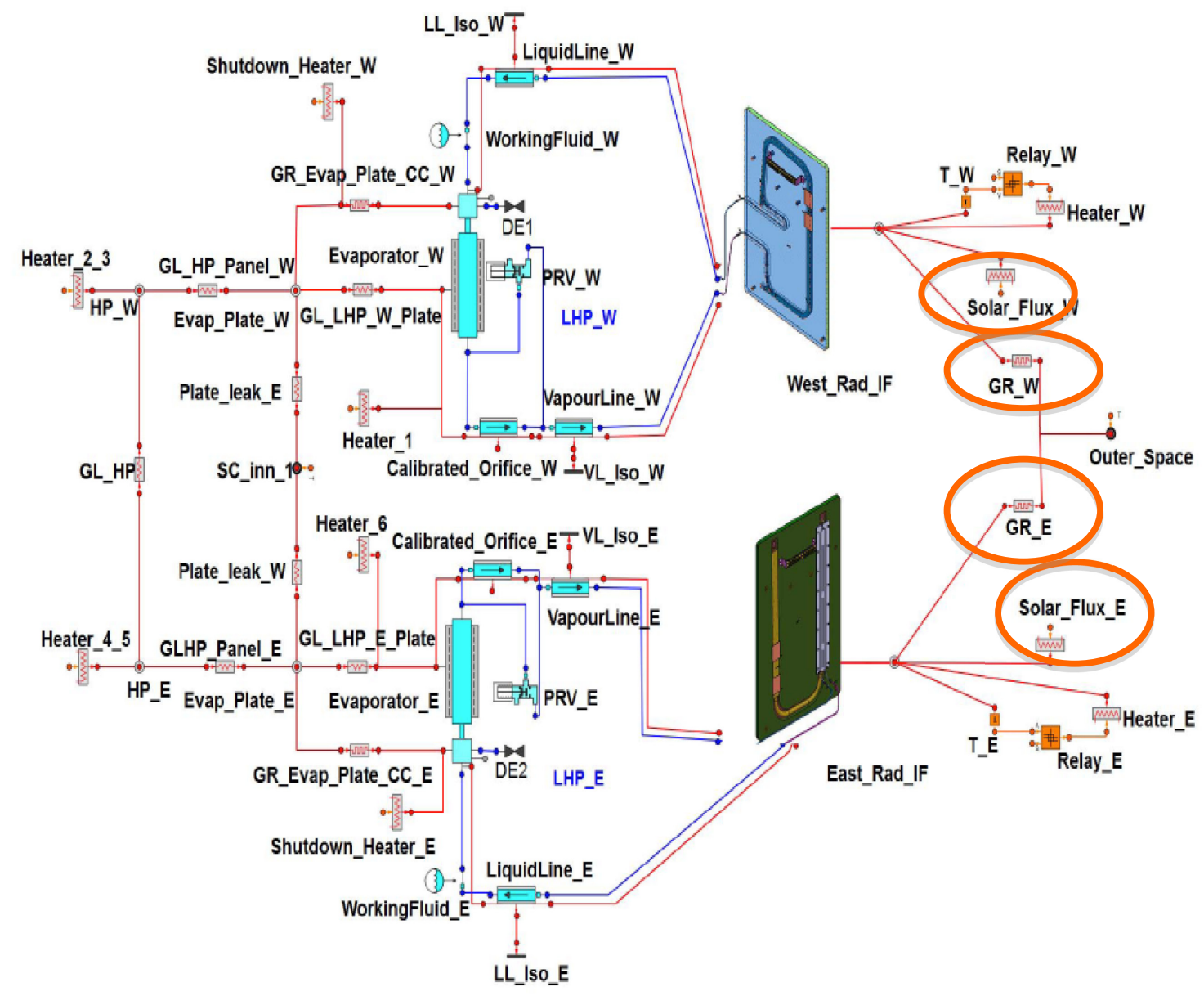

Figure 6.8. Modified numerical model schematics. Circled items were adjusted according to the flight data.

The results of the corrected radiator temperature calculation were provided in Fig. 6.9, where the correlation between the measured and calculated temperatures prior to switching on the demonstrator was presented. The results show a very good agreement between mathematical model predictions and flight data. 


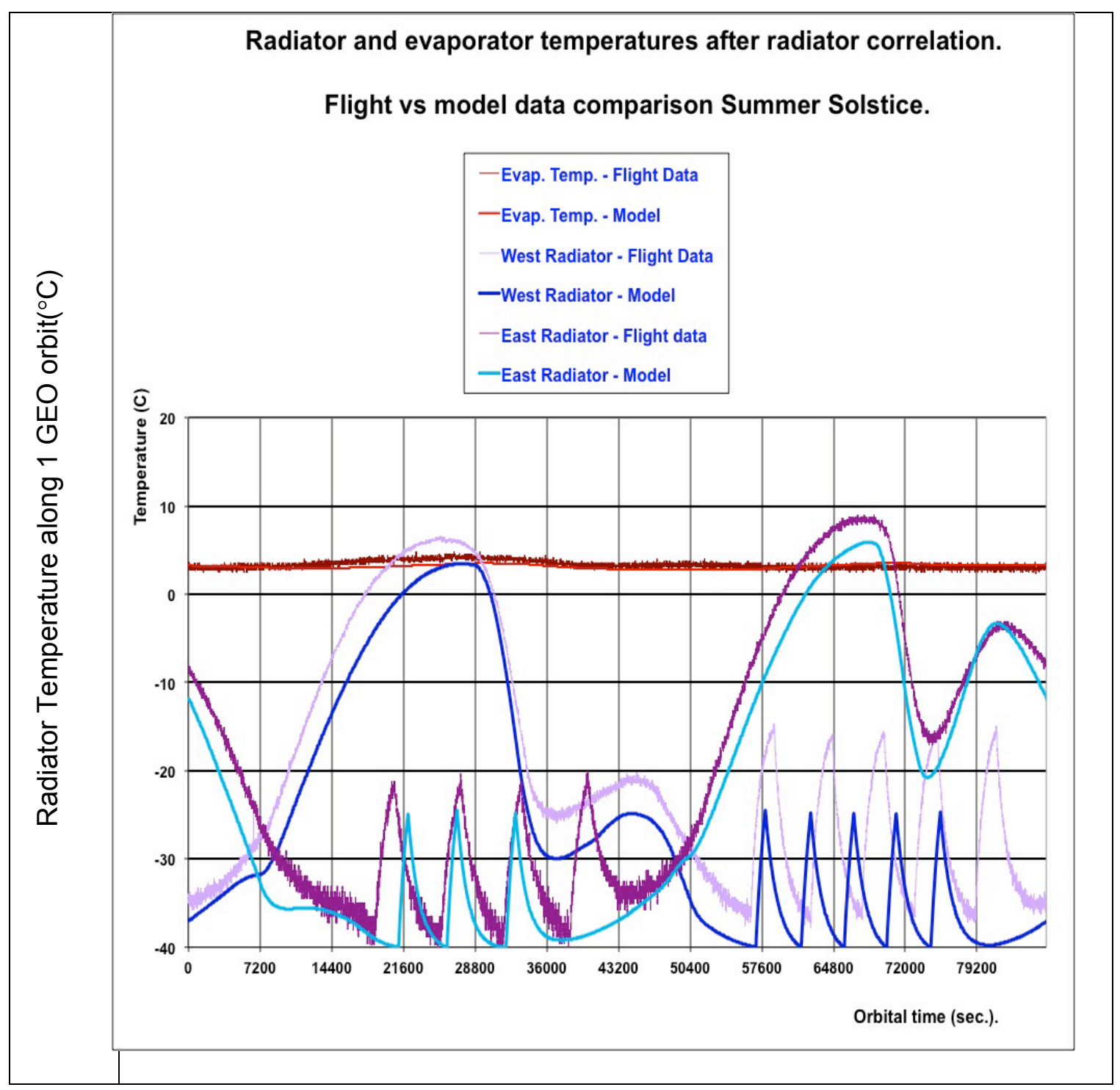

Figure 6.9. Radiator temperature comparison between measured flight data and calculations for Summer Solstice.

\subsection{Results and discussion}

Before presenting the flight data, a discussion of the PRVs and the corresponding four possible operational scenarios will be presented. The two-way PRV is able to automatically adjust the hydraulic resistance of the flow by changing the cross section of the line, thus varying the LHP pressure drop. In this way, the temperature of the evaporator is maintained nearly constant and it is independent of the condenser temperature. For the in-flight demonstrator, the two-way valve 
has been modified to implement a calibrated orifice near the piston seats as shown in Fig. 6. 10.

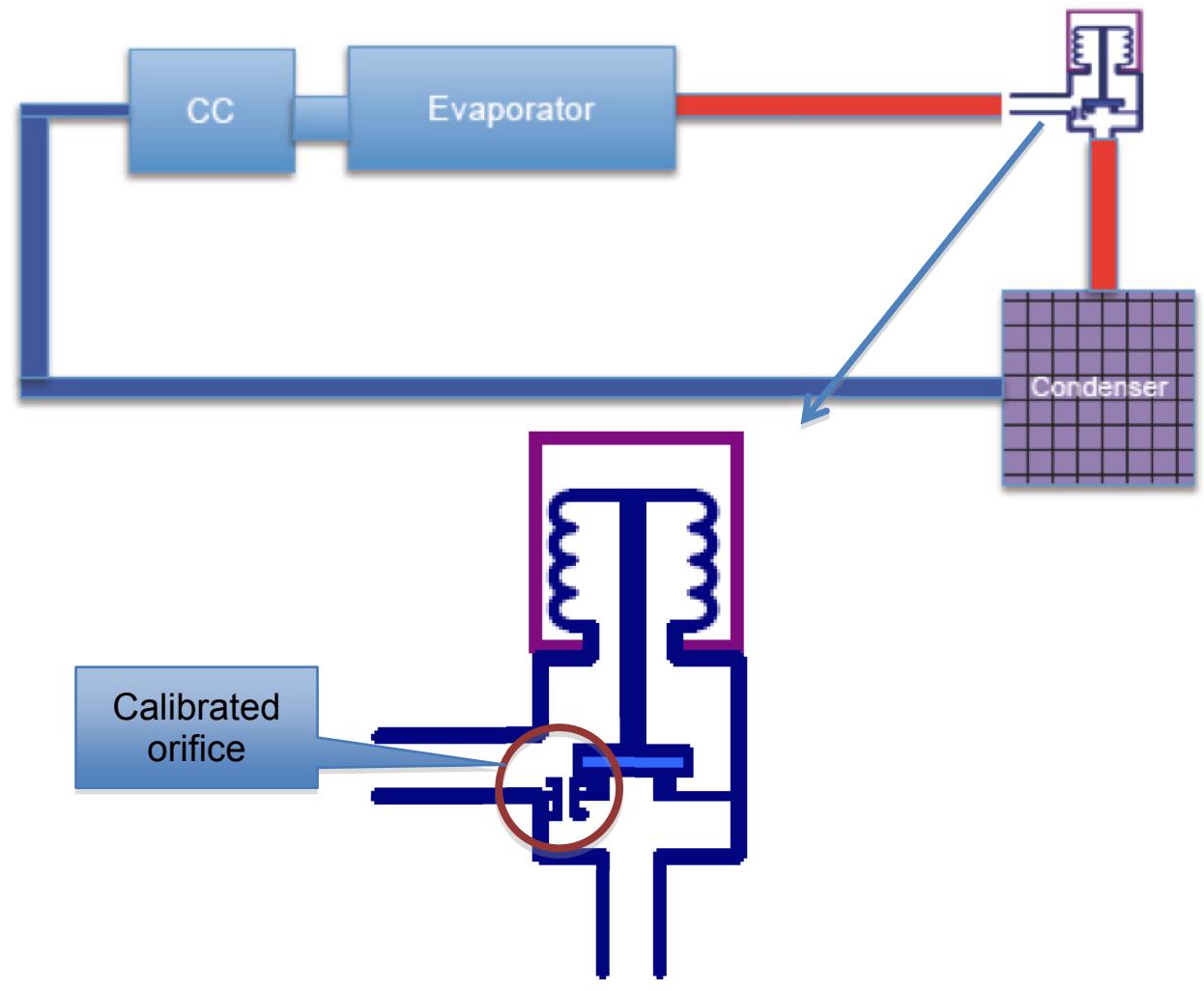

Figure 6.10. Calibrated orifice location.

Decision to introduce a calibrated orifice was based on following considerations:

1. The full range of internal satellite temperature variation for a given location of the demonstrator is rather wide and temperature can significantly change during satellite service operation (unknown). Certain combination of low power and low environmental temperature can lead to situation that vapor modulated LHP (VMLHP) will not reach set-point and therefore the system would not start. 
2. Available power budged for demonstrator continuous operation (years) was not fixed until the IOT campaign. Relatively low power levels (less than $\sim 20$ $25 \mathrm{~W}$ per LHP) in combination with low environmental temperature can also lead to situation that all power is dissipated into surroundings and system temperature will stabilize at the temperature below PRV set-point (LHP startup) temperature.

By implementing the orifice, the above mention problems were solved and the system has the possibility to start and operate below the set-point at low powers and cold environment. Fig. 6.11 qualitatively provides the possible operation scenarios of the PRV operation as a function of applied power and satellite environmental temperature.

- Scenario I, provides the case when no power is applied to the system and therefore the demonstrator is at an equilibrium temperature equal to satellite environmental temperature. PRV is closed.

- Scenario II corresponds to a situation with low power (less than $50 \mathrm{~W}$ ) and cold environment (less than $6^{\circ} \mathrm{C}$ ). The system starts and operates without regulation as a normal LHP. The payload, therefore, follows the sink (radiator) temperatures. PRV is closed. The LHP is at the constantconductance mode.

- Scenario III shows the control or regulating operation mode of the payload. The environmental satellite temperature is above $6^{\circ} \mathrm{C}$ and operation temperature corresponds to the PRV set-point $\left(30^{\circ} \mathrm{C}\right)$ for any 
applied power. PRV is open and adjusting according to the LHP internal pressure drop. The LHP is in the variable-conductance mode as a consequence of the position change of the valve piston.

- Scenario IV presents the hot case where the radiators have temperatures above $25^{\circ} \mathrm{C}$, leading to a fully open PRV and therefore the operational payload temperature is above the set-point. The payload, therefore, follows the sink (radiator) temperatures. The LHP is in the constant-conductance mode.

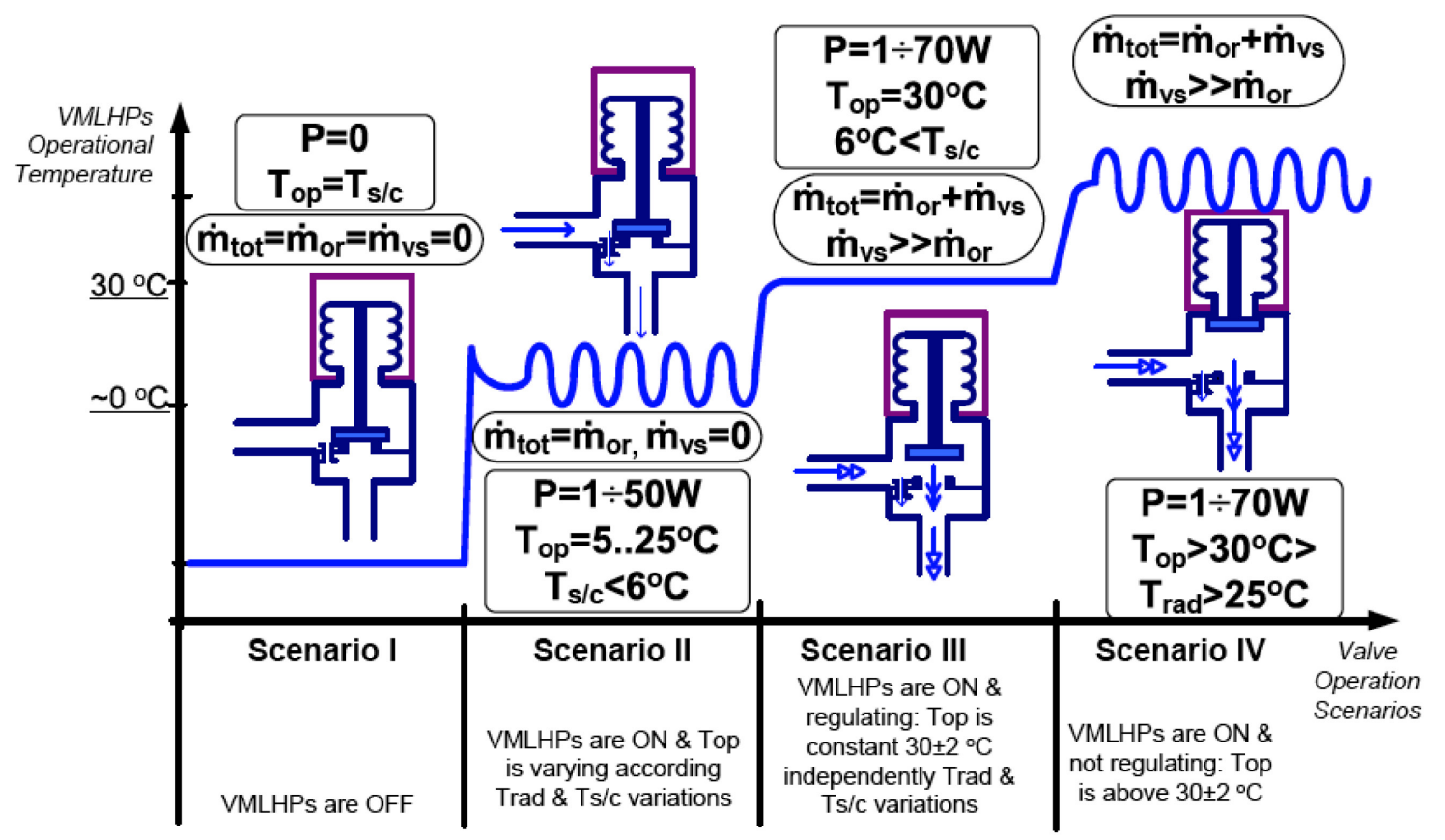

Figure 6.11. Valve operation scenarios as a function of applied payload power and satellite environmental temperature.

The flight data were collected by the thermistors placed on the critical locations of the system. The identification tags and position of the flight thermistors are shown on Fig. 6. 12. 

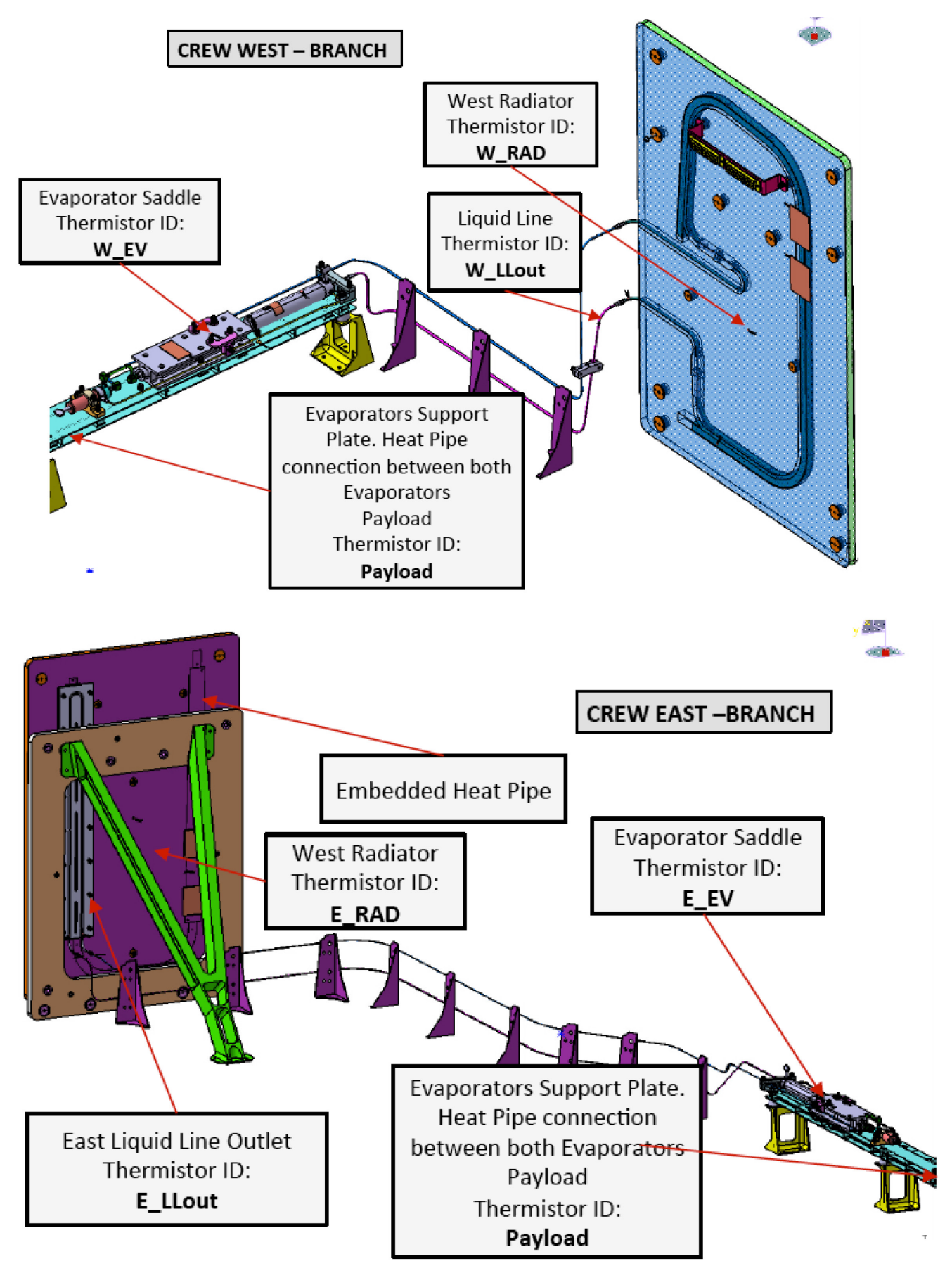

Figure 6.12. Identification tags and position of the flight thermistors.

The daily average temperatures of the critical system parts (radiators, payload, compensation chamber, liquid lines and evaporators) are presented in Fig. 6. 13. The environment satellite temperatures are also shown to correlate demonstrator operation according to LHP scenarios and satellite environmental conditions. Data provided extends from July 2011 (activation of demonstrator) to March 2013. In 
Fig. 6.3, the first three scenarios can be distinguished. The first one corresponds to the scenario I. The scenario II lasts from July $11^{\text {th }}, 2011$ up to October $19^{\text {th }}, 2012$. With an applied power of $50 \mathrm{~W}$, the both LHPs started and operated without regulation as a normal LHP. The payload, therefore, followed the sink (radiator) temperatures. PRV was closed and the LHPs were in the constant-conductance mode. The payload temperature was varying around $27^{\circ} \mathrm{C}$ with an amplitude of $\pm 3^{\circ} \mathrm{C}$ in spite of more than $30^{\circ} \mathrm{C}$ east and west radiator excursions. This was due to the actual connection between the east and west radiators.

The third one, the scenario III, runs from October $19^{\text {th }}, 2012$ onwards. As a result of the increased number of operational transponders, an increase in the internal satellite environment temperature was observed. This was more pronounced for the west than for the east demonstrator branch. This condition forced the west LHP to operate according to scenario III while the east one stayed in scenario II. The payload temperature was stabilized around $32^{\circ} \mathrm{C}$. 


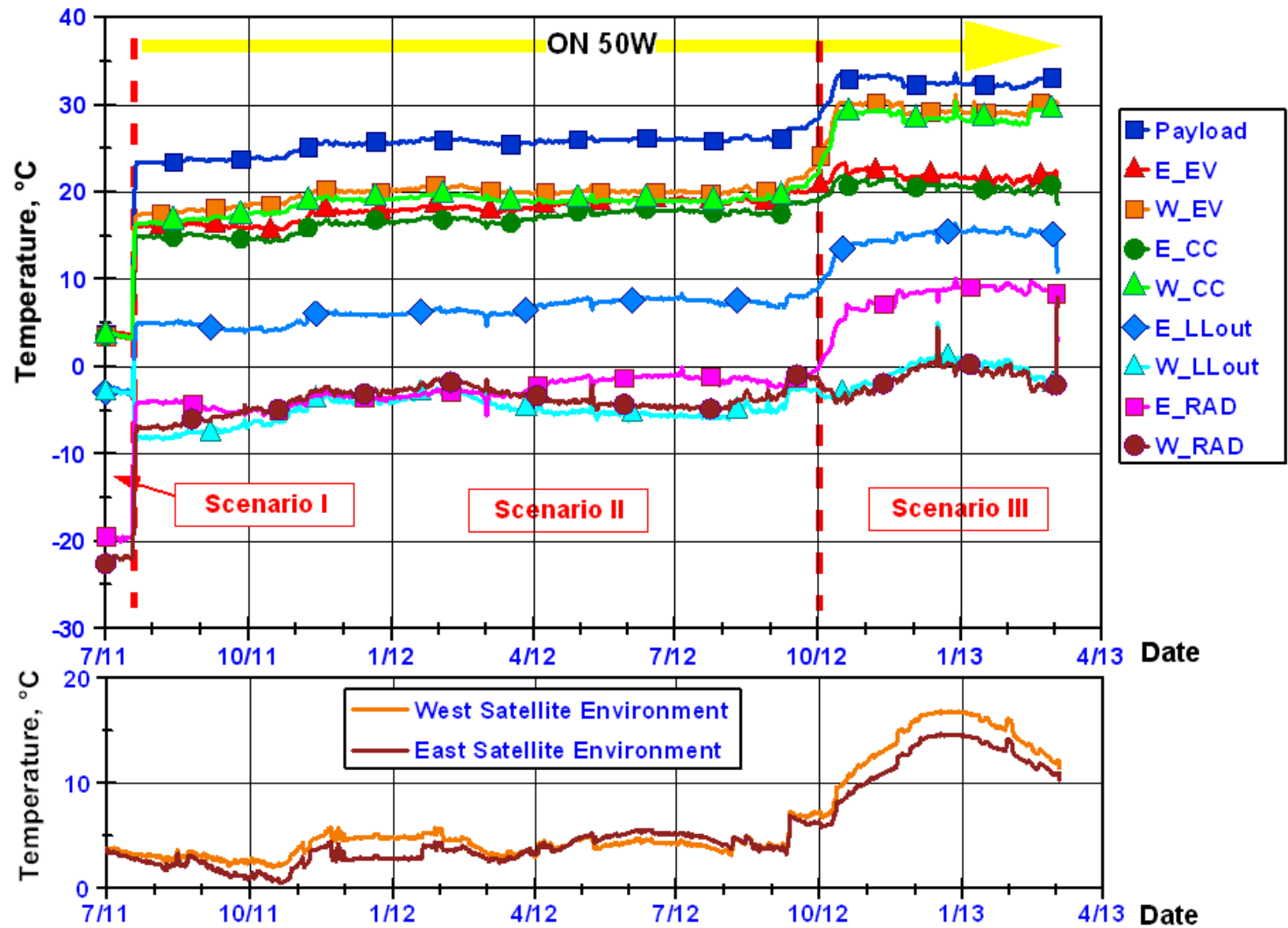

Figure 6.13. Demonstrator and satellite daily average temperatures from July 2011 to March 2013.

The demonstrator temperatures for the three different seasons that have been used to validate the mathematical model are shown in Figs. 6.14 to 6.17.

Start-up event details of both LHPs are given in Fig. 6.14. Once the payload power was applied (50 W), the west branch LHP was the first to start-up. The east branch LHP started few minutes later. This condition was also observed during the IOT operations, and it was caused by the slightly higher conductance of the west branch having a direct condenser.

After the start-up, payload temperature stayed around $27 \pm 3^{\circ} \mathrm{C}$. The applied power was shared between the two LHPs as presented in Fig. 6. 14. Out of the 
applied power of $50 \mathrm{~W}$, a total of $45 \mathrm{~W}$ was transferred and shared by the LHPs. The remaining $5 \mathrm{~W}$ lost to environment through conduction and radiation.

It is important to note that the payload temperatures were very stable in spite of the strong temperature variations induced by the radiators and start-up event. The stable payload temperatures have been a continuous characteristic during all this time.

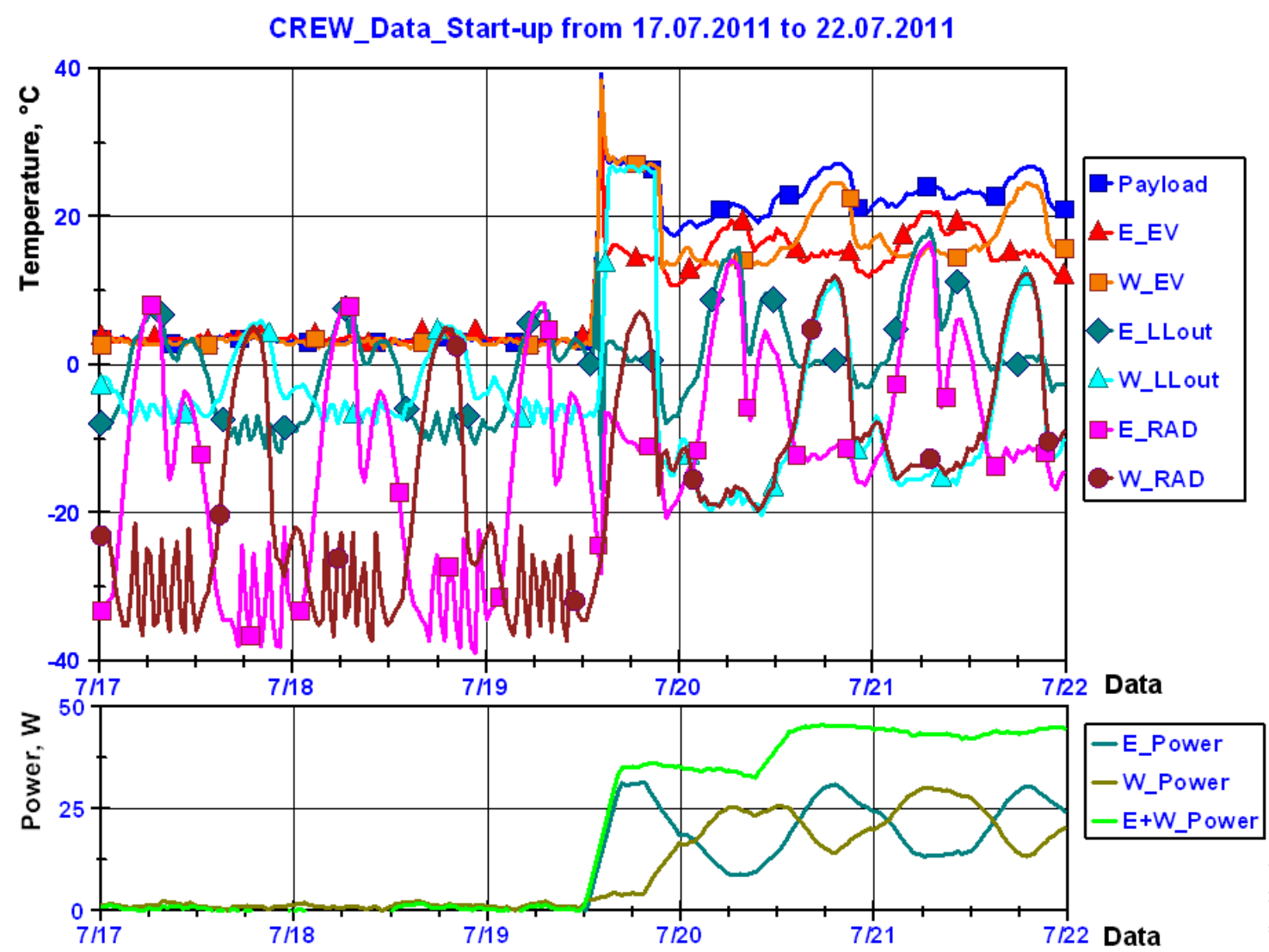

Figure 6.14. Demonstrator temperature before and after start-up, July 2011.

Figures 6.15 and 6.16 present the temperature and power variations for the first winter solstice and spring equinox seasons, respectively. The demonstrator operation was very satisfactory since its activation as it was designed. The payload 
temperatures were very stable and the power was shared almost symmetrically between the both LHPs. The LHPs were operating in the scenario II (cold environment). During these tests, no degradation of any kind has been observed. It should be noted that the changes on the thermal environment (winter solstice and equinox) had almost no influence on the system thermal performance.

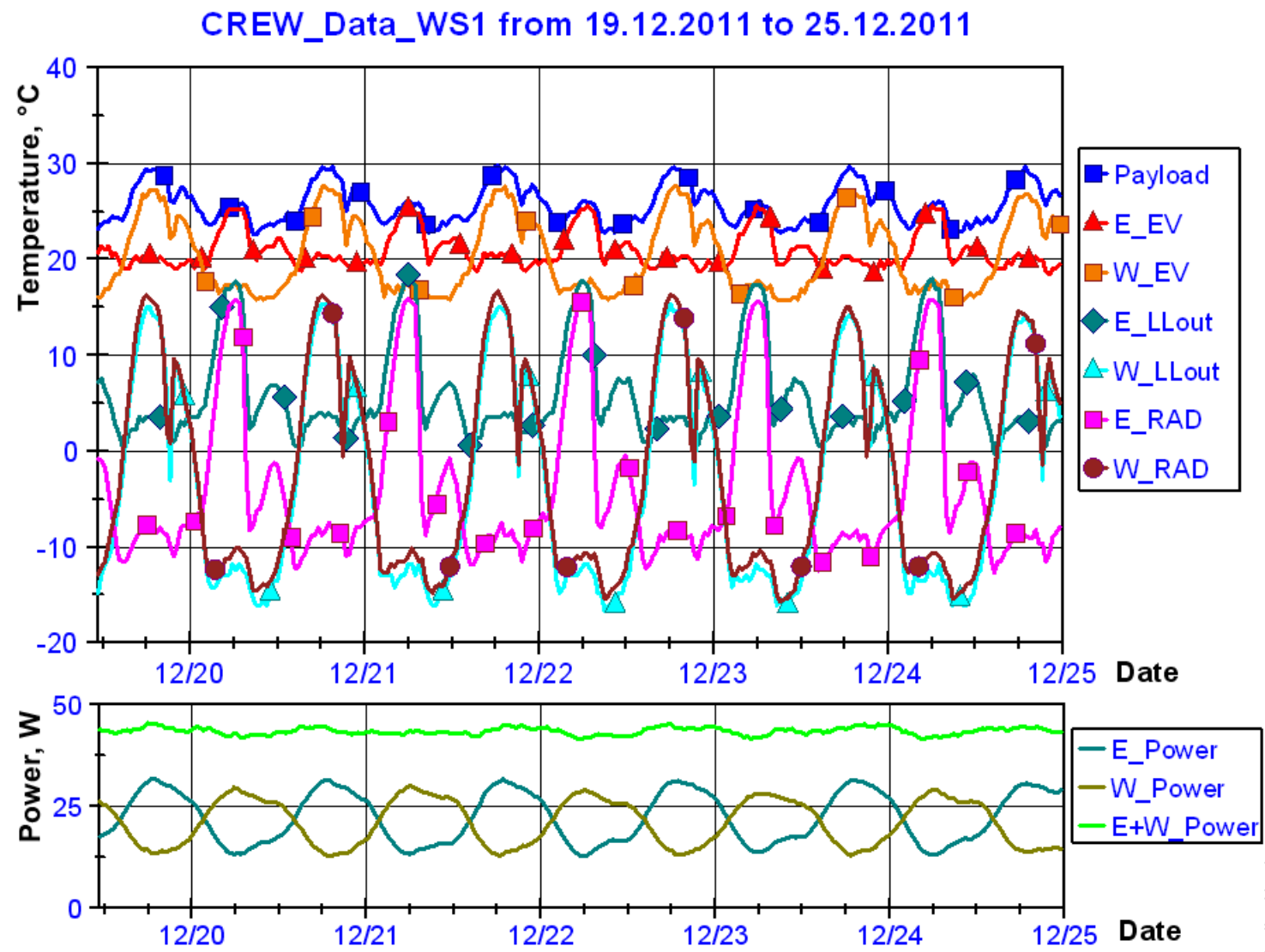

Figure 6.15. Demonstrator temperature, December 2011 (First winter solstice). 


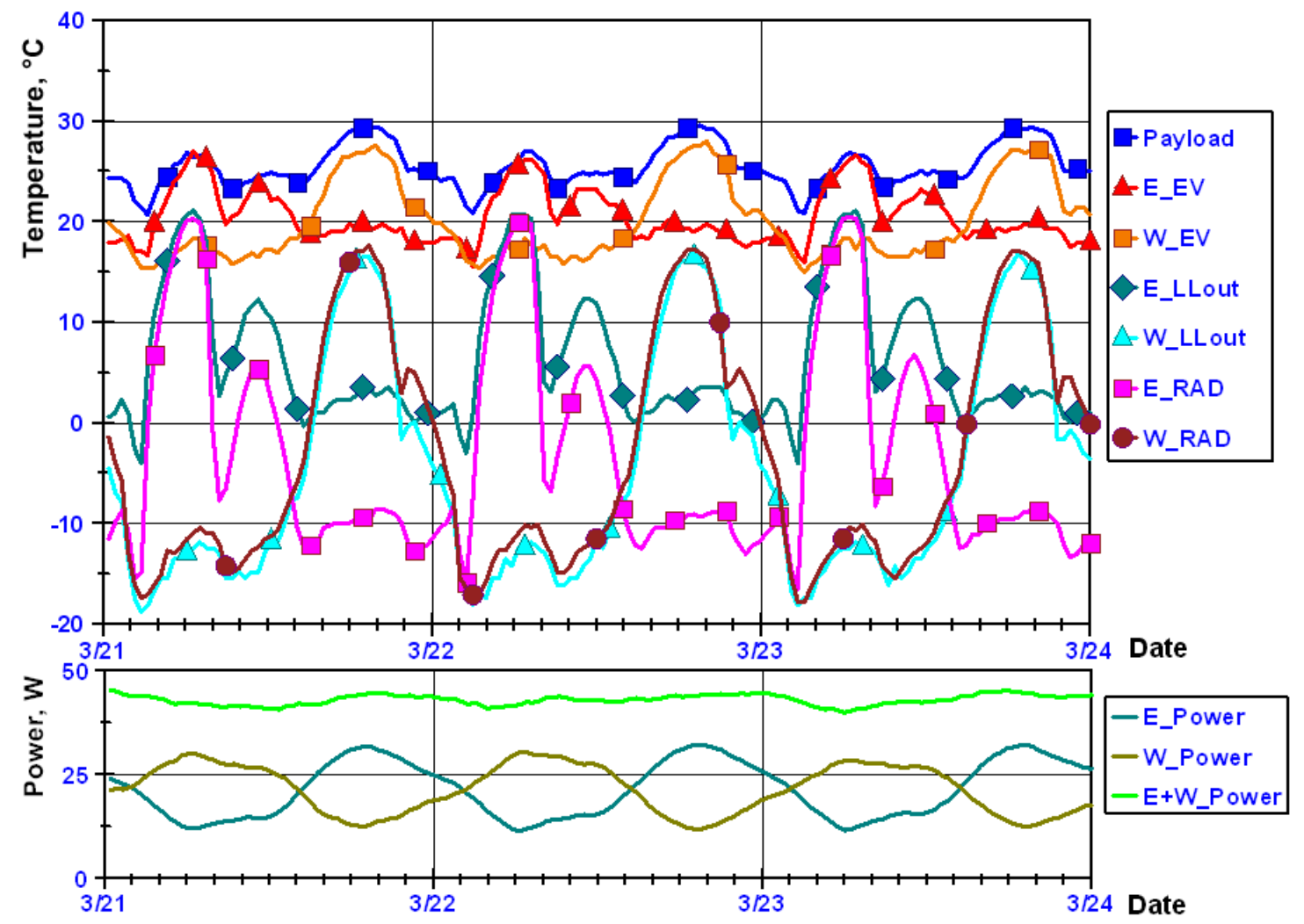

Figure 6.16. Demonstrator temperature, March 2012 (Spring equinox).

The system performance for the second winter solstice season is presented in Fig. 6. 17. Due to the increase of internal satellite environmental temperature, the west LHP operated according to the scenario III while the east one continued to operate according to the scenario II. Under this condition, the shared power between LHPs was no longer symmetric. The east LHP was taking most of the power (the east evaporator colder than the west). The west LHP operated under a reduced power of $10 \mathrm{~W}$. The temperature of the west LHP evaporator was controlled by the PRV set-point at $30^{\circ} \mathrm{C}$. The stabilization achieved was within $32 \pm 1^{\circ} \mathrm{C}$ for most of the orbit, except for a duration of 2 hours corresponding to maximum solar heat input on the east radiator. 


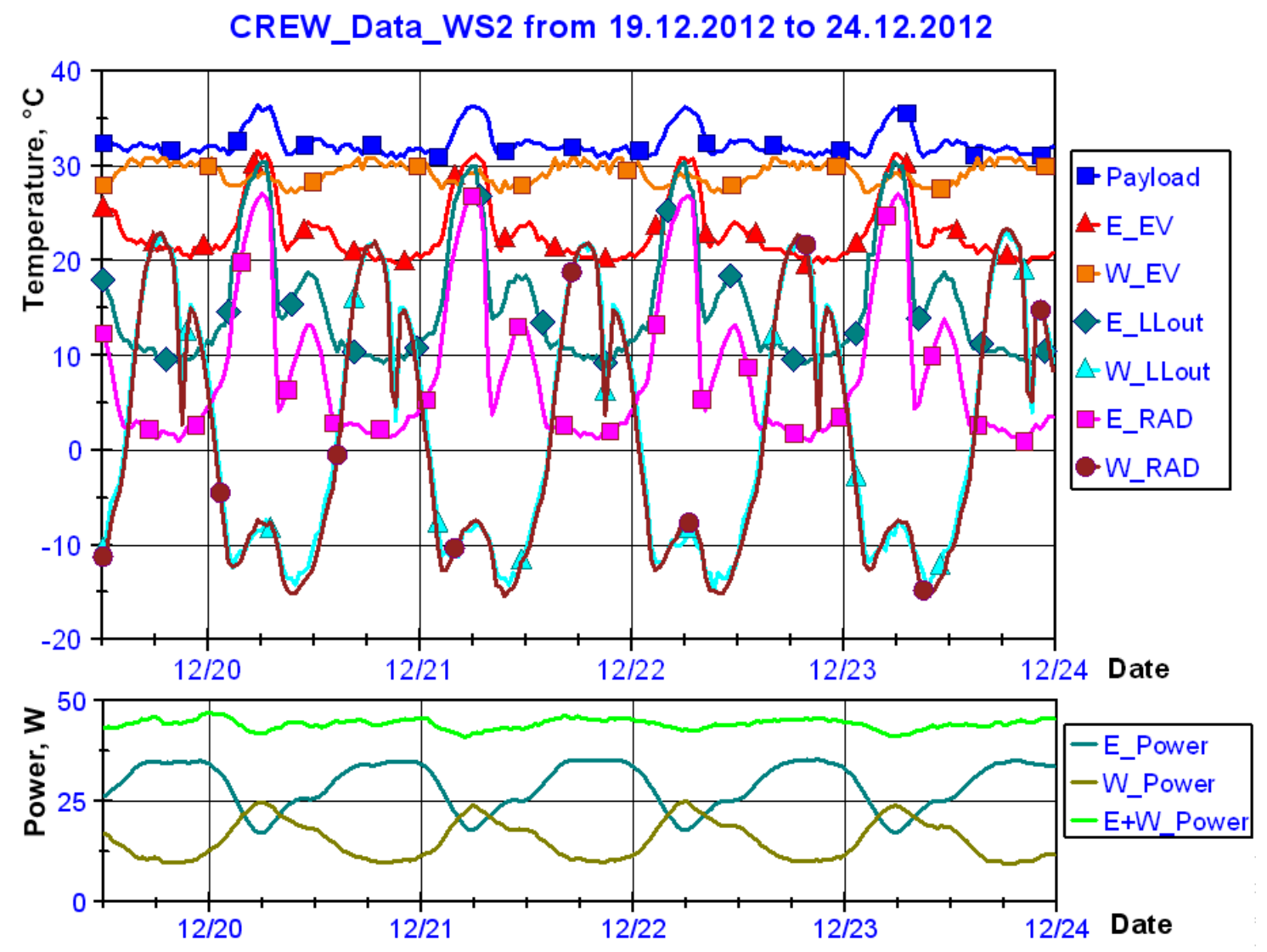

Figure 6.17. Demonstrator temperature, December 2012 (Second winter solstice).

The flight data were compared against the results of the mathematical model. The data from the winter solstice and spring equinox were used for comparison. The results for December 19 ${ }^{\text {th }}, 2011$ and 2012 during the winter solstice are presented in Fig. 6. 18. The model predictions were very satisfactory for all the system components and the results were within $4^{\circ} \mathrm{C}$. More importantly, there was no significant time delay between the data and predictions. 


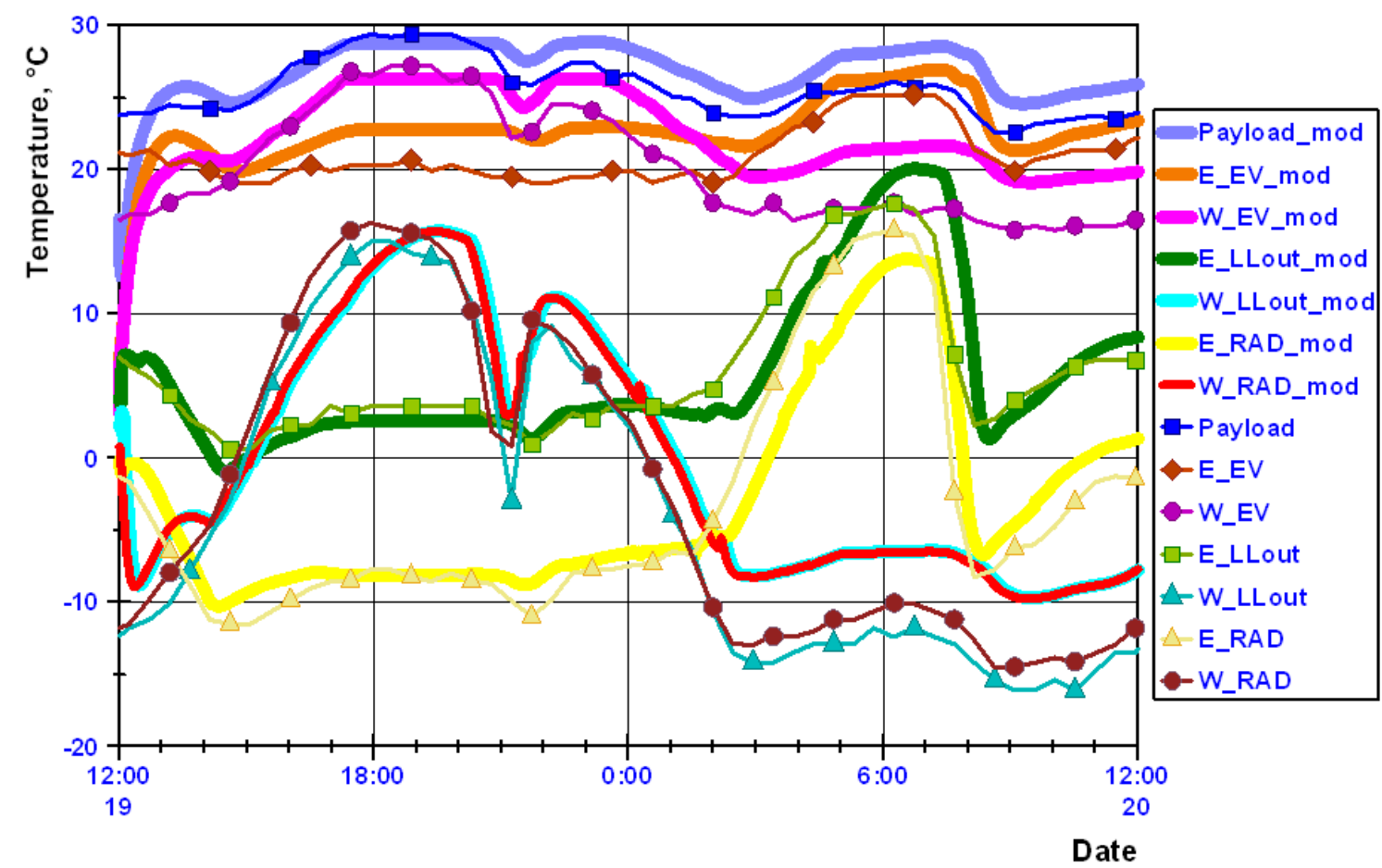

CREW_Data_WS2 24 hours from 19.12.2012

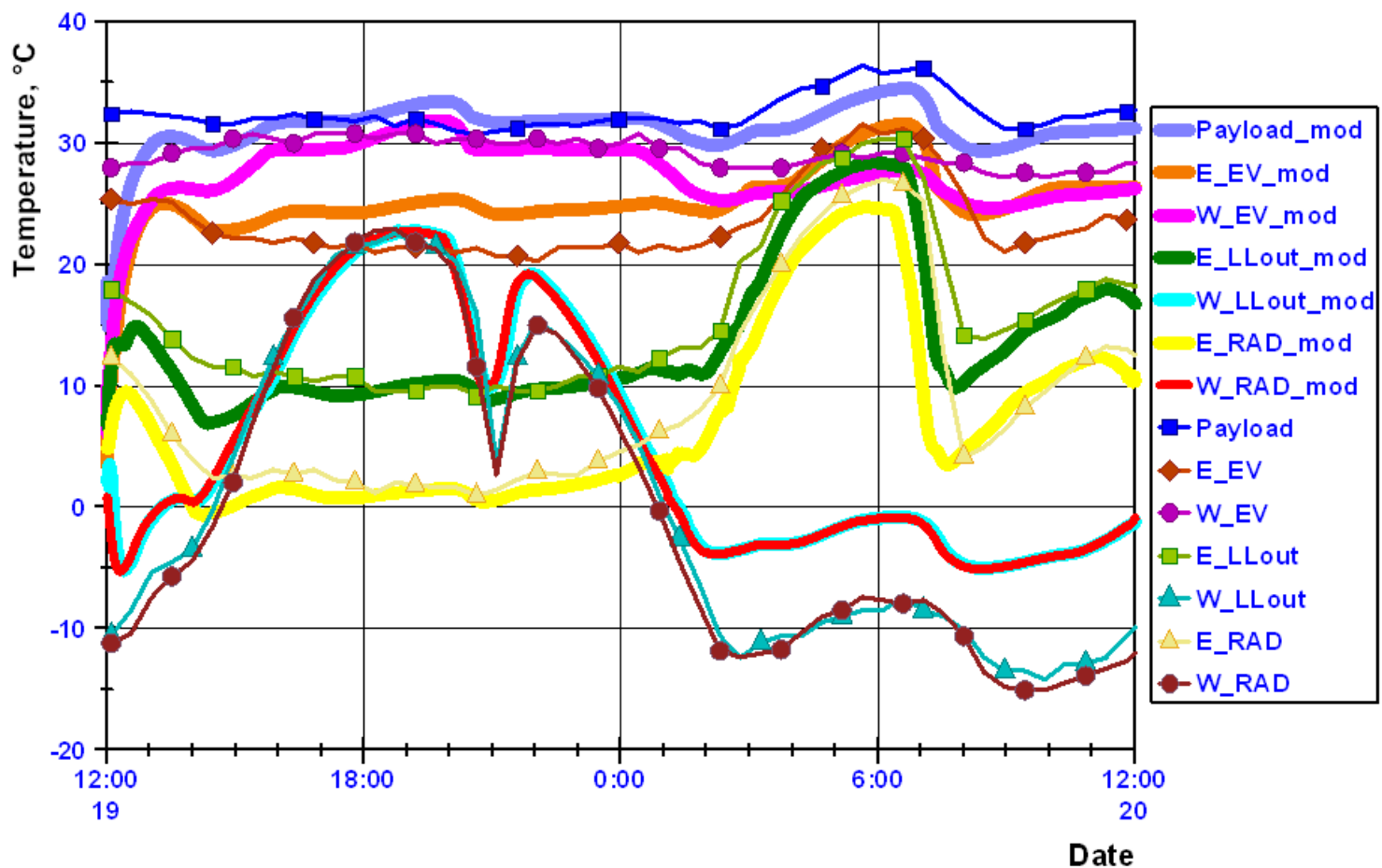

Figure 6.18. Mathematical model and flight data comparison for winter solstice 2011 and 2012. 
A similar conclusion can be drawn for the data and model comparison during the spring equinox presented in Fig. 6. 19. The general trend was captured very well in spite of the complexity of the overall system. These results successfully validated the mathematical model and give us great confidence to use the mathematical model for more complex architectures such as connecting all the possible radiator panels in a spacecraft through a set of LHPs.

CREW_Data_EQS 24 hours from 21.03.2012

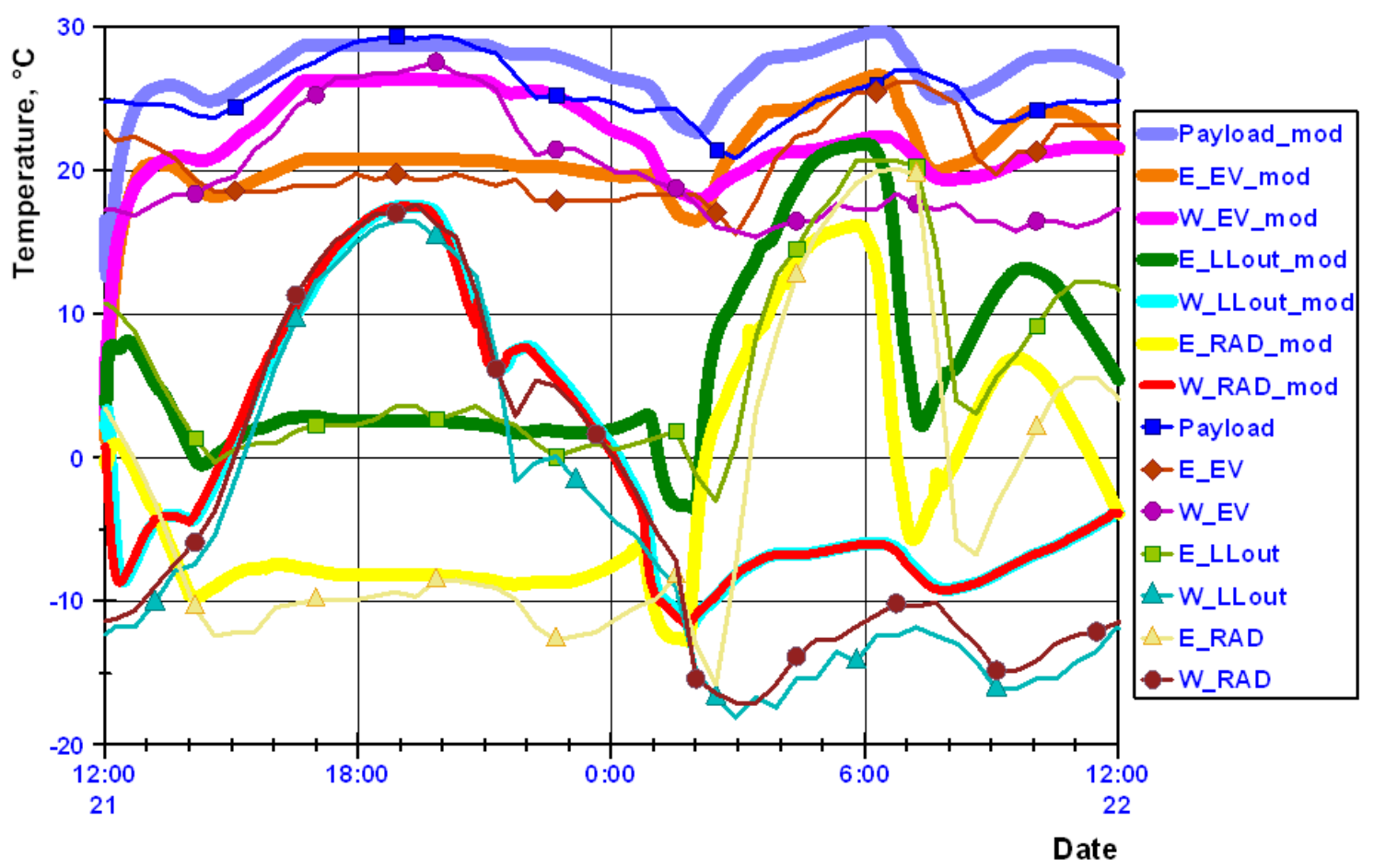

Figure 6.19. Mathematical model and flight data comparison for spring equinox 2012.

\subsection{Conclusions}

A novel thermal architecture connecting the east and west geostationary satellite radiators have been developed and qualified in orbit. The reported architecture allows maximizing the heat rejection capability of the spacecraft and 
optimizing both the needed radiator area and equipment arrangement, and performance.

The flight data collected during the nearly three years of the demonstrator operation on board telecommunication satellite Hispasat 1E were analyzed and the most typical data sets were presented. The data provided proved the successful inorbit operation of the novel architecture. The remarkable robustness of the system has been demonstrated in space in spite of strong environmental changes at the radiator and satellite levels. The autonomy of the system without a need of ground command provides an important advantage during satellite control operations.

A transient numerical model specifically developed for this system was also validated. The model predictions and flight data compared very well within $4{ }^{\circ} \mathrm{C}$ and no significant time delay in the simulated results was observed. More advanced and complex architectures for satellite thermal control can be analyzed and designed using the presented mathematical model.

\section{References}

[6.1] J. Romera, J.L. Pastor, J. Alvarez, J.M. Boix, A. Torres, Coupled radiator east-west experiment flight data, Portland, Oregon, International Conference on Environmental Systems, Paper No. AIAA 2011-5164, 2011.

[6.2] V. Lapshin, Y. Shevchenko, K. Goncharov, G. Noskin, O. Surguchev, A. Elchin, Continuous operating experience of nickel-hydrogen storage batteries 18nh-100 with independent thermal control system using heat pipes within 
spacecraft Yamal-200, Minsk, Belarus, VIII International Seminar Heat Pipes, Heat Pumps, Refrigerators, Power Sources, 2011.

[6.3] H. Tsunemi, H. Tomida, H. Katayama, M. Kimura, A. Daikyuji, K. Miyaguchi, K. Maeda, In Orbit performance of the MAXISSC on-board the ISS, PASJ Publ. Astron. Soc. Japan 62, 1371-1379, 2010.

[6.4] C. Baker, D. Butler, E. Grob, P. Jester, Geoscience Laser Altimetry System (GLAS) loop heat pipe anomaly and on orbit testing, Portland, Oregon, International Conference on Environmental Systems, Paper No AIAA-2011-5209, 2011.

[6.5] T. Hoang, W. Armiger, R. Baldauff, B. Nguyen, D. Mahony, W. Robinson, Performance of COMMx loop heat pipe on TacSat 4 spacecraft, San Diego, California, International Conference on Environmental Systems, AIAA-2012-3498, 2012.

[6.6] F. Mena, C. Ricolleau, In orbit heritage of LHP on Eurostar 3000, Noordwijk, Holland, International Two-Phase Thermal Control Technology Workshop, 2008. [6.7] D. Wolf, F. Mena, INMARSAT-4 loop heat pipe performance update, Noordwijk, Holland, International Two-Phase Thermal Control Technology Workshop, 2008.

[6.8] A. Okamoto, H. Kawasaki, T. Yabe, H. Ishikawa, T. Nomura, Y. Saito, Onorbit experiment of loop heat pipe on board Kiku-8, International Conference Heat Pipes for Space Applications, Moscow, 2009.

[6.9] A. Torres, D. Mishkinis, A. Kulakov, F. Romera, C. Gregori, T. Kaya, Thermal control of loop heat pipe with pressure regulating valve, Heat Pipe Science and Technology Journal 1-4 (2010) 329-357. 
[6.10] T. Kaya, R. Perez, C. Gregori, A. Torres, Numerical simulation of transient operation of loop heat pipes, Applied Thermal Engineering 28 (2008) 967-974.

[6.11] A. Torres, D. Mishkinis, T. Kaya, Mathematical modeling of a new satellite thermal architecture system connecting the east and west radiator panels and flight performance prediction, Applied Thermal Engineering, Vol. 65, pp. 623-632, 2014. doi: 10.1016/j.applthermaleng. 2013.11.040. 


\title{
Chapter 7
}

\section{LHP as strategic thermal control element for space and planetary missions}

(Manuscript submitted to 29th International Symposium on Space Technology and Science (ISTS), Nagoya, Japan, June 2013).

\begin{abstract}
Most of the components and subsystems of a spacecraft must operate in restricted temperature ranges. This makes thermal control a key matter in the design and operation of a spacecraft with a significant mass, power and cost impact in the overall spacecraft budget.
\end{abstract}

Spacecraft thermal control relies on the global spacecraft thermal balance: the heat loads must be rejected to deep space acting as thermal sink via thermal radiation through dedicated radiators installed on the satellite external surfaces. Large satellites must reject important heat loads through external radiators. The available area for these radiators is limited mainly due to restrictions on the launcher's dynamic envelope. Most of the dissipative equipment is installed on the available radiators, so the density of equipment, and therefore power dissipation is increasing importantly. The paper first presents a review of current thermal architectures to provide design solutions to challenging thermal requirements of 
current spacecraft. Then, an innovative thermal architectures is introduced, which connects north-south-east-west radiators by using a set of loop heat pipes and pressure regulator valves. A numerical model is presented and the results for two typical orbit scenarios are verified using data obtained from an engineering model on the ground. The presented mathematical model provides satisfactory temperature predictions, less than $4^{\circ} \mathrm{C}$. The payload temperature stability at relatively high powers, i.e. $1500 \mathrm{~W}$ and at varying radiator temperatures is demonstrated.

Key Words: Spacecraft thermal control, loop heat pipe, thermal architecture 


\section{Nomenclature}

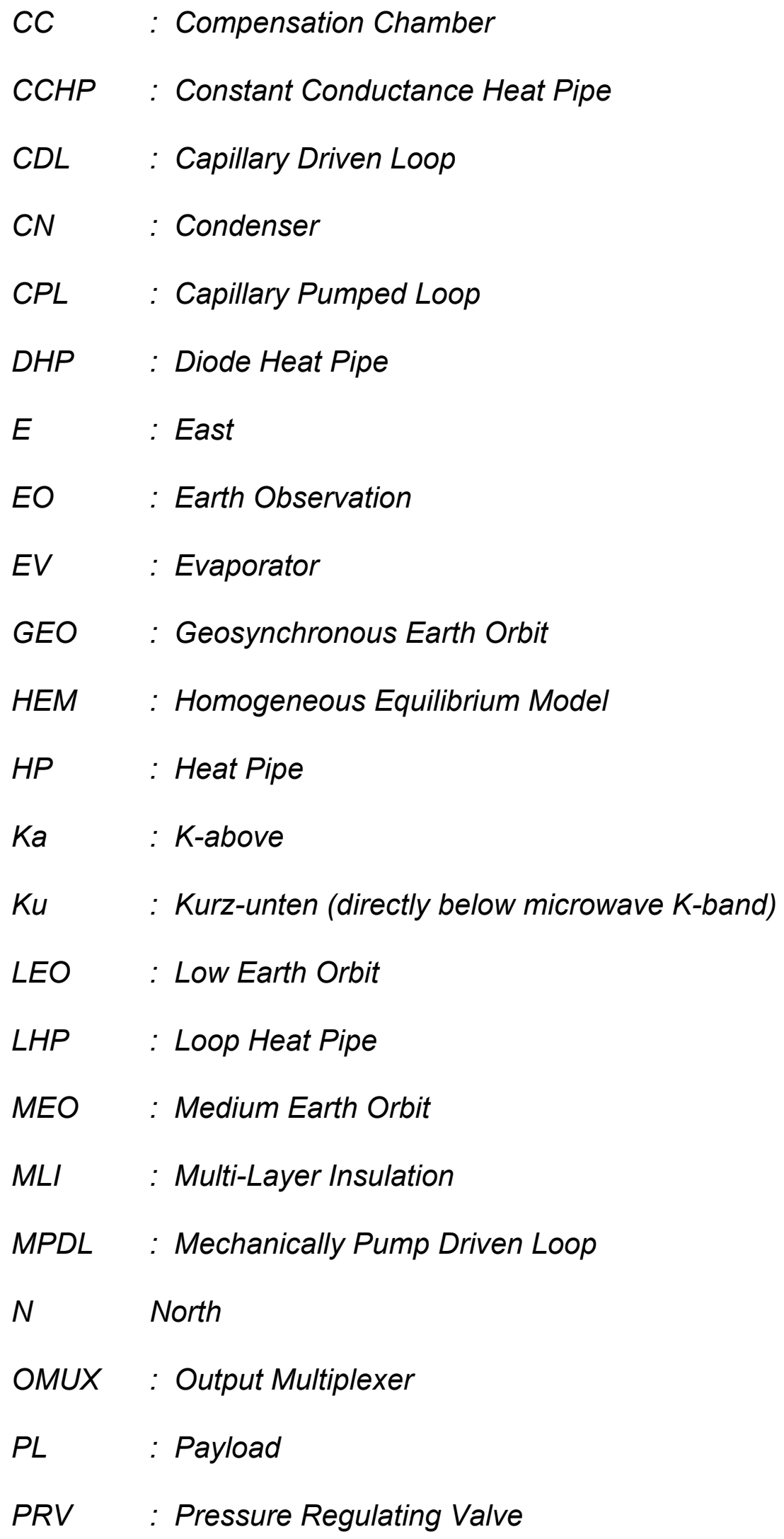


$S$

: South

SMTP : Spacecraft Modular Thermal Platform

TPL : Two-Phase Loop

VCHP : Variable Conductance Heat Pipe

W : West 


\subsection{Introduction}

The ever-increasing level of power, integration and complexity induced by new technologies characterizes the natural evolution of on-board equipment, antennas and sub-systems. Traditional thermal control techniques are reaching the limit of their potential. To accept the future challenges in terms of performance and reliability, new architectures based on high performance heat transfer devices must be developed. The integration of such technologies within equipment, antennas or sub-systems could provide very efficient solutions for the next generation of products.

To overcome these challenges, the two-phase heat transport systems present a significantly powerful potential technology.

The available technologies and classification associated to two-phase heat transport systems are presented in Figure 7.1.

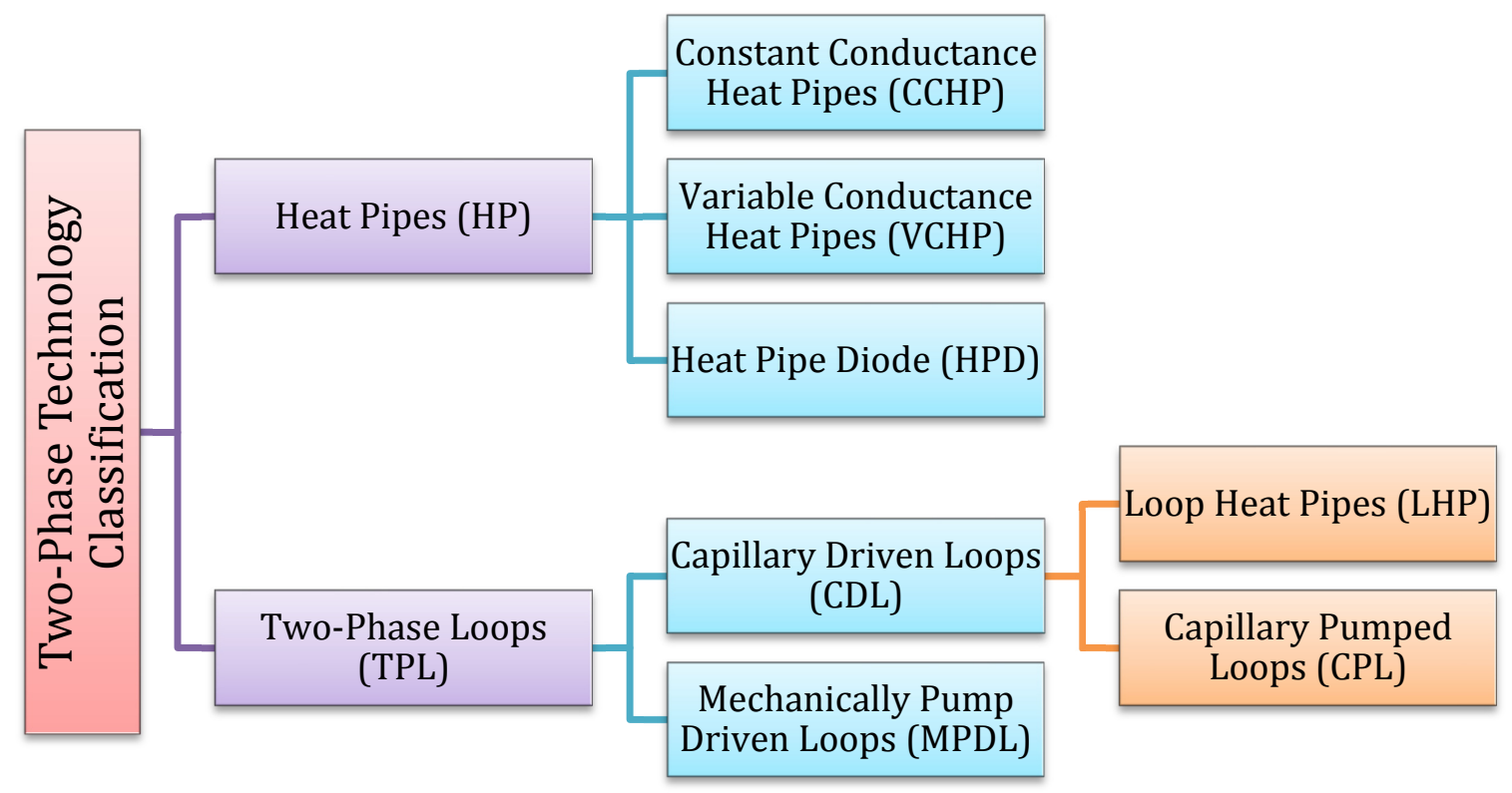

Figure 7.1. Two-Phase technology classification 


\subsection{Thermal Control Technologies Survey.}

Besides the ability to easily dump the effects of the harsh environment on the design temperatures of the electronics, the thermal designer faces other challenging issues, having its origin in the telecommunication satellites and it is mainly due to two reasons. On one side, to increase the number of transponders per satellite to make more profitable each satellite for the telecommunication operators. On the other side, the incorporation of new type of antennas (highly dissipative), such $\mathrm{Ka}$ and $\mathrm{Ku}$ bands, to response to the new telecommunication market demands such High Definition TV

Since the satellite volumes are still restricted to the launchers firing envelops and the available north-south radiators area in the telecom satellites limited, the result is: equipment concentration and high power densities.

This new situation has originated the necessity to improve the heat rejection capability of this type of satellites. There are two mains areas where the specialists are working. One is to raise the radiator temperatures, so that the amount of power to be rejected via radiation increases. The second is to provide new architectures combining new thermal control devices (LHP, CPL, VCLHP) to transport the dissipated heat to radiators far from the source or areas of the satellite that have not been traditionally used because of its very changing external environment, this is, east-west panels. Additionally, these devices have proved the ability to be flexible enough to allow radiator deployment. 
Although rising the temperature is, from the thermal management point of view, the easiest to be implemented it turns to be the most difficult to be realized today, for the vast majority of on-board electronics. The main reason is the materials of the electronics and the derating issues (failure rates at large thermal cycling). New components, based on Gallium Nitrate technology, are now under space qualification process, but it will take time to have all the required electronics running at temperatures close to $100^{\circ} \mathrm{C} \div 150^{\circ} \mathrm{C}$. The technology associated to this type of solution is beyond the scope of this paper and it is not further investigated.

Regarding the second approach (new architectures), a review of existing thermal control system technologies and patents is provided hereafter.

\subsubsection{Thermal Architectures}

Among the interesting advanced thermal architectures, a heat-pipe based thermal control system has been proposed in [7.1]. The purpose of the Thermal Canister Experiment carried by the Space Shuttle STS-3 flight was to determine the ability of a device using controllable heat pipes to maintain simulated instruments at selected temperature levels, in zero gravity and under varying internal and external thermal loads. A total of 11 data points were achieved during the flight, including the control of canister walls, of instrument simulators and of temperatures in two different zones, as well as passive thermal control. The set point variation ranged from $5^{\circ} \mathrm{C}$ to $23^{\circ} \mathrm{C}$, with power changes of $165-325$ watts. Better fluid distribution in the heat pipes during zero-g operation showed improved performance over ground tests, and a temperature stability of $\pm 2^{\circ} \mathrm{C}$ was 
demonstrated between orbiter maneuvers in which the cargo bay was shadowed from the sun and those in which full solar exposure of the cargo bay existed.

Another thermal control system for a spacecraft minimizing the generation of vibration and inertia force by eliminating or minimizing rotation of a radiator was presented in [7.2]. The fluid system comprises a radiator panel, a control unit and selector valves. The heat generated inside the spacecraft is radiated into space by switching the selector valves without rotation of the radiator panel, so that generation of inertia force or vibration is prevented.

In 1998, Loral Space communication patented an increased satellite heat rejection system using a radiative surface, which was based on VCHP architecture [7.3]. The radiative surfaces were exposed to direct sunlight on an intermittent basis. The consequences of the direct solar exposure were a large increase in the radiator surface temperatures due to degradation of the absorptance value of the space radiator over the mission lifetime (15 years). This high temperature precludes utilization of these surfaces as radiators for continuously operating electronic equipment, which is normally constrained to a maximum mounting surface temperature of $55^{\circ} \mathrm{C}$. Therefore, these surfaces are only employed for equipment that can withstand high temperatures above $55^{\circ} \mathrm{C}$, or intermittently operated equipment, such as $(\mathrm{Ni} / \mathrm{H} 2)$ Batteries.

For a three-axis stabilized geosynchronous satellite in its orbit [7.3], four out of the six usual satellite surfaces is exposed to direct solar illumination on a 24-hour basis. Over a 24-hour orbital day, only north and south faces of the satellite escape 
direct solar illumination although even these faces are subject to $23.5^{\circ}$ incident angle for solar illumination in solstice, further limiting satellite thermal dissipation capacity. Therefore, with a right prismatic geometry, $67 \%$ of the satellite surface area is unavailable for electronic equipment, which operates continuously at $55^{\circ} \mathrm{C}$. This substantially limits high power capability of satellites and may lead to either multiple satellites for a single mission or larger body size satellites. Both of these solutions add cost. The patent in [7.3] provides two approaches for continuous utilization of these radiator surfaces.

- Connect the thermal load to a phase change material (PCM), which is in turn connected to an intermittently available radiative surface with variable conduction heat pipe (VCHP) or diode heat pipe (DHP).

- Connect the thermal load to two or more opposed intermittently available radiative surface (east/west or earth/anti-earth) with sets of thermal conductors such as VCHPs or diode heat pipes (DHPs) which will not conduct heat from a hot radiator to the internal equipment.

The system provides a thermal radiator mounted on a face of the satellite for discharging heat from a thermal load to deep space. A heat conductor extends between the thermal load and the thermal radiator. The system also includes thermal switches operable for connecting/disconnecting the thermal load to the thermal radiator for cooling/heating when the temperature of the thermal load is above/below a predetermined level. One way of accomplishing this process is the use of VCHP architecture with active temperature control. Heaters are installed on VCHP reservoirs filled by non-condensable gas. Computers govern the heater 
power as a function of radiator temperatures; and dedicated temperature sensors have to be installed in every radiator. Although this system is based on a passive thermal control device, the complexity of the system in terms of operation is relevant.

In [7.4], a thermal control system controlling spacecraft`s internal temperature by changing the reflectivity properties of the satellite walls.

A sandwich of two layers made of inner aluminized Mylar composes the system. The sandwich is installed on the satellite walls. In the external layer of the sandwich, thermal control flaps are manufactured. Each flap contains a looped wire to create a magnetic field. Underneath each flap, a permanent magnet is installed under the internal sandwich layer. Both magnetic fields are opposite. A current regulation device similar to a thermostat switch controls (i.e. on/off) the current running on the wire of the flap, and therefore generating a magnetic field.

When the satellite is exposed to direct solar radiation, the internal temperature of the spacecraft increases forcing the switch to close and allowing current to flow. This current causes the generation of a magnetic field opposite to the magnetic field generated by the permanent magnets. The repellent force created by the opposite magnetic fields causes the thermal control flaps to rise and exposing the aluminum surface of the internal sandwich layer.

The patent presented in [7.5] describes a scalable instrument thermal control arrangement. The arrangement comprises one or more active cryo-coolers 
mounted on the spacecraft far from the instrument location to reduce the impact of cooler-induced mechanical vibrations. The cold side of the cryo-cooler is thermally connected to the instrument focal planes or other assemblies requiring cryogenic cooling. The warm side is connected to the spacecraft radiator panels for waste heat removal. The cooling needs to maintain the required instrument focal plane temperatures can be controlled during the mission by on-board flight software.

Another attempt to develop advanced thermal control system was described in [7.6]. The objective was to provide a system to store heat generated by a battery to reduce the amplitude of a temperature excursion. A heat absorber is thermally coupled to the battery. The heat absorber consists of high heat capacity heat absorbing (HA) material. The HA material is selected to exhibit an endothermic phase change at specified temperature within a range about $50{ }^{\circ} \mathrm{C}$ to $80^{\circ} \mathrm{C}$. A proposed HA material is paraffin and is selected to have a melting point of about $75^{\circ} \mathrm{C}$, deposited into a fibrous containment mat preferably formed of dielectric fibers, such as Kevlar or fiberglass.

A spacecraft battery thermal management system was presented in [7.7] in which multiple radiator panels are thermally coupled to a battery using heat pipes. The heat pipes allowed the radiator panels to be located far from the battery and positioned on opposite sides of the spacecraft. When the sun illuminates one radiator panel, other radiator panel on the opposite side of the spacecraft dissipates excess heat from the battery. In this manner, the radiator panels can be positioned on the east and west facing sides of a spacecraft in a GEO orbit. One of main drawbacks of the system is that when the radiator is too cold the battery falls 
in temperature. To prevent this, compensation heaters are installed, and therefore satellite power consumption increases. Other important drawback is the limitation of the potential locations of the batteries within the satellite, since the length and number of bends of a heat pipe is limited.

In 2009, Astrium Ltd. patented a non-planar payload module structure, which was configured to support complete payload comprising sufficient closely packed mechanical/thermal modules [7.8]. This concept was developed to avoid the disadvantages of the standard concept for satellite payload configuration, which consisted of attaching the payload equipment on aluminum sandwich panels. A number of such panels make up an assembly called the Communications Module. Thermal dissipation is typically handled by a combination of locating the dissipative units on north and south facing radiator panels. The internal panels were thermally linked to the north and south facing radiators by heat pipes or pumped loops.

The LHP cooling system presented in [7.9] comprises LHP routed from internally facing surfaces of one or more internally located equipment panels to externally located radiator panels. Heat is collected at evaporator ends of each LHP and is transported to their respective condenser ends The LHP used in the cooling system have flexible transport lines, so that they can be routed to multiple radiator panels in order to optimize heat sharing between radiator panels. The total number of LHP used in the cooling system depends on the overall heat load. The system also comprises one or more fixed conductance heat pipes mounted to selected internally facing surfaces of the internally located equipment panels. The problem of this system is an impossibility to control the temperature of the 
equipment since LHP without a control mechanism will be subject to the sink temperature fluctuations.

In [7.10] the Satellite Modular Thermal Platform (SMTP), a standardized multiradiator LHP-based thermal architecture was proposed. The basic idea is to couple thermally one or several equipment via a thermal bus (by VCLHP) to several radiators to take the advantage at any time of the most favorable sink temperature for rejection. The system allows:

- Radiating areas far from heat sources (delocalization of the radiator).

- Efficient high thermal conductance linking of the dissipating element to the radiator.

- Accommodating the radiator anywhere.

- Common heat collectors at the dissipating units. 
A simplified comparison between the traditional and the SMTP concepts is presented in Table 7.1.

Table 7.1. Traditional concept vs. SMTP. [7.10]

\begin{tabular}{|l|l|}
\hline \multicolumn{1}{|c|}{ Traditional Concept } & \multicolumn{1}{|c|}{ SMTP concept } \\
surface of external panels with & Dissipative units mounted anywhere \\
radiators to minimize temperature & area \\
drops: limited mounting area & \\
\hline Radiator and electronics temperature & Dedicated radiators temperature \\
averaged: reduced rejection capability & bands. High, medium, low: maximized \\
\hline Electronic temperature requirements & rejection capability \\
mixed in a radiator: non optimal & Electronics grouped by temperature \\
electronic operation & requirements: optimized electronic \\
\hline Important heater budget (heater lines, & Radiators decoupling in cold cases. \\
control, and heaters) to survive cold & Important savings in heater budget \\
\hline
\end{tabular}


A general scheme of the complete SMTP system is presented in table 7.2

Table 7.2. General overview of the SMTP system. [7.10]

\begin{tabular}{|l|l|l|}
\hline \\
\hline 13
\end{tabular}

The main features of this concept are:

- Modularity.

- Scalability. 
- Self-regulation.

- Independence on satellite orientation.

- Autonomous operation.

- Passive and energy efficient. In fact, the power budget for thermal control system is reduced to zero or to minimum in case of a need for survival heaters to avoid freezing of the working fluid in the radiators.

- Possibility to manage high heat loads.

- Precision temperature control. It depends only on the PRV design and characteristics.

- Flexibility in electronic equipment arrangement inside the satellite. The LHP tubing lines have small diameters and it is very easy to make complex routing.

- Generality. The module of SMTP can be used for different space missions/orbits.

- Possibility to test satellite on ground at any orientation. The LHP can operate at any position in the gravity field in contrast to constant or variable conductance HP.

This approach provides large freedom in designing new spacecraft and significantly reduces time, expenses and resources required for spacecraft, manufacturing, integration and testing phases because standard, off-the-shelf, space qualified modular platforms will be used for the satellite onboard equipment arrangement and installation. 
As it can be seen the most promising thermal architectures, in a short term, are all based on loop heat pipes as the key device. An exhaustive description and historical development of such devices are provided by [7.11].

As a conclusion, during last decade a significant increase of the amount of patents, publications and applications dedicated to solve new thermal challenges for spacecraft applying two-phase technology and in particular LHPs is very significant. More important is that the types of missions having LHPs base-lined in their thermal subsystems designs have also experience an important demand. Very recent example of this extend is the thermal control system of the Mars rover under development at the European Space Agency. This thermal system is devoted to control the temperature levels of the RHU units at all mission phases implementing LHP with PRV. Other example combining both devices (LHP+PRV) can be found in the heat transport system of the Laser Communication Terminal (LCT) developed by Astrium TESAT. The system provides a high orbital stability to ensure laser pointing for communication purposes.

Larger thermal systems based on LHP at satellite level are found in the full electric propulsion satellites. During the transfer orbit from launcher delivery to nominal geostationary orbit, with typical durations of around 200 days, the main radiators (north and south) need to be covered so that the equipment temperatures stay within the temperature design range. The method to cover the main fixed radiators is realized by means of deployable radiators having LHP with flexible transport lines, folded against the main fixed radiators. Once the satellite reaches the geo nominal orbit, these deployable radiators are deployed, leaving the main 
fixed panels exposed to space. The deployed radiator system is then used to dump the heat of the high dissipative transponders. Boeing has been the first implementing this system in their full electric telecommunication satellite version. Other satellite manufacturers are following similar approach to resolve the transfer orbit duration in their satellites.

Other application gaining more interest within the satellite manufacturers is the use of deployable radiators, this time to increase the heat rejection capability of the satellite. Space Systems Loral/MDA is under the development of a new version of deployable radiator as part of their new $25 \mathrm{~kW}$ telecommunication platform.

\subsection{North, south, east and west radiators GEO satellite connection. An example.}

The following architecture provides the insight of a thermal system connecting north-south-east-west radiators in a typical GEO telecom satellite as an example of the SMTP implementation.

An overall view of the engineering model is presented in Figure. 7.2. 


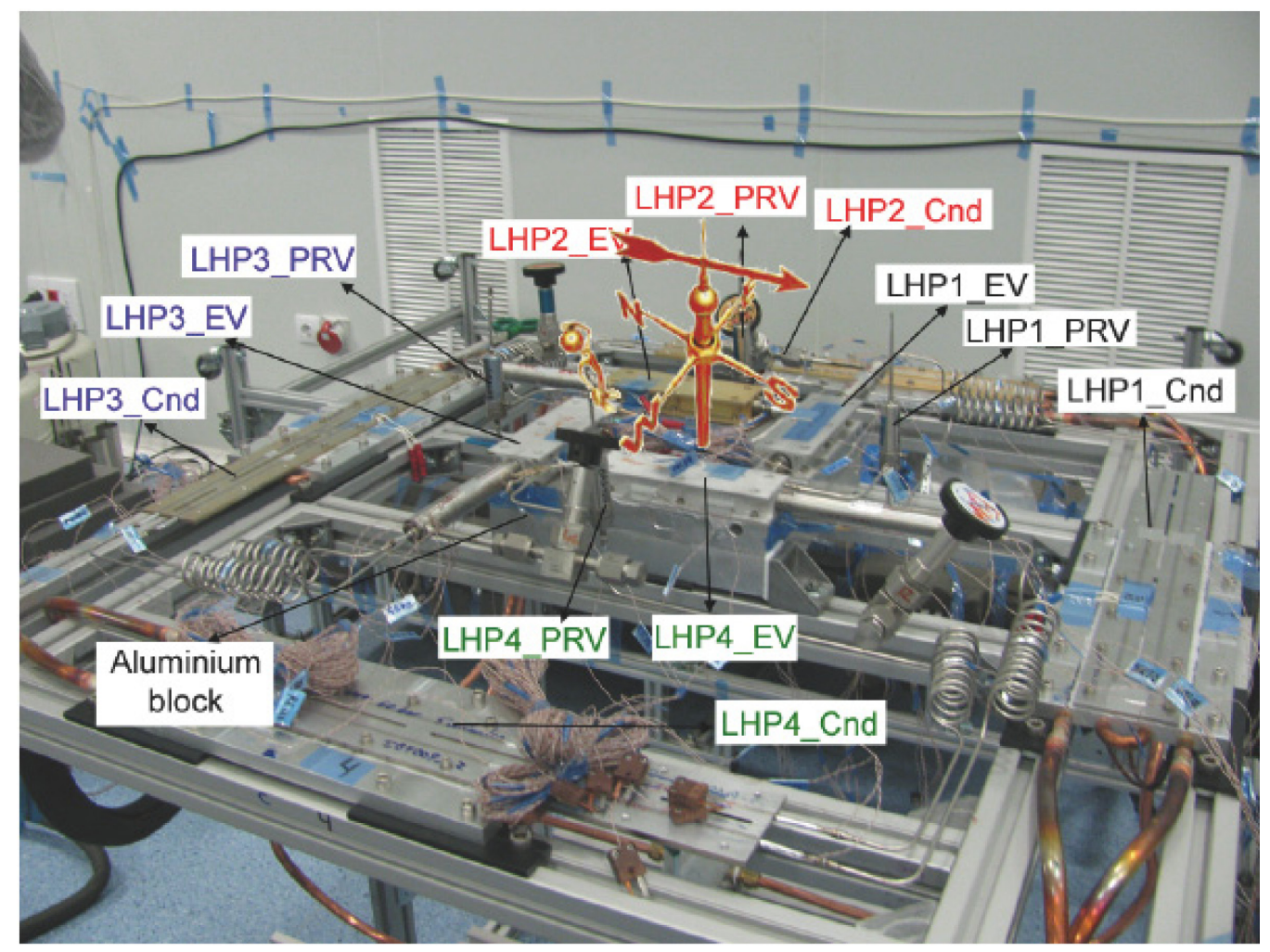

Figure 7.2. Engineering model general overview

The hardware is split into three main architecture blocks:

- Heat collection area: Composed by a set of axial grooved heat pipes (AGHP) of $12.5 \mathrm{~mm}$ diameter and $1 \mathrm{~m}$ length. The AGHPs are attached underneath an aluminum block to simulate a given amount of thermal inertia. The heat is applied to this aluminum block (not shown in Figure. 7.2).

- Heat transportation and regulation system: Composed of four LHPs, each one equipped with a PRV. All LHPs have identical evaporators. Transport lines (vapor and liquid) are also similar. The condenser of each LHP is a attached to the radiator, so that the type of condensation is indirect in the 
sense that heat goes through contact interfaces. A set of PRVs regulates the access to the radiators. All PRVs are two-way valves. Complete functioning description of the valves is reported in [7.12].

- Heat rejection area: Four cold plates (simulating radiators for test purposes in ambient conditions) to reject the heat. Each plate is connected to a different chiller to be able to program different sink temperature profiles independent to each other. For vacuum tests, the radiators will be attached to condensers.

Evaporators are bolted to an aluminum block of $15 \mathrm{~kg}$ to simulate on-board electronic payload box. Cartridge heaters are embedded into the aluminum block. Isolation hardware (Armaflex for ambient and MLI for vacuum) completes the system.

\subsubsection{Numerical model and simulation cases.}

A complete numerical model for simulation has been developed. EcosimPro software was used to build the complete model. The software provides the capability to model each component of the thermal system individually and in modular approach. The LHP building block is the one used for simulation of the flight demonstrator performance. The demonstrator connects east and west satellite dedicated radiators. This architecture was launched on-board Hispasat 1E in December 2010 to validate SMTP concept. The mathematical model has been correlated with the provided flight data [7.13]. 
For the last two years, the demonstrator is being continuously operating under $50 \mathrm{~W}$ power. Thermal environmental conditions of east and west radiators are significantly varying along the orbit. Under these conditions the systems demonstrate the ability to maintain the payload temperature almost constant. 3ure 7.2 shows daily average temperatures flight data of the coupled radiators east-west (CREW) system from launch in December 2010 till March 2013. Figure 7.4 provides an example of applied power sharing on the electronics between radiators in February 2013.

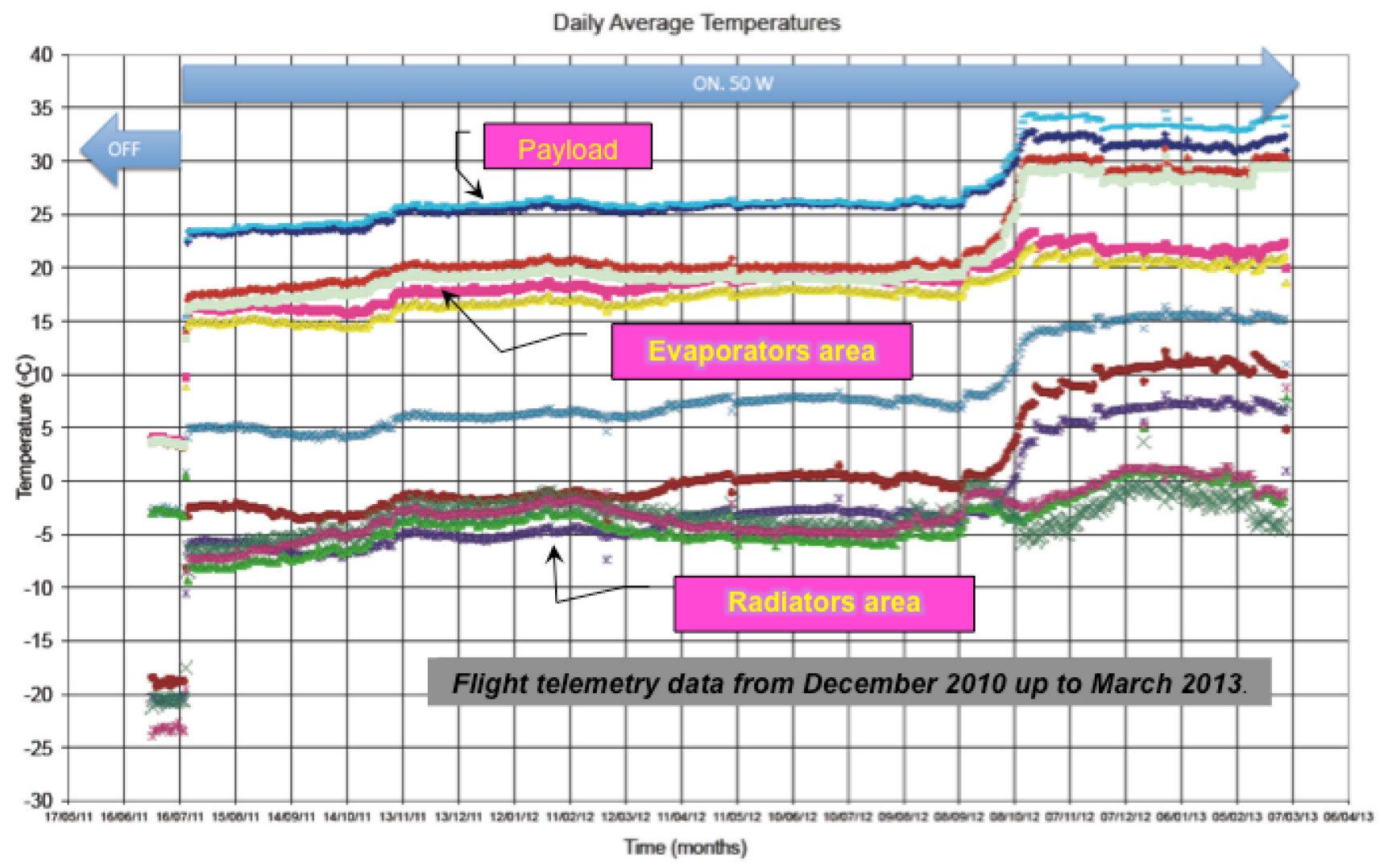

Figure 7.3. Daily average temperature flight data CREW 


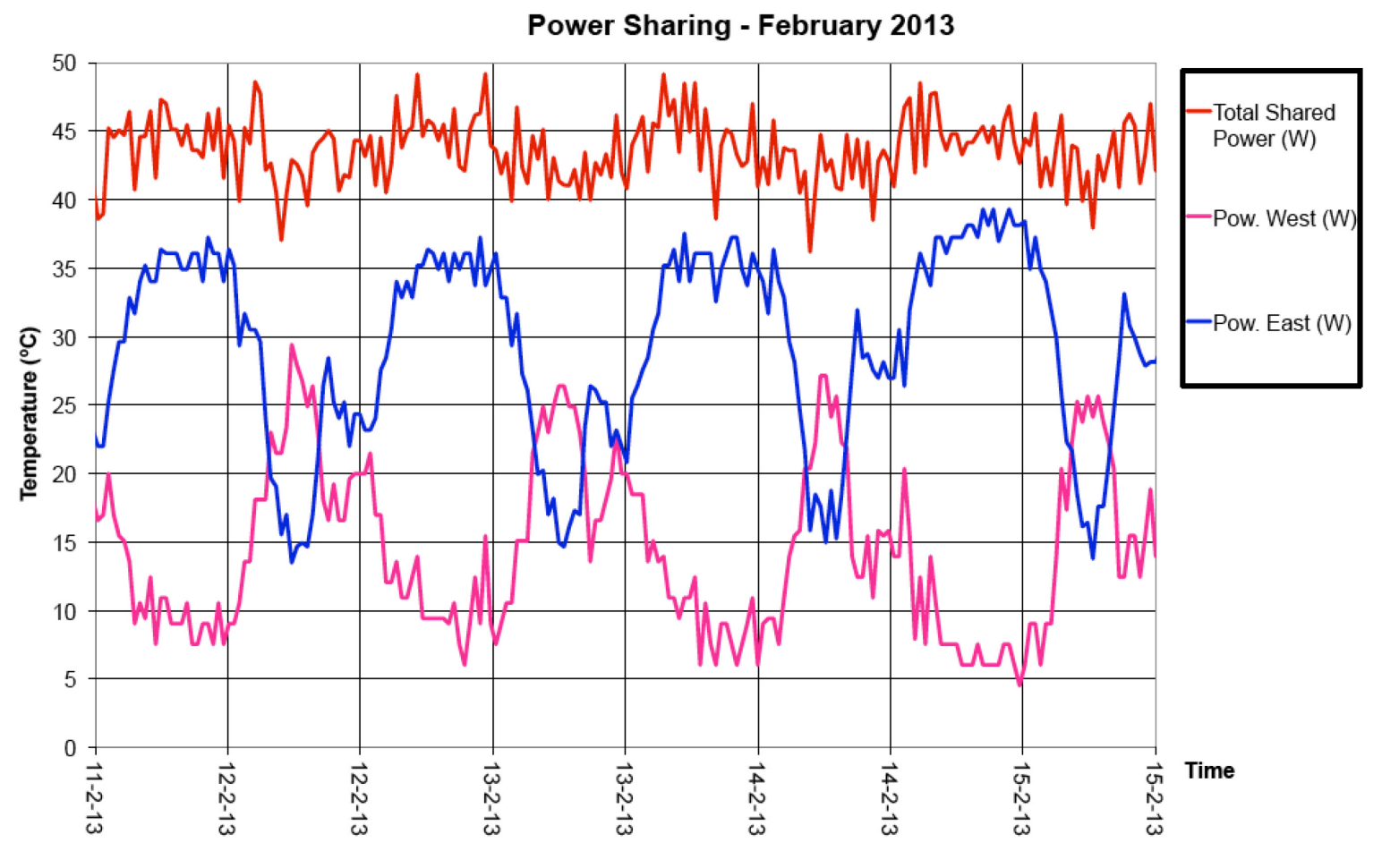

Figure 7.4. Power sharing flight data CREW. February 2013 
The EcosimPro schematic for the four radiator model is presented in Figure 7.5

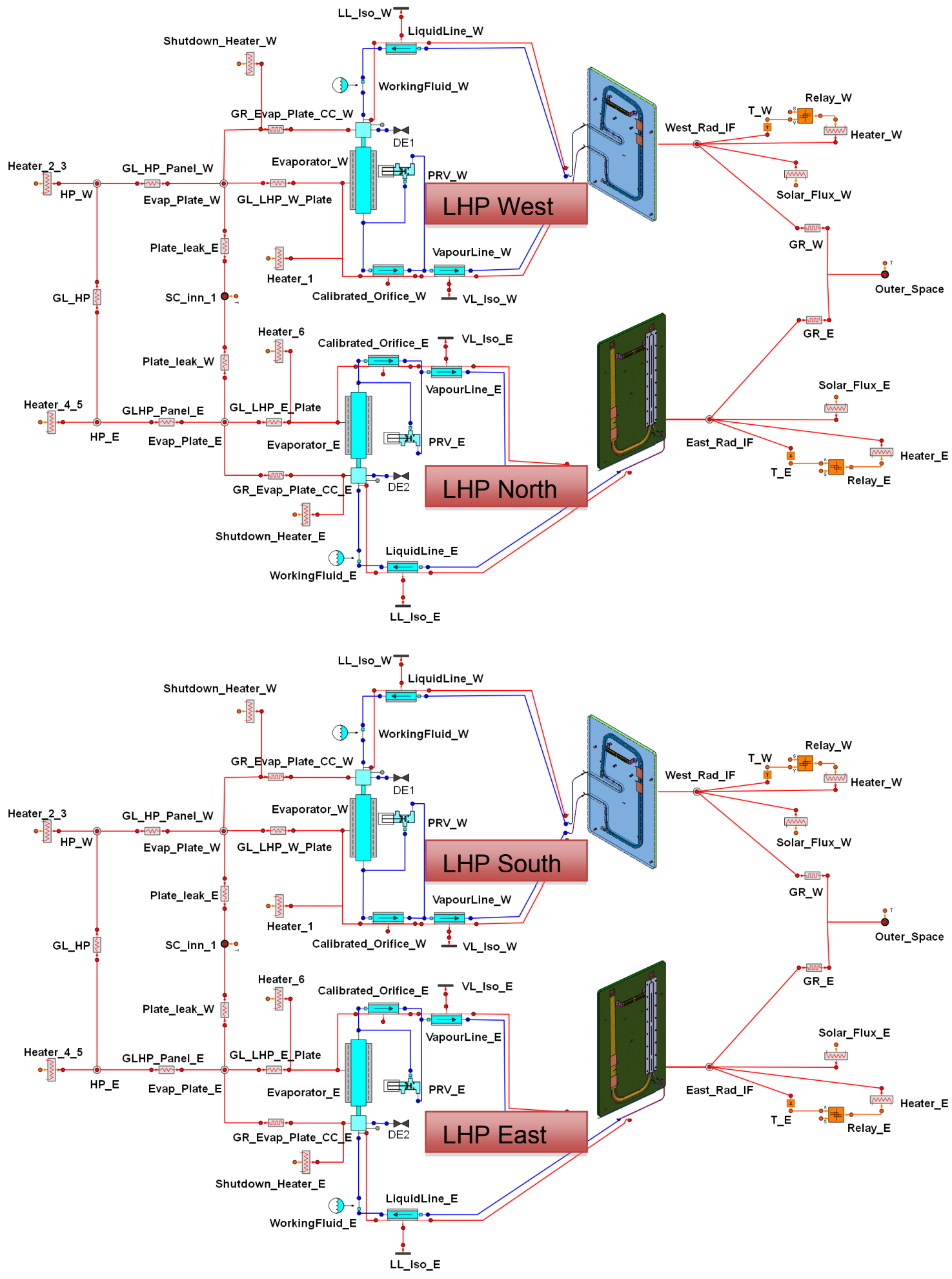


Figure 7.5. Numerical model connecting north-south-east-west radiators 
Table 7.3 presents the simulation cases carried out.

Table 7.3. Simulation cases definition

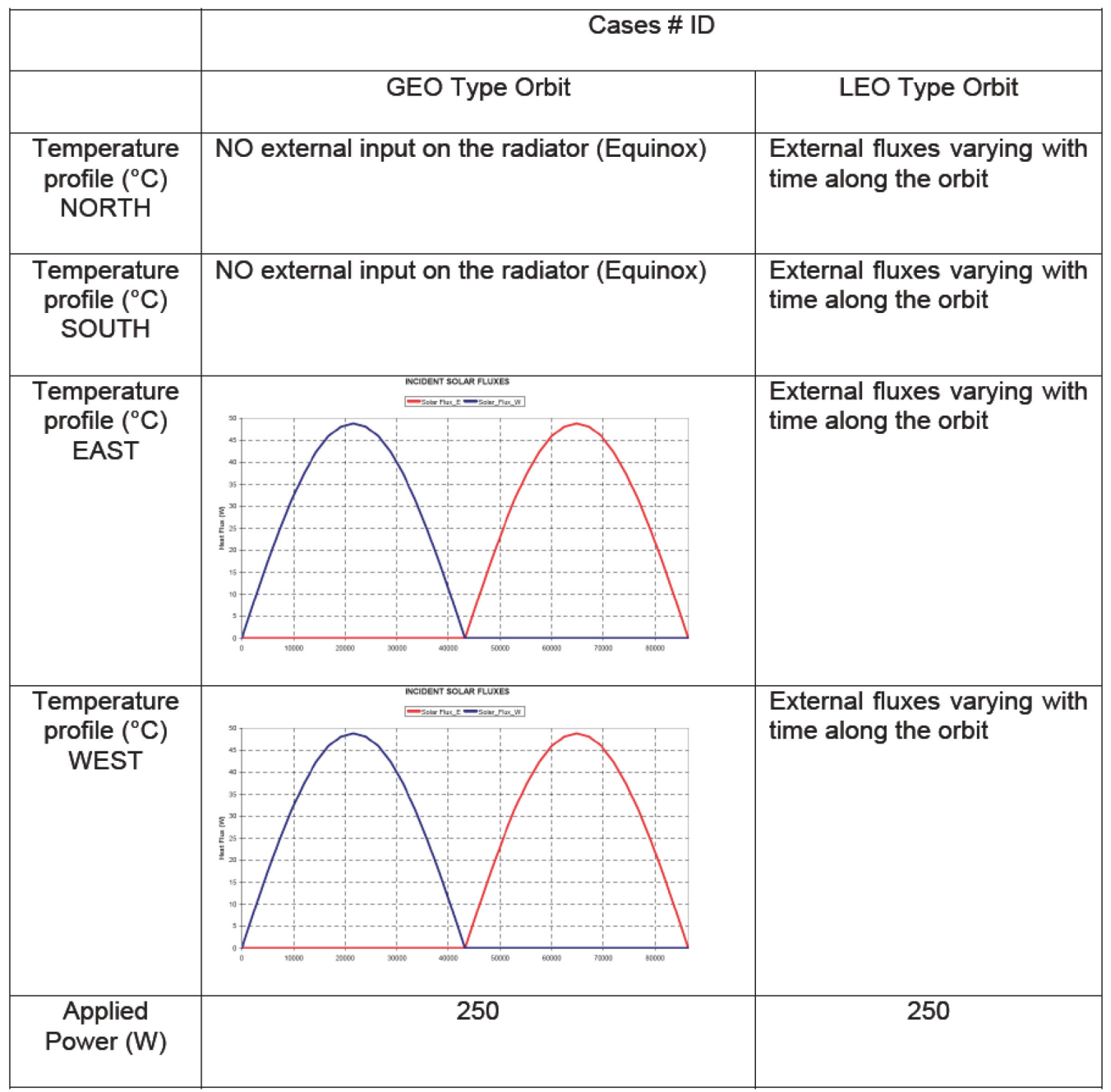

\subsubsection{Numerical Results}

Figure 7.6 shows the simulation of a GEO orbit for a power dissipation of 250 W in the electronics payload. Figure 7.7 provides the corresponding power sharing in the radiators as a consequence of the radiator environment. As it can be noticed, the north and south radiators without external heat input remain almost at constant temperature during the whole orbit. On contrary, east and west rejection capability 
fluctuate in a sine type shape due to the external inputs along the orbit. The payload temperature remains constant regardless the fluctuating behavior of the radiators.

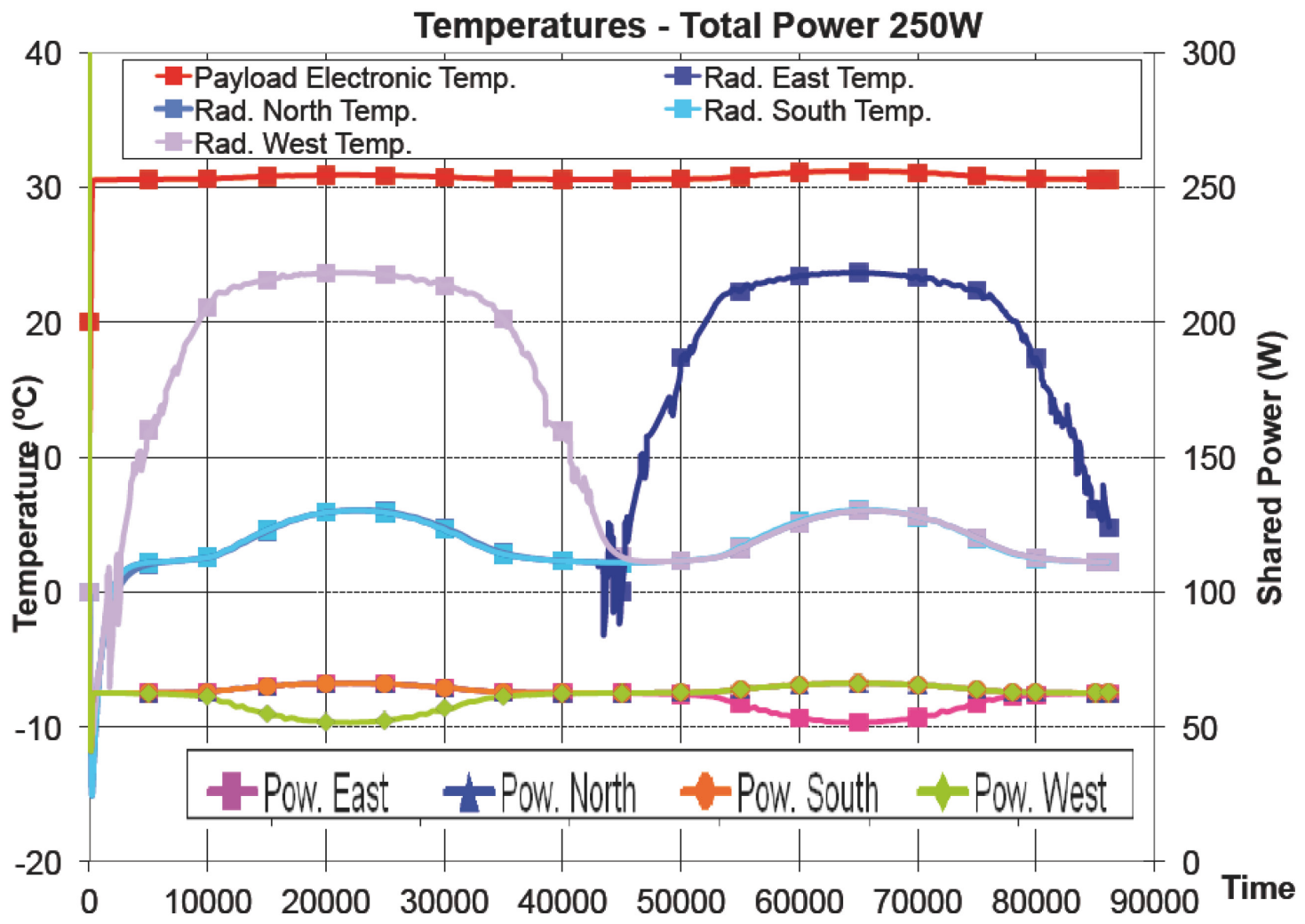

Figure 7.6. Temperature vs time for a GEO orbit 


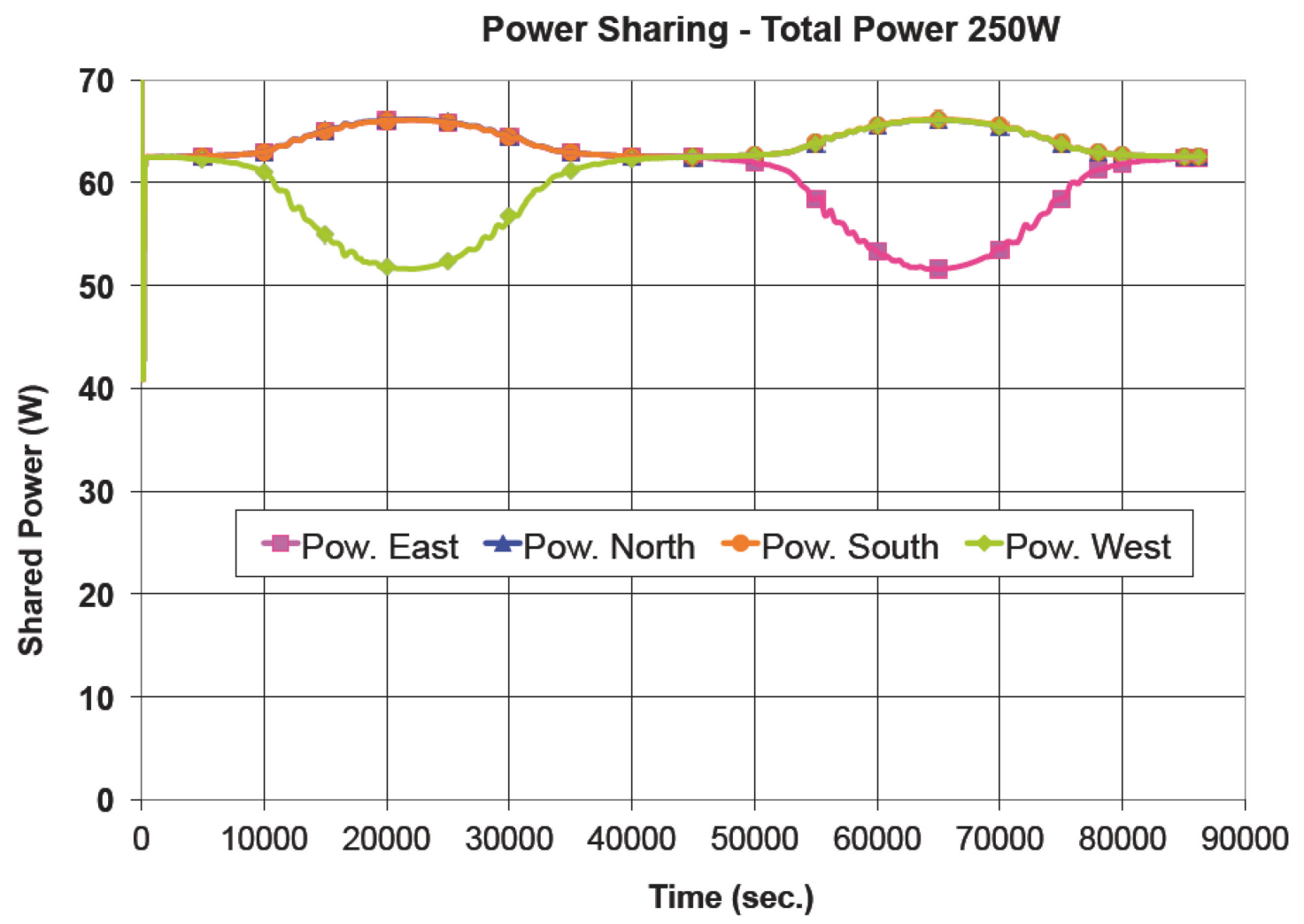

Figure 7.7. Power sharing vs. time for a GEO orbit

Figure 7.8 shows the simulation of a LEO orbit for a power dissipation of 250 $\mathrm{W}$ in the electronics payload. Figure 7.9 provides the corresponding power sharing in the radiators as a consequence of the radiator environment. In this case, thermal conditions for all thermal radiators are significantly varying along the orbit. Again under these conditions the temperature of the payload is constant and corresponding to the PRV set point $\left(30^{\circ} \mathrm{C}\right)$. 


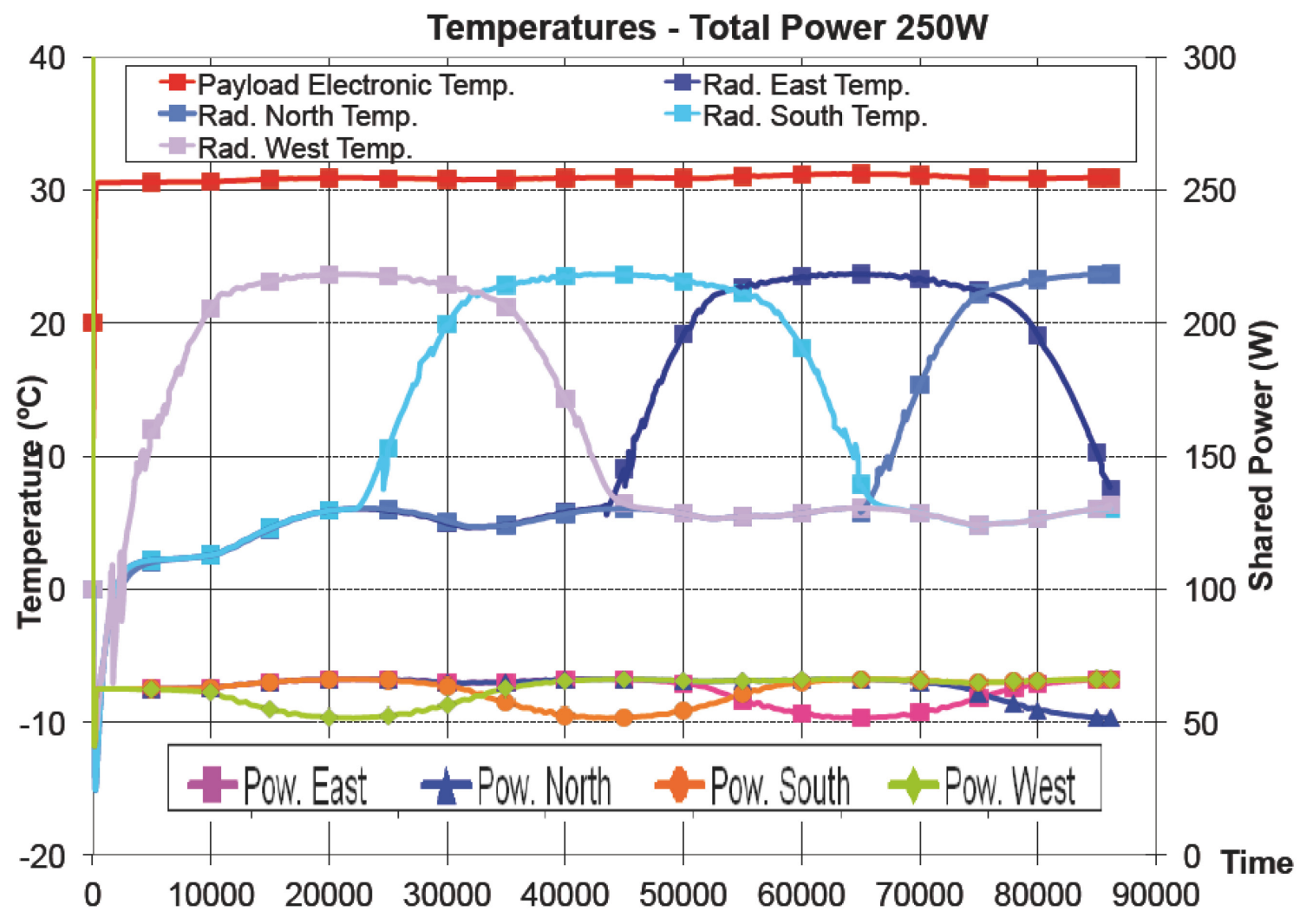

Figure 7.8. Temperature vs time for a LEO orbit 


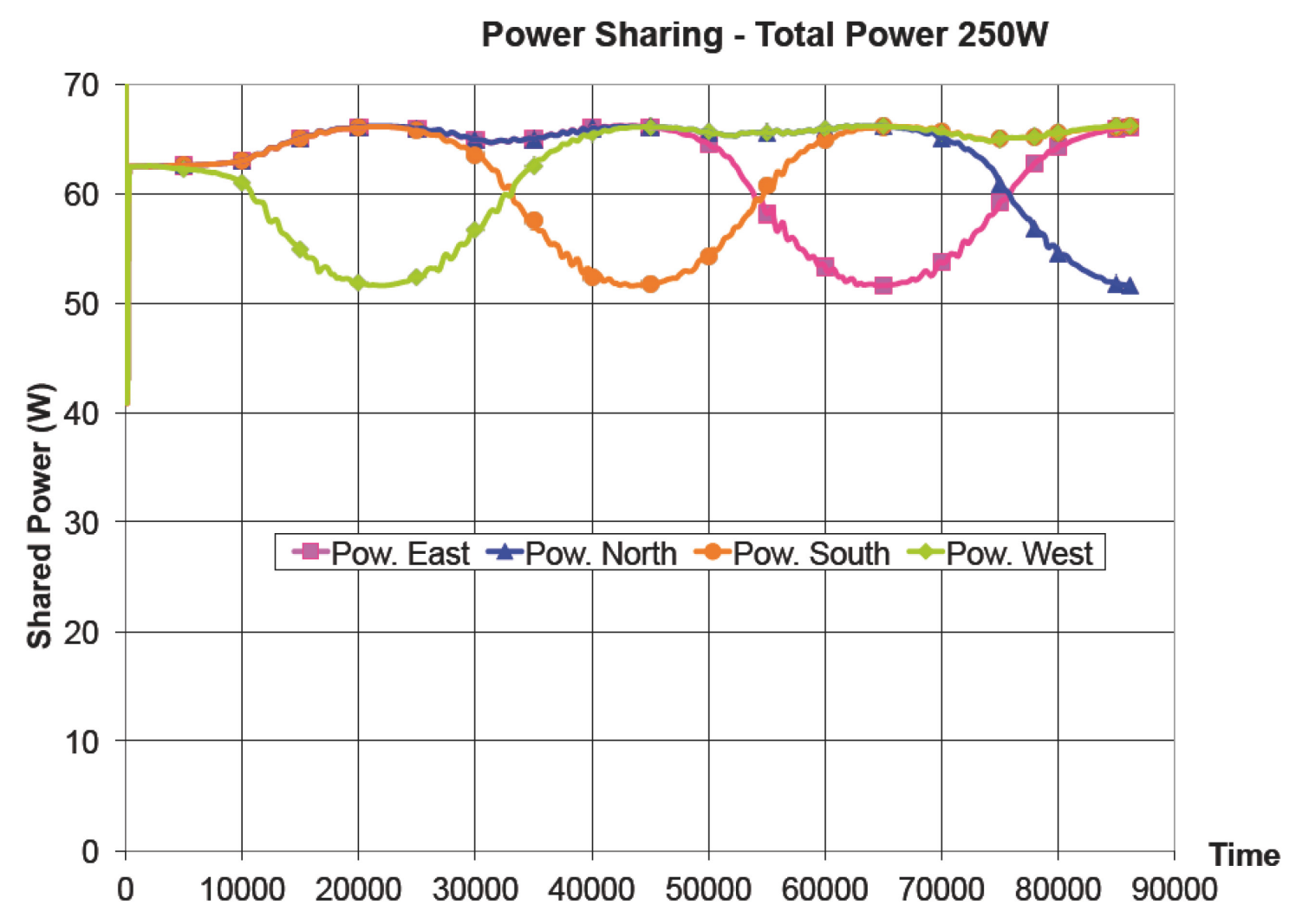

Figure 7.9. Shared power vs. time for a LEO orbit

\subsection{Results and Discussion}

The engineering model set-up has been subject to three representative radiator orbit environments presented in Fig. 7.10. The applied power profiles for each case is: $1500 \mathrm{~W}-1200 \mathrm{~W}-900 \mathrm{~W}-600 \mathrm{~W}-300 \mathrm{~W}-100 \mathrm{~W}$. PRVs set points are fixed as following: north and south at $32^{\circ} \mathrm{C}$, east at $31^{\circ} \mathrm{C}$ and west at $30.5^{\circ} \mathrm{C}$. The reason to implement different set points is to verify whether the model is able to reproduce the test results with a reasonable approximation. 


\begin{tabular}{|c|c|c|c|}
\hline & $\begin{array}{c}\text { Sink @ constant temperature. } \\
\text { No external solar heat inputs. }\end{array}$ & \multicolumn{2}{|c|}{$\begin{array}{r}\text { Sink @ oscillating temperature } \\
\text { External solar heat inputs. }\end{array}$} \\
\hline North & $-40^{\circ} \mathrm{C}$ & $10^{\circ} \mathrm{C}$ & $-25^{\circ} \mathrm{C}$ \\
\hline South & $-40^{\circ} \mathrm{C}$ & $10^{\circ} \mathrm{C}$ & $-25^{\circ} \mathrm{C}$ \\
\hline East & $-40^{\circ} \mathrm{C}$ & $10^{\circ} \mathrm{C}-30^{\circ} \mathrm{C}$ & $-25^{\circ} \mathrm{C}-30^{\circ} \mathrm{C}$ \\
\hline West & $-40^{\circ} \mathrm{C}$ & $10^{\circ} \mathrm{C}-30^{\circ} \mathrm{C}$ & $-25^{\circ} \mathrm{C}-30^{\circ} \mathrm{C}$ \\
\hline
\end{tabular}

Figure 7.10. Engineering model performed tests definition

To test the predictive capability of the mathematical model, two cases have been studied.

Figures 7.11 and 7.12 represent the complete test data for the two radiators (north and south) case at a constant temperature of $10^{\circ} \mathrm{C}$ and the other two (east and west) having a temperature variation between $10^{\circ} \mathrm{C}$ and $30^{\circ} \mathrm{C}$. When the power applied is between $600 \mathrm{~W}$ and $1500 \mathrm{~W}$ the saturation temperatures are above the PRV regulation set points; therefore, the LHPs behave without regulation. In this condition, the variations in the east-west radiators, are reproduced in the evaporators and therefore in the payload. For powers below 600 $\mathrm{W}$, the evaporators and payload remain at constant temperature regardless the variations at radiator level. The saturation temperature is now below the PRVs set points and the LHPs are regulated.

These regulation conditions and the effects in the shared power can also be seen in Fig. 7.12, where two distinct areas are observed, i.e. above and below 600 W. 


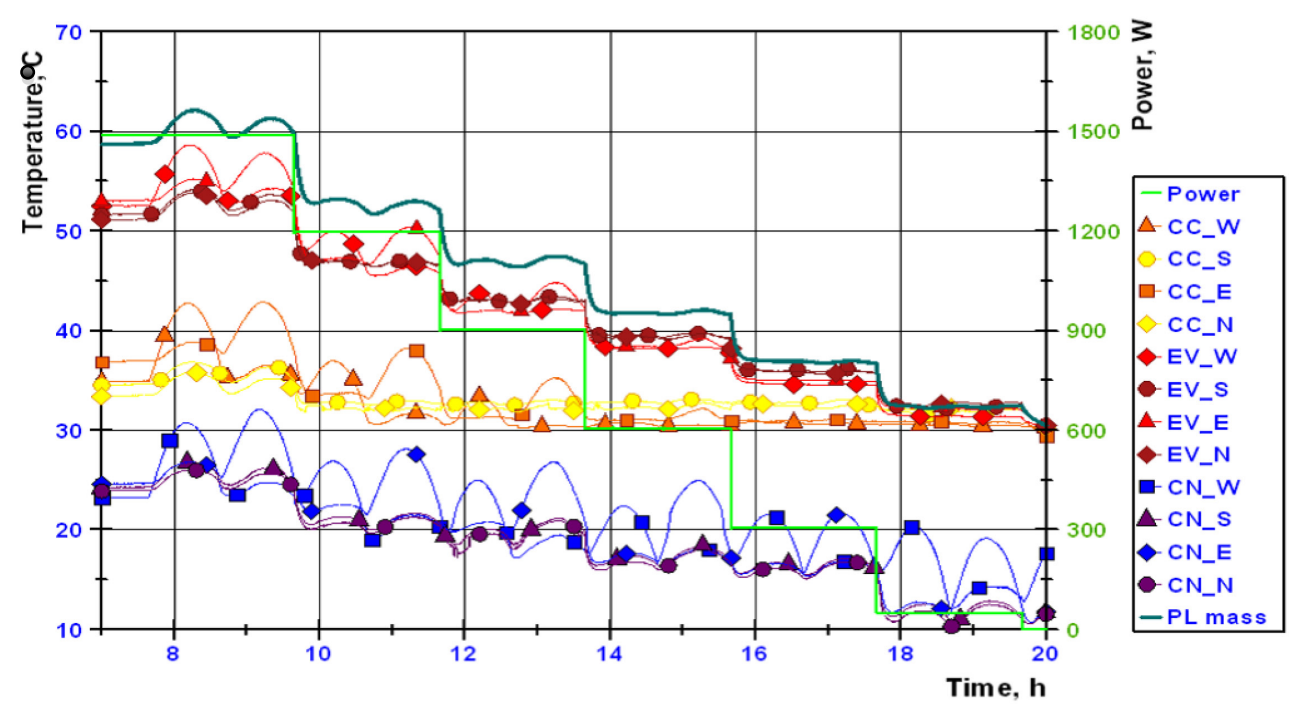

Figure 7.11. Measured temperatures for north-south radiators at $10^{\circ} \mathrm{C}$ and eastwest varying between $10^{\circ} \mathrm{C}$ and $30^{\circ} \mathrm{C}$

IEF009 SMTP 21-05-2013 (11.46)

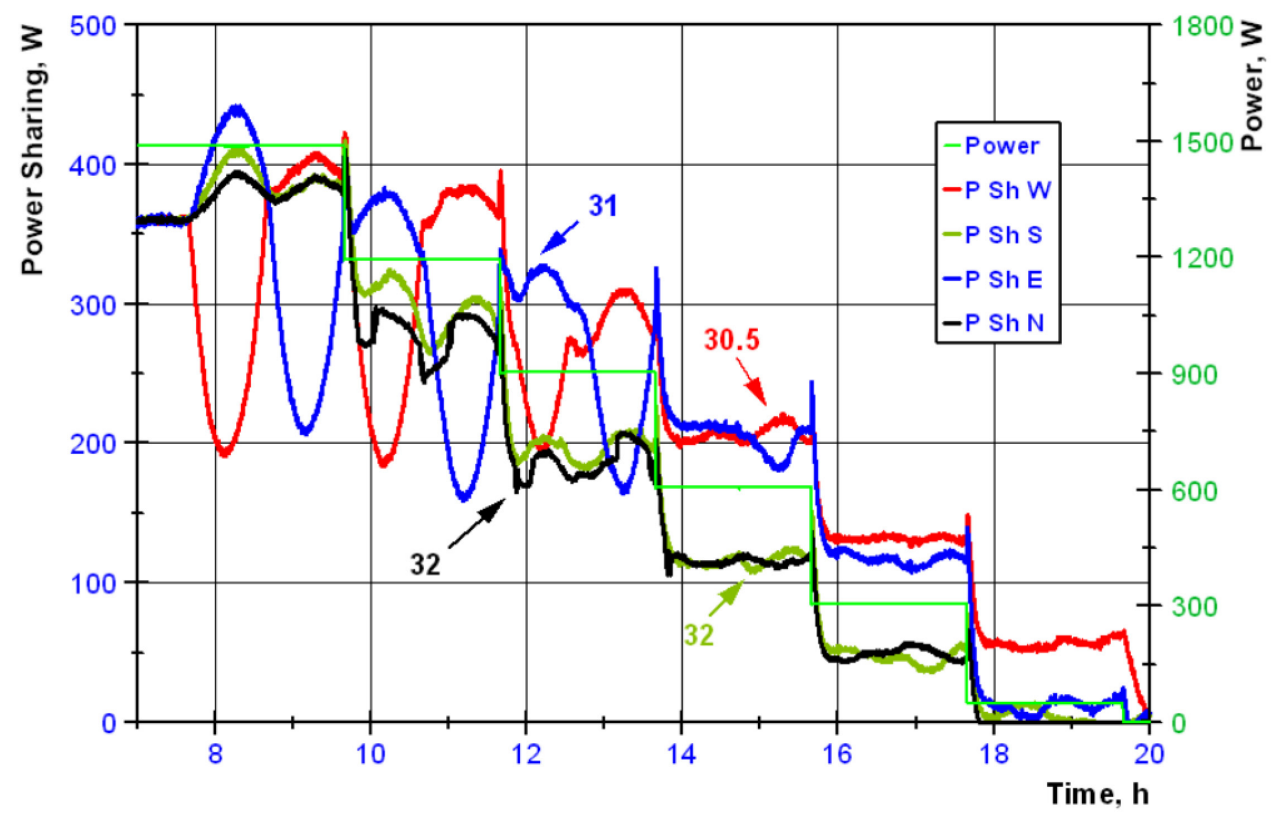

Figure 7.12. Measured shared power values for north-south radiators at $10^{\circ} \mathrm{C}$ and east-west varying between $10^{\circ} \mathrm{C}$ and $30^{\circ} \mathrm{C}$ 
Figures $7.13,7.14,7.15$ and 7.16 provide the comparison of temperature values between data and mathematical model for each north, south, east and west LHPs respectively. Thick lines represent the mathematical model predictions at the payload electronic box (PL Mass_mod), evaporator temperature (EV_mod), compensation chambers temperature (CC_mod) and condensers temperature (CN_mod). Test data are represented for the same locations using thinner lines. As it can be seen the level of correlation is very good even in case of sudden power changes. The predictions are within four degrees.

IEF009 SMTP 21-05-2013 (11.46)

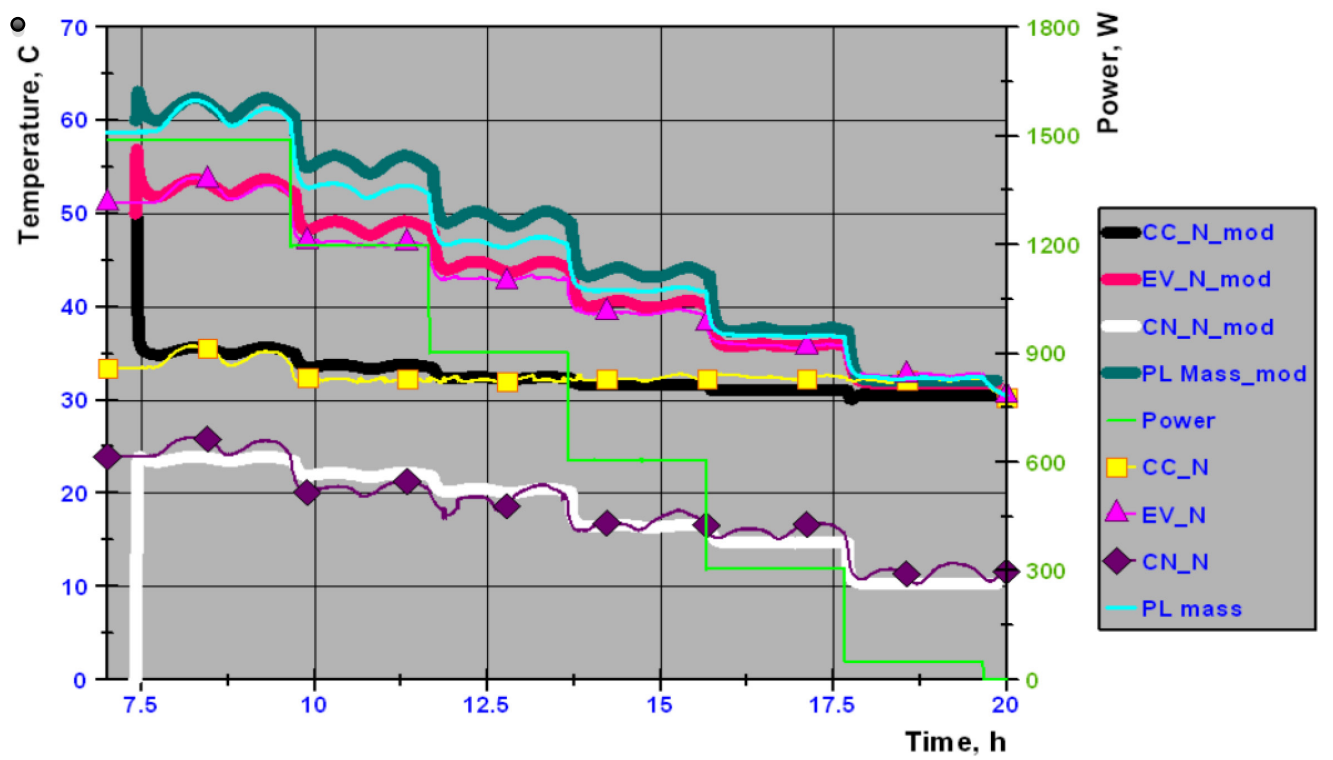

Figure 7.13. North LHP test data and mathematical model comparison for northsouth radiators at $10^{\circ} \mathrm{C}$ and east-west varying between $10^{\circ} \mathrm{C}$ and $30^{\circ} \mathrm{C}$ 


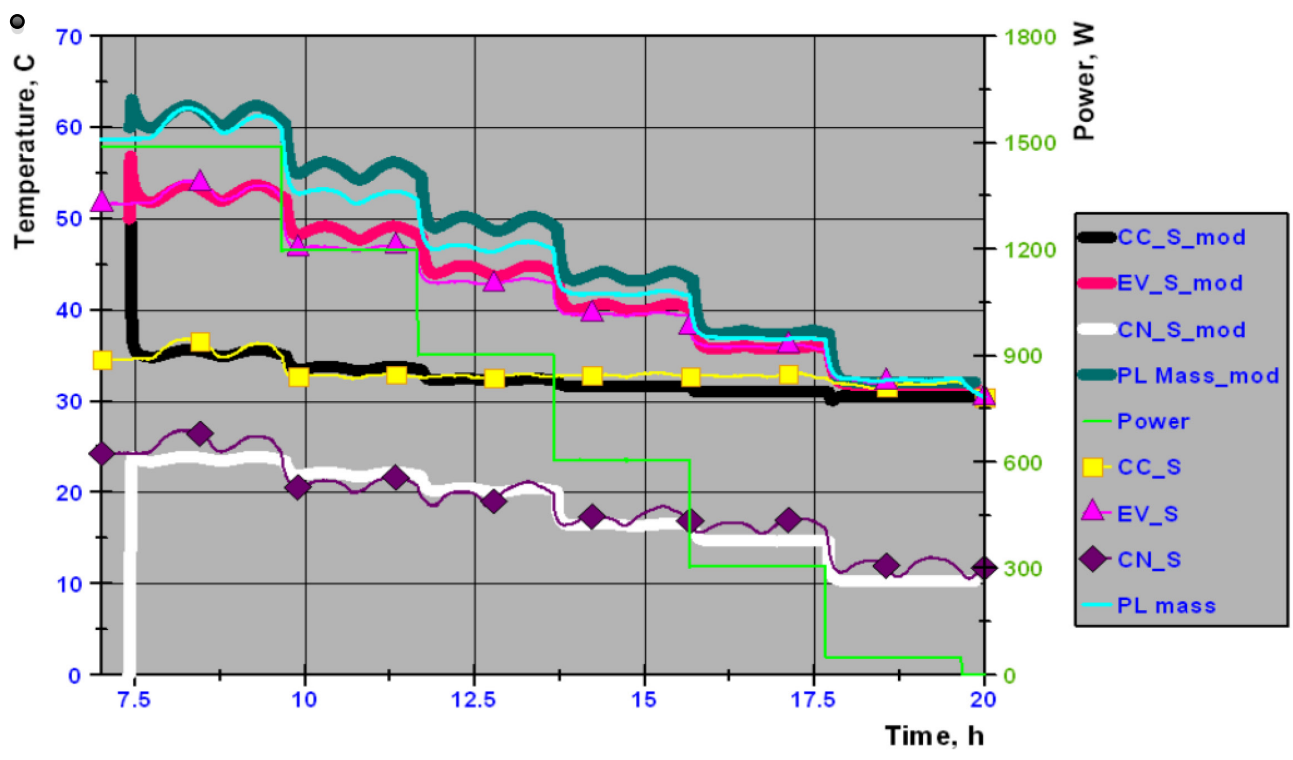

Figure 7.14. South LHP test data and mathematical model comparison for northsouth radiators at $10^{\circ} \mathrm{C}$ and east-west varying between $10^{\circ} \mathrm{C}$ and $30^{\circ} \mathrm{C}$

IEF009 SMTP 21-05-2013 (11.46)

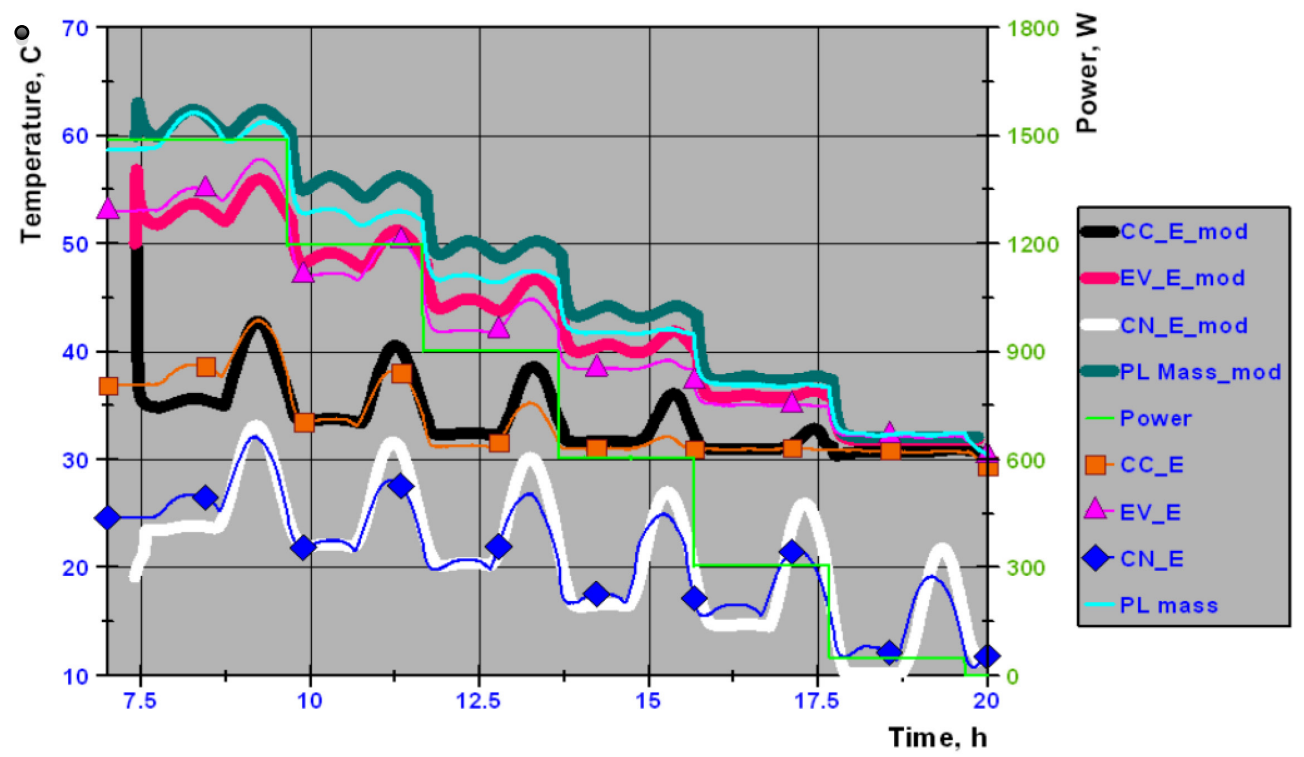

Figure 7.15. East LHP test data and mathematical model comparison for northsouth radiators at $10^{\circ} \mathrm{C}$ and east-west varying between $10^{\circ} \mathrm{C}$ and $30^{\circ} \mathrm{C}$ 


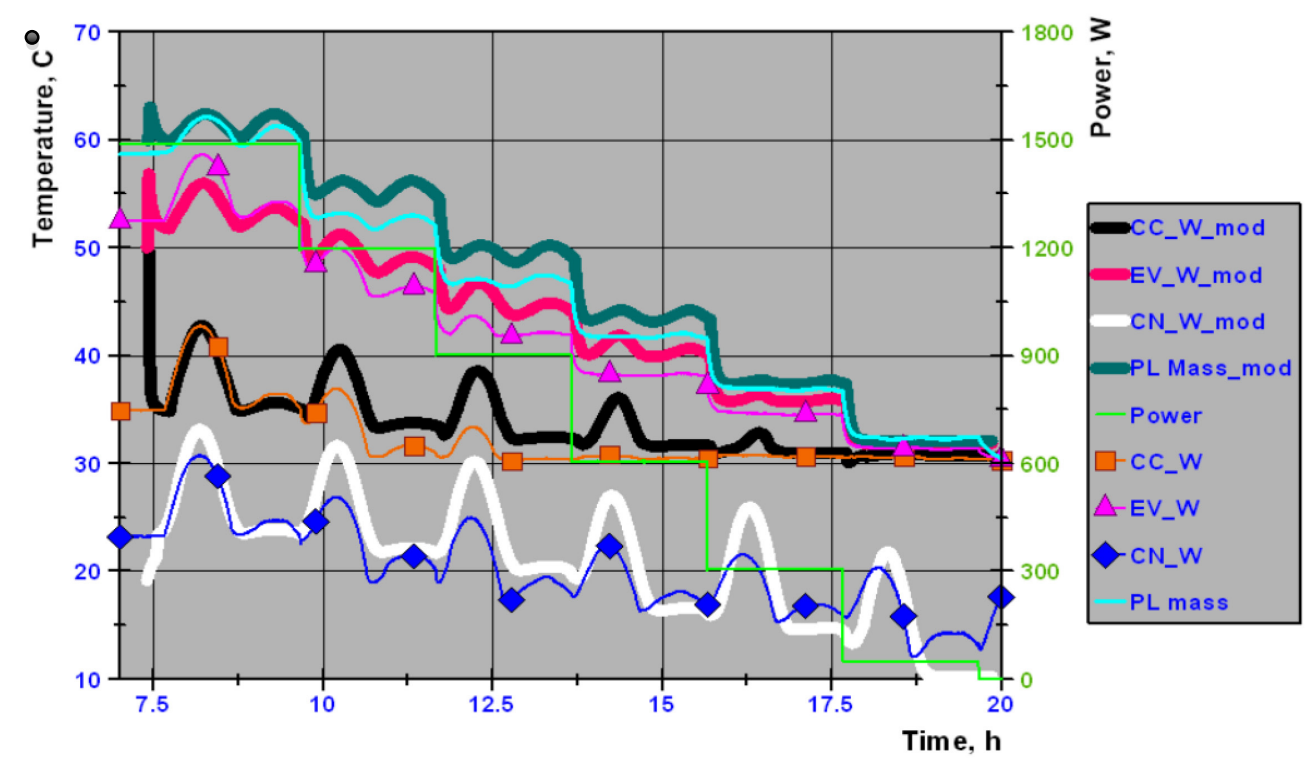

Figure 7.16. West LHP test data and mathematical model comparison for northsouth radiators at $10^{\circ} \mathrm{C}$ and east-west varying between $10^{\circ} \mathrm{C}$ and $30^{\circ} \mathrm{C}$

Figure 7.17 represents the results when four radiators at constant temperature of $-40^{\circ} \mathrm{C}$. Thick lines represent the mathematical model predictions at the payload electronic box (PL Mass_mod), average evaporators temperature (EV_mod), average compensation chambers temperature (CC_mod) and average condensers temperature (CN_mod). Similarly, the thinner lines represent the test data. It is also found that the model predictions are very satisfactory with lower than four degrees. 


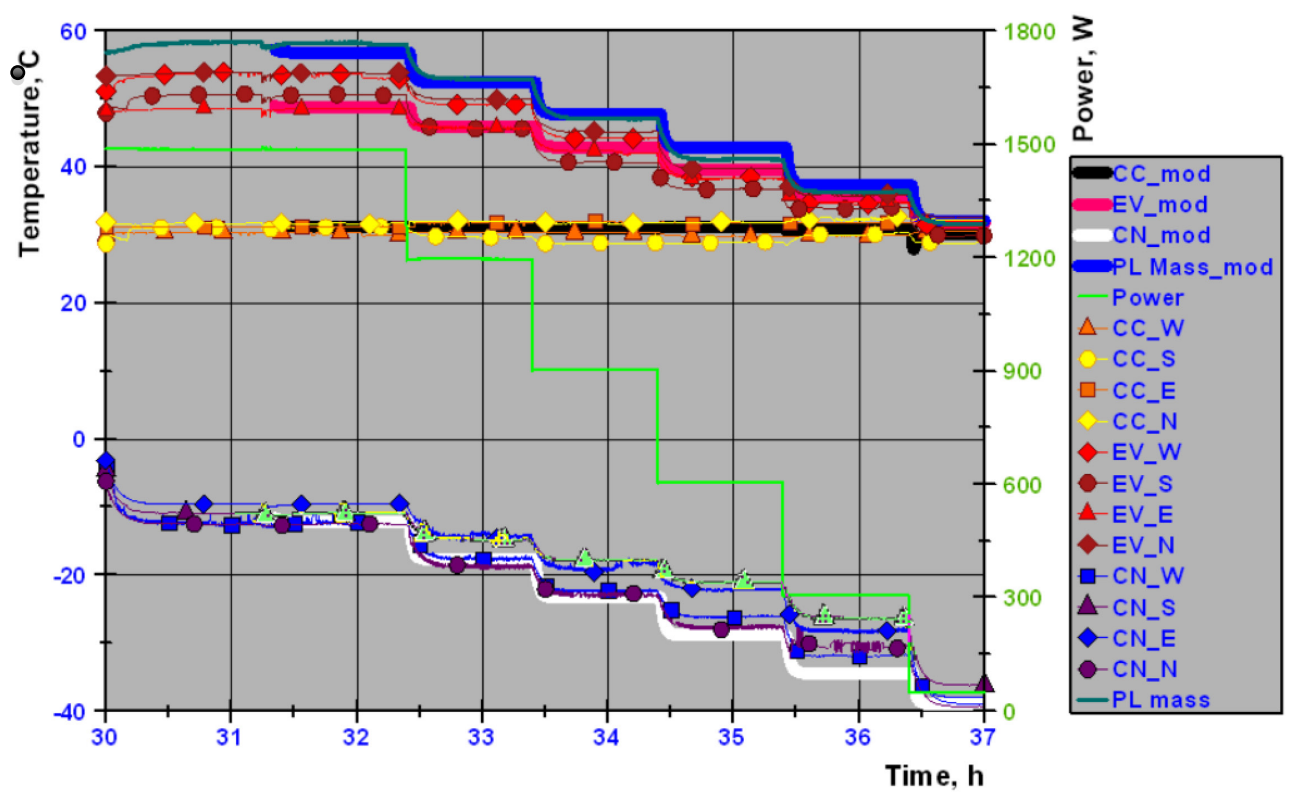

Figure 7.17. Test data and mathematical model comparison for north-south-eastwest radiators at $-40^{\circ} \mathrm{C}$

Figure 7.18 represent the complete temperature test data for the two radiators (north and south) at constant temperature of $-25^{\circ} \mathrm{C}$ and the other two (east and west) having a temperature variation between $-25{ }^{\circ} \mathrm{C}$ and $30{ }^{\circ} \mathrm{C}$. Figure 7.19 provides the shared power among the radiators during the complete test.

Similar to the above analysis, when the power applied is higher than $600 \mathrm{~W}$, the saturation temperatures are above the PRV regulation set points; therefore, the LHPs operate without regulation. In this condition, the variations in the east-west radiator temperatures are followed by the evaporators, and therefore by the payload. For powers below $600 \mathrm{~W}$, the evaporators and payload remain at constant temperature regardless of the variations at radiator temperatures. The saturation temperature is now below the PRVs set points and the LHPs are regulated. 


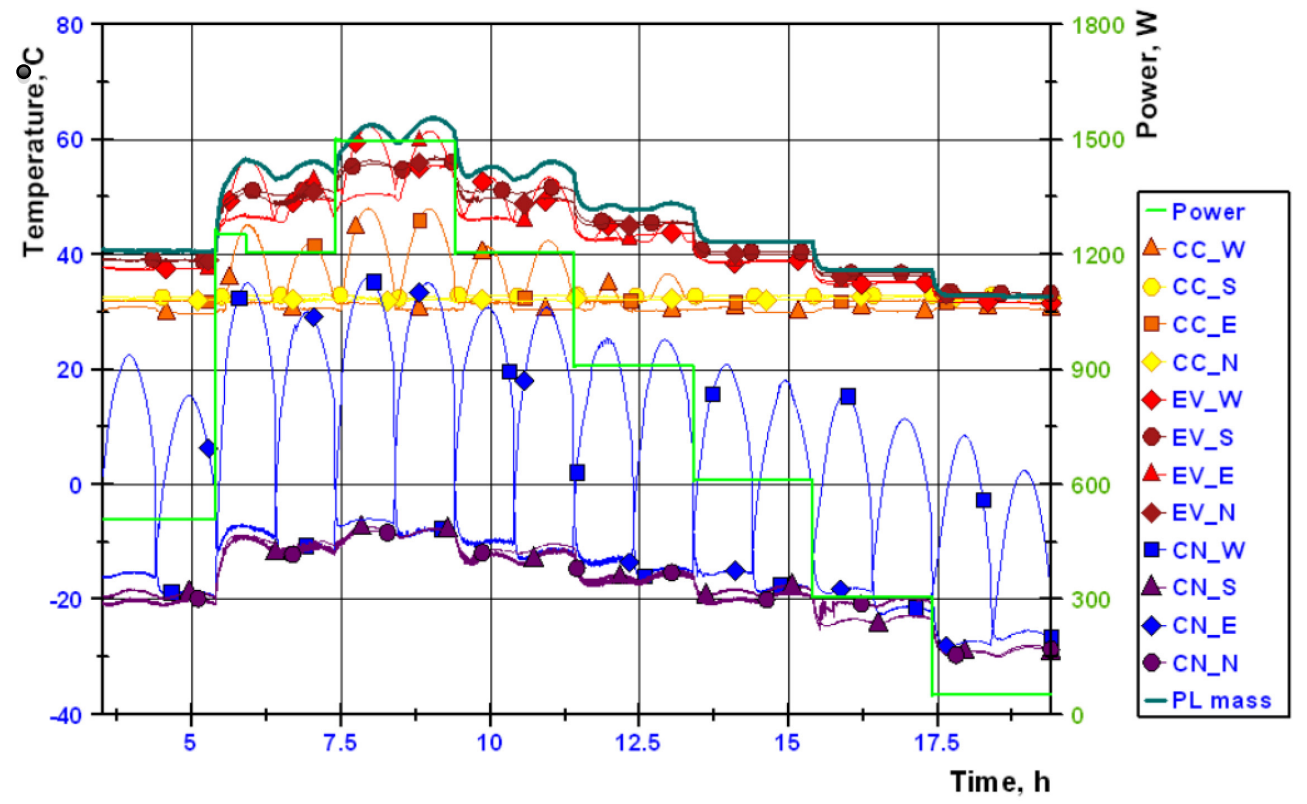

Figure 7.18. LHPs temperature test data for north-south radiators at $-25^{\circ} \mathrm{C}$ and east-west varying between $-25^{\circ} \mathrm{C}$ and $30^{\circ} \mathrm{C}$ 
The regulation conditions and their effects on the shared power can be seen in Fig. 7.19 where two distinct areas are observed above and below $600 \mathrm{~W}$.

IEF009 SMTP 28-05-2013 (12.36)

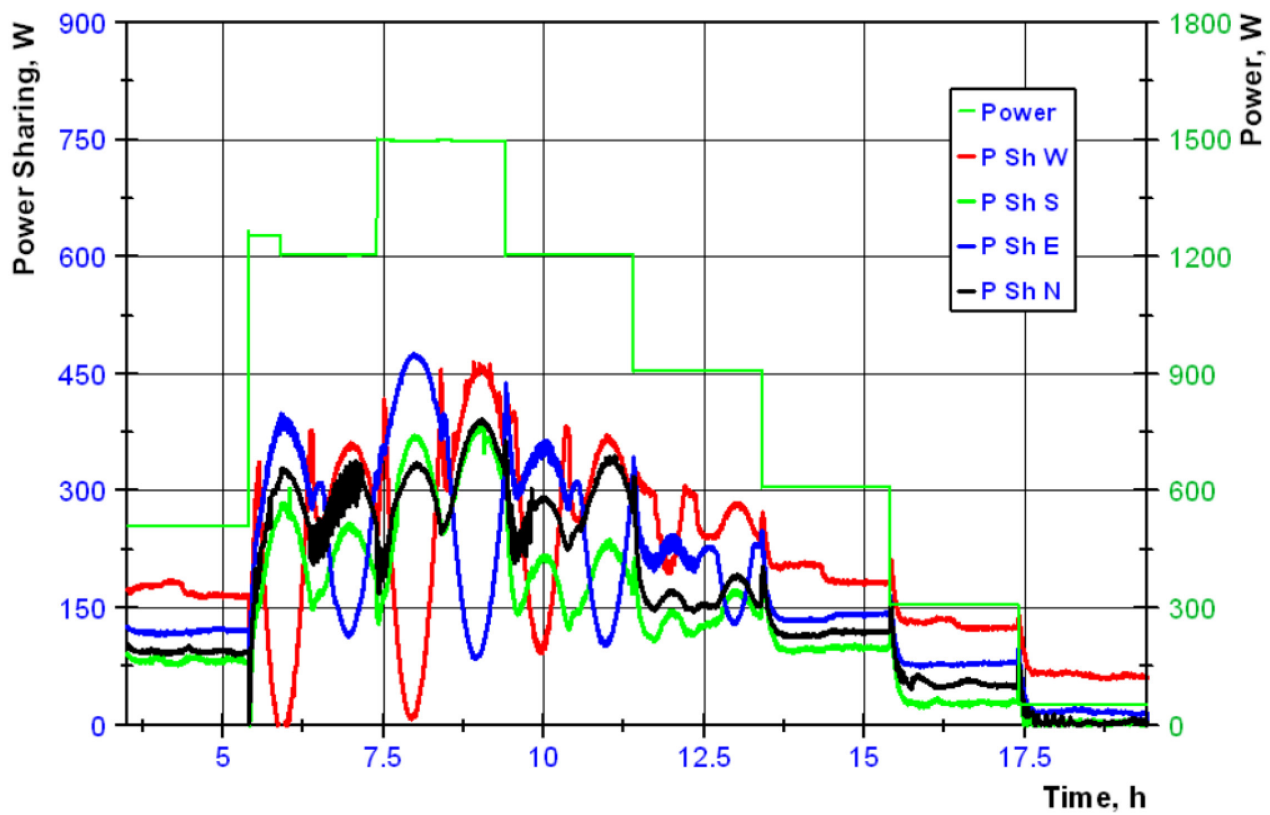

Figure 7.19. Measured shared power values for north-south radiators at $-25^{\circ} \mathrm{C}$ and east-west varying between $-25^{\circ} \mathrm{C}$ and $30^{\circ} \mathrm{C}$

\subsection{Conclusions}

During the last decade, a significant increase in the amount of patents and publications dedicated to solve the new thermal challenges for spacecraft using the two-phase technology, in particular LHPs, is observed. The review of different thermal systems confirms that an LHP-based modular thermal concept provides a valuable solution to the future spacecraft thermal architecture needs. 
The presented example of SMTP provides an insight of what can be achieved. The system allows mounting dissipative units anywhere inside spacecraft, placing radiator at any spacecraft location and grouping electronics by temperature requirements. These features in turn lead to maximize the heat rejection capability of the spacecraft and to optimize radiator area, equipment arrangement and performance.

The presented mathematical model provides satisfactory temperature predictions, less than $4^{\circ} \mathrm{C}$. Therefore, the model can safely be used to provide orbital temperature predictions with an acceptable level of accuracy.

To our best knowledge, for the first time, the concept of connecting northsouth-east-west radiators is successfully demonstrated. The payload temperature stability at relatively high powers, i.e. $1500 \mathrm{~W}$ and at varying radiator temperatures is confirmed. An important heater budget saving (heater lines, control heaters and heater power) to survive cold cases is also expected. Evidences of easy integration and testing are also foreseen.

\section{References}

[7.1] Thermal control canister. US Patent 4162701. S. Ollendorf, NASA, 1979.

[7.2] Thermal control system for spacecraft. JP Patent 2001315700. S. Kawashaki, MHI, 2001.

[7.3] Sequenced heat rejection for body stabilized geosynchronous satellites. US Patent 6073888. W.S. Gelon, J.C. Hall, C. J. Goodman, Loral Space \& Communications Ltd., 2000. 
[7.4] Thermal control system for controlling temperature in spacecraft. US Patent 6511021. N.A. Keramidas, 1998.

[7.5] Scalable thermal control system for spacecraft mounted instrumentation. US Patent 7270302. H. Wong, N. Goodzeit, LMM, 2007.

[7.6] Method and apparatus for amplitude limiting battery temperature spikes. US Patent 7893659. H. Tsukamoto, D. Skinlo, C. Kishiyama, J. Dodd, Quallion LLC, 2008.

[7.7] Spacecraft battery thermal management system. US Patent $7967256 . \mathrm{H}$. Wong, LMM, 2007.

[7.8] Payload modules. US Patent 8096512. A. G. Russell, Astrium Ltd. 2012.

[7.9] Spacecraft multiple loop heat pipe thermal system for internal equipment panel application. US Patent 6478258. E. M. Yee, SS/L Inc., 2002.

[7.10] Spacecraft modular thermal platform. JP patent No: 2011-529586. A. Torres, D. Mishkinis, J. L. Pastor. 2014.

[7.11] D. Mishkinis, G. Wang, D. Nikanpour, E. MacDonald, T. Kaya, Advances in two phase loop with capillary pump technology and space applications, International Conference on Environmental Systems, Rome, Paper no. 2005-012883, 2005.

[7.12] A. Torres, D. Mishkinis, A. Kulakov, F. Romera, C. Gregori, T. Kaya, Thermal control of loop heat pipe with pressure regulating valve, Heat Pipe Science and Technology Journal 1-4 pp. 329-357. 2012.

[7.13] A. Torres, D. Mishkinis, T. Kaya, Mathematical model validation of a thermal architecture system connecting east/west radiators by flight data, Applied Thermal Engineering 66/1-2 (2014), pp. 1-14, DOI:10.1016/j.applthermaleng.2014.01.050. 


\section{Chapter 8}

\section{Conclusions and recommendations for future work}

\subsection{Conclusions}

The main objective of this thesis was to design, manufacture and test a complete thermal architecture based on LHPs with PRVs connecting four radiators of a typical telecommunications satellite. Each compound LHP and PRV constitute a building block. As a result, the investigated architecture ended up with four of these blocks.

As a fundamental part of the research, a mathematical model was developed to support the design of the thermal architecture. The first part of the numerical model development included the mathematical model development of the existing flight demonstrator, consisting of two building blocks. The second part focused on the validation of this model with satellite flight data. Finally, the third phase concentrated on using one of the validated building blocks to create the complete mathematical model of the novel architecture, i.e. with four building blocks. The numerical results were validated once again by comparison with the test results obtained from the engineering breadboard on-ground.

The resulting numerical model was able to provide the key functioning parameters of the system, including orbital transients due to environmental condition changes and heat load sharing among the radiators. The developed 
modular approach of the mathematical model has been proven during the design of the four-radiator concept allowing the extension of the number of building blocks to provide even more complex satellite thermal architectures to be integrated into larger mathematical models at satellite level.

The two-way PRVs developed for the proposed thermal architecture demonstrated the precise temperature control capability at low power and low temperature levels, increasing reliability and temperature stability of the system for both in-flight and on-ground conditions.

The flight data collected during almost three years of the demonstrator operation on board the telecommunications satellite Hispasat 1E were analyzed for the most typical orbital environmental conditions. The analysis of the flight data demonstrated the successful in-orbit operation of the thermal architecture. The remarkable robustness of the system has been shown despite the extreme environmental changes at the radiator and satellite levels. The autonomy of the system, which does not need telecommanding, provides an important advantage during satellite control operations.

Finally, the manufactured engineering breadboard model proved the concept of connecting north-south-east-west radiators. The payload temperature stability for relatively high powers, i.e. $1,500 \mathrm{~W}$ under the oscillating radiator temperatures has been demonstrated. The mathematical model predictions were within $4{ }^{\circ} \mathrm{C}$ of the experimentally measured values. 
The proposed system allows mounting dissipative units anywhere inside the spacecraft, placing radiators at any satellite location and grouping electronics by temperature requirements. This system will enable satellite manufacturers to manage more efficiently the increasing thermal demands of the modern telecommunication satellites by offering a flexible and modular architecture.

\subsection{Recommendations for future work}

1. Next step is to qualify in space a flight demonstrator with four radiators. Even though the engineering breadboard has proven the concept and the system with the two building blocks is in flight now, most of the telecommunications satellite operators would require a three-year flight heritage to approve the thermal architecture for a mission.

2. If an accurate control is required, i.e. $\pm 2^{\circ} \mathrm{C}$ for LNA's or optical bench subsystems, active controlled PRVs need to be used. A specific test qualification should be performed.

3. The manufactured engineering breadboard comprised four identical LHPs. A breadboard having four LHPs with different heat transport capability would be beneficial to prove the concept of combining electronic equipment with different power dissipations. This would help to understand the potential limitations of the investigated thermal architecture.

4. LHP start-up is always a critical event during flight, especially when anomalies occur. The mathematical model needs to be improved to 
reproduce fast transients such as LHP start-up. The present mathematical model requires prescribing the conditions inside the wick core: namely liquid, vapour or two-phase. The model is not able to identify wick core conditions out of external environmental conditions.

5. Current approach of using a constant evaporation heat transfer coefficient in the model can lead to errors, especially for low and high heat flux densities. This coefficient is a function of many parameters, such as heat flux, physical properties of working fluid, capillary porous wick material and geometry of vapor collecting and removing grooves. Microgravity conditions can also have significant influence on the evaporation process. This subject requires additional theoretical and experimental investigation.

6. Current homogeneous flow condensation model has to be improved to represent real flow pattern, which takes place inside small diameter pipes typically used as condensers of LHPs.

7. Further investigations are also needed in the field of contact conductances between evaporator and payload. For moderate power dissipations, i.e. from $500 \mathrm{~W}$ to $1,000 \mathrm{~W}$, dry interfillers develop a reasonable temperature drop across the interface; however, for higher powers the thermal resistance between evaporator and payload can be much larger than that of the LHP leading to a considerable error in model predictions. 


\section{Appendix A}

\section{Friction and heat transfer coefficients. Evaporator mathematical equations}

\section{A.1 Correlations for Friction}

The pressure loss coefficient $\xi$ is calculated as follows:

$\xi=\xi_{\text {misc }}+\xi_{\text {bends }}+f \frac{L}{D}$

The calculation of the terms assumes the following

$\xi_{\text {misc: }}$ Input data that represents some additional concentrated load losses.

$\xi_{\text {bends: }}$ Represents the total bend pressure drop coefficient. It is calculated as follows:

$x_{\text {bends }}=\sum_{n_{-} \text {bends }} x_{\text {bend }}$

$\square_{\text {end }}$ is the pressure drop coefficient for each bend and it is function of the relative radius of curvature of the bend, the relative roughness and the bend angle $(\alpha)$. According to [A.1], the total resistance coefficient of pipe bends is the product of the following coefficients Fig. A.1 


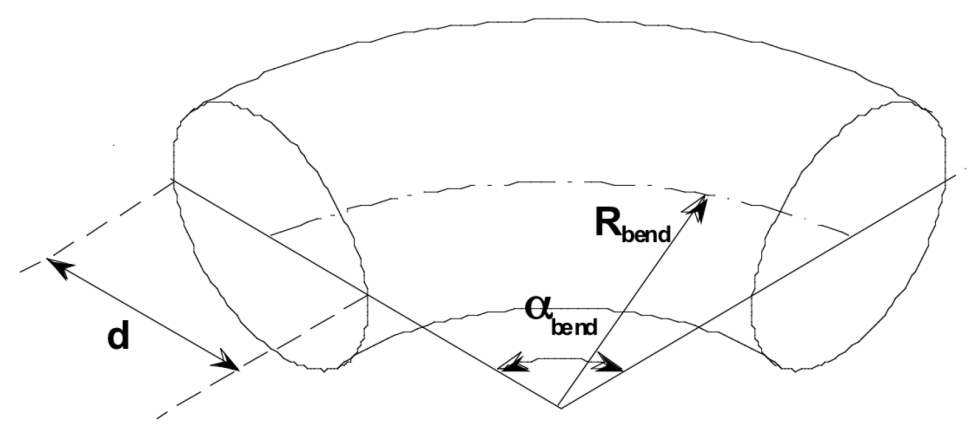

Figure A.1. Bend pipe parameters

$$
x_{\text {bend }}=x_{\text {bend }}\left(a, \frac{R_{\text {bend }}}{d}, \frac{e}{d}\right)
$$

The pressure drop coefficient is:

$$
\xi_{\text {bend }}=\xi_{\text {angle }} \cdot \xi_{\text {radius }} \cdot \xi_{\text {rug }}
$$


a) Angle Effect:

$\xi_{\alpha / \gamma / \hat{\varepsilon}}=0.957 \frac{\alpha}{90}+0.226 \sqrt{\frac{\alpha}{90}}+0.407 \sin (\alpha)-0.833 \sin (\alpha / 2)$

b) Radius Effect:

$$
\begin{aligned}
& x_{\text {radus }}=\frac{0.21}{\frac{\bar{R}}{d}}\left(\frac{R}{d}>1\right) \\
& x_{\text {radus }}=\frac{0.21}{\left(\frac{R}{d}\right)^{0.25}} \quad\left(\frac{R}{d}<1\right)
\end{aligned}
$$

c) Roughness Effect:

$$
\begin{aligned}
& \xi_{r u g}=\min \left(2,1+10^{6}\left(\frac{R u g}{d}\right)^{2}\right)\left(\frac{R}{d}>1.5\right) \\
& \xi_{r u g}=\min \left(2,1+10^{3}\left(\frac{R u g}{d}\right)\right)\left(\frac{R}{d} \leq 1.5\right)
\end{aligned}
$$

f: Friction factor and it is function of the local Reynolds Number and the relative roughness [A.2]. The friction factor is calculated by means of a simple correlation valid for laminar, turbulent and transient flow.

$$
f=8\left[\left[\frac{8}{\operatorname{Re}}\right]^{12}+\frac{1}{(A+B)^{3 / 2}}\right]^{\frac{1}{12}}
$$

where

$$
A=\left[2.457 \ln \frac{1}{(7 / \mathrm{Re})^{0.9}+0.27 \varepsilon / D}\right]^{16} ; \quad B=\left[\frac{37530}{\mathrm{Re}}\right]^{16} ; \quad \varepsilon=\text { roughness }
$$




\section{A.2 Correlations for Heat Transfer}

Internal and external heat transfer coefficients are evaluated using single or two-phase empirical correlations depending on the flow regime.

\section{Single Phase:}

$$
h_{\text {so }}=N u \frac{k}{D_{\text {int }}}
$$

where $k$ is the fluid thermal conductivity, $D_{\text {int }}$ is the inner diameter and $N u$ is the equivalent Nusselt number. Transition laminar to turbulent is calculated as follows:

$$
N u=\left(N_{l a m}^{16}+N_{\text {turb }}^{16}\right)^{1 / 16}
$$

The Nusselt Numbers for laminar and turbulent flow regimes are defined as $[$ A.3,A.4]:

$$
\begin{aligned}
& N u_{\text {lam }}=4 \\
& N u_{\text {turb }}=0.023 \operatorname{Re}^{0.8} \operatorname{Pr}^{0.4}
\end{aligned}
$$

$R e$ is the Reynolds Number and $P r$ is the Prandtl Number. These numbers depend on the fluid properties and are calculated according to the following equations:

$$
\operatorname{Re}=\frac{\dot{m} D}{A \mu} ; \quad \operatorname{Pr}=\frac{C_{p} \mu}{k}
$$

where $\mu \square$ s the fluid viscosity. 


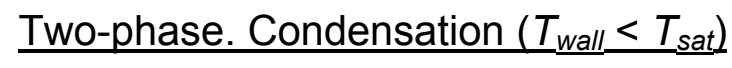

Calculations have been performed using the Traviss correlation [A.5]. This correlation can be used for every regime (laminar, wavy or turbulent) in annular flow. The condensation film coefficient is calculated as follows:

$$
h_{\text {cond }}=\frac{k_{l}}{D} \frac{0.15 \operatorname{Pr}_{l} \operatorname{Re}_{l}^{0.9}}{F_{t}}\left(\frac{1}{X_{t t}}+\frac{2.85}{X_{t t}^{0.476}}\right)
$$

The parameters involved in the previous equation are the following:

- ki: Liquid thermal conductivity;

- Pri: Prandtl Number for the liquid;

$$
\mathrm{Re}_{l}=\frac{\dot{m}(1-x) D}{\mu_{l}}: \text { Reynolds Number for the liquid; }
$$

- Xtt: Martinelli parameter for the turbulent-turbulent flow [A.6], defined as:

$$
X_{t t}=\left(\frac{1-x}{x}\right)^{0.9}\left(\frac{\rho_{v}}{\rho_{l}}\right)^{0.5}\left(\frac{\mu_{l}}{\mu_{v}}\right)^{0.1}
$$

- $F_{t}:$ Parameter calculated as follows depending on the value of $R e_{j}$ :

$$
\begin{array}{ll}
F_{t}=5 \mathrm{Pr}_{l}+5 \ln \left(1+5 \mathrm{Pr}_{l}\right)+2.5 \ln \left(0.0031 \mathrm{Re}^{0.812}\right) & \mathrm{Re}_{l}>1125 \\
F_{t}=5 \mathrm{Pr}_{l}+5 \ln \left[1+\operatorname{Pr}_{l}\left(0.0964 \mathrm{Re}_{l}^{0.585}-1\right)\right] & 50<\mathrm{Re}_{l}<1125 \\
F_{t}=0.707 \operatorname{Pr}_{l} \operatorname{Re}_{l}^{0.5} & \mathrm{Re}_{l}<50
\end{array}
$$

$\underline{\text { Two-Phase. Superheated Condensation (Vapor and } T_{\text {wall }}<T_{\text {sat }} \text { ) }}$

The film coefficient is calculated using the following equation in order to avoid discontinuities between the single phase and two phase regimes: 


$$
h=\frac{h_{\text {spov }}\left(T_{\text {sat }}-T_{\text {wall }}\right)+h_{\text {cond }}\left(T_{\text {fluid }}-T_{\text {sat }}\right)}{\left(T_{\text {fluid }}-T_{\text {wall }}\right)}
$$

where $h_{s p, v}$ is the single phase film coefficient corresponding to the vapor.

Two-Phase. Boiling $\left(0<\mathrm{x}<0.7\right.$ and $\left.T_{\text {wall }}>T_{\text {sat }}\right)$

The correlation for convective boiling by Chen [A.7] and later modified by Carey [A.8] is applicable for annular turbulent flow when the stratification is not too severe. The heat transfer coefficient is calculated as follows:

$$
h_{\text {Chen }}=h_{\text {mac }}+h_{\text {mic }}
$$

where $h_{\text {mac }}$ is the macroscopic (convection) contribution and $h_{\text {mic }}$ is the microscopic (nucleate boiling) contribution.

$$
h_{\text {mac }}=h_{l} F\left(X_{t t}\right) \operatorname{Pr}_{l}^{0.296}
$$

where $X_{t t}$ is the Martinelli parameter for the turbulent-turbulent flow, $h_{l}$ is the heat transfer coefficient for the liquid and it is calculated by using the following correlation:

$$
h_{l}=0.023\left(\frac{k_{l}}{D}\right) \operatorname{Re}_{l}^{0.8} \operatorname{Pr}_{l}^{0.4}
$$

and $F\left(X_{t t}\right)$ is a parameter which depends on the Martinelli parameter and it is calculated according to the following correlations:

$$
\begin{aligned}
& F\left(X_{t t}\right)=1 \quad X_{t t}^{-1} \leq 0.1 \\
& F\left(X_{t t}\right)=2.35\left(0.213+\frac{1}{X_{t t}}\right)^{0.736} \quad X_{t t}^{-1}>0.1
\end{aligned}
$$




$$
h_{\text {ric }}=0.00122\left[\frac{k_{l}^{0.79} C p_{l}^{0.45} \rho_{l}^{0.49}}{\sigma^{0.5} \mu_{l}^{0.29} h_{f g}^{0.24} \rho_{v}^{0.24}}\right]\left[T_{w}-T_{\text {set }}\left(P_{l}\right)\right]^{0.24}\left[P_{\text {sat }}\left(T_{w}\right)-P_{l}\right]^{0.75} S
$$

where $\sigma$ is the superficial tension, $h_{f g}$ is the latent heat of vaporization and $S$ is the suppression factor which is calculated as follows:

$$
\begin{aligned}
& S=\left[1+2.5610^{-6}\left[\operatorname{Re}_{2 p}^{1.17}\right]\right]^{-1} \\
& \operatorname{Re}_{2 p}=\operatorname{Re}_{/}\left[F\left(X_{t t}\right)\right]^{1.25}
\end{aligned}
$$

Two-Phase. Boiling $\left(x>0.9\right.$ and $\left.T_{\text {wall }}>T_{\text {sat }}\right)$

For qualities higher than 0.9 , a post dry-out correlation by Dougall and Roshenow [A.9] is used to calculate the film coefficient for boiling:

$$
h_{p d}=h_{v} \Phi^{0.8}
$$

where $h_{v}$ is the heat transfer coefficient for the vapor, $\square$ is a parameter and are calculated by using the following correlations:

$$
\begin{aligned}
& h_{v}=0.023\left(\frac{k_{v}}{D_{\text {int }}}\right) \operatorname{Re}_{v}^{0.8} \operatorname{Pr}_{v}^{0.4} \\
& \Phi=x+(1-x) \frac{\rho_{v}}{\rho_{l}}
\end{aligned}
$$

Two-Phase. Boiling $\left(0.7<\mathrm{x}<0.9\right.$ and $\left.T_{\text {wall }} \geq T_{\text {sat }}\right)$

In order to avoid discontinuities, when the value of the quality is between 0.7 and 0.9 , the film coefficient is calculated by a cubic spline interpolation between the Chen and Dougall-Rohsenow correlations. 


\section{Subcooled Boiling}

The film coefficient is calculated using the following equation in order to avoid discontinuities between the single phase and two phase regimes:

$$
h=\frac{h_{\text {sp }, I}\left(T_{\text {sat }}-T_{\text {fluid }}\right)+h_{\text {Chen }}\left(T_{\text {wall }}-T_{\text {sat }}\right)}{\left(T_{\text {wall }}-T_{\text {fluid }}\right)}
$$

where $h_{s p, l}$ is the single phase film coefficient corresponding to the liquid.

\section{External environment exchange}

The heat exchange between LHP components and ambient via natural convection, it is used correlation from Holman [A.10]

$$
h_{n c}=1.32\left(\frac{T_{\text {wall }}-T_{\text {amb }}}{D}\right)^{0.25}
$$

For the radiation heat exchange, the radiative conductance is given by:

$$
G_{i j}=\sigma \varepsilon_{e f f} F_{i j} A_{i}
$$

\section{A.3 Evaporator mathematical modelling}

A specific mathematical model has been developed for the evaporator due to the complexity of the physical phenomena that take place inside. The evaporator model includes the formulation of evaporator case, primary wick grooves, primary wick and core, Fig. A.2.

The main assumptions considered to model the evaporator are:

- The wick is completely flooded (saturated liquid). 
- The wick is divided in several radial nodes in order to calculate the transient temperatures distribution along the primary wick and the heat leak from the evaporator to the compensation chamber.

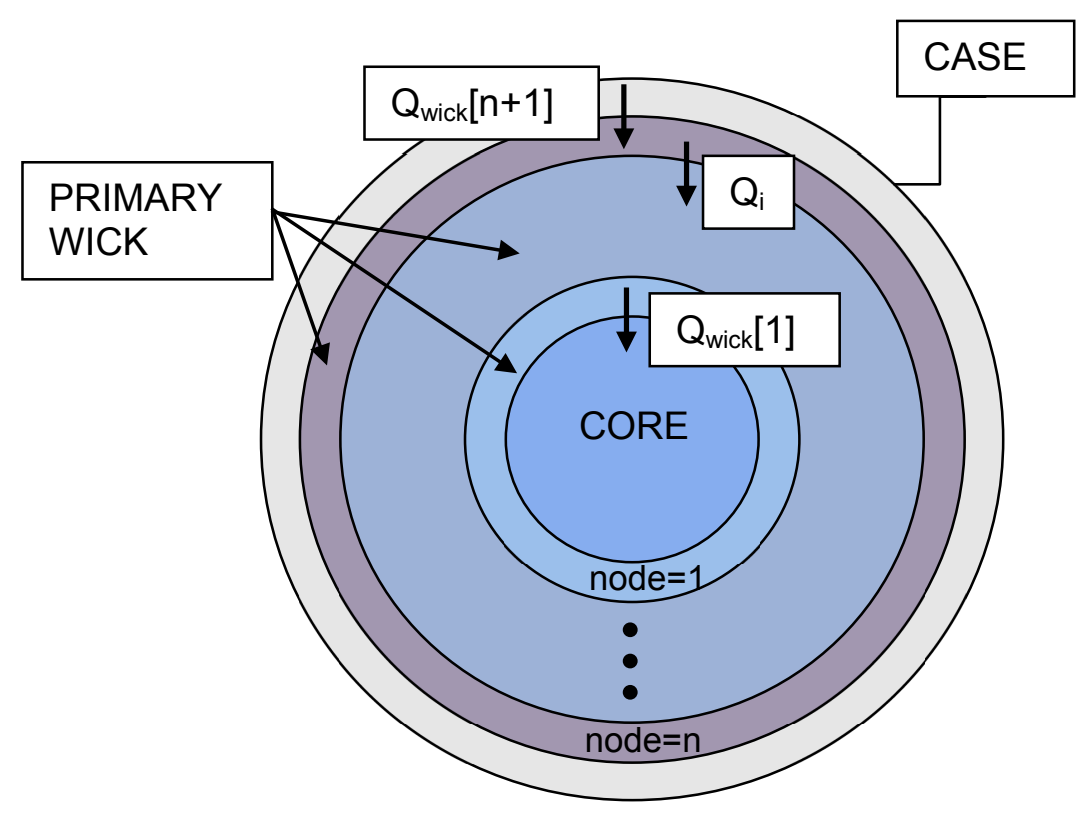

Figure A.2. Evaporator cross-section representation

- The fluid inside the evaporator is always in saturated conditions.

- All the temperatures are calculated dynamically, that means that the temperatures are calculated every integration step time.

\section{$\underline{\text { Case equations }}$}

The total power applied $\left(Q_{a p p}\right)$ to the evaporator is divided in two parts: The heat flow from the case to the primary wick $\left(Q_{c-w}\right)$ and the heat flow from the case to the grooves $\left(Q_{c-g}\right)$ :

$$
\dot{Q}_{a p p}=\dot{Q}_{c-w}+\dot{Q}_{c-g}
$$

These heat flows are calculated according to the following expressions: 


$$
\begin{aligned}
& \dot{Q}_{c-w}=h_{c-w} A_{\text {wick }}\left(T_{\text {case }}-T_{\text {int }}\right) \\
& \dot{Q}_{c-g}=h_{c-g} A_{\text {groves }}\left(T_{\text {case }}-T_{\text {groveses }}\right)
\end{aligned}
$$

where $h_{c-w}, h_{c-g}$ are the heat transfer coefficients between case-wick and between case-grooves, respectively, $A_{\text {wick}}, A_{\text {grooves }}$ are the corresponding contact areas, $T_{\text {case }}$ is the case temperature, $T_{\text {grooves }}$ is the grooves temperature and $T_{\text {int }}$ is the temperature of the interface where the evaporation of the working fluid occurs. The case temperature is obtained from the energy conservation equation:

$C_{\text {case }} \frac{d T_{\text {case }}}{d t}=\dot{Q}_{a p p}-\dot{Q}_{c-w}-\dot{Q}_{c-9}$

where $C_{\text {case }}$ is the case heat capacity.

\section{$\underline{\text { Interface Equations }}$}

The evaporated mass flow in the interface is calculated by applying the following equation:

$$
\begin{aligned}
& m_{e v a p}=\frac{\dot{Q}_{c-w}-\dot{Q}_{\text {wick }}[n+1]}{h_{f g}} \quad \Delta T_{e v-c c}>\Delta T_{\text {start_up }} \\
& m_{\text {evap }}=0 \quad \Delta T_{e v-c c} \leq \Delta T_{\text {sart up }}
\end{aligned}
$$

$\Delta T_{\text {start_up }}$ is an empirical parameter that allows the simulation of the start-up independently of the conditions. It has been found to be from 0 to $2,9^{\circ} \mathrm{C}$.

The temperature of the interface is obtained from the energy conservation equation: 


$$
C_{\text {int }} \frac{d T_{\text {int }}}{d t}=\dot{Q}_{c-w}-\dot{Q}_{\text {wick }}[n+1]-\dot{m}_{\text {evap }} h_{f g}
$$

\section{Grooves Equations}

The grooves temperature is determined by applying the energy conservation equation as follows:

$$
C_{\text {grooves }} \frac{d T_{\text {groves }}}{d t}=\dot{Q}_{c-g}-\dot{m}_{\text {evap }} C_{g}\left(T_{\text {grooves }}-T_{\text {int }}\right)
$$

\section{Primary Wick Equations}

Radial temperatures distribution and pressure losses are considered.

The primary wick is divided in several radial nodes. From energy conservation equation it follows:

$$
C_{i} \frac{d T_{i}}{d t}=\dot{m}_{\text {evap }}\left(h_{i-1}-h_{i}\right)+\dot{Q}_{i}-\dot{Q}_{i+1}
$$

where $\dot{Q}_{i \text { is }}$ the radial heat transfer from node $i-1$ and it is calculated as follows:

$$
\dot{Q}_{i}=\frac{2 \pi k_{\text {eff }} / w\left(T_{i}-T_{i-1}\right)}{\ln \left(\frac{D_{0, i}}{D_{i, i}}\right)}
$$

The parameters involved in the previous equation are the following:

- I eff: Length of the wick.

- $D_{o, i}, D_{i, i}$ : External and internal diameters of the radial node of the wick. 
- $k_{\text {eff: }}$ Effective thermal conductivity of the wick. It is calculated by using the correlation proposed by Dunn and Reay:

$$
k_{\text {eff }}=k_{s}\left(\frac{2+\left(k_{L} / k_{s}\right)-2 \phi\left(1-\left(k_{L} / k_{s}\right)\right)}{2+\left(k_{L} / k_{s}\right)+\phi\left(1-\left(k_{L} / k_{s}\right)\right)}\right)
$$

where $\phi$ is the porosity, $k_{L}$ is the thermal conductivity of the liquid and $k_{s}$ is the thermal conductivity of the solid material of the wick.

The pressure losses in the wick are calculated by applying the following equation:

$$
d P_{\text {loss }}=m_{\text {evap }} \frac{\ln \left(D_{0} / D_{i}\right) \mu_{L}}{\rho_{L} 2 \pi L \kappa}
$$

where $\mu_{L}$ is the liquid viscosity, $\rho_{L}$ is the liquid density and $\kappa$ is the permeability of the wick.

\section{Mass and Heat Exchanges with the Compensation Chamber}

The mass flow exchanged with the compensation chamber can be obtained applying the mass conservation equation:

$$
\dot{m}_{\mathrm{CC}}=\dot{m}_{\mathrm{LL}}-\dot{m}_{\text {evap }}
$$


where $\dot{m}_{L L}$ is the mass flow returning from the liquid line. The heat transfer from the evaporator to the compensation chamber is calculated taking into account the sub-cooled heat from the liquid line and the heat back conduction through the wick:

$$
\dot{Q}_{C C}=-\dot{Q}_{\text {wicki } i=1}-\dot{Q}_{s C}
$$

where:

$$
\dot{Q}_{w i c k=1}=\frac{2 \pi k_{\text {eff }} \ln \left(T_{w i=1}-T_{\text {core }}\right)}{\ln \left(\frac{D_{o, w i=1}}{D_{i, w i=1}}\right)}
$$




\section{References}

[A.1] I.E. Idelchik, Handbook of Hydraulic Resistance, third ed., CRC 586 Press, Florida, 1994.

[A.2] S.W. Churchill, Friction factor equation spans all fluid-flow regimes, 588 Chem. Eng. 84 (24) (1997) 91.

[A.3] D.K. Edwards, V.E. Deny, A.F. Mills, Transfer processes, second ed., Hemisphere, Washington DC, 1979.

[A.4] F.W. Dittus, L.M.K. Boelter, Univ. Calif. Publ. Eng. 2 (1930) 433.

[A.5] D.P. Traviss, W.M. Rohsenow, A.B. Barton, Forced convection condensation in tubes: A heat transfer correlation for condenser 594 design, ASHRAE Trans. 79 (I) (1973) 157-165.

[A.6] R.C. Martinelli, D.B. Nelson, Prediction of pressure drop during forcedcirculation boiling of water, Trans. ASME 70 (1948) 695-702.

[A.7] J.C. Chen, Correlation for boiling heat transfer to saturated fluids in convective flow, Ind. Eng. Chem. Proc. Des. Dev. 5 (3) (1966) 322-339.

[A.8] V.P. Carey, Liquid-vapor phase-change phenomena, Taylor \& Francis, 1992. [A.9] R.S. Dougall, W.M. Rohsenow, Film boiling on the inside of vertical tubes with upward flow of the fluid at low qualities, MIT report no. 9079-26, Cambridge, 1963. [A.10] J.P. Holman, Heat transfer, McGraw-Hill, New York, 1997 